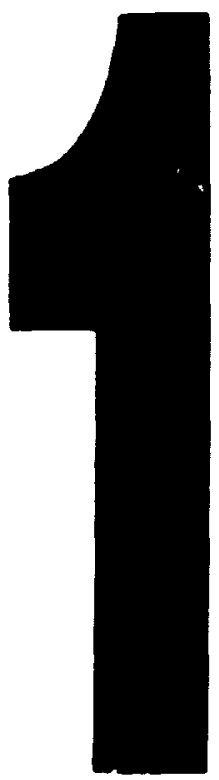

PM-1 31\%" $\times 4$ " PHOTOGRAPHIC MICROCOPY TARGET NBS 1010 A ANSI/ISO \#2 EOUIVALENT

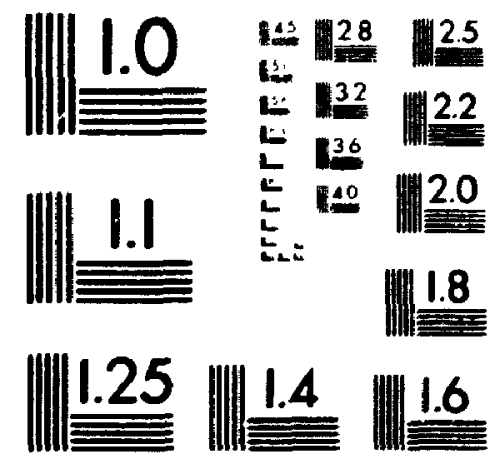

PRECISIONSM RESOLUTION TARGETS 
National Library

ol Canada

Acquisitions and

:? Jliographic Services Branch

395 Wettinglon Street

Ontawa. Ontano

K1A ONA
Bibliotheque nationale

du Canada

Direction des acquisitions et

des services bibliographiques

395. rue Wellungton

Ottawa (Ontano)

KIA ONA rout the vow. isterence

Ou the Notre interence

NOTICE

AVIS

The quality of this microform is heavily dependent upon the quality of the original thesis submitted for microfilming. Every effort has been made to ensure the highest quality of repioduction possible.

If pages are missing, contact the university which granted the degree.

Some pages may have indistinct print especially if the original pages were typed with a poor typewriter ribbon or if the university sent us an inferior photocopy.
La qualité de cette microforme dépend grandement de la qualité de la these soumise au microfilmage. Nous avons tout fait pour assurer une qualité supérieure de reproduction.

S'il manque des pages, veuillez communiquer avec l'université qui a conféré le grade.

La qualité d'impression de certaines pages peut laisser à désirer, surtout si les pages originales ont ité dactylographiées à l'aide d'un ruban usé ou si l'université nous a fait parvenir une photocopie de qualité inférieure.

La reproduction, même partielle, de cette microforme est soumise à la Loi canadienne sur le droit d'auteur, SRC 1970, c. C-30, et ses amendements subséquents.
Reproduction in full or in part of this microform is governed by the Canadian Copyright Act,

R.S.C. 1970, c. C-30, and subsequent amendments. 


\title{
Design of Plywood Sheathed Wood Floors and Roofs
}

By

\author{
Changjiang Liu
}

\author{
A thesis submitted to \\ the Faculty of Graduate Studies and Research
}

in partial fulfillment of the

requirements for the degree of

DOCTOR OF PHILOSOPHY

in

CIVIL ENGINEERING

DEPARTMENT OF CIVIL \& ENVIRONMENTAL ENGINEERING

CARLETON UNIVERSITY

OTTAWA, CANADA

January, 1995

OTTAWA-CARLETON INSTITUTE FOR CIVIL AND ENVIRONMENTAL ENGINEERING JOINT PROGRAM OF UNIVERSITY OF OTTAWA AND CARLETON UNIVERSITY OTTAWA, CANADA.

(c) 1995 Changjiang Liu 
National Library

of Canada

Acquisitions and Bibliographic Services Branch

395 Wellington Street Ottawa, Ontario K1A ON4
Bibliothéque, nationale du Canada

Direction des acquisitions et des services bibliographiques

395. rue Wellington

Otlawa (Ontano)

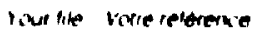

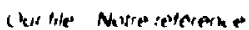

THE AUTHOR HAS GRANTED AN IRREVOCABLE NON-EXCLUSIVE LICENCE ALLOWING THE NATIONAL LIBRARY OF CANADA TO REPRODUCE, LOAN, DISTRIBUTE OR SELL COPIES OF HIS/HER THESIS BY ANY MEANS AND IN ANY FORM OR FORMAT, MAKING THIS THESIS AVAILABLE TO INTERESTED PERSONS.
L'AUT'EUR A ACCORDE UNE LICENCE IRREVOCABLE ET NON EXCLUSIVE PERMETTANT A LA BIBLIOTHEQUE NATIONALE DU CANADA DE REPRODUIRE, PRETER, DISTRIBUER OU VENDRE DES COPIES DE SA THESE DE QUELQUE MANIERE ET SOUS QUELQUE FORME QUE CE SOIT POUR METTRE DES EXEMPLAIRES DE CETTE THESE A LA DISPOSITION DES PERSONNE INTERESSEES.

L'AUTEUR CONSERVE LA PROPRIETE DU DROIT D'AUTEUR QUI PROTEGE SA THESE. NI LA THESE NI DES EXTRAITS SUBSTANTIELS DE CEL.LECI NE DOIVENT ETRE IMPRIMES OU AUTREMENT REPRODUITS SANIS SON AUTORISATION.

ISBN $0-612-02956-5$ 
3 The Effect of Aspect Ratio on the Deflection of Floors 68

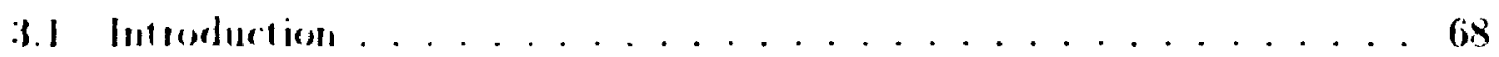

3.2 The lower Bonnd - C.hed Floors . . . . . . . . . . . . . . . 68

3.2 .1 Thr T beam Formula . . . . . . . . . . . . . 69

3.2.2 The Maximum Deflection of a Plate Simply Supported on Four Sides .................... . . 69

3.2.3 T'er Ratio of Deflections: Plate over T.beam . . . . . . 70

3.2 .1 Comparison and Discussion .............. 11

4 Guidelines in Designing Medium and Long Spañ Floors 80

1.1 Differences Botween T-beam and Plate Theory for Different Floors. . 80

1.2 Effrects of comnections on the Deflection Ratio a . . . . . . . . . 82

1.3 Design of Long Span Floors .................... . 82

1.3.1 I sing Charts ..................... 8.3

1.3.2 l sing Formula and Approximation . . . . . . . . . 83

1.1 Summary ..................... 84

5 Design of Plywood Sheathed Floors Subject to Concentrated Load113

..1 Introduction . . . . . . . . . . . . . . . . . 113

5.2 Test Results from Forest Product Lab. ISDA. McCutcheon . . . . 114

5.3 An Example Ising the T-beam Theory . . . . . . . . . . 115

5.1 Result From Orthot ropic Plate Theory . . . . . . . . . . . 117

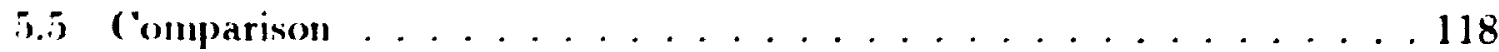

i.6 Parammetric Study . . . . . . . . . . . . . . . . . . 119

T.7 Location of Maximum Deflections, $\left(x_{0}, y_{0}\right) \ldots \ldots$. . . . . . . . . 20

5.7.1 In the Direction Perpendicular to Joists, $y_{0} \ldots \ldots . . . . . .120$

5.7.2 In the Direction of Joists. $x_{0} \ldots \ldots \ldots . \ldots . \ldots . \ldots 25$ 
The undersigned hereby recommend to

The Faculty of (iraduate Studies and Researci acceptance of the thesis.

\section{Design of Plywood Sheathed Wood Floors :nd Roofs}

submitted by

Changjiang Liu

in partial fulfilment of the requirements

for the degree of Doctor of Philosophy

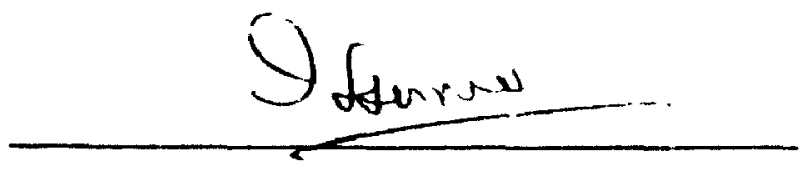

Civil Engineering

1

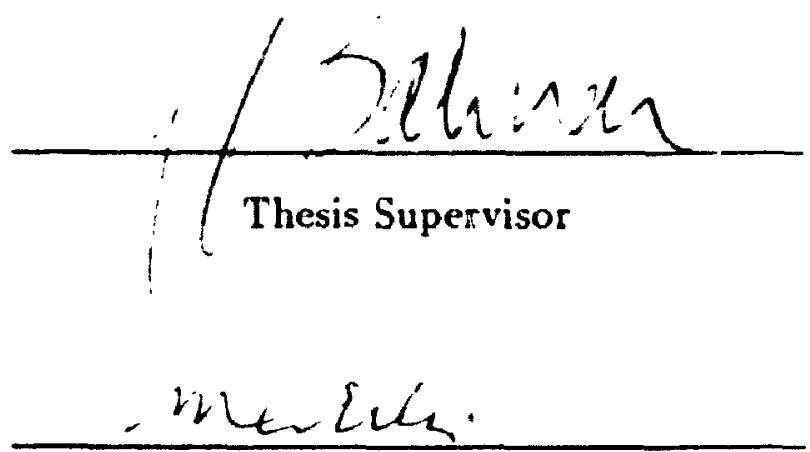

External Examiner

Carleton University

January 23, 1995 


\section{Abstract}

Fxist ing design methodologies for wood joist floor systems using finite element methods and T.beam models exhibit some short comings. The T-beam nodel is incapalile of predicting deffections of floors subjected to concentrated loads or longspall llours subjected to uniformly distributed loads. On the other hand, the finite element approach is olten too complicated to be adopted in practice which is one of the reasoms why the T-beam model is still being used in design practice. The design iswum of plywood sheathed wood joist floors and roofs are examined using orthot ropic plate theory, which provides a simpler approach than finite element analysis and more comprehensive than the simple T-beam method. A simple procerlure is proposed for the design of floors subjected to concent rated loads. Ising the fact that plywood sheathed floors are stiffer in the direction of the joists than in the transterse direction, the determination of maximum deflections is done using a simplified procedure. The maximum deflection can be calculated from one singlo formula. This procedure is valid in the scope of current available sizes of joists and plywood panels. The effects of ponding on the deflection of flat roofs is also examined. Roofs are then classified as stable and unst able with respect to ponding. A critcrion is derived for design purposes, which defines roofs as stable or unstable deper ding on the dimensions and rigidity of the roof. Limit states design of wood st rue tures revpures not only sound structural analysis procedures to determine the structural lxhaviour of systems. but also reliable assessment of wood members. A unitied theory that combines the effects of size and loading configuration using a total damage accumulation model to assess wood member strength is proposed. 


\section{Acknowledgements}

The author wishes to acknowledge with gratitude the invaluable help and an couragement received from his thesis supervisor, Dr. J. J. Salinas, who has offered guidance and support. His sense of humor and encouragement made life so pleasint and memorable at Carleton.

Most sincere thanks also go to all members of the Ph.D. advisory commithere. especially Professors M.A. Erki, J. Humar, G. Hartley, D. Lau, (.L. Tan and Dr. Alien, Dr. Baltacioglu, for their assistance and encouragement along the road. Sper cial thanks are extended to Professors N.M. Holtz and D. Lan for their lielp with questions regarding computing facilities in the Department of (ivil and Huvironmental Engineering.

Best regards are extended to my fellow students in the Department for thrir friendship, cooperation and fruitful discussions.

This research would not have been possible without the scholarship awardey to the author by Carleton Viniversity.

Final thank goes to my wife, Hong Zhang, for her patience, to my parchits and other members of my family for their support and encouragernent. 


\section{Contents}

1 Introduction 1

I.I Background .....................

1.2 Literature Review . . . . . . . . . . . . . . 2

1.2.1 Colorado State University, 1971, Mathematical Model and Test, Vanderbilt et. al . . . . . . . . . . . . . 3

1.2.2 Colorado State University, 1975, Finite Element Analysis FEAFLO, Thompson, et. al . . . . . . . . . . . 4

1.2.3 Colorado State University, 1979, Design Procedures Proposed, Sazinski, Vanderbilt . . . . . . . . . . . . . 5

1.2.4 Forest Product Lab, U.S., 1977, T-beam, Simplified Design Procedure, McCutcheon . . . . . . . . . . . 6

1.2.5 Forest Product Lab. USDA, 1984, A Beam-Spring Analog, McCutcheon ................. 8

1.2.6 Forintek Canada, Western Lab. 1982, A Combined Fourier Series and Finite Element Analysis, Foschi . . . . . . . 9

1.2.7 University of British Columbia, 1983, Test of 13 Floors, Foschi 9

1.2.8 Reliability Analysis, 1983, Foschi . . . . . . . . . 10

1.2.9 University of Texas at Austin, 1986, Test of 15 Floors, Wheat 11

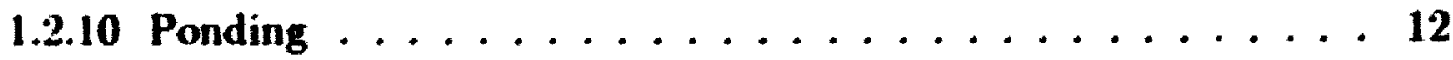


1.2.11 The Bending Strength of Wood Members. Damage Acrumu. lation Model . . . . . . . . . . . . . . . . . . . . II

1.3 Objectives ....................... 16

1.4 Organization of the Thesis $\ldots \ldots \ldots \ldots \ldots \ldots$

2 Designing Wood Joist Floors as Orthotropic Plates 27

2.1 Intioduction . . . . . . . . . . . . . . . 27

2.2 Deflection of Floors as Described by Orthotropic Plate Therry . . . 2 29

2.3 Wood Joist Floors Subject to Uniformly Distributed Load $4_{0} \quad \ldots \ldots$

2.4 Unfastened Floors - Upper Bound of Floor Deflection . . . . . . . . 31

2.5 Deflection of Floors as Described by the T-beam Theory . . . . . 31

2.5.1 Lower Bound . . . . . . . . . . . . . . . . . 34

2.5.2 Upper Bound . . . . . . . . . . . . . . . . . 35i

2.5.3 Composite Action - Comparison Betwern the Upper and Lower Bound . . . . . . . . . . . . . . . 35

2.5.4 Upper Bound of Deflection - Comparison of Three Approachess $3 \times$

2.5.5 Floors with Joist and Plywood Nailed Together . . . . . . . 39

2.6 Interpretation of Test Results using Orthotropic Plate Throry . . . 40

2.6.1 Forest Product Laboratory, U.S., 1977, McCutchicon . . . . . . 10

2.6.2 Forintek Canada, 1982, Foschi . . . . . . . . . . . 12

2.6.3 UBC, Canada, 1985, Foschi $\ldots \ldots \ldots \ldots \ldots$. . . . . .

2.7 Parametric Study . . . . . . . . . . . . . . . . . 46

2.7.1 Effect of Plywood Thickness on Deflection . . . . . . . . 16

2.7.2 Effect of Joists Size on Deflection . . . . . . . . . . . A6

2.7.3 Effect of Nail Size on Deflection . . . . . . . . . . . 1n

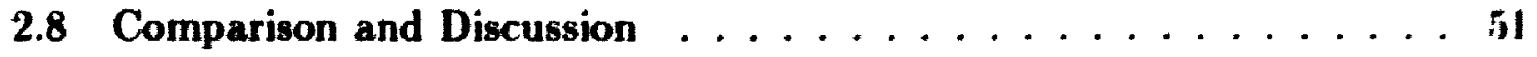

2.9 Effects of Boundary Conditions: Vpper Bound for Deffection of a Floor Simply Supported on Two Opposite Sides . . . . . . . . . . . it 


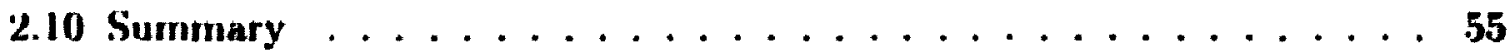

3 The Effect of Aspect Ratio on the Deflection of Floors 68

3.1 Introduction . . . . . . . . . . . . . 68

3.2 The Lower Bound - Glued Floors . . . . . . . . . . . . 68

3.2.1 The T-bearn Formula . . . . . . . . . . . . 69

3.2.2 The Maximum Deflection of a Plate Simply Supported on Four Sides . . . . . . . . . . . . . . . 69

3.2.3 The Ratio of Deflections: Plate over T-beam . . . . . . . 70

3.2.4 Comparison and Discussion . . . . . . . . . 71

4 Guidelines in Designing Medium and Long Span Floors 80

4.1 Differences Hetween T-beam and Plate Theory for Different, Floors . . 80

4.2 Effects of Connections on the Deflection Ratio a . . . . . . . . 82

4.3 Design of Long Span Floors . . . . . . . . . . . . . 82

4.3.1 Using Charts . . . . . . . . . . . . 83

4.3.2 Using Formula and Approximation $\ldots \ldots \ldots \ldots$

4.4 Summary $\ldots \ldots \ldots \ldots \ldots \ldots$

5 Design of Plywood Sheathed Floors Subject to Concentrated Load113 5.1 Introduction . . . . . . . . . . . . . . . 113

5.2 Test Results from Forest Product Lab. USDA, McCutcheon . . . . 114

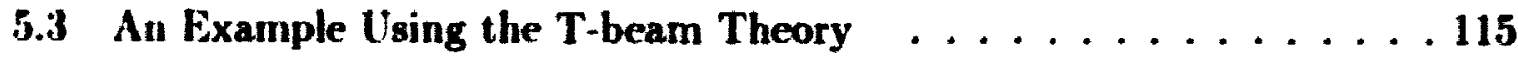

5.4 Result From Orthotropic Plate Theory . . . . . . . . . . . 117

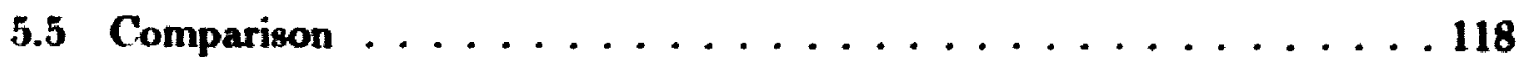

5.6 Parametric Study . . . . . . . . . . . . . . . 119

5.7 Location of Maximum Deflections, $\left(x_{0}, y_{0}\right) \ldots \ldots \ldots$

5.7.1 In the Direction Perpendicular to Joists, yo . . . . . . . 120

5.7.2 In the Direction of Joists, $x_{0} \ldots \ldots \ldots \ldots \ldots \ldots$ 
5.8 Guidelines in Designing Floors Subject to Point Load . . . . . . . . 1:26

6 Failure Criteria for Flat Roofs Subject to Ponding 145

6.1 Introduction . . . . . . . . . . . . . . . In

6.2 Governing Equations for Orthotropic Plates . . . . . . . . . Ifli

6.3 Ponding of Orthotropic Plate Simply Supported on Four Sidiss . . . 1.17

6.4 Critical Dimensions to Develop Instability . . . . . . . . . . . I!!

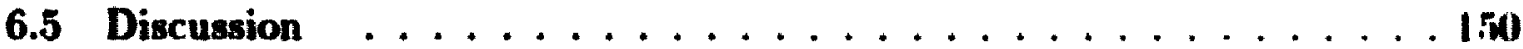

6.5.1 Stable and unstable regions. $\ldots \ldots \ldots \ldots \ldots \ldots$

6.5.2 Higher order approximation of roof deflertion, $u$. . . . , 150

6.6 Practical Applications $\ldots \ldots \ldots \ldots \ldots . \ldots \ldots 2$

6.7 Critical Dimensions That Define Stable and Unstabk Koofs . . . Iist

6.8 Comparison with Other Research $\ldots \ldots \ldots \ldots \ldots$. . . . . . . . .

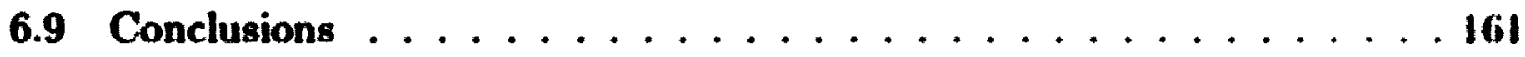

7 Modeling Bending Strength of Wood Members Using Damage Accumulation Concepts 172

7.1 Introduction . . . . . . . . . . . . . . 172

7.2 Characterization of Size and Load Configuration Efferts . . . . . 174

7.5 The Total Damage Accumulation Model . . . . . . . . . . . 175

7.4 Interpretation of Test Results . . . . . . . . . . I81

7.5 A Unified Approach . . . . . . . . . . . . . 18.3

7.5.1 Length Effects . . . . . . . . . . . . . 18:3

7.5.2 Depth Effects . . . . . . . . . . . . . 184

7.5.3 Load Configuration Effects . . . . . . . . . . . . 144

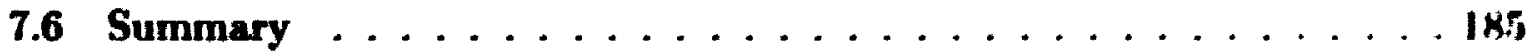

8 Summary and Future Work 186

8.1 Summary $\ldots \ldots \ldots \ldots \ldots \ldots \ldots \ldots$ 
8.1.1 Design Procedures for Short Span Floors Subject to Uniformly Distributed Load . . . . . . . . . . . . . . 187

8.1.2 Design Procedures for Medium and Long Span Floors Subject to Uniformly Distributed Load . . . . . . . . . . . . . . 190

8.1.3 Design Procedures for Floors Subject to Concentrated Load . 191

8.1.4 Design Procedures for Roofs Subject to Ponding Load . . . . 193

8.1.5 Damage Acrumulation Model for Bending Strength of Wood Members . . . . . . . . . . . . . . . . . . . 194

8.2 Future Work . . . . . . . . . . . . . . . . . 194 


\section{List of Tables}

1.1 Summary of Floor Tests at FPL, USDA, 197., Mrc'utcheom . . . . T

1.2 Description of test floors, University of Texas at Aust in . . . . . 11

2.1 Maximum deflection of $\mathrm{T}$-beam, joist : $38 \times 89 \ldots \ldots$

2.2 Maximum deflection of T-beam, joist: $38 \times 184 \ldots \ldots \ldots$

2.3 Deflection ratios $(u-1) / 1 \ldots \ldots \ldots \ldots \ldots \ldots$ is

2.4 Effects of nail sizes on floor deflection, joist size $3 \times \times k !$, ply wowd thick ness $12.5 \mathrm{~mm} \ldots \ldots \ldots \ldots \ldots \ldots$

2.5 Conversion of nail sizes between Penny-weight and lnchess _ . . . . I!!

2.6 Effects of sizes of nails, joist $38 x 89$, plywood $20.5 \mathrm{~mm} \ldots \ldots$

2.7 Improvement ratios of nailed floor over unfasteried flow . . . . . ist

2.8 Comparison between the deflection of floor using orthot ropic platc model and T-beam model. joist 38x89, nail sire $2 d$. . . . . . . . 51

2.9 Comparison between the deflection of floor using orthotropic plate model and T-beam model with $38 \times 184$ joists and $2 d$ nails. . . . . . \$2

2.10 Comparison betwen the deflection of floor using orthot ropic plate model and T-beam model. joist 38x89, nail size 60d. . . . . . . . .3.3

3.1 Rate of convergence $\ldots \ldots \ldots \ldots \ldots \ldots \ldots$

4.1 $\gamma_{0}, \alpha$ and $\alpha_{0}$ for different nailed floors, plywood thirkness: $12.5,15.5$

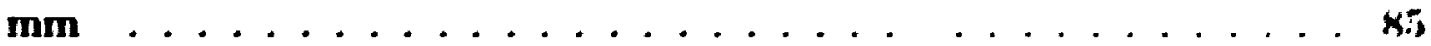


4.2 $\gamma_{0}, \alpha$ and $\alpha_{0}$ for different nailed floors,plywood thickness: $18.5,20.5$ $\mathbf{m m} \ldots \ldots \ldots \ldots \ldots \ldots \ldots \ldots$

4.3 $\gamma_{0}, \alpha_{0}$ and $\alpha$ for different glued floors,plywood thickness: $12.5,15.5$ $\mathbf{m m} \ldots \ldots \ldots \ldots \ldots \ldots \ldots$

4.4 $\gamma_{0}, \alpha$ and $\alpha_{0}$ for different glued floors,plywood thickness: 18.5, 20.5 $\mathbf{m m} \ldots \ldots \ldots \ldots \ldots \ldots \ldots$

5.1 Deflection of different floors calculated using both orthotropic plate theory and T-beam formula with different joist sizes. Joist sizes: 38x89 to 38x286. Plywood thickness: $12.5 \mathrm{~mm}$. 2d nail. . . . . . 120

5.2 Deflection of different floors calculated using both orthotropic plate theory and T-beam formula with different nail sizes. Joist sizes: 38x89. Plywood thickness: $12.5 \mathrm{~mm}$. Nails: $2 \mathrm{~d}$ to $60 \mathrm{~d}$. . . . . . . 121

5.3 Location of maximum deflections of floors subject to point load. . 123

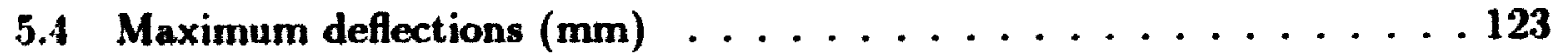

6.1 Effects of sheathing thickness on floor deflection. . . . . . . . 154

6.2 Effects of joist spacing on floor deflection $\ldots \ldots \ldots \ldots$

6.3 Maximum width for different plywood thickness . . . . . . . . 156

6.4 Maximum length for different joists, plywood thickness: $12.5 \mathrm{~mm} \quad \ldots 157$

6.5 Maximum length for different joists, plywood thickness: $15.5 \mathrm{~mm} \quad \ldots 158$

6.6 Maximum length for different joists, plywood thickness: $18.5 \mathrm{~mm} \quad \ldots 159$

6.7 Maximum length for different joists, plywood thickness: $20.5 \mathrm{~mm} \ldots 160$ 


\section{List of Figures}

1.1 Layerd beams or T-beams . . . . . . . . . . . . . . . 19

1.2 Idealization of a floor system $\ldots \ldots \ldots \ldots$

1.3 CSU result: Composite and two-way behaviour of wood joist floor system with varying joirt moduli. . . . . . . . . 2!

1.4 Typical load-deflection behaviour of floors. . . . . . . . . 22

1.5 Crossing beam model of wood joist floor system with gaps. . . . 23

1.6 Deflections of floors vs aspect ratio (floor-span/width). . . . . . 24

1.7 T-beam model. . . . . . . . . . . . . . . . 25

1.8 Beam-Spring Analog model. $\ldots \ldots \ldots \ldots \ldots \ldots$

1.9 Deflection of joists under ponding load. $\ldots \ldots \ldots \ldots$

2.1 Comparison between the test data and calculation from orthotropic plate theory . . . . . . . . . . . . . . 56

2.2 An unfastened floor - sheathing not fastened to joists $\ldots \ldots \ldots$

2.3 A plywood sheathed wood joist floor subject to uniformly distributed load, and its T-beam cross section $\ldots \ldots \ldots \ldots \ldots$

2.4 Deflection of floors with $38 \times 89$ joists and $2 \mathrm{~d}$ nails, orthotropic plate theory vs $\mathrm{T}$-beam formula. $\ldots \ldots \ldots \ldots$

2.5 Deflection of floors with $38 \times 184$ joists, $2 \mathrm{~d}$ nails, orthotropic: plate: theory us $\mathrm{T}$-beam formula. $\ldots \ldots \ldots \ldots \ldots \ldots$ fio 
2.6 Deflection of floors with $38 \times 89$ joists, $60 \mathrm{~d}$ nails, orthotropic plate theory vs T-beam formula. . . . . . . . . . . 61

2.7 Tbeam - an example . . . . . . . . . . . . . . 62

2.8 Effects of plywood sheathing thickness on deflection of floors, joist:

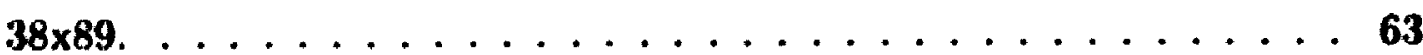

2.9 Effects of plywood sheathing thickness on deflection of floors, joist: $38 \times 184$

2.10 Effects of joist sizes and plywood thickness on floor deflection, represented by using deflection $r a t i o s(u-1) / 1 \ldots \ldots \ldots$

2.11 Effects of nail sizes on floor deflection $\ldots \ldots \ldots 6$

2.12 Effects of nail sizes on floor deflection shown in terms of deflection ratios for floors with different plywood thickness and different joist sizes. ........................67

3.1 Effects of aspect ratios on floor deflections for a nailed floor . . . . 75

3.2 Effects of aspect ratios on deflections of floors with different sizes of nails ......................... 76

3.3 Long span floor vs short $\operatorname{span}$ floor $\ldots \ldots \ldots \ldots \ldots$

3.4 Effects of plywood thickness on floor deflections . . . . . . . . 78

3.5 The most commonly used floor layouts $\gamma<2 \ldots \ldots \ldots$

4.1 Deflection ratio vs aspect ratio. Joist sizes: $38 \times 89$ to $38 \times 286$. Plywood thickness: $12.5 \mathrm{~mm} . \ldots \ldots \ldots$

4.2 Deflection ratio vs aspect ratio. Joist sizes: $38 \times 89$ to $38 \times 286$. Plywood thickness: $15.5 \mathrm{~mm} . \ldots \ldots \ldots \ldots$

4.3 Deflection ratio vs aspect ratio. Joist sizes: $38 \times 89$ to $38 \times 286$. Plywood thickness: $18.5 \mathrm{~mm} \ldots \ldots \ldots \ldots$

4.4 Deflection ratio vs aspect ratio. Joist sizes: $38 \times 89$ to $38 \times 286$. Plywood thickness: $20.5 \mathrm{~mm} \ldots \ldots \ldots \ldots$ 
4.5 Deflection ratio vs aspect ratio. Joist sizes: $89 \times 114$ to $89 \times 286$. Plywood thickness: $12.5 \mathrm{~mm} \ldots \ldots \ldots \ldots$

4.6 Deflection ratio vs aspect ratio. Joist sizes: $89 \times 114$ to $89 \times 286$. Plywood thickness: $15.5 \mathrm{~mm} \ldots \ldots \ldots \ldots \ldots$

4.7 Deflection ratio vs aspect ratio. Joist sizes: $89 \times 114$ to $89 \times 286$. Plywood thickness: $18.5 \mathrm{~mm} \ldots \ldots \ldots \ldots$

4.8 Deflection ratio vs aspect ratio. Joist sizes: $89 \times 114$ to $89 \times 286$. Ply wood thickness: $20.5 \mathrm{~mm} \ldots \ldots \ldots$

4.9 Influence of connections on deflection ratio, $38 \times 89 \ldots \ldots$

4.10 Influence of connections on deflection ratio, $38 \times 286 \ldots \ldots$

4.11 Influence of connections on deffection ratio, $89 \times 114 \ldots \ldots$

4.12 Influence of connections on deflection ratio, $89 \times 286 \ldots \ldots$

4.13 Convergence of $\mathrm{m}$ terms, $38 \times 89,12.5 \mathrm{~mm} \ldots \ldots \ldots 1$

4.14 Convergence of $\mathrm{m}$ terms, $38 \times 89,20.5 \mathrm{~mm} \ldots \ldots \ldots$

4.15 Convergence of $\mathrm{n}$ terms, $38 \times 89,12.5 \mathrm{~mm} \ldots \ldots \ldots$

4.16 Convergence of $\mathbf{n}$ terms, $38 \times 89,20.5 \mathrm{~mm} \ldots \ldots \ldots \ldots$. . . . . 105

4.17 Convergence of $\mathrm{n}$ terms, $89 \times 286,12.5 \mathrm{~mm} \ldots \ldots \ldots$

4.18 Convergence of $\mathrm{n}$ terms, $89 \times 286,20.5 \mathrm{~mm} \ldots \ldots \ldots$

4.19 Convergence of $\mathrm{m}$ terms, $89 \times 286,12.5 \mathrm{~mm} \ldots \ldots \ldots$

4.20 Convergence of $\mathrm{m}$ terms, 89x286, $20.5 \mathrm{~mm} \ldots \ldots \ldots$

4.21 Medium span floors, joists: $2 \times 8,2 \times 10,2 \times 12,2-1 / 2^{n}$ nails $\ldots \ldots \ldots 110$

4.22 Extreme cases, medium span, $12.5 \mathrm{~mm}, 2 \times 12$ and $20.5 \mathrm{~mm}, 2 \times 8 ; 2$ -

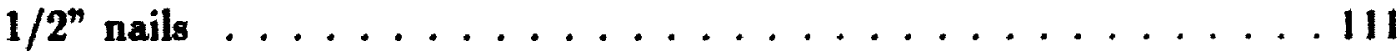

4.23 Upper and lower limit, medium span $\ldots \ldots \ldots \ldots \ldots$. . . . . 112

5.1 Simply supported beams subject to point load $\ldots \ldots \ldots \ldots$. . . . . 25

5.2 A plywood sheathed floor subjects to concentrated load. . . . . . I 128 
5.3 Deflection of different floors calculated using both orthotropic plate theory and T-beam formula with different joist sizes. Joist sizes: 38x89 to 38x286. Plywood thickness: $12.5 \mathrm{~mm}$. 2d nail. . . . . 129

5.4 Deflection of different floors calculated using both orthotropic plate theory and T-beam formula with different joist sizes, upper bound, lower bound and nailed. Joist sizes: $38 \times 89$ to $38 \times 286$. Plywood thickness: $12.5 \mathrm{~mm}$. $2 \mathrm{~d}$ nail. . . . . . . . . . . . . 130

5.5 Ratio of deflections obtained from Tbeam formula and orthotropic plate theory. Joist sizes: $38 \times 89$ to $38 \times 286$, Plywood thickness: 12.5 $\mathrm{mm}$, nail size: $2 \mathrm{~d}$.

5.6 Deflection of different floors calculated using both orthotropic plate theory and T-beam formula with different nail sizes. Joist sizes: 38x89. Plywood thickness: $12.5 \mathrm{~mm}$. Nails: $2 \mathrm{~d}$ to $60 \mathrm{~d}$.

5.7 Deflection of different floors calculated using both orthotropic plate theory and T-beam formula with different plywood thicknesses. Joist sizes: 38x184. Plywood thickness: 12.5 to $20.5 \mathrm{~mm}$. Nails: $8 \mathrm{~d}$. . . 133

5.8 Deflections along the span when $P$ acts at varies points along the span

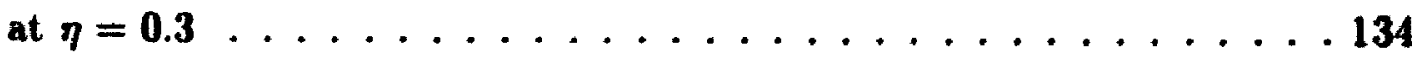

5.9 Deflections along the span when $P$ acts at varies points along the span

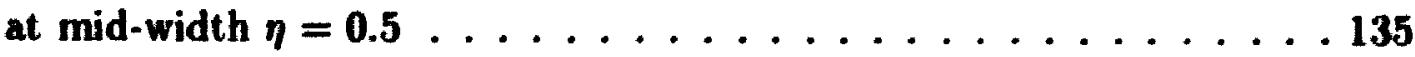

5.10 Deflections along the span when $P$ acts at mid-span $\ldots \ldots \ldots$

5.11 Deflections along the width when $P$ acts at mid-span $\ldots \ldots \ldots 137$

5.12 Deflections along the width when $P$ acts at mid-span,38x89,12.5 $\mathrm{mm} 138$

5.13 Deflections along the width when $P$ acts at mid-span, 38x89, $20.5 \mathrm{~mm} 139$

5.14 Deflections along the width when $P$ acts at mid-span,89x286,12.5 mm 140

5.15 Deflections along the width when $P$ acts at mid-span,89x286,20.5 mm 141

5.16 Deflections along the width when $P$ acts at mid-span, $38 \times 89,12.5 \mathrm{~mm}$

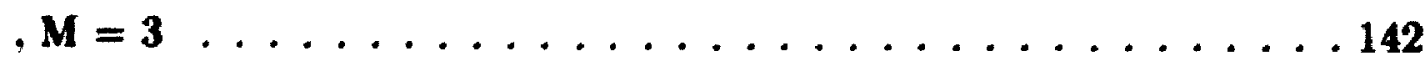


5.17 Deflections along the span when $P$ acts at $(0.3 \mathrm{~L}, 0.5 \mathrm{~B}) \ldots \ldots$

5.18 Deflections at $\left(x_{b}, \eta\right.$ B) and maximum deflection when $P$ acts at $(0.3$ L, 0.5 B), plywood 12.5, 15.5, 18.5, $20.5 \mathrm{~nm}$; joists $38,64,89 \times 89 \rightarrow$ 284

6.1 An orthotropic plate $\ldots \ldots \ldots \ldots \ldots$. . . . . . . . . . . . .

6.2 Critical dimensions of roofs subject to ponding $\ldots \ldots \ldots \ldots$

6.3 Higher order critical dimensions . . . . . . . . . . . . . 165

6.4 Plywood sheathed roofs subject to ponding load $\ldots \ldots \ldots \ldots$. . . 66

6.5 Deflection in a stable region $\ldots \ldots \ldots \ldots \ldots \ldots \ldots$

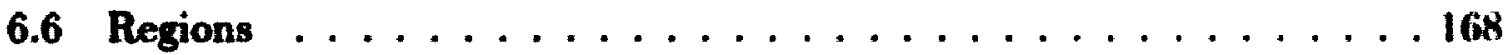

6.7 Deflections when span, $L$, approaching unstable region $\ldots \ldots \ldots 9$

6.8 Deflection vs plywood thickness . . . . . . . . . . . 170

6.9 Deflection vs joist spacing $\ldots \ldots \ldots \ldots \ldots \ldots \ldots \ldots$

7.1 Beams with different length $\ldots \ldots \ldots \ldots \ldots \ldots \ldots$

7.2 Beams with different depth $\ldots \ldots \ldots \ldots \ldots$

7.3 Beams with different load scheme $\ldots \ldots \ldots \ldots \ldots$. . . . . 174

7.4 Pre-existing damage $\ldots \ldots \ldots \ldots \ldots \ldots \ldots$

7.5 Stress induced damage accumulation $\ldots \ldots \ldots \ldots \ldots$

7.6 Accumulated damage at failure $\ldots \ldots \ldots \ldots \ldots$

7.7 Beam subjected to 2 points load $\ldots \ldots \ldots \ldots \ldots \ldots \ldots$

8.1 Plywood sheathed floor modeled as a T-beam subjects to load on the

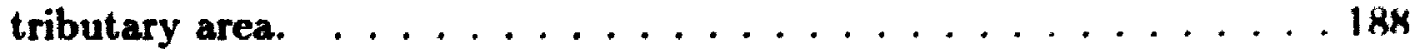

8.2 A beam subjects to a concentrated load, $P \ldots \ldots \ldots \ldots$ 


\section{Chapter 1}

\section{Introduction}

\section{$1.1 \quad$ Background}

Canada has one of the biggest forest inventories in the world. The Canadian forest resource contains a wood volume of about 24 billion $\mathrm{m}^{3}$ and covers one third of the land in Canada. The forest sector provides during each year (1990 data, [69]):

- 270000 jobs in logging, lumber, pulp and paper

- $\$ 7.4$ billion in salaries and wages

- $\$ 32.8$ billion worth of products. $\$ 16.2$ billion export. $\$ 14$ billion balance of trade.

- More than $30 \%$ of the worid's supply of news-print.

On the other hand, as a renewable material, wood products can be produced without exhausting our forest resources. Wood produces less waste than man-made materials and hence has less environmental impact if it is managed wisely.

Light-frame residential wood buildings represent the largest single construction type in North- America, and they are usually built on the base of experience. These 
buildings have traditionally demonstrated high reliability, but the mechanisms behind their behaviour are not always fully understood.

One of the largest sub-systems in light-frame wood construction is the wood joist floor assembly. Although wood joist and sheathing systems are simple in concept, they are complicated systems to analyze. Not only are they usually multi-layered with each layer made of orthot ropic materials, but also in nailed and elastomet rically glued systems, there exists an interlayer slip of sufficient magnitude to have a ma jor effect on the deflection and stresses in the system. In addition, gaps al joints in the sheathing layers produce discontinuities, which have a significant effert on the composite action of the system. These factors, coupled with the variability of the material in each component, make the analysis of the floor systen difficult.

In a plywood sheathed wood joists floor, joists are the primary componn'ms which carry much larger proportion of bending in the direction of joists than plywood. However, the contribution of plywood to the bending stiffuess of floors in this direction can not be ignored. The composite action between plywood and joist in this direction forms a $T$-beam cross-sertion. In the direction perpendicular $($ ) the joists, on the other hand, it is the plywood that provides bending strongth and stiffness. Connections between the plywood and joist determine the maguit ude of the composite action. A glued connection could lead to a much stiffer $T$-heam than could a loose connection. The stiffness of the floor in the transversal dirertion is much smaller than in the direction of the joists. Yet, it cannot bre ignored in sommcases. Gaps between the sheathing panel also constitute a fartor that influenres thestiffness of floors.

\subsection{Literature Review}

In the past, safe house construction methods have been found by the inefficient method of trial and error. If modern research efforts, so successful in the solution of other problems, had been applied to housing, houses would be more satisfartury as dwellings and, much more important, the cost would be smaller. A more effirient and economic use of wood materials in housing construction would be an outstanding 
contribution to the problem of providing acceptable housing for the low-income groups in this country (Whittemore, 1948 [91] [30] ).

\subsubsection{Colorado State University, 1971, Mathematical Model and Test, Vanderbilt et. al}

In early seventies, it was recognized that the over-simplified design procedures imposed on frame floor systems penalizes wood. There are additive performance effects of the materials and fastenings used in wood frame floor systems. In 1971, a comprehensive study to develop a rational analysis and design procedure for wood joist floor systems began at Colorado State University (Vanderbilt, Goodman, Criswell, 1974 [91]). As the first step, a study of layered beams, the major structural component of the floor system, was carried out. The layered beams or $\mathrm{T}$-beams were considered as having two layers, the sheathing and the joist, connected with mechanical fasteners or glue as shown in Figure 1.1.

Then floors were simplified as a system of crossing beams as shown in Figure 1.2 which ignored the contribution of the torsional stiffnesses of the sheathing and T-bearns. A set of equations were developed and solved using matrix structural theory. The mathematical model incorporates two-way action and incomplete composite action as well as variations in material and fastener properties. The two-way action represents the load-distribution effect of sheathing on the transverse direclion. Incompletc composite action defines the contribution of sheathing, connections and joists toward the stiffness of the T-beam. The model of an idealized floor under examination contains 11 T-beam and 11 sheathing strips. Simple supports were assumed at all edges.

As demonstrated in Figure 1.3, the model describes the two-way action and composite action well. In the figure, four different cases were demonstrated: 1) joists only, no sheathing; 2) distribution of loads by two-way action but neglecting composite action, two-way and no $T$-beam; 3) conposite action due to 8-inch nail spacing with no two-way action; 4) complete composite and two-way action as predicted by the complete mathematical model. 
It can be seen that the composite action improves the stiffness of floors while the two-way action redistributes loads among joists and thus reduces the impact of of variations of joist stiffness to achieve a smooth deflection curve.

Experiments were conducted for T-beams and floors (Vanderbilt el. al. 1973. [91]). The floor was tested by applying a concentrated load at the middle of the center joist. Plywood sheathing was glued thus eliminating gaps. It was found that:

- the mathematical model agrees well with the tests at the scrvice load level;

- the floor will not collapse after the failure of the first joist or even a couple of subsequent failures, Figure 1.4.

- the floor failed when the point load punched through the sheathing.

After the initial failure of a joist, the deflection was increased without the increasing the load. The load was re-distributed to adjacent joists. This proved the existence of two-way action and the role of plywood sheathing in a floor.

\subsubsection{Colorado State University, 1975, Finite Element Anal- ysis - FEAFLO, Thompson, et. al}

This study has already used a concept of finite element analysis by brcaking down a continuous floor system into crossing beams and calculating the deflertion at the crossing points (Vanderbilt et. al. 1974 [91], Goodman et. al. 1974 [30]). In order to account for gaps, Figure 1.5, the finite element method has to be implemented, (Thompson 1975, [85] [86]).

The gaps were modelled using two different elements: a special element and a soft element. In the first method, a special element of zero length is int roducid wherever there is a gap. Gaps can also be modelled using a soft element of finite small length with low modulus of elasticity. No numerical instability occurs when a low MOE is used since at least one layer (the joist) is always continuous at the gap. The result is a program called FEAFLO (Finite Element Analysis of FL(Oors). This program can analyze rectangular wood joist floors subject to any pattern of loading 
perpendicular to the plane of the sheathing. The effects of interlayer slip, variable material properties, and gaps at points, are correctly considered. The joints can be in both layers of sheathing independently and both parallel and perpendicular to the floor joists. Input data include a description of floor geometry, number of layers (2 or 3), axial and bending MOE data, gap data, slip moduli, and load data. Output data at ench node point include the deflection, extreme fiber stresses in each layer, interlayer shear flows, relative layer slip, nail forces, and the axial force and moment in each layer. The model predicts the deflection of floors with gaps in sheathing very well.

\subsubsection{Colorado State University, 1979, Design Procedures Proposed, Sazinski, Vanderbilt}

The last stage of the research work at Colorado State University presents a procedure that can be used by code writing committees and design engineers. Three methods were proposed (Sazinski et. al., 1979, [82]). The most accurate and time consuming of the three proposed design methodologies is the use of the finite element program, FEAFLO, which requires computer resources and knowledge of floor behaviour. This method is unlikely to be used in design practice, but could be very useful in research. The second method is to use dimension-less charts. The third method is to use span tables that give complete ansemblies of joists, sheathing and connectors that meet sperified acceptance criteria. Both the chart and span tables can be produced using FEAFLO.

It was also noticed that when the aspect ratio (joist length divided by the width of the floor) is more than unity, the deflection varies with different aspect ratio as shown in Figure 1.6. The deflection remains the same when the aspect ratio is less than unity while it decreases when the aspect ratio increases. However, no explanation was given. It was assumed that the aspect ratio was less than one, which defines a short floor, in all the subsequent studies. 


\subsubsection{Forest Product Lab, U.S., 1977, T-beam, Simplified Design Procedure, McCutcheon}

Research has also been carried out at the Forest Products Laboralory, Forest Service. U.S. Department of Agriculture (McCutcheon, 1977 [62]). The rescearch was ained at developing a simple procedure that can be used in design practice.

A floor was designed as a T-beam with sheathing attached to the joist cither by glue or nails. Gaps between sheathings along the joist were also considervil, Figure 1.7. Only two-layer floors were studied. Maximum deflertion of the T-bram is then calculated as

$$
\begin{gathered}
\Delta=\Delta_{R}\left[1+f_{\Delta}\left(\frac{E I_{R}}{E I_{U}}-1\right)\right] \\
f_{\Delta}=\frac{10}{(L a)^{2}+10} \\
E I_{R}=E I_{U}+\frac{\left(E A_{1}\right)\left(E A_{2}\right)}{E A_{1}+E A_{2}} h^{2}
\end{gathered}
$$

where

$\Delta$

$\Delta_{R}$

$E I_{R}$

$E I_{U}$

$\boldsymbol{f}_{\Delta}$

$L$

$\alpha^{2}$

$S$

$E A_{1}$

$E A_{2}$

$\boldsymbol{h}$ deflection of the beam

deflection if the components of the beam are rigidly connerted.

bending stiffness if the components are rigidly connerted.

stiffness if the components are completely unconnectud.

a constant function of La.

beam span.

$\frac{h^{2} s}{E I_{R}-E I_{U}}\left(\frac{E I_{R}}{E I_{V}}\right)$

load per unit length which causes a unit slip in the nail or adhesiwe joint.

the axial stiffness of the flange (shenthing)

the axial stiffness of the web (joist)

the distance between the centroids of the flange and the web. 
Table 1.1: Summary of Floor Tests at FPL, USDA, 1974, McCutcheon

\begin{tabular}{|c|c|c|c|c|}
\hline Floor & Average E & Deflection at $500 \mathrm{lbs}$ & Deflection at $50 \mathrm{psf}$ & Failure load \\
\hline Nailed & $10^{6}$ lbs $/ \mathrm{in}^{2}$ & inch & inch & $L b / \mathrm{ft}^{2}$ \\
\hline $\mathrm{N}-1$ & 1.57 & 0.155 & 0.376 & 128 \\
\hline $\mathrm{N}-2$ & 2.20 & 0.126 & 0.280 & 190 \\
\hline $\mathrm{N}-3$ & 2.00 & 0.115 & 0.312 & 120 \\
\hline $\mathrm{N}-4$ & 1.49 & 0.152 & 0.368 & 140 \\
\hline Glued & & & & \\
\hline G-1 & 1.53 & 0.104 & 0.246 & 200 \\
\hline G-2 & 2.20 & 0.087 & 0.189 & 315 \\
\hline G-3 & 2.00 & 0.095 & 0.190 & 225 \\
\hline
\end{tabular}

To account for the effects of gaps in the sheathing, $L^{\prime}$ is used instead of $L$ in calculating $f_{\Delta}, L$ ' is the distance between gaps along the span of joists.

$$
f_{\Delta}=\frac{10}{\left(L^{\prime} \alpha\right)^{2}+10}
$$

To verify the T-beam formula, seven floors were constructed. Each consisted of nine No. 2 or better $38 \times 184 \mathrm{~mm}$ Douglas-fir joists spaced $400 \mathrm{~mm}$ on centers. Floors were 3 ineters wide and were tested on a span of $3658 \mathrm{~mm}$. This gives an aspect ratio of 1.11 (span/width). Four of them used nail connection, while the other three used glue. Concentrated load as well as uniformly distributed loads were applied to the floors. The results from the T-beam formulation were in good agreement with the tewts results of floors subjected to uniformly distributed load. However, the T-beam formulation can not predict the defiection of floors subjected to concentrated bad.

The summary of the test results is reproduced in Table 1.1. 


\subsubsection{Forest Product Lab. USDA, 1984, A Beam-Spring Analog, McCutcheon}

In order to account for the two-way action and the variability of joist propmertins. McCutcheon (1984) [63] proposed a new model. The floor systems were modeled in two steps. First, the sheathing is assumed to be compressed into a narrow beall that spans the simply supported joists and serves as the bad-distriluting denk-nt. Sirond, the joists are modeled as linear elastic springs that support the loud-dist ributing beams, Figure 1.8. The stiffness of the springs is derived from the bending stiffutws of the T-beam, as mentioned before. The beam-epring analog involvex just onc digrev of freedom. A 10-joist floor can be analyzed with just 10 simultancous crjuatious. Compared to hundreds of equations involved in finite element analysis, the munluer of equations involved has been greatly reduced and hence the anount of computation. The process can be handled by a simple BASIC program on a hand hell calculator. This is of practical implication for design enginerrs.

The model was accurate as demonstrated by a comparison with finite chenont. analysis and foor tests. However, the process is still complicated since it involves solving multiple complicated equations. It is difficult to predict foor behaviours by simply examining the equations.

McCutcheon (1986) [64] also proposed a simple procedure to compute tlu. (x)inposite stifiness of a wood bending member with sheathing attached mu-rigidly to one or both edges to form a T-beam or an I-beam. The sheathing consistud of plywood and oriented strand-board (OSB). A so-called "transformed area" procesdure: was introduced to include the inter-layer slip by modifying the axial stiffurss of the flanges and the stifiness of the T-beam or 1-beam. 12 T-beams and 24 I-bmarns wrre constructed and tested to verify the formulation. 


\subsubsection{Forintek Canada, Western Lab. 1982, A Combined Fourier Series and Finite Element Analysis, Foschi}

Foschi (Forintek Canada, 1982, [20]) used a combined Fourier series and finite element method to analyse floors. It was pointed out that the model in FEAFLO restricts some degrees of freedom, since it does not consider the torsional deformation. These deformations are small but cannot be neglected. As shown by the effect that joist bridging has on floor deflection. As a consequence, the model is stiffer than the actual structure and, as shown by experimental data ([86]), predicted deflection were found to be consistently smaller than test measurements. An improvement in modelling, including all degrees-of-freedom was introduced to try to avoid the need to introduce parameters, such as flexible gap's properties, which are not well-defined and difficult to estimate.

This permits the consideration of the effect that joist bridging has on the maximum floor deflection and the maximum bending stress. The analysis was still in the linear range, i.e. nonlinearities in the fasteners, inelastic joist or cover behavior were not included. This is the first time a floor is analysed as a complete system.

Four floors were tested. Three of them were beams with three joists each loaded with a pair of concentrated forces lucated over the central joist. The other one was a floor containing 12 joists, supported on all sides. Gaps were produced on the sheathing. The aspect ratio is 1.19 (Span/Width).

\subsubsection{University of British Columbia, 1983, Test of 13 Floors, Foschi}

In order to assess the extent of floor nonlinear behaviour, failure mode, nail stiffness information, a series of 13 more floors were tested under uniformly distributed load at the University of British Columbia, Canada (Foschi 1985 [21]). The floors were const ructed with 12-38x184 (2" $\left.\times 8^{\prime \prime}\right)$ hemlock joists, No.2 and better grade, $15.8 \mathrm{~mm}$ $\left(5 / 8^{\prime \prime}\right)$ Douglas-fir plywood, and 8d (2-1/2") common nails at $152 \mathrm{~mm}\left(6^{\prime \prime}\right)$ o.c. Experimental results were presented for floor deflection, first joist failure load, and 
subsequent failure loads. Test results were compared with analytical results from a program called FAP developed at UBC.

It was observed that the response of the floors was nearly linear, except for sudden breaks from linearity in coincidence with a major joist failure. Thus even if the nails by themselves had strongly nunlinear load/slip behavior, the effect of this nonlinearity on the overall floor behaviour may be neglected. In particular, this is most evident at load levels below 75 psf $(3.6 \mathrm{kPa})$, which corresponds to an upper limit for usual design loads. This suggests that linear analysis programs like FEAFLO or FAP may be used with sufficient accuracy to predict floor deflertions under load, without need iv consider fastener nonlinearity, particularly at design load levels. The test results showed that, although first joist failure should be used in reliability analysis, the load carrying capacity of the floor assembly is normally higher and several more joists failures usually occur before total collapse. It was also recognized that the variability in floor strength is substantially lower than the variability in bending strength of individual joists. It was also concluded that the joists which have lower $E$ are not generally the ones that fail first in a floor. In only three of the thirteen floors tested was the joist with the lowest modulus of alastirity the first to fail.

\subsubsection{Reliability Analysis, 1983, Foschi}

In the process of implementing reliability-based structural design for wood structures, it was realized that load duration and loading history plays a role in the assessment of long term strength for wood members. It was also realized that another aspect of reliability assessment in light-frame wood structures is that, because: of the usually large variability in material properties, it is important to focus on the structural system rather than the single member.

Foschi (1983, [22]) combined a damage accumulation modei with structural analysis of light-frame wood structures, and examined the safety in the wood structural system during the prescribed service life. 
Table 1.2: Description of test floors, University of Texas at Austin

\begin{tabular}{|c|c|c|c|c|}
\hline Floor groups & Span (ft-in) & Joists, No.2 or better & Joist Spacing (in) & Sheathing \\
\hline 1 & $11-0$ & $2 \times 8, \mathrm{SP}$ & 24 & $3 / 4$-in SP \\
\hline 2 & $14-4$ & $2 \times 10, \mathrm{SP}$ & 24 & $3 / 4$-in. SP \\
\hline 3 & $14-7$ & $2 \times 10, \mathrm{DF}$ & 24 & $3 / 4$-in. SP \\
\hline 4 & $13-1$ & $2 \times 8, \mathrm{DF}$ & 16 & $23 / 32$-in. SP \\
\hline 5 & $12-10$ & $2 \times 8, \mathrm{SP}$ & 16 & $23 / 32$-in. SP \\
\hline \hline
\end{tabular}

\subsubsection{University of Texas at Austin, 1986, Test of 15 Floors, Wheat}

In an attempt to study the behaviour of wood-joist floors loaded to their ultimate capacity, 15 full sized wood-joist floors - each having 10 joists - were tested under uniformly distributed loads at the Ferguson Structural Engineering Laboratory of the University of Texas at Austin (Wheat et. al. 1986, [94]). 15 floors covers a variety of spans. Five groups of floors were tested with 3 replications per group. The spans of each of the five groups, measured from the centers of bearing, were 11 feet $(3353 \mathrm{~mm}) ; 12$ feet 10 inch $(3912 \mathrm{~mm}) ; 13$ feet 1 inch $(4000 \mathrm{~mm}) ; 14$ feet, 4 inch $(4370 \mathrm{~mm})$ and 14 feet 7 inch $(4445 \mathrm{~mm})$. They are listed in Table 1.2.

Behaviour was noted at the design load and at the limit states of first joist rupture and ultimate strength. The general stiffening effect of the sheathing and the twoway action in each system were compared with the assumed bare-joist behaviour at the design load level. It was concluded according to the test of 15 full-size floors that

- The stiffness of the floors at the design load level were greater than required in design. This is due to the contribution of the sheathing with incomplete composite action and two-way action.

- The average strengths at first joist rupture for the floors with $2 \times 10$ joist were lower than those with $2 \times 8$ joists. 
- The mode of failure at ultimate appeared to depend on the rate of loading.

- Regardless of joist spacing, the floors with $2 \times 8$ joists had higher average ultimate strengths than those with $2 \times 10$ joists.

Rosowsky and Ellingwood (1992) [52] realized that strength and servireability limit states are closely inter-related in wood construction. The design of wood beams is often governed by limits on deflection, and the resulting sertion is larger than that required for flexure or shear strength.

Members used in light-frame construction are chosen from standard available dimension lumber sizes. The number of available sizes is relatively small for wood compared to the other materials such as steel. The sertion selected in wood design may be significantly larger than what would otherwise be required by the design" equations.

The reliability increased with respect to ultimate strength by including the deflection limit state and by considering the availability of standard sertions for individual wood members and parallel-member systems. The significance of system effects from load sharing in serviceability reliability is assessed.

The implications that these effects have for the ongoing development of load and resistance factor design (LRFD) provisions for engineered wood construction were examined.

\subsubsection{Ponding}

Other than uniformly distributed load and concentrated load, ponding load can be experienced by flat roofs. Flat roofs may fail due to ponding of rairwaler as evidenced by reports of failures of flat roofs in rain storms. If the roof was initially deflected due to its dead load or due to lack of initial straightness, and if water get access to fill the resulting depression, then the total load at any point on the roof will be increased by an amount proportional to the deflection. The increase: in the load gives rise to more deflection, consequently more load and so on, until the: deflection becomes either stable or continues to increase to failure. The roofs which can stand the ponding load with enough stiffness are considered stable: structures, 
while those which can not stand the ponding load are called unstable structures as far as ponding is concerned. The question is what are the criteria that govern this phenomenon. (Liu and Salinas 1992,[42]).

The amplifying effects of the ponding load were studied by Haussler R.W. (1962, [33] ). These studies were motivated by reports of failures caused by instability in wood, steel and aluminum roofs. In this study, the roof was modeled as a beam deflected in a sine curve subjected to ponding load which is proportional to the deflection of the beam, Figure 1.9.

Kuenzi and Bohannan [39] in 1964 derived an approximate solution for the deflection, bending stresses, and increase in load on beams and decking due to ponding of water or other fluids on roofs or floors. Cases considered are simply supported and clamped beams with uniformly distributed and concentrated load, plus load due to ponding. Roofs were simplified as a beam. Tests of aluminium beams were purformed to verify the theory and significant ponding effects were observed.

The load per unit length of a beam of unit width is given by the formula:

$$
w=w_{0}+k y
$$

where $w_{0}$ is uniformly distributed load, $k$ is weight of ponding fluid per unit depth per unit area, and $y$ is deflection.

The beam deflection is approximated by

$$
y=A \sin \frac{\pi x}{L}
$$

where $L$ is span length, $x$ is distance from reaction and $A$ is a constant to be evaluated.

The constant $A$ is therefore determined as

$$
A=\frac{4 w_{0} L^{4}}{\pi^{5} E I\left(1-\frac{k L}{\pi^{4} E I}\right)}
$$

where $E$ is modulus of elasticity of the beam, and I is moment of inertia. The magnification factor can be defined as 


$$
f_{\mathrm{amp}}=\frac{1}{1-\frac{k L^{4}}{\pi^{4} E l}}
$$

A beam is unstable wa can produce large deflection with the increase of ponding when

$$
k>\frac{\pi^{4} E I}{L^{4}}
$$

A more detailed study can be found in Sawyer's paper (Sawyer, 1967 [81]). The basic function is described as

$$
E I \frac{d^{4} y}{d x^{4}}-k S y=0
$$

in which $\mathrm{E}=$ Young's modulus for the material, I the moment of inertia of the Ix'am, $k$ unit weight of the ponding liquid, $S$ the transverse spacing of beams and $y$ is the deflection of the beam as a function of $x$.

Salama and Moody (1967, [70]) extended the study of the ponding effects using isotropic plate theory, treating the roofs as isotropic plates. Critical stiffness of such a roof was derived.

Folz and Foschi $(1990,[16])$ studied the structural reliability of roofs of lumber joists that are subjected to ponding loads. An approximate ponding amplification factor was derived and a simple design equation is proposed in the context of reliability based design, which is suitable for implementation in a limit-states design code. The basic model involves simplifying the roof into a beam subjected to ponding load on the tributary area.

\subsubsection{The Bending Strength of Wood Members, Damage Accumulation Model}

The limit state design of light frame wood structures requires reliability nssessment of the structures. This process involves structural analysis of the systern to define: various limit states and also properties of individual members. 
The moment resistance of wood members, e.g. beams, is given by many design standards in terms of the geometric properties of the cross-section and the specified or characteristic bending strength of the material, modified by a resistance factor and by a series of adjustment factors accounting for, among other things, moisture effects, rate of loading, preservative treatment, load sharing, bearing, lateral stability, length effect, volume effect, etc. Each one of these adjustment factors is the product of independent research. Studies on the effects of certain parameters on the bending strength of wood flexural members have been adopted by the code-making committees only after serious discussions and deliberations. Adjustment factors concerned with size, rate of loading and duration of load effects have received particular attention by the research community in Canada and the United States. Size effects have also been incorporated into the design formulas as depth factors, length factors and/or volume factors. Load-history effects and creep-rupture phenomena have been studied using damage accumulation models and taken into account by means of a "Load Duration Factor".

Size effects on the strength of lumber have been reported by Madsen (1978, [47]). Madsen and Nielson (1981, [50]) conducted in-grade tests on lumber subjected to hending. These studies showed that:

- longer beams had lower strength

- deeper beams had lower strength

- strength depends on the configuration of the loading scheme

- beams with higher stress volume had lower strength

The size effect was reported by Madsen and Buchanan (1986, [46]) and explained using the modified weakest link theory, assuming that lumber is perfectly brittle and consisting of a series of small, discrete, elements. Failure of any one of these elements - the weakest link - signals the failure of the material. 


\subsection{Objectives}

Limit state design of wood joist structures such as floors and roofs requires a sound structural analysis and an accurate understanding of material properties of the components. The design procedures so derived should be accurate enough to warrant. the safe design of a structure and also simple enough to be used in prartire and easily adopted by structural engineers.

As described in the literature review, the current approach toward designing wood joist floors has some short comings.

- The simple T-beam approach ignores the two-way action. It is therefore not suitable to describe deflection of floors subject to concentrated load, since the load sharing among adjacent joists is ignored. This load sharing has herel observed by a number of tests cited in the literature.

- The finite element analysis was used to account for most of the factors afferting floor deflection. This approach, however, is most suitable to be used in a research environment and too complicated to be adopted as a practical design procedure.

This thesis is, therefore, aimed at finding a practical approach to the design of wood joist floors and roofs. By using orthotropic plate theory, a floor or a roof is treated as a whole structure instead of breaking it into small components. Hecauseof the simplicity of T-beam formula and it's wide acceptance, it will be- very useful to reach the final result in the form of a T-beam formula with a modification factor. Study focuses on the serviceability of the structures. The study of the strength of the floors and roofs can be carried out in a similar approach.

The formula derived from orthotropic plate theory is verified by tests reportud in the literature. The orthotropic plate theory is then compared to the T-bearn formula to determine the suitability of using the T-beam formula. If the T-beam formula can not be used directly, then it can be modified. T wo loading conditions will be considered for floors: uniformly distributed load and concent rated load. For roofs, ponding and its amplification effects will also be investigated. 
Factors that affect the bending strength of wood members will also be discussed. A total damage accumulation model will be proposed to assess the bending strength of wood components. This model and derived formula from structural analysis can be used in a reliability assessment of wood joist floors and roofs.

\subsection{Organization of the Thesis}

Chapter 1 Background, literature review and objective of the research

Chapter 2 Floors are modeled as an orthotropic plale. Deflection of floors are computed and compared against tests and results from the T-beam formula. Upper and lower bound of floor deflection are defined. The upper bound is also verified using a different approach. Only uniformly distributed load is considered. A parametric study is also carried out. Formulations for other boundary conditions other than simply supported are derived.

Chapter 3 Effects of aspect ratios on deflection of floors are examined in this chapter. The value of the aspect ratios defines the scope in which the T-beam formulation can be used. Long span floors with high aspect ratio, span divided by width of the floor, have to be designed according to plate theory instead of T-beam formula.

Chapter 4 As an extension of last chapter, procedures for designing long span floors are examined.

Chapter 5 A simple procedure to determine the maximum deflection of plywood sheathed wood joist floors subjected to concentrated load is introduced. By realizing that the plywood sheathed floors are much stiffer in the direction of joists than in the transverse direction, determination of the location of maximum deflection is carried out using a simplified approach. Then the maximum deflection can be calculated from one single formula. This procedure is valid for the range of current commercially available sizes of joists and plywood panels. 
Chapter 6 Flat roofs subject to ponding load are studied. Criteria are derived to define ponding stable rooks.

Chapter 7 Bending strength of wood members is studied $A$ total damage arcumulation model is proposed to unify size effects, load configuration efferts on bending strength of lumber into one single formula. This model can be adopted in reliability analysis of wood joist floors and roofs. 

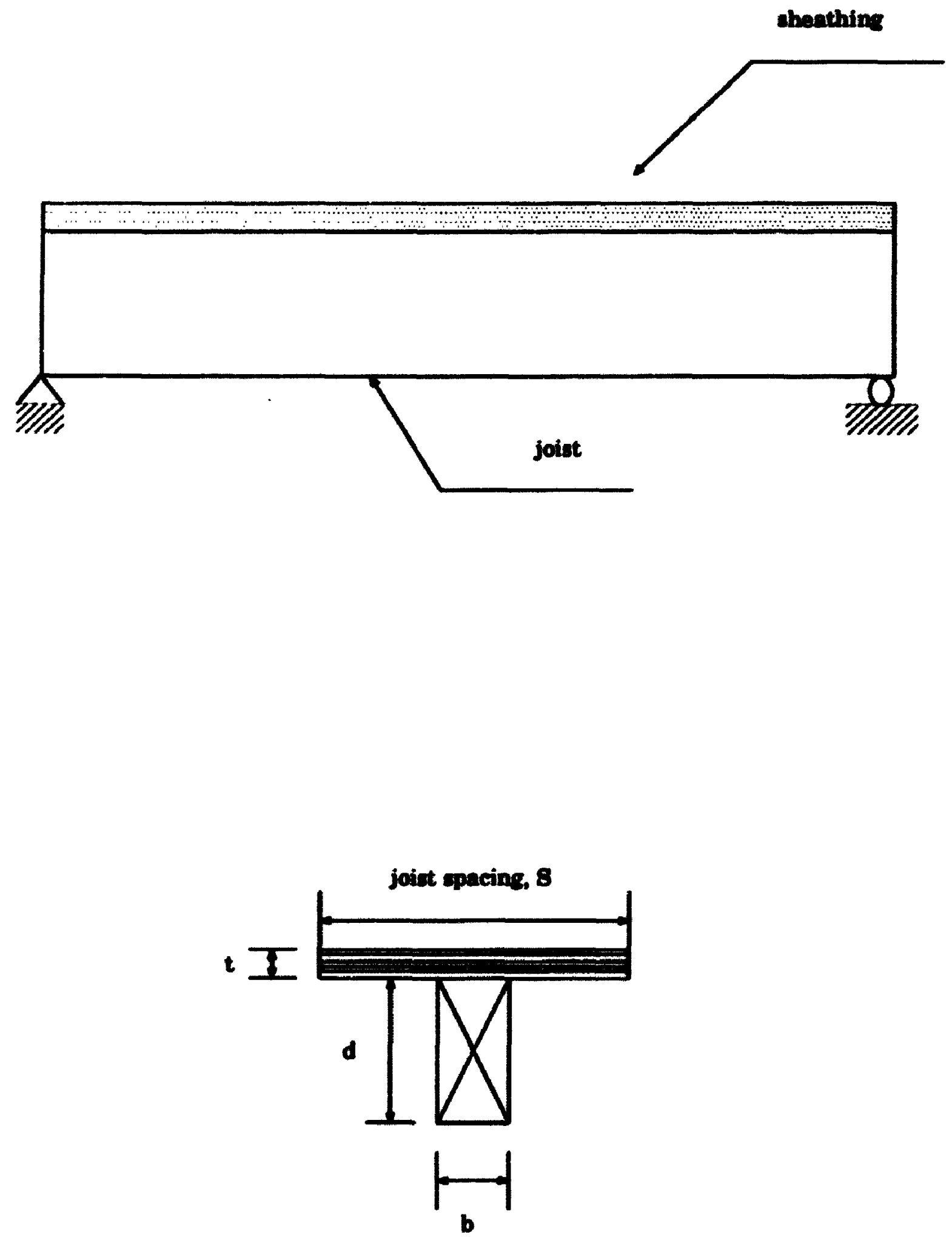

Figure 1.1: Layerd beams or T.beams 

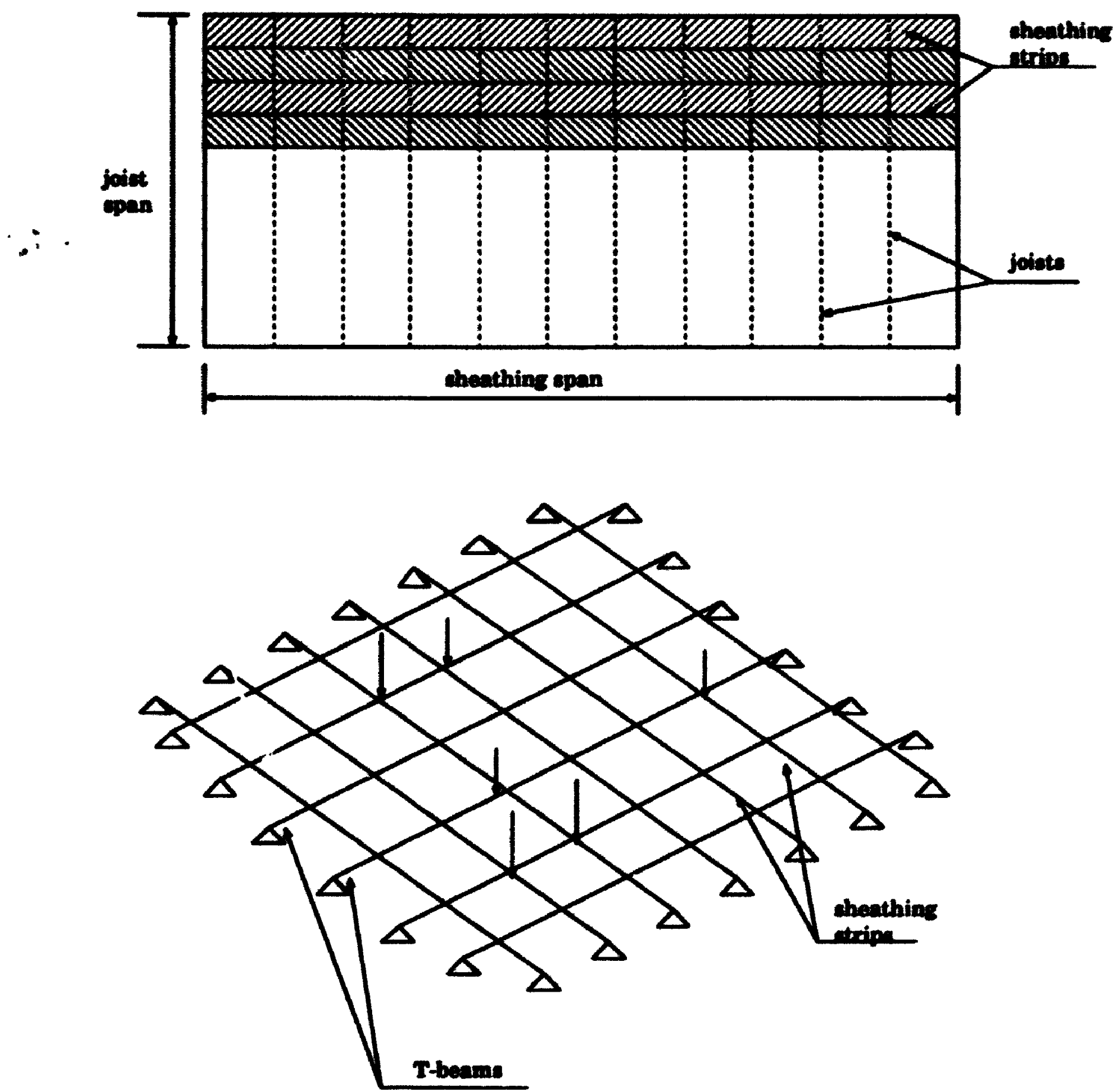

Figure 1.2: Idealization of a floor system 


\section{CSU model}

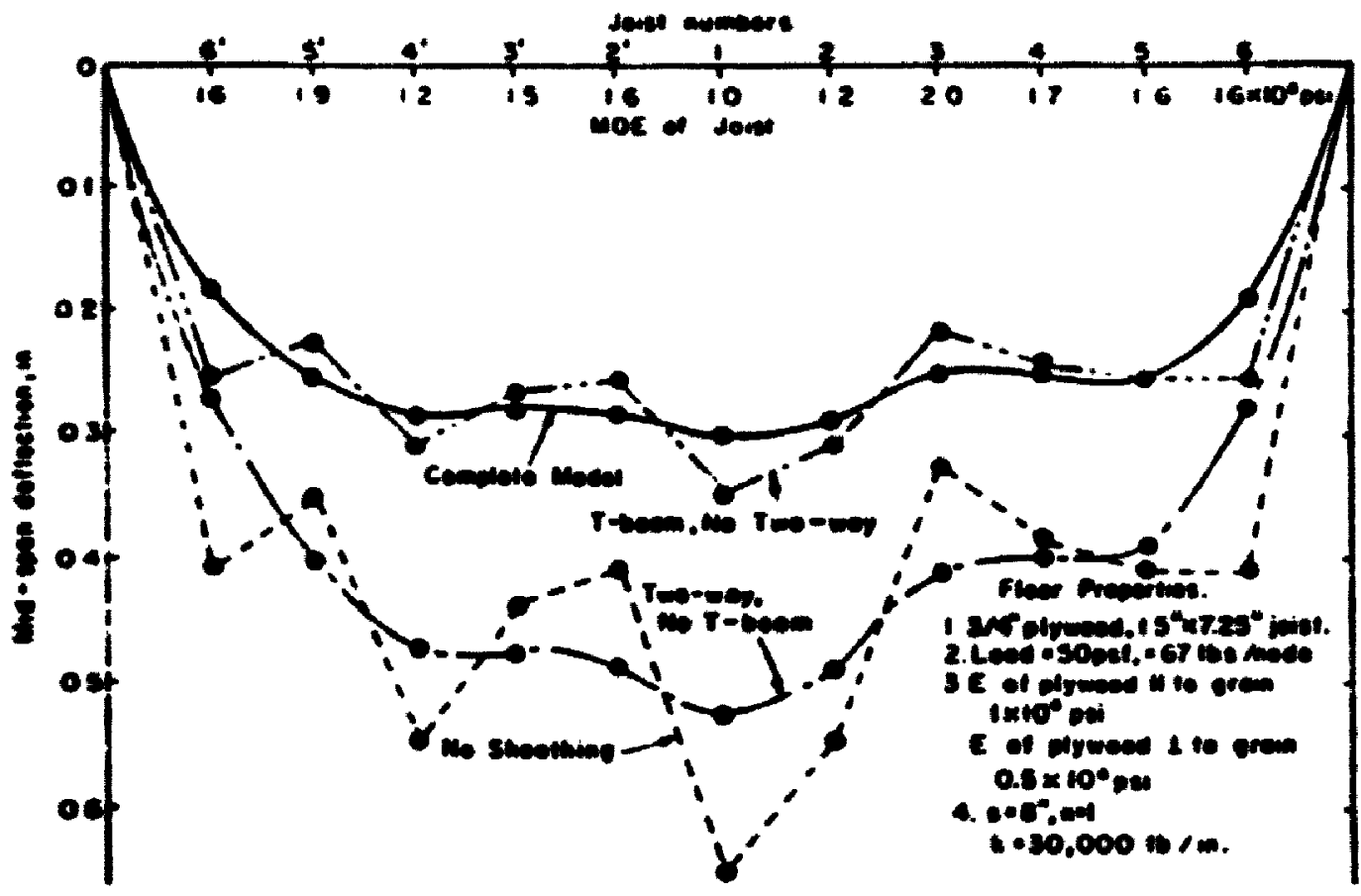

Figure 1.3: CSU result: Composite and two-way behaviour of wood joist floor system with varying joist moduli. 


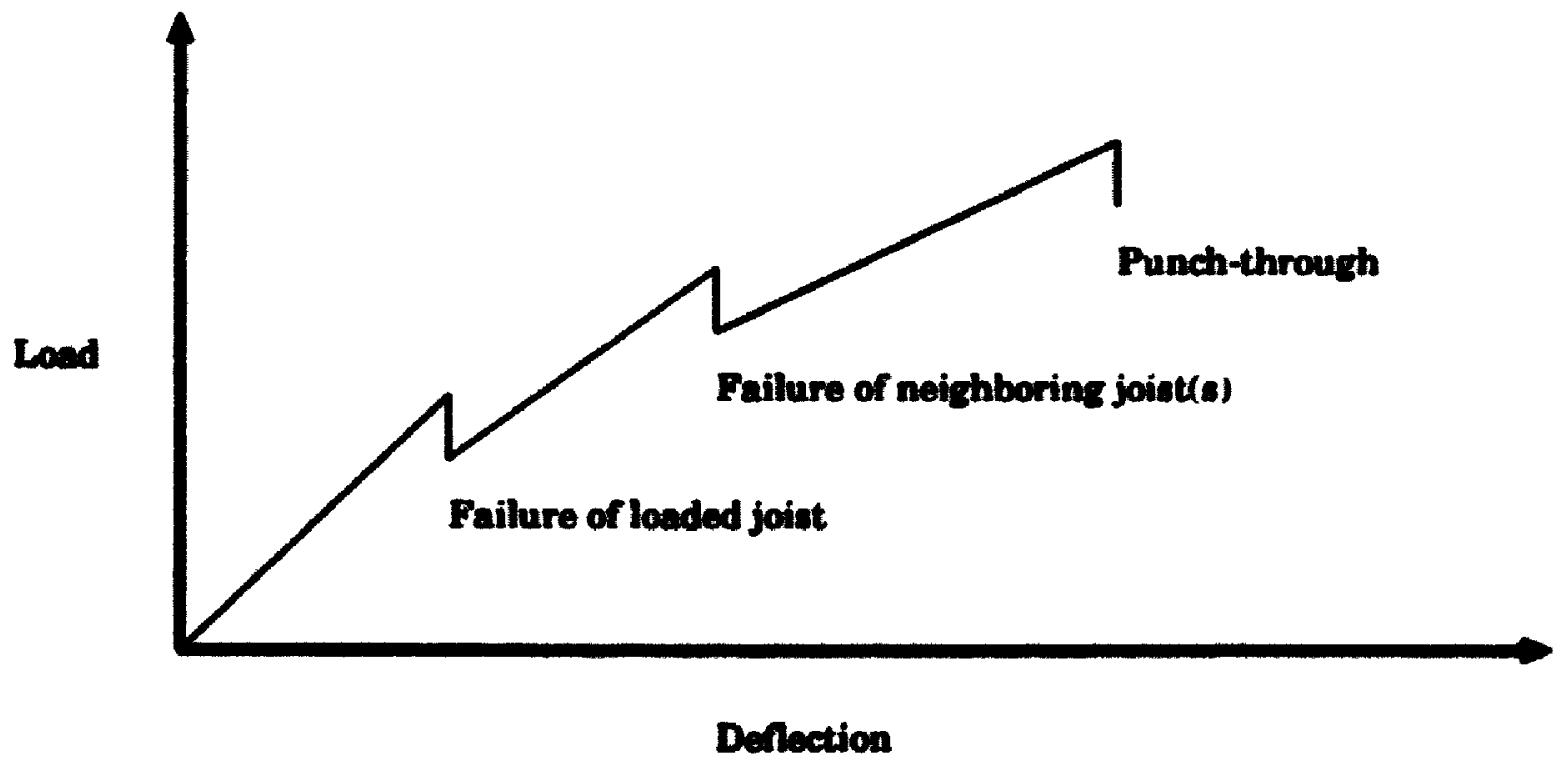

Figure 1.4: Typical load-deflection behaviour of flowrs. 


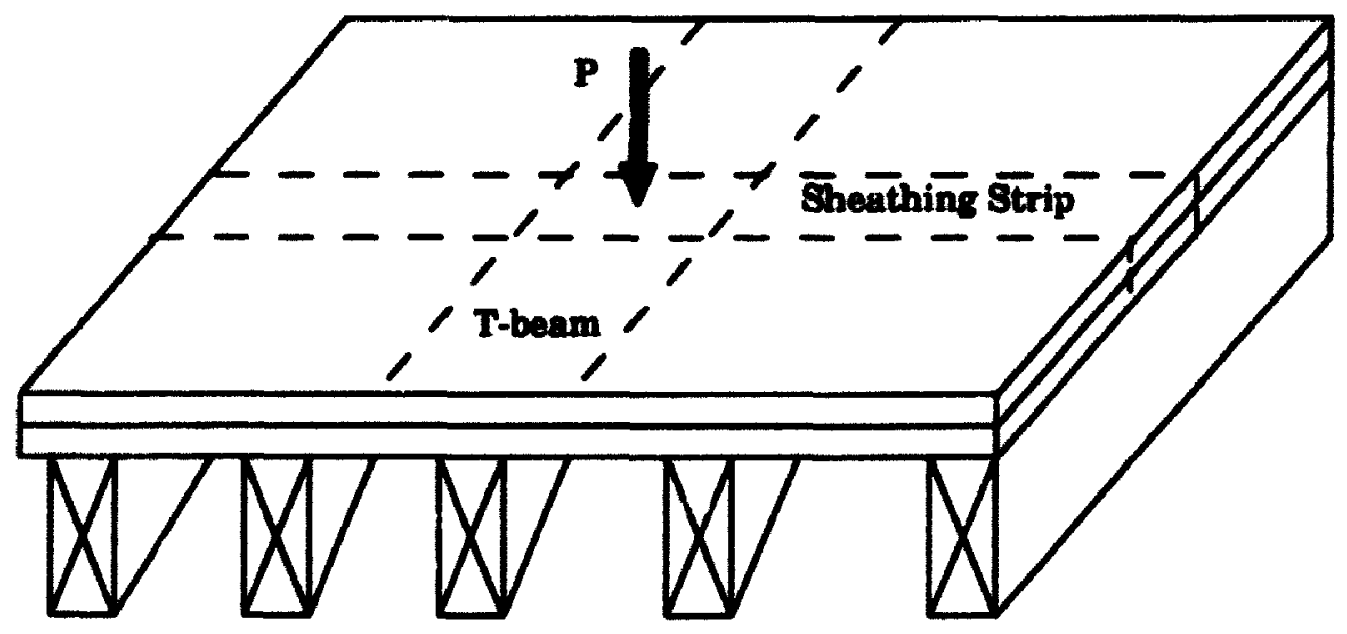

T-beam
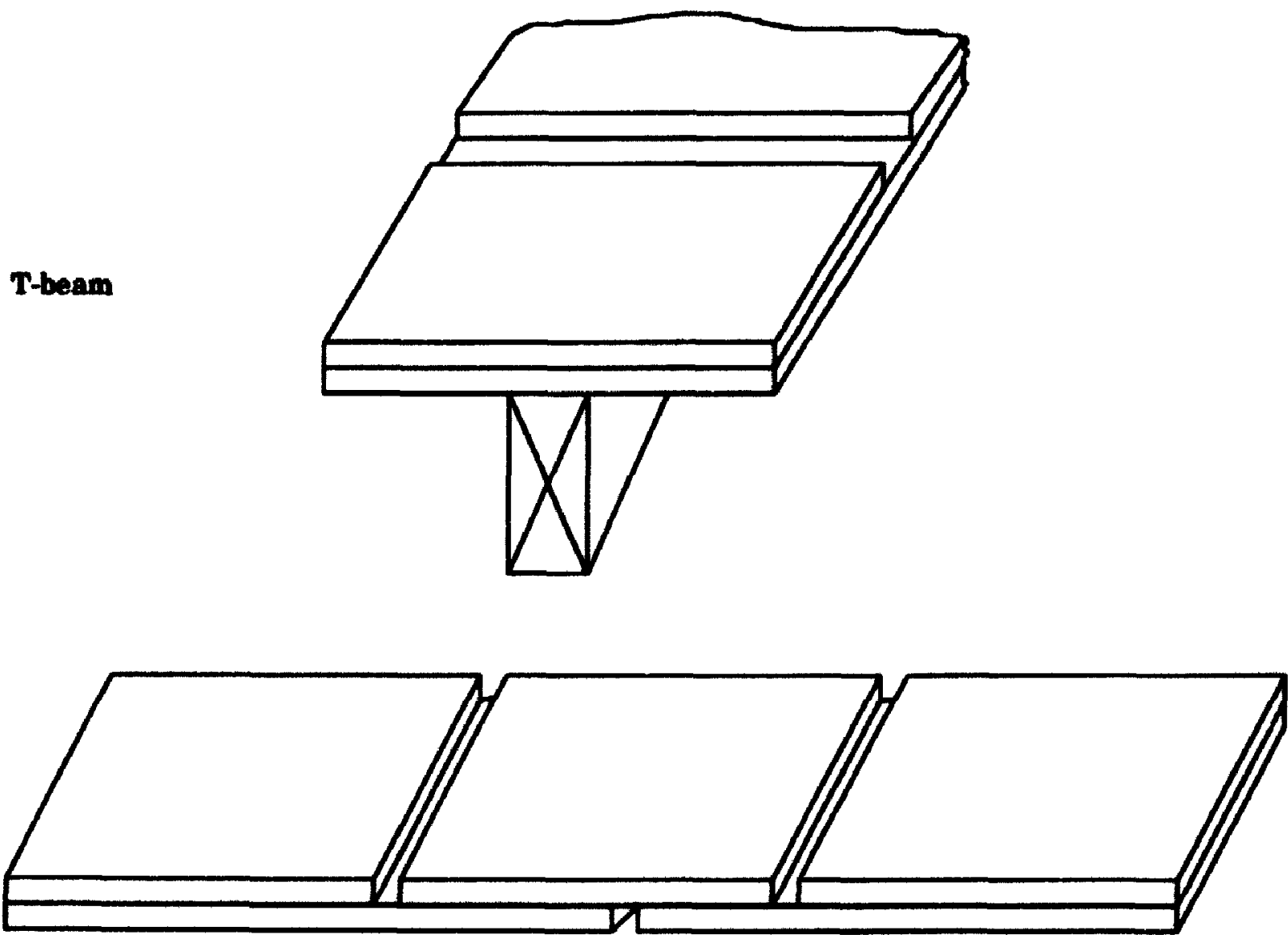

Sheathing otrip

Figure 1.5: Crossing beam mode] of wood joist floor system with gaps. 


$$
\mathbb{L L}
$$



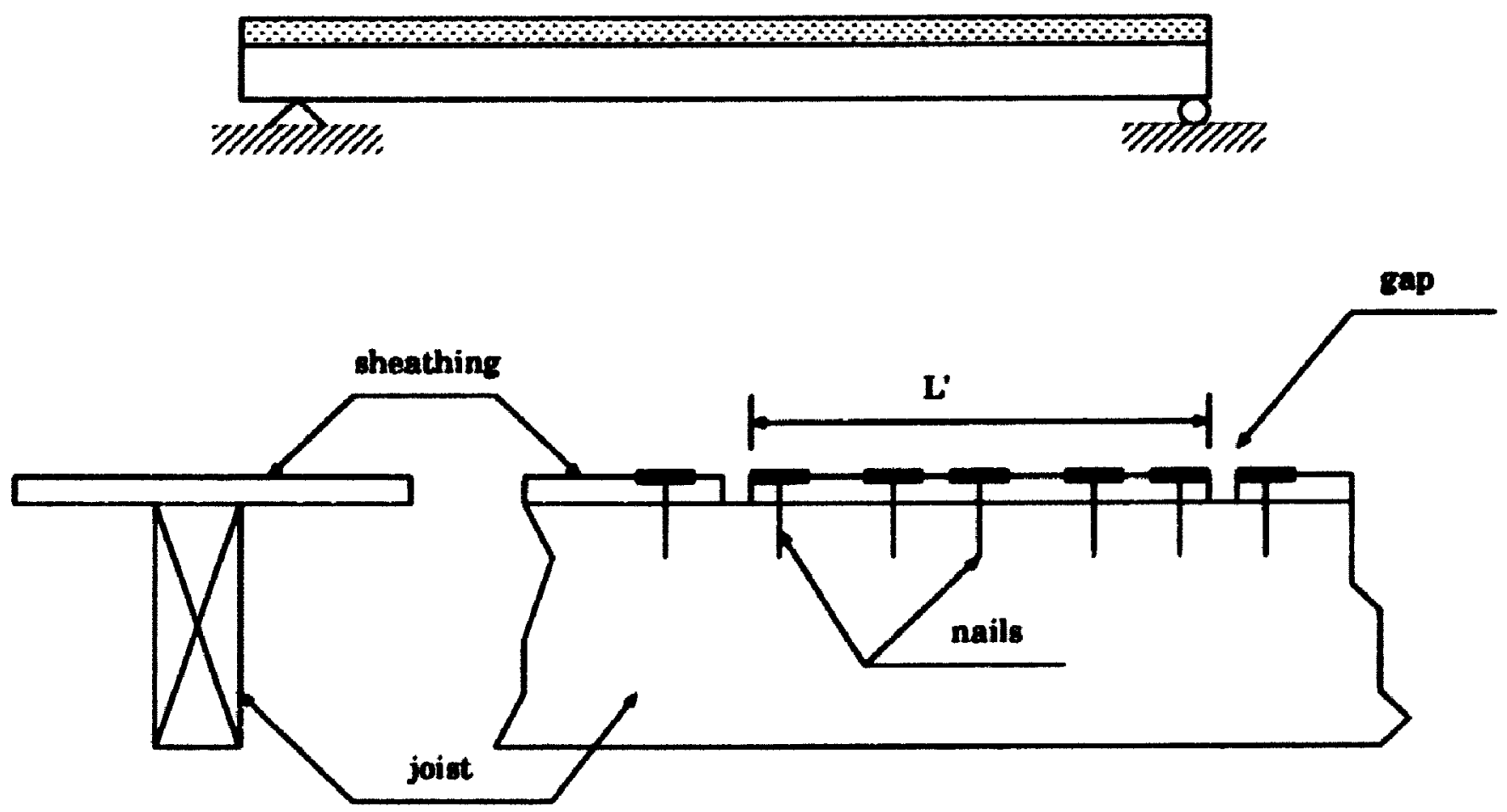

Figure 1.7: T-beam model. 

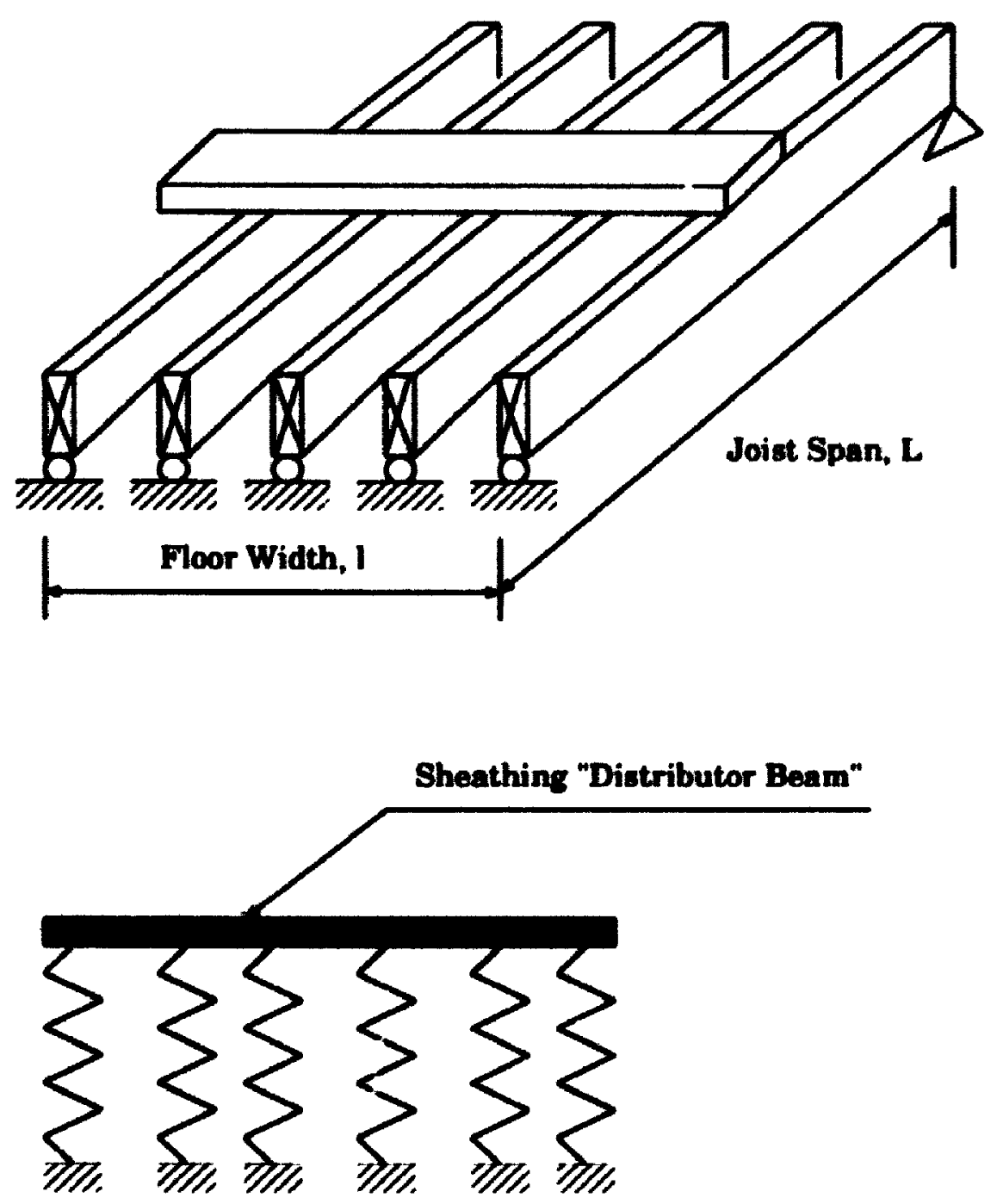

Figure 1.8: Beam-Spring Analog model.

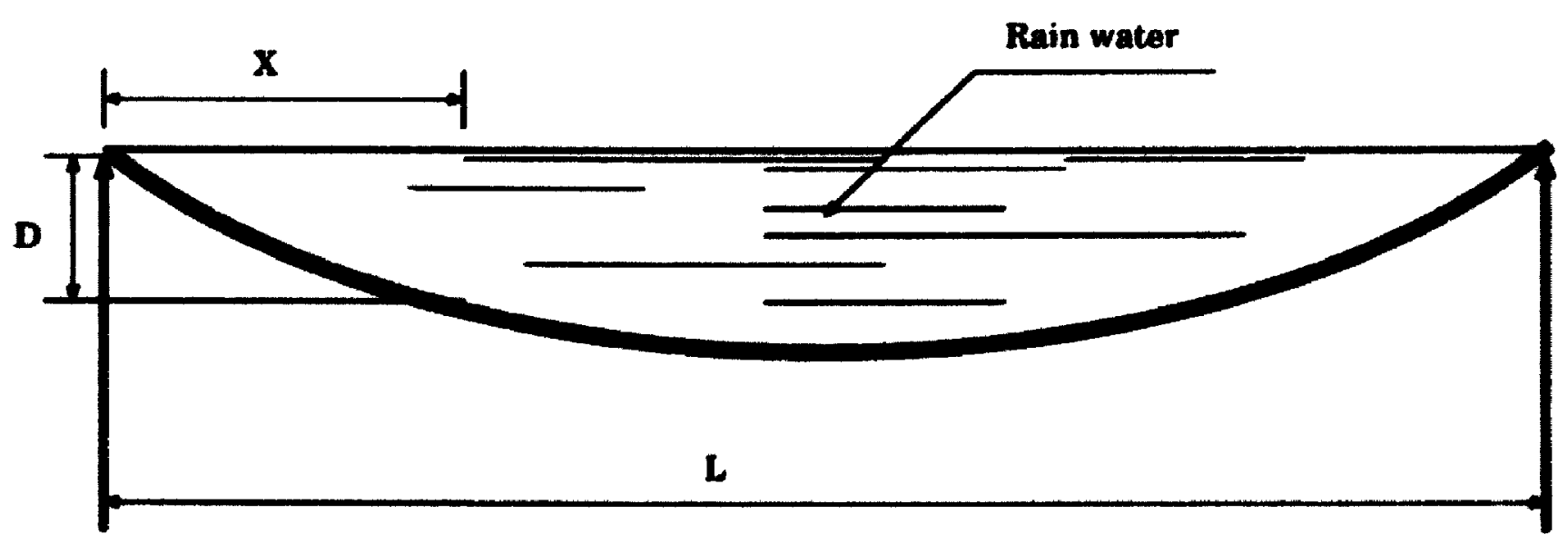

Figure 1.9: Deflection of joists under ponding kad. 


\section{Chapter 2}

\section{Designing Wood Joist Floors as Orthotropic Plates}

\subsection{Introduction}

Wood joist floors consist of joists and sheathing. The sheathing can be plywood panel, waferboard or other panel products. The sheathing can be nailed or glued to the joists. Since several panels are needed for each floor, there are usually gaps between panels. There can be several layers of sheathing, Figure 2.3. The floor is subject to uniformly distributed load, concentrated load or other forms of loads.

Wood joist floors used to be designed as a bare joist subjected to uniformly distributed load on the tributary area. In the 1970 s, it was realized that the contribution of the sheathing materials to the stiffness of floors is significant. Research war carried out in the United States and Canada to find ways to design these floors in a more realistic approach. Several models have been developed since. One approach is to design the floor as a T-beam (McCutcheon 1977, [62]). The T-beam consists of a joist as the web, plywood sheathing as the flange. Partial composite action due to non-rigid connections was also considered. In order to consider the variability of modulus of elasticity (MOE) of joists, a beam-spring analog approach was proposed, based on the T-beam theory. Using an analog which represents a floor as a beam supported by elastic springs, the T-beam method is extended to account for variability of joist stiffness and two-way action due to the cross-joist 
distributional properties of the sheathing. It is shown that this method computes individual midspan joist deflection, which are virtually identical to those obtained from large-scale finite element program (Thompson et al. [86] 1975, [85] 1977), and is capable of accurately predicting the performance of real floors.

The most comprehensive study is the finite element analysis. Thompson, Vanderbilt and Goodman (1977, [85]) developed a finite element computer program. FEAFLO for calculating the performance of wood floors. Based on a crowsing beam analysis, this model considers some factors not included in the simpler T-beam model, such as joist-to-joist variability and two-way action. Foschi (1982, [20]) presented a finite element analysis technique which includes lateral and torsional joist. deformations as degrees of freedom and considers plate action in the sheathing. The finite element analysis is an excellent tool in research to examine the behavior of floors. It can be used to study the details like gaps in the sheathing, multi-layer sheathing, non-rigid connections, variability of joist MOE and different boundary conditions. However, it is not easily used directly by designers in prartice. ('harts or span tables have to be produced using finite element analysis.

The research at FPL, Forest Product Laboratory U.S., was aimed at finding out design procedures to be used in practice. The proposed beam-spring analog involvers solving multiple equations. The simplest approach is the $\mathbf{T}$-beam approach which uses conventional beam theory and accounts for details such as gaps in sheathing, partial composite action between joists and sheathing.

Joists in the floor assembly have different MOE and the sheathing distributes loads so that, the stiffer, and hence stronger joist carries more load, thus guaranteeing a smooth surface of deflection. Every joist in a floor assernbly has an mual chance of having a certain stiffness if they are selected from the same grade. Fach floor will have the same probability of having a certain behaviour as the rest of the floors assembled using joists and plywood of the same grade. It is the "average" properties of a floor that should be used to assess design procedures. It is therefore the statistical "average" properties that should appear in the LRFD formula for design purpose.

The primary component in a wood-joist floor assembly is the joist. The joists 
sustain the major part of the load acting on the floor. The plywood sheathing is a secondary material. It has two major functions. One is to increase the bending rigidity of the floor in the joist direction. This is evidenced by the study of the T-beam. It is also called composite action. The other function of the sheathing is to transfer load laterally from the weaker joists to the stronger ones. In case of a failure of one of the joists, the load will be redistributed to the adjacent of the joists. This is also shown by tests where the floor continued to sustain load even after several joists have failed. The influence of boundary conditions in the transverse direction is directly related to the stiffness of the sheathing.

Instead of breaking the floor up into crossing beams to account for the invidual stiffness, the floor assembly can be treated as an orthotropic plate by assuming that all the joists have the same property statistically. The rigidity of the plate in the direction perpendicular to the joists is assumed to be the rigidity of the plywood. The contribution of joists to the torsional stiffness is not considered. The effects of bridging between joists are not studied, but can be a topic of further investigation. Bridging makes a floor stiffer since it increases the torsional stiffness and bending stiffness of the floor in the transverse direction. It is assumed that the floors are not bridged. The rigidity of the plate in the direction of joists is the rigidity of the composite T-beam. The torsional rigidity of the plate is that of the plywood. This orthotropic plate approach gives a reasonable description of floor behavior with joists of the same grade.

In this chapter, deflection of a floor is described using the orthotropic plate theory and then compared against $T$-beam theory and tests from previous studies.

\subsection{Deflection of Floors as Described by Orthotropic Plate Theory}

The governing equation for an orthotropic plate is ([40] or [95])

$$
\left(D_{x} \frac{\partial^{4}}{\partial x^{4}}+2 H \frac{\partial^{4}}{\partial x^{2} \partial y^{2}}+D_{y} \frac{\partial^{4}}{\partial y^{4}}\right) w(x, y)=q(x, y)
$$


where

$x \quad$ coordinate in the joist direction

$y \quad$ coordinate in the direction perpendicular to joists

$D_{x} \quad$ bending stiffness in the direction of joists $(\mathrm{N} \mathrm{mm}$ ) taken as the hending rigidity of the T-beam, $D_{x}=(E I)_{r} / S$.

$D_{v} \quad$ bending rigidity of the floor in the direction perpendicular to joists. It therefore equals the bending rigidity of plywood sheathing, $D_{y}=B_{h}$. $H$ torsional rifridity, assumed to be $2 H=D_{y}$.

$(E I)_{e}$ the effective bending stiffness of the T-beam

$S \quad$ spacing between two joists

\subsection{Wood Joist Floors Subject to Uniformly Dis- tributed Load $q_{0}$}

For a wood joist floor subjected to uniformly distributerl load $q_{0}$, Figure 2.3

$$
q(x, y)=q_{0}
$$

Assuming that the floor is simply supported on four sides, the solution for requa. tion 2.1 is

$$
\begin{aligned}
& w(x, y)=\sum_{m=1}^{\infty} \sum_{n=1}^{\infty} w_{m n} \sin \frac{m \pi x}{L} \sin \frac{n \pi y}{B} \\
& w_{m n}=\frac{q_{m n}}{\frac{m^{4} n^{4}}{L^{4}} D_{x}+2 H \frac{m^{2} n^{3} n^{4}}{L^{2} B^{2}}+\frac{n^{6} \pi^{4}}{B^{4}} D_{y}} \\
& q_{m n}=\frac{4 q_{0}}{m n \pi^{2}}(1-\cos m \pi)(1-\cos n \pi)
\end{aligned}
$$

The bending rigidity $D_{z}$ is the effective rigidity of the T-beam, $D_{x}=(E /)_{r} / S$. $(E I)_{e}$ is the bending stiffness of the T-bearn. 
The following sections are devoted to examining the upper and lower bound of floor deflection so that parametric study can be conducted for the scope of all possible deflection.

\subsection{Unfastened Floors - Upper Bound of Floor Deflection}

The joists are usually attached to the sheathing using either nails or glue. In an extreme case, when the stiffness of nails becomes zero, the sheat hing is not attached to the joists at all. This defines the maximum possible deflection, i.e. the upper bound. The upper bound can also be obtained by assuming the stiffness of connection to be zero in computing the stiffness of the T-beam which is used in the orthotropic plate theory. The lower bound will be defined by floors with plywood glued to the joists. Throughout this thesis, the term "glued" implies a rigid connection, even though in reality a glued connection does not guarantee a perfect bonding.

We will assume the plywood is not attached to the joists at all. Then the floor assembly is considered to be an orthotropic plate (the sheathing itself) sitting on top of a series of joists, as shown in Figure 2.2. The result from this approach should be the same as the result by assuming the nail stiffness being zero in calculating $D_{\boldsymbol{x}}$. The solution for the lower bound of deflection is derived as follows.

The deffection of an orthotropic plate $w(x, y)$ is represented in the following differential equations:

$$
\begin{gathered}
\left(D_{x} \frac{\partial^{4}}{\partial x^{4}}+2 H \frac{\partial^{4}}{\partial x^{2} \partial y^{2}}+D_{y} \frac{\partial^{4}}{\partial y^{4}}\right) w(x, y)=q(x, y) \\
q(x, y)=Q(x, y)-\frac{Q_{j}(x)}{d y} \delta\left(y-y_{j}\right) \quad j=1,2, \ldots, N \\
Q_{j}(x)=\left.(E I)_{b} \frac{d^{4} w(x, y)}{d x^{4}}\right|_{y=y,}
\end{gathered}
$$

where 
$Q(x, y) \quad$ normal load on the floor

$Q_{j}(x) \quad$ reaction from the jth joist

$y_{j} \quad$ position of the jth joist

$(E I)_{b}$ bending rigidity of the joists

dy $\quad$ width of supports

For a floor simply supported on four sides, assume

$$
w(x, y)=\sum_{m=1}^{\infty} \sum_{n=1}^{\infty} A_{m n} \sin \frac{m \pi x}{L} \sin \frac{n \pi y}{B}
$$

$q(x, y)$ can be expanded to a Fourier series

$$
q(x, y)=\sum_{m=1}^{\infty} \sum_{n=1}^{\infty} q_{m n} \sin \frac{m \pi x}{L} \sin \frac{n \pi y}{B}
$$

where

$$
q_{m n}=\frac{4}{L B} \int_{0}^{L} \int_{0}^{B} q(x, y) \sin \frac{m \pi x}{L} \sin \frac{n \pi y}{B} d x d y
$$

for a floor supported by joists and subjected to uniformly distributed kad qu,

$$
Q(x, y)=q_{0}
$$

Substitute the above equation into Equation 2.5 and 2.6

$$
\begin{aligned}
q_{m n}= & \frac{4}{L B} \int_{0}^{L} \int_{0}^{B} q_{0} \sin \frac{m \pi x}{L} \sin \frac{n \pi y}{B} d x d y \\
& -\frac{4}{L B} \int_{0}^{L} Q_{j}(x) \sin \frac{n \pi y_{1}}{B} \sin \frac{m \pi x}{L} d \tau
\end{aligned}
$$

from equation 2.7

$$
\begin{aligned}
q_{m n}= & \frac{4 q_{0}}{m n \pi^{2}}(1-\cos m \pi)(1-\cos n \pi) \\
& -\left.\frac{4}{L B} \int_{0}^{L}(E I)_{b} \frac{\partial^{4} w(x, y)}{\partial x^{4}}\right|_{y=v}, \sin \frac{n \pi y_{2}}{B} \sin \frac{m \pi x}{L} d x
\end{aligned}
$$

from equation 2.8 


$$
\begin{aligned}
q_{m n}= & \frac{4 q_{0}}{m n \pi^{2}}(1-\cos m \pi)(1-\cos n \pi) \\
- & \frac{4}{L B}(E I)_{b} \sin \frac{n \pi y_{j}}{B} \\
& \left(\int_{0}^{L} \sum_{i=1}^{\infty} \sum_{k=1}^{\infty} A_{i k}\left(\frac{i \pi}{L}\right)^{4} \sin \frac{i \pi x}{L} \sin \frac{k \pi y_{j}}{B} \sin \frac{m \pi x}{L} d x\right)
\end{aligned}
$$

Apply orthogonal rule and integrate over the range of 0 to $L$ in the $x$ direction,

$$
\begin{aligned}
q_{m n} & =\frac{4 q_{0}}{m n \pi^{2}}(1-\cos m \pi)(1-\cos n \pi) \\
& \left.-\frac{2}{B}(E I)_{b}\left(\frac{m \pi}{L}\right)^{4} \sin \frac{n \pi y_{j}}{B} \sum_{k=1}^{\infty} A_{m k} \sin \frac{k \pi y_{j}}{B}\right)
\end{aligned}
$$

from equation 2.52 .8 and 2.9

$$
\left[D_{x}\left(\frac{m \pi}{L}\right)^{4}+2 H\left(\frac{m \pi}{L}\right)^{2}\left(\frac{n \pi}{B}\right)^{2}+D_{y}\left(\frac{n \pi}{B}\right)^{4}\right] A_{m n}=q_{m n}
$$

then

$$
D_{m n} A_{m n}+\sum_{i=1}^{\infty} B_{m n i} A_{m i}=Q_{m n}
$$

where

$$
\begin{aligned}
& D_{m n}=D_{x}\left(\frac{m \pi}{L}\right)^{4}+2 H\left(\frac{m \pi}{L}\right)^{2}\left(\frac{n \pi}{B}\right)^{2}+D_{y}\left(\frac{n \pi}{B}\right)^{4} \\
& B_{m n i}=\frac{2}{B}(E I)_{b}\left(\frac{m \pi}{L}\right)^{4} \sin \frac{n \pi y_{j}}{B} \sin \frac{i \pi y_{j}}{B} y_{j} \\
& Q_{m n}=\frac{4 g_{0}}{m n \pi^{2}}(1-\cos m \pi)(1-\cos n \pi)
\end{aligned}
$$

For a floor with $N$, joists:

$$
B_{m n i}=\sum_{j=1}^{N_{j}} \frac{2}{B}(E I)_{b}\left(\frac{m \pi}{L}\right)^{4} \sin \frac{n \pi y_{j}}{B} \sin \frac{i \pi y_{j}}{B}
$$

The unknowns $A_{m n}$ can be solved from the above equations. The results from this approach and the stiffened plate approach will be compared later when the bending stiffiness of the T-beam, $D_{x}$, is defined. 


\subsection{Deflection of Floors as Described by the $T$. beam Theory}

A $T$-beam is modelled as shown in Figure 2.3. The flange is the plywood sherathing with width $S$, where $S$ is the spacing between the joists. The wob is the joist. The maximum deflection is

$$
\Delta=\frac{5}{384} \frac{q L^{4}}{(E I)_{e}}
$$

The upper bound of the maximum deflection can be found by assuming that there is no attachment between the joists and the plywood. This is calked an unfastened floor. The lower bound can be found by assuming the plywood is rigidly gluevl to the joists. The effective rigidity $(E I)_{e}$ is described in the following morticuns.

\subsubsection{Lower Bound}

Assume that the web and flange are rigidly glued having no relative slip wo cach other. This kind of floors is called a glued floor. "he cross-sertion is shown in Figure 2.3. According to Timoshenko, the neutral axis can be calculated as

$$
\begin{aligned}
y_{0} & =\frac{d}{2}+\frac{d+t}{2} \frac{E_{2} A_{2}}{E_{2} A_{2}+E_{1} A_{1}} \\
& =\frac{d}{2}+\frac{d+t}{2} \frac{B_{a} S}{B_{a} S+E_{j} d b}
\end{aligned}
$$

where

$$
\begin{aligned}
& \text { yo distance between the neutral axis and the bottom of the woll, } \\
& \text { d height of the web or joist } \\
& t \text { thickness of the flange or plywood } \\
& E_{1}, E_{2} \text { modulus of elasticity of the web and the flange respectively } \\
& A_{1}, A_{2} \text { area of the joist and plywood respectively } \\
& B \text {. tensile stiffness of the plywood } \\
& B_{a} \quad \text { bending stiffness of the plywood }
\end{aligned}
$$




$$
\begin{array}{ll}
S & \text { joist spacing } \\
E & \text { MOE of joists }
\end{array}
$$

It can be rewritten as

$$
\begin{gathered}
y_{0}=\frac{d}{2}+\delta \\
\delta=\frac{d+t}{2} \frac{E_{2} A_{2}}{E_{2} A_{2}+E_{1} A_{1}} \\
=\frac{d+t}{2} \frac{B_{a} S}{B_{a} S+E_{j} b d}
\end{gathered}
$$

The $b$ represents the effects of the flange or the contribuiion of the plywood sheathing. The effective rigidity $(E I)$, is therefore

$$
\begin{aligned}
(E I)_{c} & =(E I)_{1}+(E A)_{1} \delta^{2}+(E I)_{2}+(E A)_{2}\left(\frac{d+t}{2}-\delta\right)^{2} \\
& =E_{j} \frac{b d^{3}}{12}+E_{j} b d \delta^{2}+B_{b} S+B_{a} S\left(\frac{d+t}{2}-\delta\right)^{2}
\end{aligned}
$$

\subsubsection{Upper Bound}

Assume that the web and the flange are not attact.ad to each other at all. The plywood sheathing simply sits on top of joists. This will give the maximum possible deflection of the T-beam. The cross section is shown in Figure 2.3 .

The effertive bending rigidity is

$$
\begin{aligned}
(E I)_{e} & =(E I)_{1}+(E I)_{2} \\
& =E_{j} \frac{b d^{3}}{12}+B_{b} S
\end{aligned}
$$

\subsubsection{Composite Action - Comparison Between the Upper and Lower Bound}

Let's compare the upper and lower bound of the maximum deflection. Let $K_{1}$ represent the effective rigidity of the unfastened floor, $K_{2}$ represent the effective 
rigidity of the glued floor. Then:

$$
\begin{aligned}
K_{1}=(E I)_{e} & =(E I)_{1}+(E I)_{2} \\
& =E, \frac{b d^{3}}{12}+B_{6} 5
\end{aligned}
$$

and

$$
\begin{aligned}
K_{2} & =(E I)_{1}+(E A)_{1} \delta^{2}+(E I)_{2}+(E A)_{2}\left(\frac{d+t}{2}-\delta\right)^{2} \\
& =E_{j} \frac{b d^{3}}{12}+E_{j} b d \delta^{2}+B_{b} S+B_{a} S\left(\frac{d+t}{2}-\delta\right)^{2}
\end{aligned}
$$

$\delta$ is in Equation 2.26, or in a different form:

$$
K_{2}=h_{1}+f_{v}
$$

where

$$
\begin{aligned}
f_{v} & =(E A)_{1} \delta^{2}+(E A)_{2}\left(\frac{d+t}{2}-\hbar\right)^{2} \\
& =E_{j} b d \delta^{2}+B_{a} S\left(\frac{d+t}{2}-\delta\right)^{2}
\end{aligned}
$$

is the adheaive factor which describes the effects of connertion betwern the joists and sheathing.

An Example.

As an example to illustrate the upper bound and lower bound of the maximum deflection of a T-beam, consider the following floor configuration (Talsk-2 1, Sluer wood and Moody [84] ).

joists:

D.Fir, No.1/No.2

E

$11000 \mathrm{MPa}$

$38 \times 184$ or $2^{\prime \prime} \times 8$ "

spacing $S=16^{n}$ or $406 \mathrm{~mm}$ 
span $L=12$ or $3660 \mathrm{~mm}$

plywood: (Table 7.3D, CWC [6])

Canadian softwood plywood, standard construction

regular grades, unsanded, 4 plies

orientation of applied force relative to face grain: $0^{0}$

plywood thickness: $15.5 \mathrm{~mm}$

$\mathrm{Hb}=430,000 \mathrm{~N} \cdot \mathrm{mm}^{2} / \mathrm{mm}$

$\mathrm{Ba}=75,000 \mathrm{~N} . \mathrm{mm} / \mathrm{mm}$

load:

$$
\begin{aligned}
\mathrm{q} & =40 \mathrm{lbf} / \mathrm{ft}^{2} \\
& =1.9 \mathrm{kPa}
\end{aligned}
$$

Ro'sults of the calculation is shown below:

From 2.29 and 2.30:

$$
\begin{aligned}
& h_{1}=217 k N . m^{2} \\
& h_{2}=434 k N \cdot m^{2} \\
& f_{1}=h_{2}-K_{1}=217 k N . m^{2} \\
& \delta=28.4 \mathrm{~mm} \\
& \delta / h=15.4 \% \\
& h_{1} / K_{2}=50 \%
\end{aligned}
$$

Maximum deffections (Equation 2.22):

Cpper bound: $\Delta=8.36 \mathrm{~mm}$

Lower bound: $\Delta=4.18 \mathrm{~mm}$

Test result: $\Delta=6.78 \mathrm{~mm}$ (Sherwood and Moody, [84])

In this example. the upper bound is twice as big as the lower bound. The test result of a nailed floor is in the middle of the upper and lower bound. The composite artion is significant as evidenced by the value of $f_{v}$. 


\subsubsection{Upper Bound of Deflection - Comparison of Three Approaches}

There have been three approaches toward computing the upper hound of deflection. The first one is as described in section 2.3. It can be called the stiffened plate approach. The second one is as described in section 2.4. This approach can be called unfastened floor approach. The last one is the T-beam approach. A rompuler program has to be written for the unfastened floor approach. Data used in the comparison is listed below:

\begin{tabular}{|c|c|c|}
\hline load: & $1.9 \mathrm{kPa}$ & $40 \mathrm{psf}$ \\
\hline joists: & Douglas-fir & No.1/No.2 \\
\hline No. of joists, $N_{j}$ & 8 & \\
\hline MOE & $11000 \mathrm{MPa}$ & \\
\hline size & $38 \times 184 \mathrm{~mm}$ & $2 " \times 8^{\prime \prime}$ \\
\hline spacing & $406 \mathrm{~mm}$ & $16^{m}$ \\
\hline span and width of floor & $3660 \mathrm{~mm}$ & $12^{\prime}$ \\
\hline plywood: & $\begin{array}{l}\text { Canadian softwood, standard } \\
\text { regular, unsanded }\end{array}$ & 4 plies \\
\hline thickness & $15.5 \mathrm{~mm}$ & $5 / 8^{\prime \prime}$ \\
\hline bending stiffness, $B_{b}$ & $2,500,000 \mathrm{Nmm}^{2} / \mathrm{mm}$ & $0^{\circ}$ \\
\hline $\begin{array}{l}\text { bending stiffness, } B_{b} \\
\text { axial stiffness, } B_{a}\end{array}$ & $\begin{array}{l}430,000 \mathrm{Nmm} / \mathrm{mm} \\
75,000 \mathrm{Nmm}\end{array}$ & $99^{\circ}$ \\
\hline
\end{tabular}

The results from the three approaches are listed below:

Deflection of wood joist floor

\begin{tabular}{|c|c|c|}
\hline T-beam & stiffened floor & unfastenced floor \\
\hline $8.36 \mathrm{~mm}$ & $8.36 \mathrm{~mm}$ & $8.30 \mathrm{~mm}$ \\
\hline
\end{tabular}

It is shown that the three approaches resulted in similar results. The unfastenred floor approach coincides with the upper bound of the stiffened floor with commection 
stiffness equal to zero.

\subsubsection{Floors with Joist and Plywood Nailed Together}

In the last sections, two extreme conditions are considered. One is the upper bound of deflection in which case the joist and plywood are not at all attached to each other. The other is the lower bound. In this case, the plywood sheathing is glued to the joi is and we have a solid floor.

In this section, we will consider floors that have plywood nailed to the joists. According to McCutcheon [62], the maximum deflection $\Delta$ of a composite beam (T-beam) is

$$
\Delta=\Delta_{1}\left(\frac{K_{1}}{K_{2}}+f_{\Delta} \frac{f_{v}}{K_{2}}\right)
$$

where $K_{1}$ and $K_{2}$ are defined in equation 2.29 and $2.30 ; f_{v}$ is defined in equation 2.32 ; and $\Delta_{1}$ represents the deflection of an unfastened floor with plywood unconnected to the joists. For a simply supported beam subjected to uniformly distributed load, the deflection is

$$
\Delta_{1}=\frac{5}{384} \frac{q S L^{4}}{K_{1}}
$$

where

\section{q}

L uniformly distributed load acting on the tributary area of $\mathrm{T}$-beam length of the T-beam or span of joists

and

$$
\begin{gathered}
f_{\Delta}=\frac{10}{\left(L^{\prime} \alpha\right)^{2}+10} \\
\alpha^{2}=\frac{\left(\frac{t+d}{2}\right)^{2} S_{n}}{K_{2}-K_{1}}\left(\frac{K_{2}}{K_{1}}\right) \\
S_{n}=\frac{P / \delta}{s_{n}}
\end{gathered}
$$

where 


$$
\begin{array}{ll}
L^{\prime} & \text { Length of plywood between gaps } \\
s_{n} & \text { spacing between nails } \\
P / \delta & \text { load/slip ratio }
\end{array}
$$

\subsection{Interpretation of Test Results using Orthotropic Plate Theory}

There have been a number of tests on wood joist floors conducted in the Inited States and Canada in the last two decades, as listed in Chapter 1. The following is a list of comparisons from the test results and the results calculated from the orthotropic plate theory described in this chapter.

\subsubsection{Forest Product Laboratory, U.S., 1977, McCutcheon}

Seven floors were constructed at FPL. Each consisted of nine No.2 and betticr 2-by-8 Douglas-fir joists spaced at $(106 \mathrm{~mm})(16 \mathrm{in}$.) on centers. Floors werr $4064 \mathrm{~mm}$ (13'4") wide and were tested on a span of $3660 \mathrm{~mm}$ (12').

Four of the floors (designated $\mathrm{N}-1$ to $\mathrm{N}-4$ ) used standard grade $15.5 \mathrm{~mm}(5 / \mathrm{s}$ inch) plywood nailed to the joists with face grain perpendicular to the spant. Nails were $8 d$ at $152 \mathrm{~mm}(6 \mathrm{in}$.) along the edges and $203 \mathrm{~mm}(8 \mathrm{in}$.) over intermediate. joists. A $1.5 \mathrm{~mm}$ (1/16-inch) gap was left between the plywood shexts. The other three floors (designated G-1 to G-3) had the plywood nail-glued in place using a rigid adhesive. These used tongue-and-groove plywood with the edges glucd to giv. a continuous subfloor. The relevant data is listed below. 


\begin{tabular}{|c|c|c|}
\hline load & $2.4 \mathrm{kPa}$ & 50 psf \\
\hline \multicolumn{3}{|l|}{ floor dimension: } \\
\hline length & $3660 \mathrm{~min}$ & $12^{\prime}$ \\
\hline width & $4064 \mathrm{~mm}$ & $134^{\prime \prime}$ \\
\hline \multicolumn{3}{|l|}{ joists: } \\
\hline spacing & $406 \mathrm{~mm}$ & $16^{\prime \prime}$ \\
\hline size & $38 \times 184 \mathrm{~mm}$ & $2^{n} \times 8^{n}$ \\
\hline MOE & vary & vary \\
\hline \multicolumn{3}{|l|}{ plywood: } \\
\hline thickness, t & $15.5 \mathrm{~mm}$ & $5 / 8^{\prime \prime}$ \\
\hline tensile stiffness, $E A=B_{a} S$ & $22240 \mathrm{KN}$ & $5.0 \times 10^{6} \mathrm{lbs}$ \\
\hline bending stiffness, $B_{6}$ & $430,000 N \mathrm{~mm}^{2} / \mathrm{mm}$ & \\
\hline bending stiffness, $D_{y}$ & $3,700,000 \mathrm{Nmm}^{2} / \mathrm{mm}$ & \\
\hline \multicolumn{3}{|l|}{ Nails: } \\
\hline $\begin{array}{l}\mathrm{P} / \delta, 8 \mathrm{~d} \text { or } 2-1 / 2^{\prime \prime} \text { nail } \\
\text { nail spacing, } \mathrm{Sn}\end{array}$ & $\begin{array}{l}1.062 \times 10^{6} \mathrm{~N} / \mathrm{mm} \\
203 \mathrm{~mm}\end{array}$ & $\begin{array}{l}9400 \mathrm{lbs} / \mathrm{in} . \\
8^{n}\end{array}$ \\
\hline
\end{tabular}

Using the orthotropic plate theory, the deflections of these floors are calculated and compared with the test results in the following table. The comparison is also illust rated in Figure 2.1. The points should be as close to the $45^{\circ}$ line as possible. The deflection from the tests are the average of the middle 5 joists. The deflection from the calculation is at the center point of the floor. It can be proved that for a floor of this configuration, the deflections of the center joists are approximately the same. 


\begin{tabular}{ccccc} 
McCutcheon 1977 & Forest Product & \multicolumn{2}{l}{ Lahoratory, } & U.S. \\
\hline \hline Floor No. & MOE, $10^{6}$ psi & Test (mm) & Orth. Plate & T-beam, McCutcheru \\
\hline N-1 & 1.57 & 9.6 & 10.2 & 10.0 \\
N-2 & 2.20 & 7.1 & 7.3 & 7.2 \\
N-3 & 2.00 & 7.9 & 8.0 & 8.0 \\
N-4 & 1.49 & 9.3 & 10.7 & 10.5 \\
G-1 & 1.53 & 6.2 & 6.0 & 6.0 \\
G-2 & 2.20 & 4.8 & 4.7 & 4.7 \\
G-3 & 2.00 & 4.8 & 5.0 & 5.0 \\
\hline
\end{tabular}

\subsubsection{Forintek Canada, 1982, Foschi}

One floor consisting of 12 joists was constructed and tested at Forintek Canada, British Columbia. The floor was supported on four sides, had a span of $4.27 \mathrm{~m}$ (168 inch), and was uniformly loaded with $1.95 \mathrm{kPa}(40 \mathrm{psf})$. The data is listed below: 


\begin{tabular}{|c|c|c|}
\hline Foschi 1982 & Forintek Canada & \\
\hline load & $1.95 \mathrm{kPa}$ & 40 psf \\
\hline \multicolumn{3}{|l|}{ floor dimension: } \\
\hline length & $4267 \mathrm{~mm}$ & $168^{\prime \prime}$ \\
\hline width & $4470 \mathrm{~mm}$ & $176^{n}$ \\
\hline \multicolumn{3}{|l|}{ joists: } \\
\hline spacing & $406 \mathrm{~mm}$ & $16^{\prime \prime}$ \\
\hline size & $38 \times 184 \mathrm{~mm}$ & $2^{n} \times 8^{n}$ \\
\hline MOE & $11171 \mathrm{MPa}$ & $1.62 \times 10^{6} \mathrm{psi}$ \\
\hline \multicolumn{3}{|l|}{ plywood: } \\
\hline thickness, $t$ & $15.9 \mathrm{~mm}$ & $5 / 8 "$ \\
\hline tensile stiffness, $B_{a}$ & $56,000 \mathrm{~N} / \mathrm{mm}$ & $5.44 \times 10^{6} \mathrm{lbs}$ \\
\hline bending stiffness, $B_{6}$ & $3,230,000 \mathrm{Nmm}^{2} / \mathrm{mm}$ & $28,000.0 \mathrm{lb}$ in. \\
\hline bending stiffness, $D_{v}$ & $1,040,000 \mathrm{Nmm}^{2} / \mathrm{mm}$ & $9,000.0 \mathrm{lb}$ in. \\
\hline \multicolumn{3}{|l|}{ Nails: } \\
\hline$P / \delta, 8 d$ nail & $1.210 \times 10^{6} \mathrm{~N} / \mathrm{mm}$ & $6800 \mathrm{lbs} / \mathrm{in}$. \\
\hline nail spacing, $\mathbf{S n}$ & $152 \mathrm{~mm}$ & $6^{\prime \prime}$ \\
\hline
\end{tabular}

The test data and result of calculation from the orthotropic plate theory is listed below:

\begin{tabular}{|c|c|c|c|}
\hline average MOE, joists & deflection (min), test & def., orth. plate & error \% \\
\hline $1.62 \times 10^{6}$ & 10.4 & 9.8 & $5 \%$ \\
\hline \hline
\end{tabular}

\subsubsection{UBC, Canada, 1985, Foschi}

A series of 13 wood floors were tested under uniformly distributed load. The floors were constructed with $1238 \times 184$ hemlok joists, No.2 and better grade, $5 / 8$ " or 15.8 mm Douglas-fir plywood, and 8d commond nails at 6" or $152 \mathrm{~mm}$ o.c. Data is listed below: 


\begin{tabular}{|c|c|c|}
\hline Foschi 1985 & UBC, Canada & \\
\hline load & $1.95 \mathrm{kPa}$ & $40 \mathrm{psf}$ \\
\hline \multicolumn{3}{|l|}{ floor dimension: } \\
\hline length & $3580 \mathrm{~mm}$ & $141^{\prime \prime}$ \\
\hline width & $4470 \mathrm{~mm}$ & $176^{\circ}$ \\
\hline \multicolumn{3}{|l|}{ joists: } \\
\hline spacing & $406 \mathrm{~mm}$ & $16^{\prime \prime}$ \\
\hline size & $38 \times 184 \mathrm{~mm}$ & $2^{n} \times 8^{n}$ \\
\hline MOE & vary & vary \\
\hline \multicolumn{3}{|l|}{ plywood: } \\
\hline thickness, $t$ & $15.8 \mathrm{~mm}$ & $5 / 8^{\prime}$ \\
\hline tensile stiffness, $B_{a}$ & $56,000 \mathrm{~N} / \mathrm{mmn}$ & $5.41 \times 10^{6} \mathrm{ll} \mathrm{s}$ \\
\hline bending stiffness, $B_{b}$ & $1,016,812 \mathrm{Nmm}^{2} / \mathrm{mm}$ & $9,000 \mathrm{lb}$ in. \\
\hline bending stiffness, $D_{y}$ & $3,163,417 \mathrm{Nmm}^{2} / \mathrm{mm}$ & $28,000 \mathrm{lb}$ ill. \\
\hline \multicolumn{3}{|l|}{ Nails: } \\
\hline $\mathrm{P} / 6,8 \mathrm{~d}$ or $2-1 / 2^{\prime \prime}$ nail & $2.0 \times 10^{6} \mathrm{~N} / \mathrm{mm}$ & $11360 \mathrm{lbs} / \mathrm{in}$. \\
\hline nail spacing, Sn & $152 \mathrm{~mm}$ & $6^{\prime \prime}$ \\
\hline
\end{tabular}

Test data from 10 of the 13 floors are used to compare with the results from orthotropic plate theory assuming no gaps. The list is as follows: 


\begin{tabular}{|c|c|c|c|c|}
\hline Floor No. & average MOE, $10^{6}$ psi & deflection $(\mathrm{mm})$, tests & calculation & error \\
\hline 1 & 1.6000 & 7.0 & 5.4 & $21 \%$ \\
3 & 1.6108 & 5.8 & 5.4 & $7 \%$ \\
4 & 1.6117 & 6.3 & 5.4 & $14 \%$ \\
5 & 1.6083 & 6.2 & 5.4 & $12 \%$ \\
6 & 1.6158 & 5.0 & 5.4 & $-6 \%$ \\
7 & 1.6158 & 5.3 & 5.4 & $-2 \%$ \\
8 & 1.5867 & 5.0 & 5.5 & $-9 \%$ \\
9 & 1.5908 & 6.1 & 5.5 & $10 \%$ \\
10 & 1.5842 & 5.8 & 5.5 & $5 \%$ \\
\hline average & 1.5800 & 4.6 & 5.5 & $-20 \%$ \\
\hline \hline
\end{tabular}

The average $M O E$ is calculated from the following table: $\left(E 10^{6}\right)$

\begin{tabular}{|c|c|c|c|c|c|c|c|c|c|c|c|c|}
\hline floor & \multicolumn{10}{|c|}{ Joist Number } \\
\cline { 2 - 13 } & 1 & 2 & 3 & 4 & 5 & 6 & 7 & 8 & 9 & 10 & 11 & 12 \\
\hline 1 & 1.85 & 1.56 & 1.36 & 1.69 & 1.73 & 1.24 & 1.66 & 1.14 & 1.57 & 1.96 & 2.05 & 1.44 \\
\hline 2 & 1.69 & 1.52 & 1.29 & 1.87 & 1.87 & 1.46 & 1.76 & 1.16 & 1.57 & 2.07 & 1.68 & 1.39 \\
\hline 3 & 1.69 & 1.42 & 1.20 & 1.39 & 1.15 & 1.84 & 1.76 & 2.16 & 1.61 & 1.56 & 1.61 & 1.95 \\
\hline 4 & 1.43 & 1.56 & 1.68 & 1.61 & 2.11 & 1.13 & 1.61 & 1.90 & 1.80 & 1.72 & 1.28 & 1.47 \\
\hline 5 & 1.44 & 1.68 & 1.59 & 1.74 & 1.36 & 1.64 & 2.12 & 1.79 & 1.49 & 1.55 & 1.22 & 1.94 \\
\hline 6 & 1.18 & 1.74 & 2.06 & 1.63 & 1.79 & 1.97 & 1.40 & 1.60 & 1.49 & 1.55 & 1.28 & 1.70 \\
\hline 7 & 1.74 & 1.98 & 1.65 & 1.54 & 1.40 & 1.48 & 1.72 & 1.29 & 1.91 & 1.17 & 1.82 & 1.34 \\
\hline 8 & 1.75 & 1.64 & 1.71 & 1.41 & 2.06 & 1.14 & 1.51 & 1.87 & 1.25 & 1.82 & 1.55 & 1.38 \\
\hline 9 & 1.58 & 1.67 & 1.39 & 1.40 & 1.52 & 1.54 & 1.99 & 1.96 & 1.77 & 1.20 & 1.75 & 1.21 \\
\hline 10 & 1.31 & 1.58 & 1.41 & 1.48 & 1.98 & 1.64 & 1.17 & 1.89 & 1.82 & 1.28 & 1.73 & 1.70 \\
\hline \hline
\end{tabular}

Orthot ropic plate theory describes the average behaviour of floors. 


\subsection{Parametric Study}

In this section, we will have a closer look at what is the greatest influence on the deflection of a T-beam. More importantly. how by gluing the plywood and joists together reductions on deflection are made. What affects this improvenumut the most will be examined. Take the following floor configuration as all example:

$$
\begin{aligned}
& q=40 \mathrm{lbf} / \mathrm{ft}^{2}=1.9 \mathrm{kPa} \\
& \text { joist span }=12^{\prime} \\
& \text { D.Fir No.2 } \\
& E=11000 \mathrm{MPa} \\
& \text { plywood: } \\
& D_{x}=75000 \mathrm{Nmm} \\
& D_{v}=250000 \frac{\mathrm{Nmm}}{\mathrm{mm}} @ 90^{\circ} \\
& 2 H=D_{y}
\end{aligned}
$$

\subsubsection{Effect of Plywood Thickness on Deflection}

Calculation is done by using plywood of different sizes with joists 38x89. The results are listed in Figure 2.8 and Table 2.1. It can be seen that for a thicker plywood, the reduction to deflection by gluing joists to a thicker plywood is larger than with a thinner plywood.

Calculation is also done for floors with different sizes of joists. Referring to Figure 2.9 and Table 2.2, it can be seen that for a floor with larger joists, the influsence of the plywood is not so drastic. Joists dominate.

\subsubsection{Effect of Joists Size on Deflection}

Calculation is done by using plywood of different sizes. The results are listed in Table 2.1 and 2.2 .

Refer to Figure 2.10 and Table 2.3, it can be seen that it will achicuve better improvement with smaller joist by gluing the plywood and joists together. 
Table 2.1: Maximum deflection of T-beam, joist: $38 \times 89$

\begin{tabular}{|c|c|c|c|}
\hline plywood thickness, $\mathrm{t}$ & upper bound $(\mathrm{u})$ & lower bound $(\mathrm{l})$ & ratio $=(\mathrm{u}-\mathrm{l}) / 1$ \\
\hline 7.50 & 74.50 & 42.87 & 0.74 \\
\hline 9.50 & 74.48 & 38.94 & 0.91 \\
\hline 12.50 & 74.28 & 29.70 & 1.50 \\
\hline 12.50 & 74.08 & 31.88 & 1.32 \\
\hline 15.50 & 73.99 & 25.88 & 1.86 \\
\hline 15.50 & 73.74 & 30.77 & 1.40 \\
\hline 18.50 & 72.93 & 25.06 & 1.91 \\
\hline 18.50 & 72.93 & 29.63 & 1.46 \\
\hline 18.50 & 72.93 & 25.32 & 1.88 \\
\hline 20.50 & 71.42 & 22.64 & 2.16 \\
\hline 20.50 & 72.23 & 28.87 & 1.50 \\
\hline 20.50 & 72.11 & 24.62 & 1.93 \\
\hline
\end{tabular}

Table 2.2: Maximum deflection of T-beam, joist: $38 \times 184$

\begin{tabular}{|c|c|c|c|}
\hline plywood thickness, $t$ & upper bound $(\mathrm{u})$ & lower bound $(\mathrm{l})$ & ratio $=(\mathrm{u}-\mathrm{l}) / 1$ \\
\hline 7.50 & 8.43 & 6.16 & 0.37 \\
\hline 9.50 & 8.43 & 5.79 & 0.46 \\
\hline 12.50 & 8.43 & 4.69 & 0.80 \\
\hline 12.50 & 8.43 & 5.00 & 0.69 \\
\hline 15.50 & 8.43 & 4.20 & 1.01 \\
\hline 15.50 & 8.42 & 4.94 & 0.71 \\
\hline 18.50 & 8.41 & 4.17 & 1.02 \\
\hline 18.50 & 8.41 & 4.87 & 0.73 \\
\hline 18.50 & 8.41 & 4.22 & 1.00 \\
\hline 20.50 & 8.39 & 3.84 & 1.19 \\
\hline 20.50 & 8.40 & 4.83 & 0.74 \\
\hline 20.50 & 8.40 & 4.17 & 1.01 \\
\hline
\end{tabular}


Table 2.3: Deflection ratios (u-l)/l

\begin{tabular}{|r|r|r|r|r|r|r|}
\hline $\mathrm{t}$ & $38 \times 89$ & $38 \times 114$ & $30 \times 140$ & $38 \times 184$ & $38 \times 235$ & $38 \times 286$ \\
\hline 7.54 plies & 0.74 & 0.58 & 0.48 & 0.37 & 0.29 & 0.24 \\
\hline 9.54 plies & 0.91 & 0.72 & 0.59 & 0.46 & 0.36 & 0.30 \\
\hline 12.54 plies & 1.50 & 1.21 & 1.02 & 0.80 & 0.64 & 0.53 \\
\hline 15.55 plies & 1.86 & 1.51 & 1.27 & 1.01 & 0.81 & 0.68 \\
\hline 18.56 plies & 1.91 & 1.55 & 1.29 & 1.02 & 0.81 & 0.68 \\
\hline 20.57 plies & 2.16 & 1.77 & 1.50 & 1.19 & 0.96 & 0.80 \\
\hline
\end{tabular}

\subsubsection{Bfiect of Nail Size on Deflection}

It is useful to examine effects of sizes of nails on deflertion so that a design derision can be made. The results of calculations are listed in Table 2.4, 2.6. 2.7 and Figure 2.11, 2.12 .

It can be seen from Table 2.4 and Figure 2.11 that a 4 " nail will arhievere quite significant improvements ove: the unconnected or unfastened flocors. With wails bigger than 4", the improvements are not so pronounced The difference Ix-t.wern thedeflection of a nailed floor $(38.1 \mathrm{~mm})$ and a glued floor $(29.7 \mathrm{~mm})$ is only $28 \%$ with a 4 " nail. The reduction of deflection of a nailed T-ibcam over an unfastenul T-Ix-aun $(74.28 \mathrm{~mm})$ is more than $48 \%$.

Comparing Table 2.4 with Table 2.6, it can be seen that the differrences due to the use of thicker plywood are negligible.

To understand the effects of plywood thickness, nail size and joist size, the fol lowing 3 different floors are considered.

1. joist 38x89; plywood thickness $12.5 \mathrm{~mm}$;

2. joist 38x89; plywood thickness 20.5 mun;

3. joist 89x286; plywood thickness $20.5 \mathrm{~mm}$;

The ratios of reduction in deflection of a nailed floor achieved over an unfast concd floor $\frac{\left(W_{*}-W_{n}\right)}{W_{*}}$ are calculated. The results are tabulated in Table 2.12. 
Table 2.4: Effects of nail sizes on floor deflection, joist size $38 \times 89$, plywood thickness

\section{$12.5 \mathrm{~mm}$}

\begin{tabular}{|c|c|c|c|}
\hline & \multicolumn{3}{|c|}{ deflection } \\
\hline nail diameter & deflection(mm) unfastened & deflection glued & deflection nailed \\
\hline 2d & 74.3 & 29.7 & 52.4 \\
\hline 4d & 74.3 & 29.7 & 47.3 \\
\hline 5d & 74.3 & 29.7 & 47.3 \\
\hline $6 d, 2^{\prime \prime}$ & 74.3 & 29.7 & 45.3 \\
\hline $8 d, 2-1 / 2^{\prime \prime}$ & 74.3 & 29.7 & 43.2 \\
\hline $10 d, 3^{\prime \prime}$ & 74.3 & 29.7 & 41.4 \\
\hline $16 \mathrm{~d}, 3-1 / 2^{n}$ & 74.3 & 29.7 & 40.2 \\
\hline $20 \mathrm{~d}, 4^{n}$ & 74.3 & 29.7 & 38.1 \\
\hline $30 d, 4-1 / 2^{n}$ & 74.3 & 29.7 & 37.3 \\
\hline $40 d, 5^{\prime \prime}$ & 74.3 & 29.7 & 36.3 \\
\hline 60d, $6^{n}$ & 74.3 & 29.7 & 35.0 \\
\hline
\end{tabular}

Table 2.5: Conversion of nail sizes between Penny-weight and Inches

\begin{tabular}{|c|c|c|c|c|c|c|c|c|c|c|}
\hline Penny-weight & $6 \mathrm{~d}$ & $8 \mathrm{~d}$ & $10 \mathrm{~d}$ & $12 \mathrm{~d}$ & $16 \mathrm{~d}$ & $20 \mathrm{~d}$ & $30 \mathrm{~d}$ & $40 \mathrm{~d}$ & $50 \mathrm{~d}$ & $60 \mathrm{~d}$ \\
\hline Length in inches & 2 & $21 / 2$ & 3 & $31 / 4$ & $31 / 2$ & 4 & $41 / 2$ & 5 & $51 / 2$ & 6 \\
\hline
\end{tabular}


Table 2.6: Effects of sizes of nails, joist $38 \times 89$, plywood $20.5 \mathrm{~mm}$

\begin{tabular}{|c|c|c|c|}
\hline & \multicolumn{3}{|c|}{ deflection (nm) } \\
\hline nail diameter & unfastened & glued & Inalay! \\
\hline 2d & 74.3 & 29.7 & 51.1 \\
\hline $4 d$ & 74.3 & 29.7 & +2.3 \\
\hline $5 d$ & 74.3 & 29.7 & 12.81 \\
\hline $6 d$ & 74.3 & 29.7 & 39.6 \\
\hline $8 d$ & 74.3 & 29.7 & 37.1 \\
\hline $10 d$ & 74.3 & 29.7 & $: 35.2$ \\
\hline $16 d$ & 74.3 & 29.7 & 34.0 \\
\hline $20 \mathrm{~d}$ & 74.3 & 29.7 & $: 32.3$ \\
\hline $30 d$ & 74.3 & 29.7 & $3|.6|$ \\
\hline $40 \mathrm{~d}$ & 74.3 & 29.7 & $: 31.0$ \\
\hline $60 d$ & 74.3 & 29.7 & $24 . K$ \\
\hline
\end{tabular}

Table 2.7: Improvement ratios of nailed floor over unfusterurd flowor

\begin{tabular}{|c|c|c|c|}
\hline nail diameter & floor 1 & floor 2 & floor 3 \\
\hline 2d & 0.29 & 0.29 & 0.04 \\
\hline 4d & 0.36 & 0.41 & $0.0 \times$ \\
\hline 5d & 0.36 & 0.41 & $0.0 \times$ \\
\hline 6d & 0.39 & 0.45 & 0.09 \\
\hline 8d & 0.42 & 0.49 & 0.11 \\
\hline 10d & 0.44 & 0.51 & 0.13 \\
\hline 16d & 0.46 & 0.53 & 0.14 \\
\hline 20d & 0.49 & 0.55 & 0.15 \\
\hline $30 d$ & 0.30 & 0.56 & 0.16 \\
\hline 40d & 0.51 & 0.57 & 0.16 \\
\hline 60d & 0.53 & 0.59 & 0.17 \\
\hline
\end{tabular}


Table: 2.8: Comparison between the deflection of floor using orthotropic plate model and T-beam model. joist $38 \times 89$, nail size $2 d$.

\begin{tabular}{|c|c|c|c|c|c|c|c|c|c|}
\hline & \multicolumn{3}{|c|}{ plate } & \multicolumn{3}{c|}{ T-beam } & \multicolumn{3}{c|}{ ratio: plate/T-beam } \\
\hline 1 & unfastened & glued & nailed & loose & glued & nailed & unfastened & glued & nailed \\
\hline 12.5 & 79.15 & 31.33 & 55.93 & 74.28 & 29.70 & 52.40 & 1.06 & 1.05 & 1.06 \\
\hline 15.5 & 76.38 & 32.95 & 55.81 & 73.99 & 30.81 & 52.84 & 1.03 & 1.06 & 1.05 \\
\hline 18.5 & 71.93 & 31.62 & 54.29 & 72.93 & 29.63 & 52.85 & 0.98 & 1.06 & 1.02 \\
\hline 20.5 & 67.58 & 26.17 & 51.11 & 72.11 & 24.62 & 51.42 & 0.93 & 1.06 & 0.99 \\
\hline
\end{tabular}

It can be scen from Figure 2.12 that

- The improvement is less sensitive when the joists are bigger

- It is more sensitive to joist depth than the thickness of plywood

\subsection{Comparison and Discussion}

In order to compare the results of the plate theory with the T-beam theory, a few foors are used in analysis and comparison between the two theories.

Floor no. 1:

\begin{tabular}{|c|c|}
\hline joist: & $38 \times 89$ \\
\hline L: & $3660 \mathrm{~mm}$ \\
\hline B: & $3660 \mathrm{~mm}$ \\
\hline E: & $11000 \mathrm{MPa}$ \\
\hline
\end{tabular}

No. of Joists: 8

plywood: D.Fir plywood

t: $\quad 12.5 \mathrm{~mm} \cdot 20.5 \mathrm{~mm}$

nail size: $\quad 2 d$

Floor no. 2: 
Table 2.9: Comparison between the deflection of floor using orthotropic plate model and T-beam model with $38 \times 184$ joists and $2 d$ nails.

\begin{tabular}{||c|c|c|c|c|c|c|c|c|c||}
\hline \hline & \multicolumn{3}{|c|}{ plate } & \multicolumn{3}{c|}{ T-beam } & \multicolumn{3}{c||}{ ratio: plate/T-beam } \\
\hline $\mathrm{t}$ & unfastened & glued & nailed & loose & glued & nailed & loose & glued & nailid \\
\hline 12.5 & 8.52 & 4.76 & 7.16 & 8.43 & 4.69 & 7.10 & 1.01 & 1.01 & 1.00 \\
\hline 15.5 & 8.62 & 5.00 & 7.30 & 8.43 & 4.94 & 7.17 & 1.02 & 101 & 1.01 \\
\hline 18.5 & 8.75 & 4.98 & 7.48 & 8.41 & 4.87 & 7.23 & 1.04 & 1.02 & 1.03 \\
\hline 20.5 & 8.84 & 4.29 & 7.50 & 8.40 & 4.17 & 7.17 & 1.05 & 1.02 & 1.04 \\
\hline \hline
\end{tabular}

joist: $\quad 38 \times 184$

L: $\quad 3660 \mathrm{~mm}$

B: $\quad 3660 \mathrm{~mm}$

E: $\quad 11000 \mathrm{MPa}$

No. of Joists: 8

plywood: D.Fir plywood

t: $\quad 12.5 \mathrm{~mm}-20.5 \mathrm{~mm}$

nail size: $\quad 2 d$

Floor no.3:

joist: $\quad 38 \times 89$

L: $\quad 3660 \mathrm{~mm}$

B: $\quad 3660 \mathrm{~mm}$

E: $\quad 11000 \mathrm{MPa}$

No. of Joists: 8

plywood: D.Fir

$\mathrm{t}$ : $\quad 12.5 \mathrm{~mm} \cdot 20.5 \mathrm{~mm}$

nail size: $\quad 60 \mathrm{~d}$ or 6 "

Figure 2.4, 2.5 and Figure 2.6 shows that both orthotropic plate theory and ' T-beann formula agrees well even with different joist and nail sizes. Figure 2.8 and 2.9 shows 
Table: 2.10: Comparison between the defiection of floor using orthotropic plate model and T-beam model. joist $38 \times 89$, nail size $60 \mathrm{~d}$.

\begin{tabular}{||c|c|c|c|c|c|c|c|c|c||}
\hline & \multicolumn{3}{|c|}{ plate } & \multicolumn{3}{c|}{ T-beam } & \multicolumn{3}{c||}{ ratio: plate/T-beam } \\
\hline $\mathrm{t}$ & unfastened & glued & nailed & loose & glued & nailed & loose & glued & nailed \\
\hline 12.5 & 79.15 & 31.33 & 37.06 & 74.28 & 29.70 & 34.98 & 1.06 & 1.05 & 1.05 \\
\hline 15.5 & 76.38 & 32.95 & 37.98 & 73.99 & 30.81 & 35.55 & 1.03 & 1.06 & 1.06 \\
\hline 18.5 & 71.93 & 31.62 & 36.28 & 72.93 & 29.63 & 34.20 & 0.98 & 1.06 & 1.06 \\
\hline 20.5 & 67.58 & 26.17 & 31.34 & 72.11 & 24.62 & 29.80 & 0.93 & 1.06 & 1.04 \\
\hline \hline
\end{tabular}

the effert of plywood thickness on floor deflection. Figure 2.10 shows the effects of joist sizes and plywood thicknesses on floor deflection represented in the form of deflection ratio. The deflection ratio, upper bound (deflection of unfastened floor) minus lower bound (deffection of glued floor) and then divided by lower bound, shows the increase in floor stiffness when composite action is considered. It can be scen that the thicker the plywood and the smaller the joists, the greater increase in floor stiffness. Figure 2.11 shows the effects of nail size on floor deflection. It can be seen that the difference between using a $6 \mathrm{~d}$ or 2 inch nail and a $10 \mathrm{~d}$ or 3 inch nail is significant. Considering the low cost of nails, it is advisable that a longer nail be used if possible to achieve higher stiffness on the floor assembly. However, nails bigger than 4 " or longer than 4 inches do not show significant differences than 4" nails. Figure 2.12 shows the effects of nail sizes on floor deflection represented in terms of deflection ratios for floors with different plywood thickness and different joist :izes. It can be seen that it shows similar patterns for different joist sizes and different plywood thicknesses. 


\subsection{Effects of Boundary Conditions: Upper Bound for Deflection of a Floor Simply Supported on Two Opposite Sides}

In order to examine the influence different boundary conditions have on deflection. the following procedure can be followed. It assumes that the joists are simply supported and the edge joists may be free to deflect, fixed or on elastic supports. For a stiffened floor, equation 2.5 can be used with relevant boundary conditions. (Ylassical Levy method can be used. To find out the upper bound of a foor simply supported on two opposite sides, it can be assumed that the sheathing simply sits locsely on top of the joists. The procedure to calculate deflection is outlined as follows.

According to equation 2.5 and assume

$$
\left\{\begin{array}{l}
w(x, y)=\sum_{n=1}^{\infty} w_{n}(x) \sin \left(\frac{n \pi y}{B}\right) \\
q(x, y)=\sum_{n=1}^{\infty} q_{n}(x) \sin \left(\frac{n \pi y}{B}\right)
\end{array}\right.
$$

where

$$
\begin{aligned}
q_{n}(x) & =\frac{2}{B} \int_{0}^{B} q(x, y) \sin \frac{n \pi y}{B} d y \\
& =\frac{2}{B} \int_{0}^{B} q_{0} \sin \frac{n \pi y}{B} d y+\frac{2}{B}\left(-\frac{Q_{,}(x)}{d y} \sin \frac{n \pi y_{j}}{B} d y\right) \\
& =\frac{2}{B}\left[\frac{B q_{0}}{n \pi}(1-\cos n \pi)-Q_{3}(x) \sin \frac{n \pi y_{j}}{B}\right]
\end{aligned}
$$

Equation 2.5 is then reduced by equation 2.37 to

$$
\left(D_{x} \frac{d^{4}}{d x^{4}}-2 H\left(\frac{n \pi}{B}\right)^{2} \frac{d^{2}}{d x^{2}}+D_{y}\left(\frac{n \pi}{B}\right)^{4}\right) w_{n}(x)=q_{n}(x)
$$

where

$$
q_{n}(x)=\frac{2}{B}\left[\frac{B q_{0}}{n \pi}(1-\cos n \pi)-(E I)_{b}\left(\sum_{i=1}^{\infty} \frac{d^{4} w_{i}(x)}{d x^{4}} \sin \frac{i \pi y_{i}}{B}\right) \sin \frac{n \pi y_{j}}{B}\right]
$$

for $\mathrm{Nj}$ joists, the above equation becomes

$$
q_{n}(x)=\frac{2}{B}\left[\frac{B q_{0}}{n \pi}(1-\cos n \pi)-\sum_{j=1}^{N}\left((E I)_{b}\left(\sum_{i=1}^{\infty} \frac{d^{4} w_{1}(x)}{d x^{4}} \sin \frac{i \pi y_{i}}{B}\right) \sin \frac{n \pi y_{j}}{B}\right)\right]
$$


Assume the floor is simply supported in the joists $(x)$ direction. The boundary conditions are $w=0 \quad x=0$ and $x=L$. Therefore the following can be assumed:

$$
w_{n}(x)=\sum_{m=1}^{\infty} b_{m} \sin \frac{m \pi x}{L}
$$

Substitute equation 2.42 and 2.41 into 2.39 , multiply both side by $\sin \frac{m \pi x}{L}$ and integrate. Apply orthogonal rules, the equation becomes

$$
\begin{aligned}
& \frac{L B}{4}\left[D_{x}\left(\frac{m \pi}{L}\right)^{4}+2 H\left(\frac{n \pi}{B}\right)^{2}\left(\frac{m \pi}{L}\right)^{2}+D_{y}\left(\frac{n \pi}{B}\right)^{4}\right] b_{m} \\
= & \frac{a b q_{0}}{m n \pi^{2}}(1-\cos m \pi)(1-\cos n \pi) \\
& -\sum_{j=1}^{N_{j}}\left((E I)_{b}\left(\sum_{i=1}^{\infty} b_{m} \frac{L}{2}\left(\frac{m \pi}{L}\right)^{4} \sin \frac{i \pi}{B} y_{j}\right) \sin \frac{n \pi}{B} y_{j}\right)
\end{aligned}
$$

\subsection{Summary}

In this chapter. plywood sheathed wood joist floors have been modelled as a stiffened orthotropic plate. The deflection of floors calculated using this approach compares favorably with test results obtained at other institutions. It also shows that with the configurations of floors tested, $T$-beam formula can be used with satisfactory accuracy. The upper bound and lower bound for the deflection of floors are defined. The upper bound is verified through a different approach in which an unfastened floor is modeled as an orthotropic plate (the plywood sheathing) siting loosely on top of elastic supports (the joists). Parameter study is performed to demonstrate the factors that influence the deflection of floor the most.

In the next chapter, the effects of aspect ratio on floor deflection are examined. Since $T$-beam formulation ignores boundary conditions in the transverse direction, the orthotropic plate theory can be expected to represent a more accurate approach. 


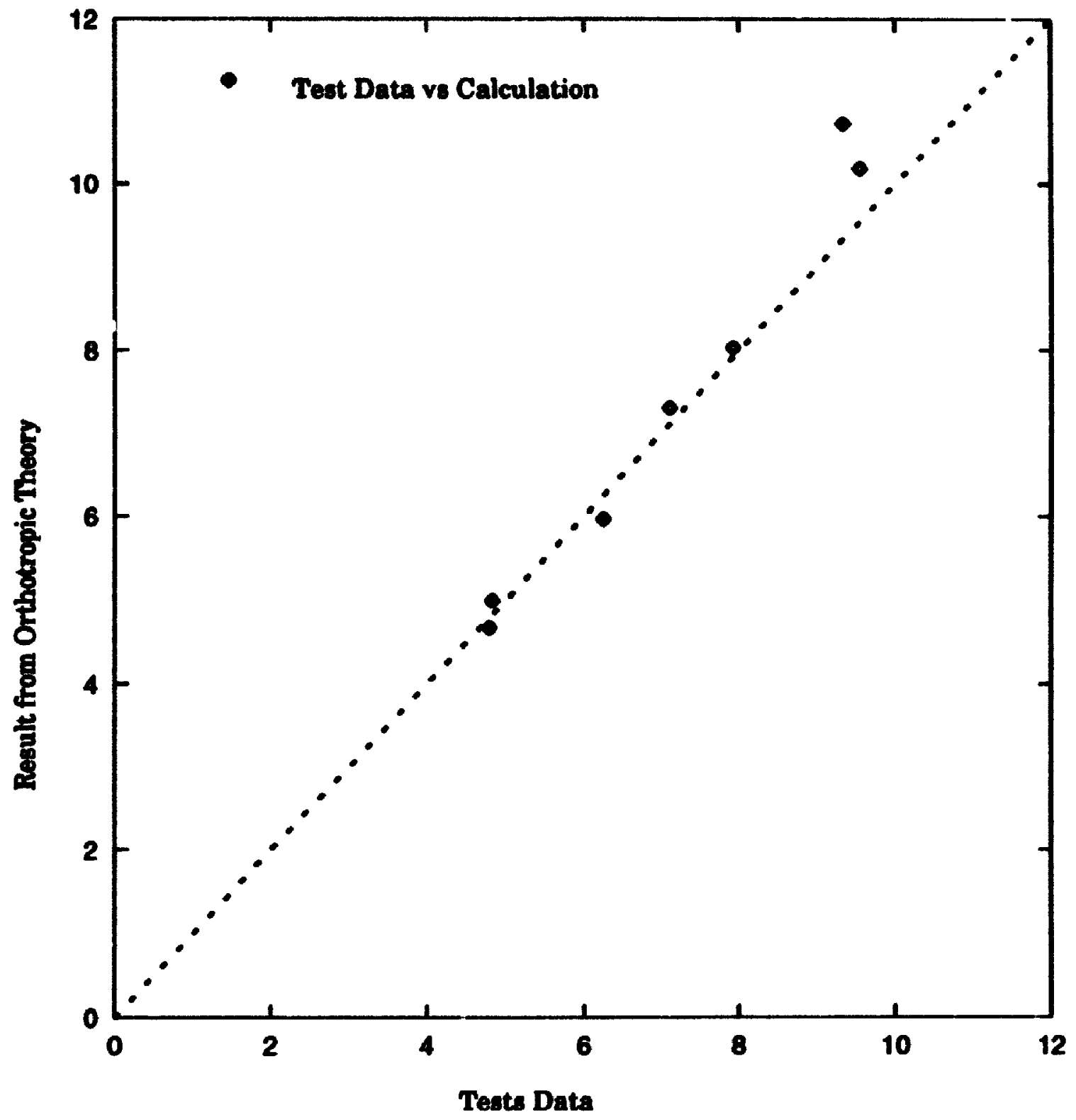

Figure 2.1: Comparison between the test data and calculation from orthotropic plate. theory 


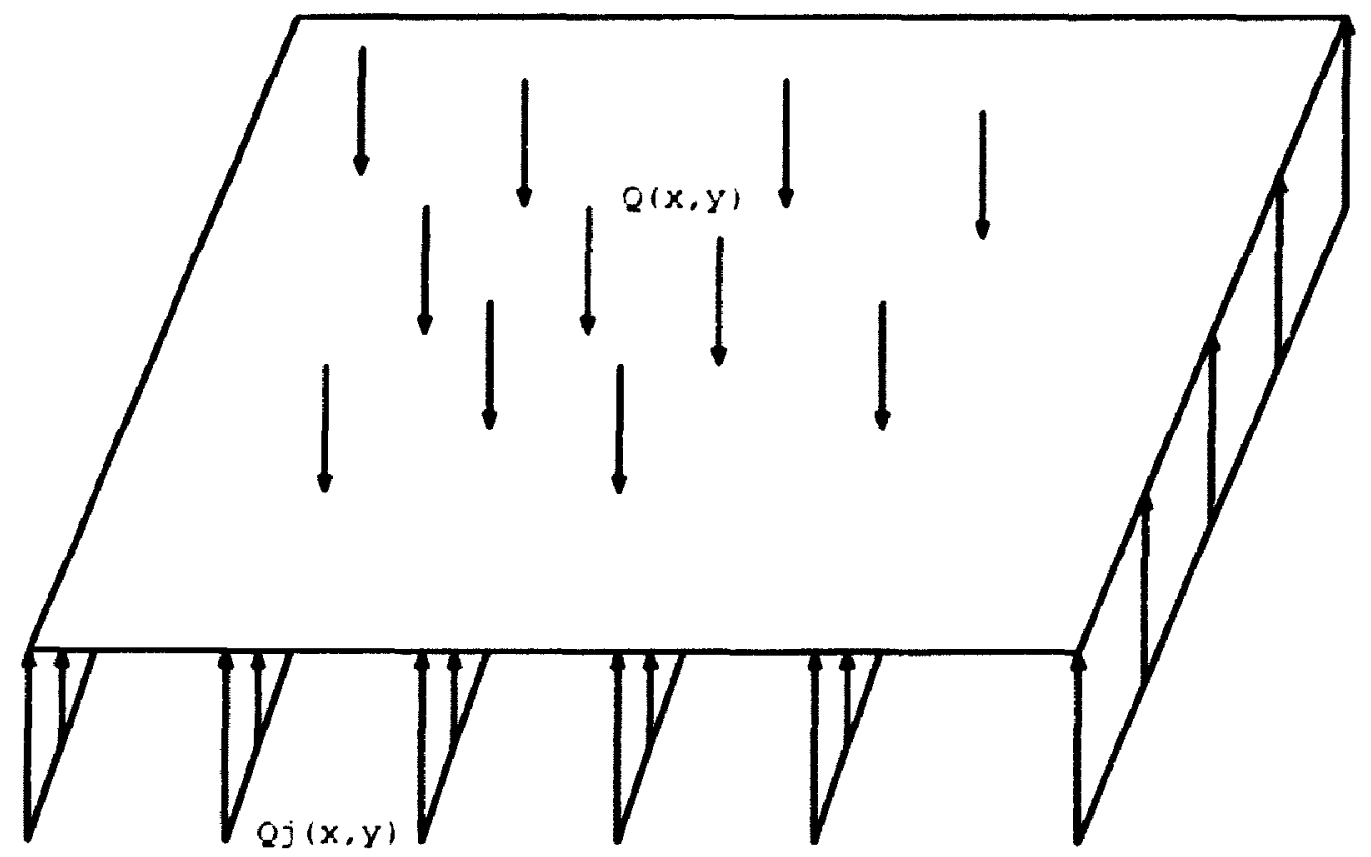

Plywod subjected to the normal load and reactions from the joists

$Q j(x, y)$

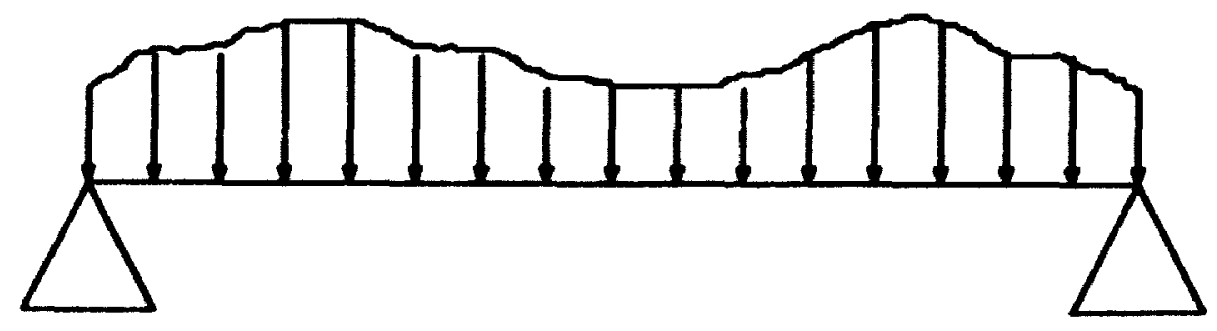

The jih joist subjected to the reactions from the plywood

Figure 2.2: An unfastened floor - sheathing not fastened to joists 

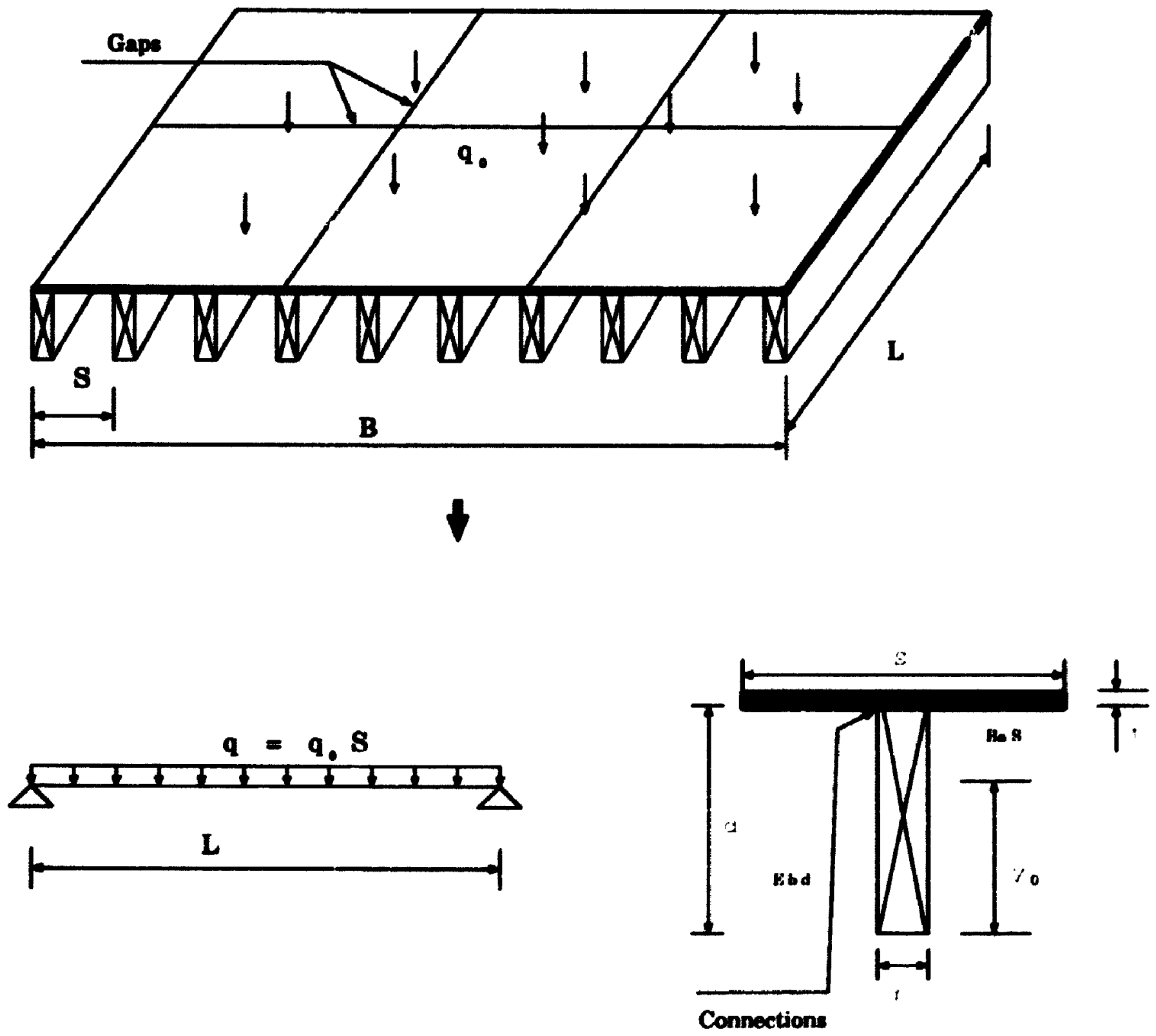

Figure 2.3: A plywood sheathed wood joist floor subjert to uniformly distributed load, and its T-beam cross section 


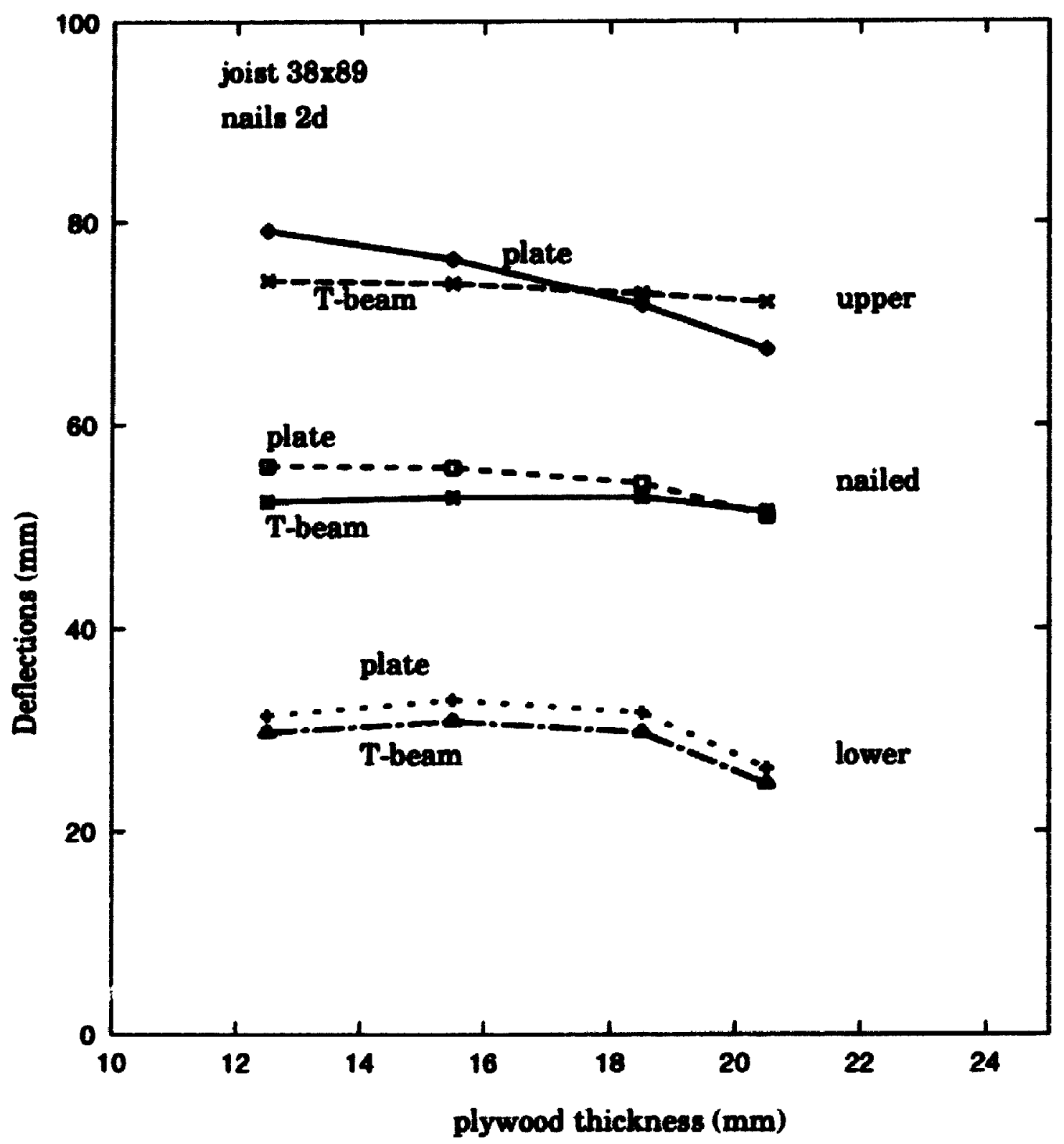

Figure 2.4: Deflection of floors with $38 \times 89$ joists and $2 \mathrm{~d}$ nails, orthotropic plate theory vs T-beam formula. 


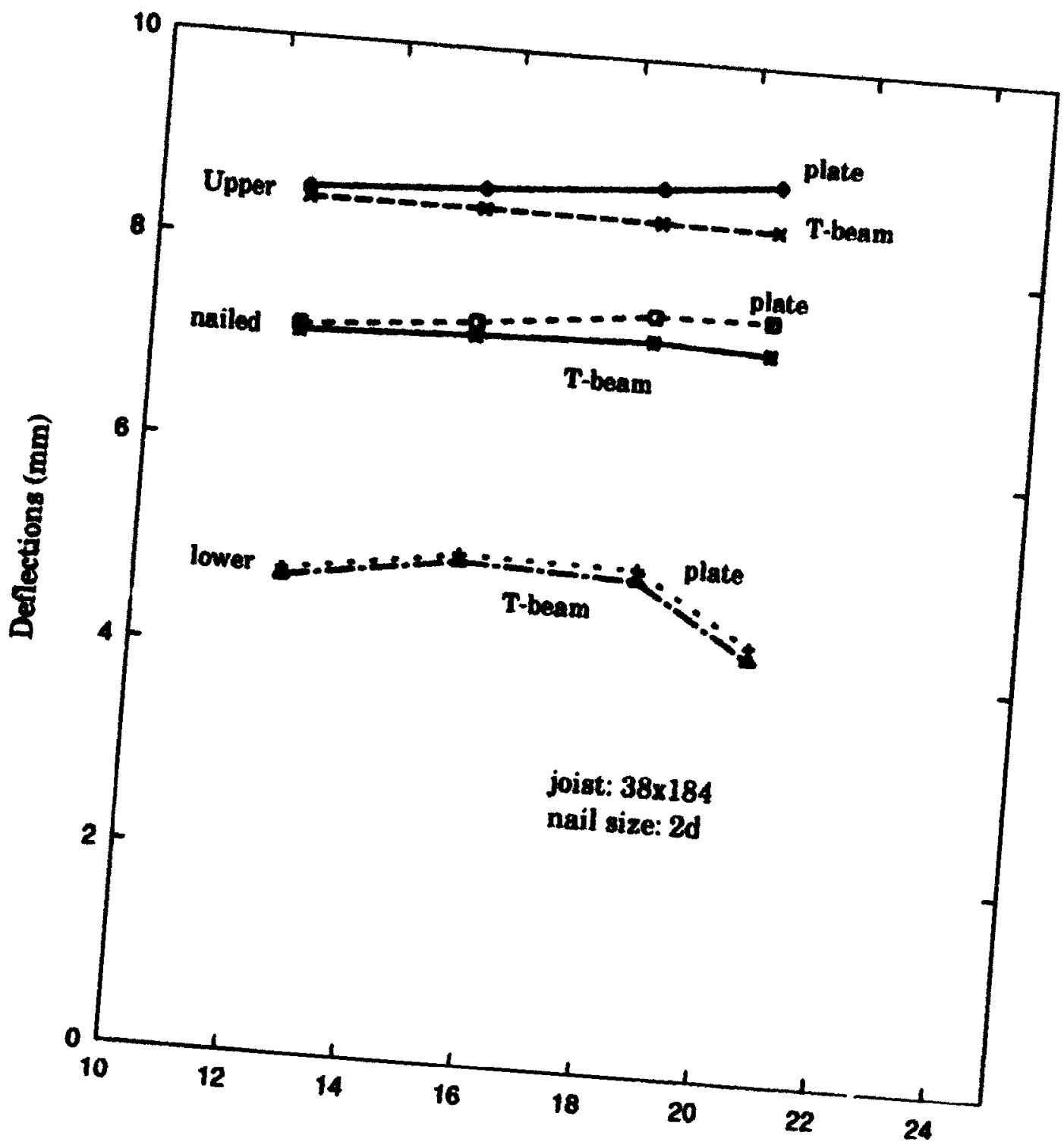

plywood thickness (mm)

Figure 2.5: Deflection of floors with $38 \times 184$ joists, $2 \mathrm{~d}$ nails, orthot ropic plat. throry
vs T-bearn formula. 


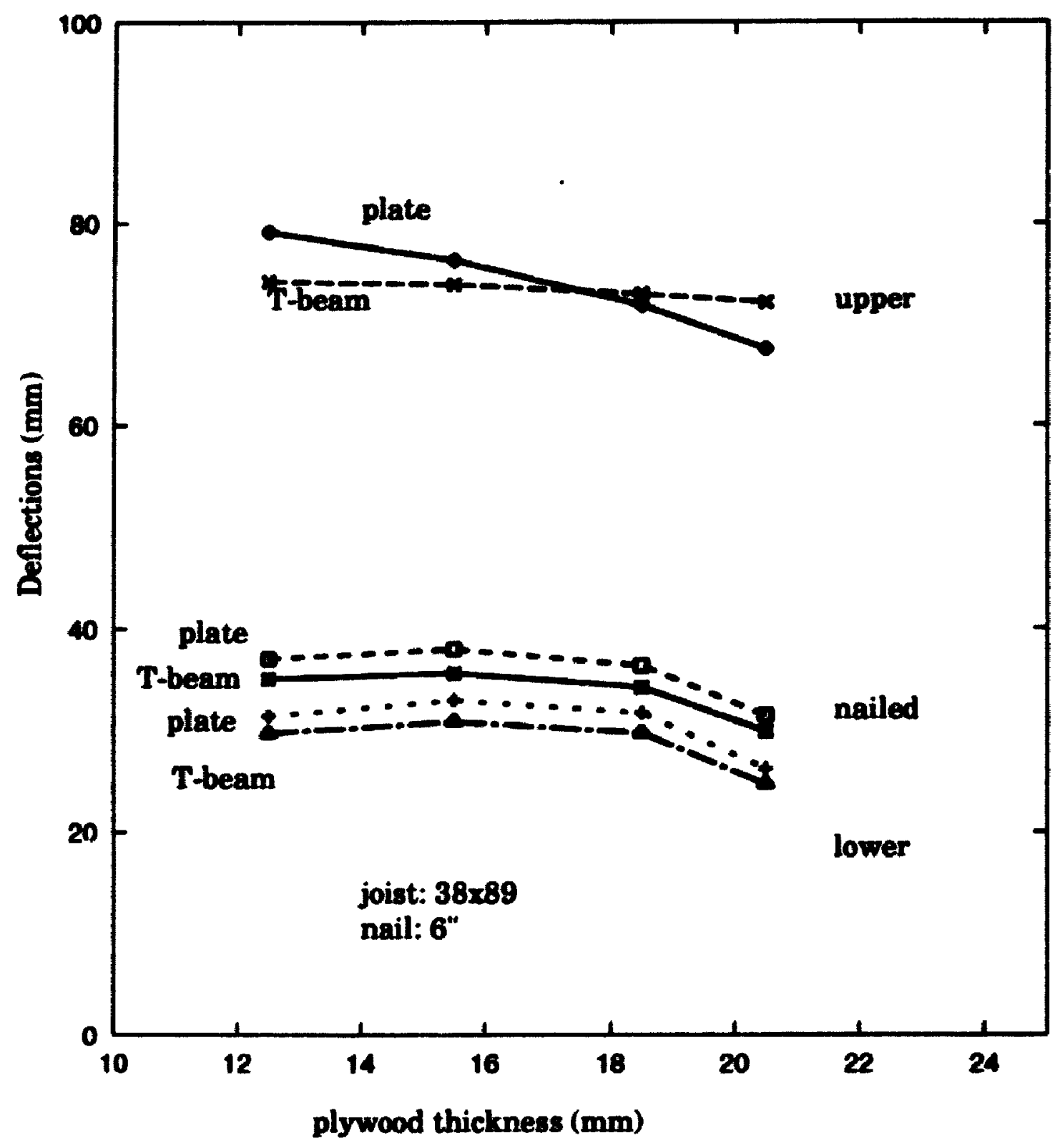

Figure 2.6: Deflection of floors with $38 \times 89$ joists, $60 \mathrm{~d}$ nails, orthotropic plate theory vs T-beam formula. 


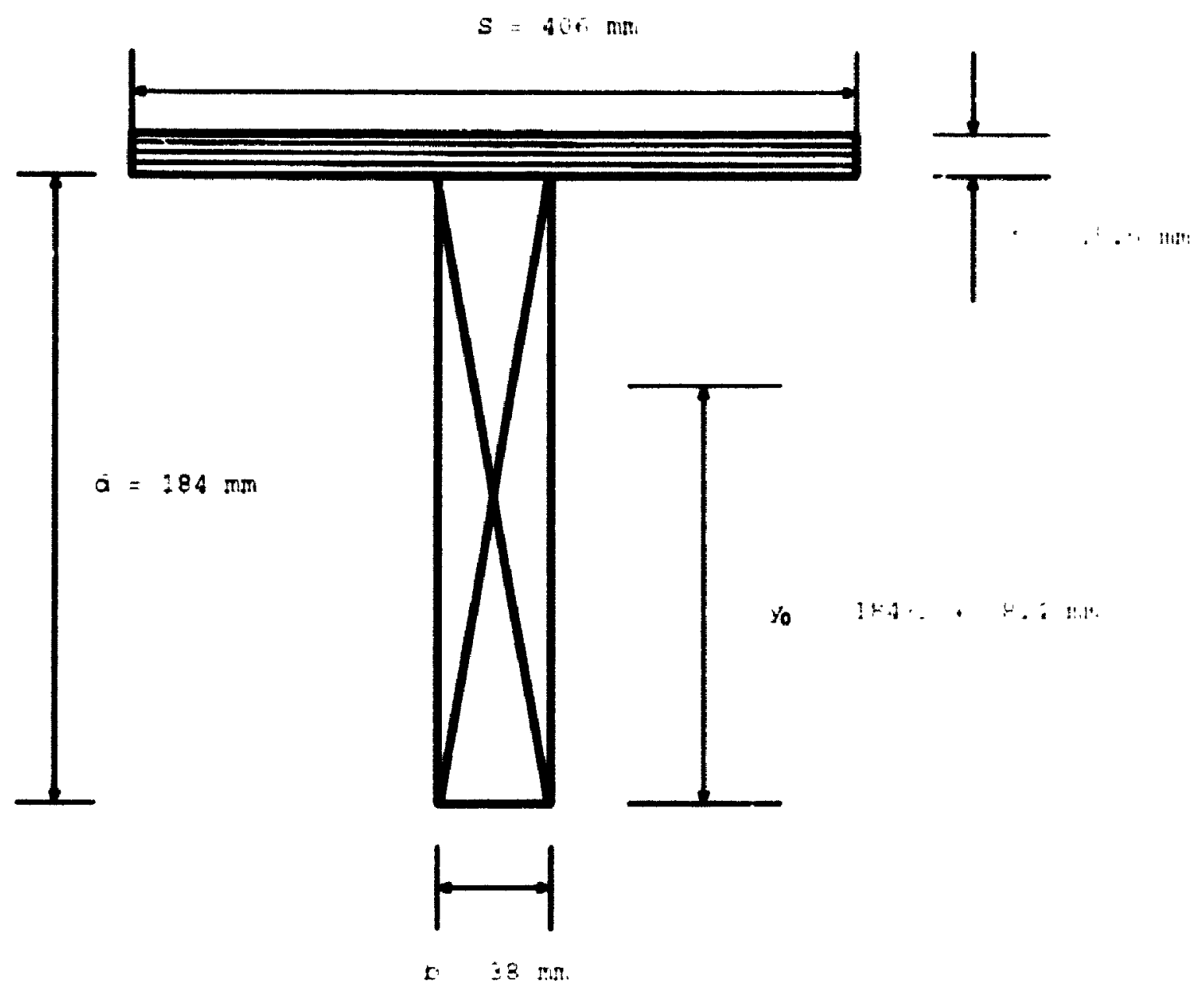

Figure 2.7: Tbeam - an cxample 


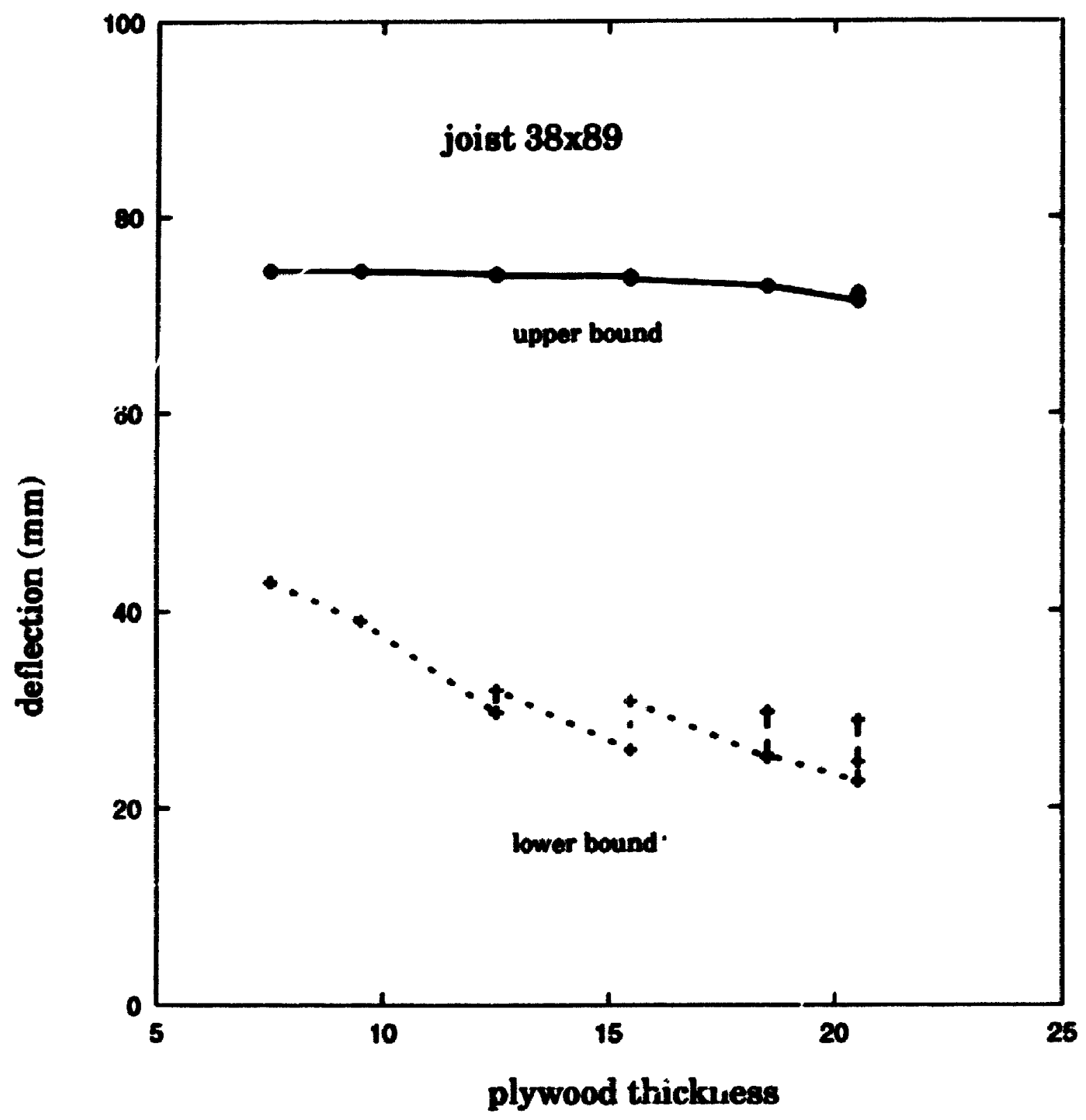

Figure 2.8: Effects of plywood sheathing thickness on deflection of floors, joist: $38 \times 89$. 


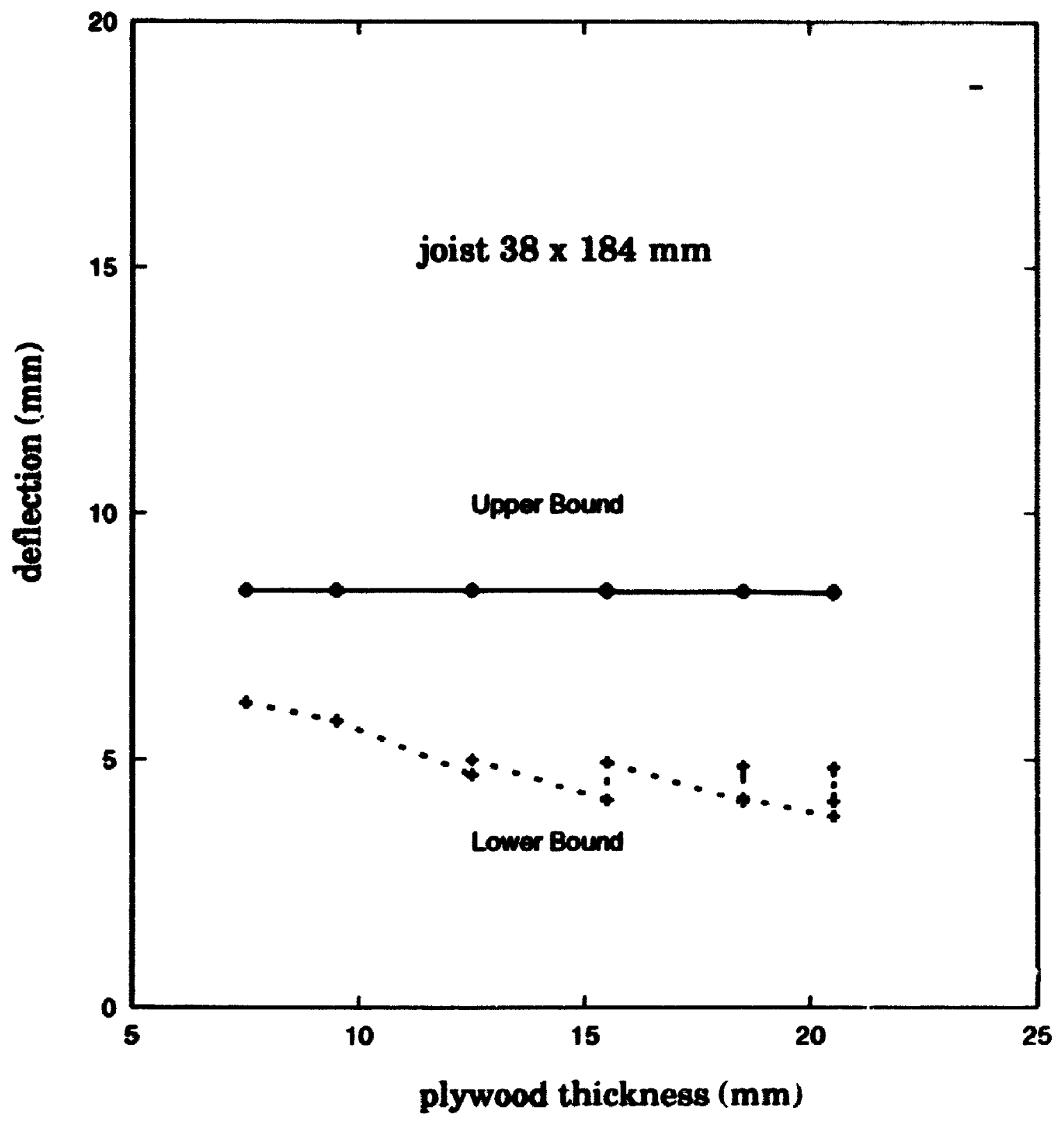

Figure 2.9: Effects of plywood sheathing thickness on deflertion of flocors, juist; $38 \times 184$ 


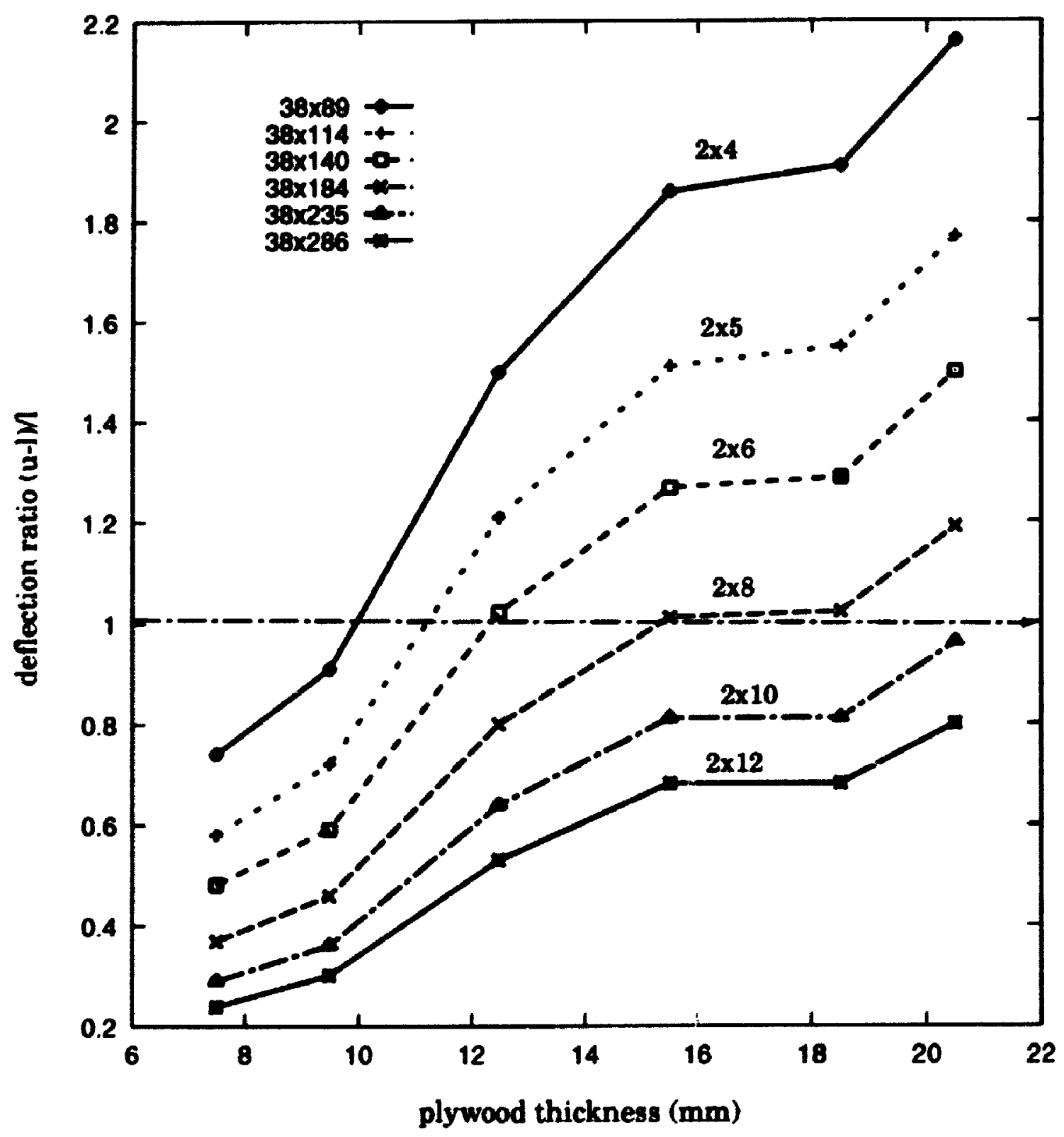

Figure 2.10: Effects of joist sizes and plywood thickness on floor deflection. represcuted by using deffection ratios $(u-1) /]$ 


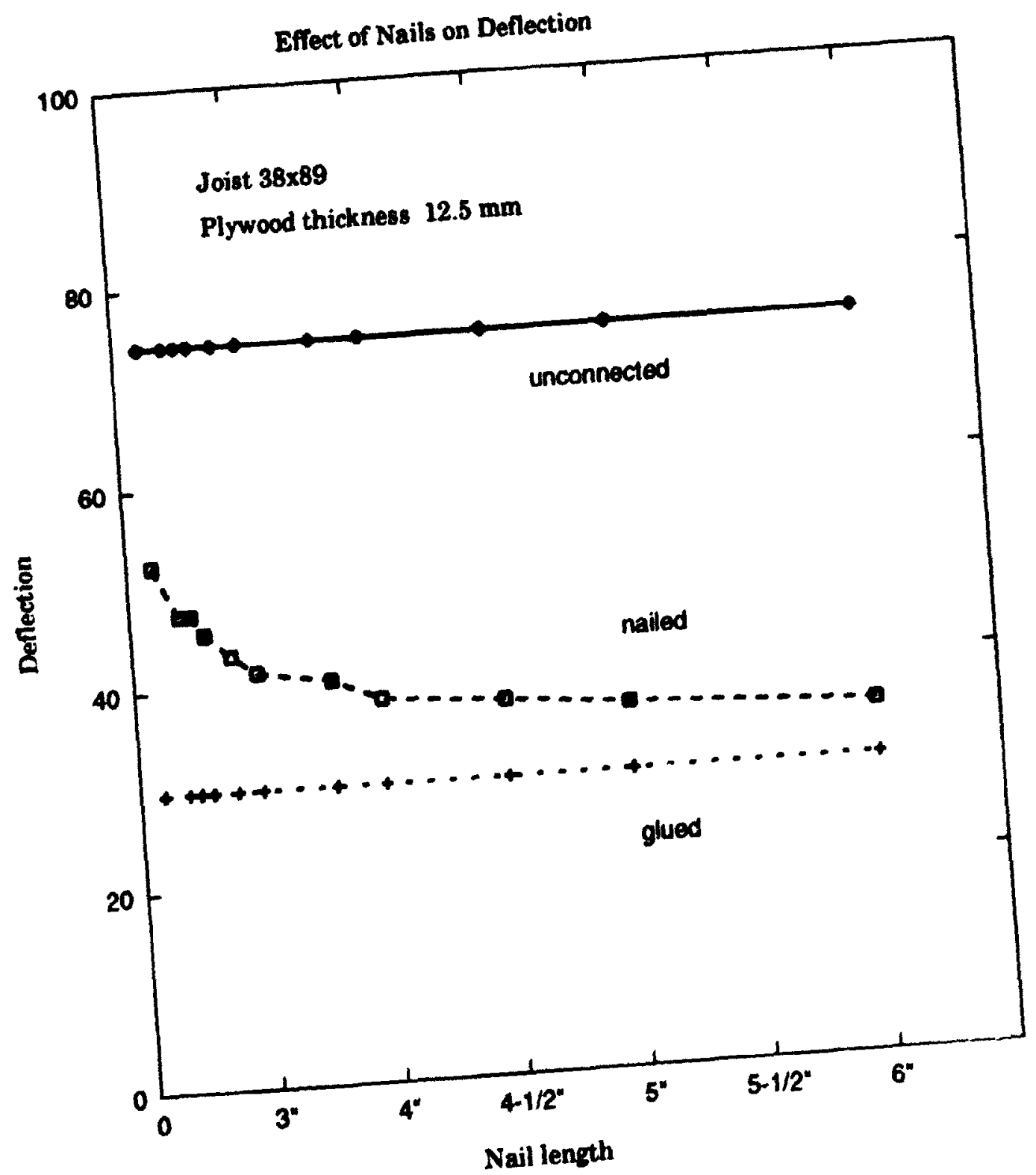

Figure 2.11: Effects of nail sizes on foor deflection 


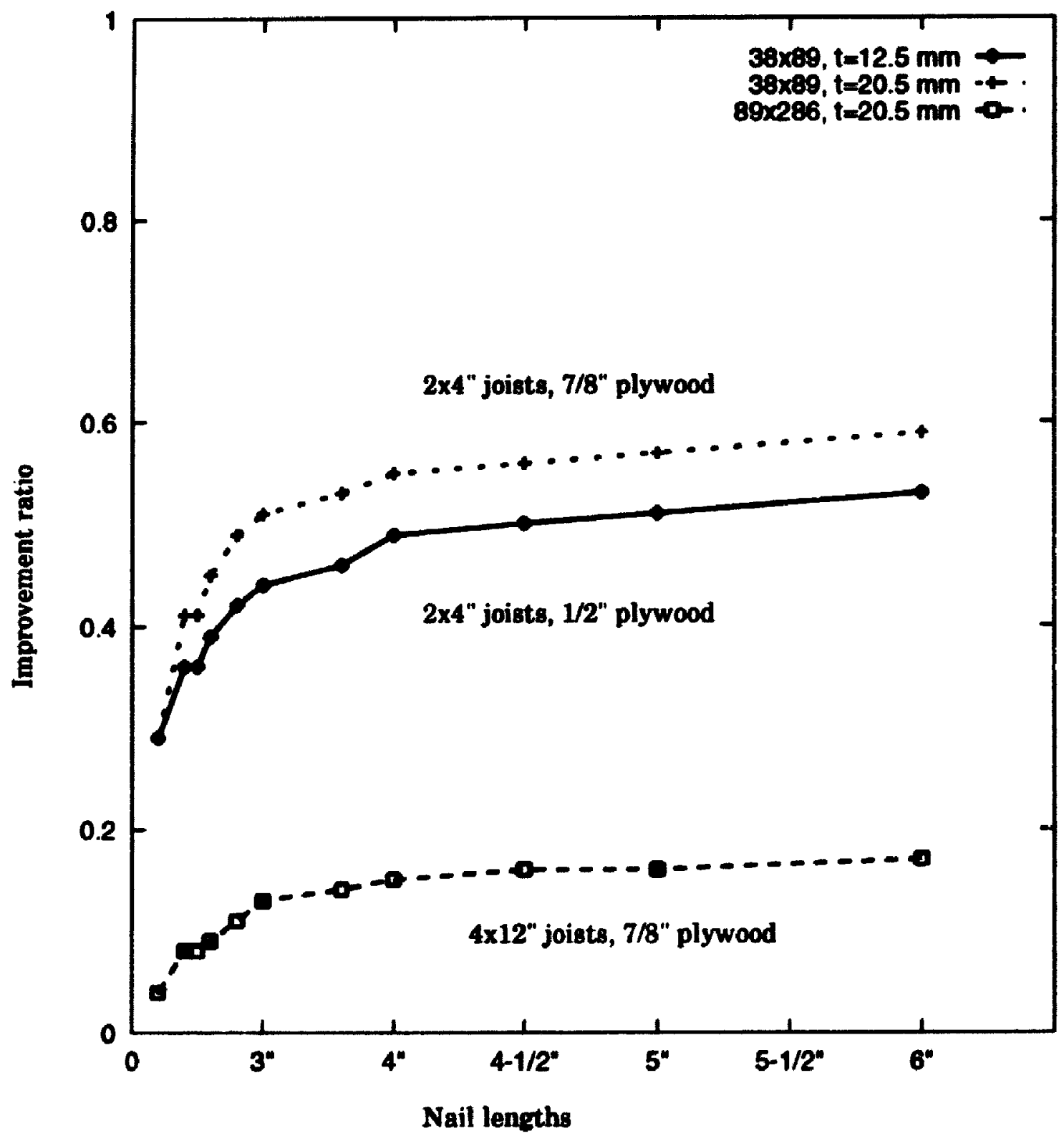

Figure 2.12: Efferts of nail sizes on floor deflection shown in terms of deflection ratios for floors with different plywood thickness and different joist sizes. 


\section{Chapter 3}

\section{The Effect of Aspect Ratio on the Deflection of Floors}

\subsection{Introduction}

In wood-joist floor assembly, the sheathing transfers load in the transverse direct ion. This is called "two way action" in literature. The thicker the sheathing, the nore" significant the two way action. A long span floor is one that has joists longer than the width of the floor. It has been noticed through tests, (Vanderbilt, 1971, [91]; Foschi, 1983, [21]; Wheat, 1985, [94]), that a floor doss not neressarily collapse whe't] one or even several joists fail. The load is often re-distributed to other joists. 'This shows the significance of two way action. It is also noticod (Sazinski ot al, 197!9, [K2]) that the aspect ratio of floors may be a factor in determining floor defloctions. 'This factor has been ignored up until now. The effects of aspert ratio actually represint the effects of edge supports. We will examine the extent of effect of aspert ration on floor deflections and subsequent impact on design procedures.

\subsection{The Lower Bound - Glued Floors}

For the purpose of comparison, let us look at the lower bound of the deflections derived from both the $\mathrm{T}$-beam and plate theories. 


\subsubsection{The T-beam Formula}

The governing :quation of a beam in bending is given by:

$$
E I \frac{d^{4} w_{6}}{d x^{4}}=q(x) S
$$

and the maximum deflection $w_{b \max }$, for a beam subjected to uniformly distributed load qu, is

$$
w_{b \max }=\frac{5}{384} \frac{q_{0} S L^{4}}{E I}
$$

where

L length of the beam

4 uniformly distributed load per unit area on the floor

S spacing of joists

bl bending stiffness of the T-beam

b subscript denotes the beam

\subsubsection{The Maximum Deflection of a Plate Simply Sup- ported on Four Sides}

Modelling the floor system as a whole, in Figure 2.3, as an orthotropic plate and assuming that the plate is simply supported on four sides. From the elastic orthotropic plate theory, the governing equation of the deflection of this plate $w_{p l}$ is

$$
\left(D_{x} \frac{\partial^{4}}{\partial x^{4}}+2 H \frac{\partial^{4}}{\partial x^{2} \partial y^{2}}+D_{y} \frac{\partial^{4}}{\partial y^{4}}\right) w_{p l}(x, y)=q(x, y)
$$

The solution for this differential equation is

$$
\begin{aligned}
w_{p l} & =\sum_{m=1}^{\infty} \sum_{n=1}^{\infty} w_{m n} \sin \frac{m \pi x}{L} \sin \frac{n \pi y}{B} \\
w_{m n} & =\frac{q_{m n}}{\frac{m^{4} \pi^{4}}{L^{4}} D_{x}+2 H^{\frac{m^{2} n^{2} \pi^{4}}{L^{2} B^{2}}}+\frac{n^{4} \pi^{4}}{B^{4}} D_{y}}
\end{aligned}
$$




$$
q_{m n}=\frac{4 q}{m n \pi^{2}}(1-\cos m \pi)(1-\cos n \pi)
$$

where

$D_{x} \quad$ bending stiffness of the plate in $\mathrm{x}$ direction $(\mathrm{N} \mathrm{mm})$

$H \quad$ torsional stiffness $(\mathrm{N} \mathrm{mm})$

$D_{y} \quad$ bending stiffness of the plate in $y$ direction $(\mathrm{N} \mathrm{mm})$

$L, B \quad$ length, width of the plate $(\mathrm{mm})$

The maximum deflection occurs at the centre point of the plate, $x=1 . / 2$ and $y=B / 2$. Then the maximum deflection of the plate $u_{p l}$ is

$$
w_{p l}=\sum_{m=1}^{\infty} \sum_{n=1}^{\infty} \frac{4 q(1-\cos m \pi)(1-\cos n \pi) \sin \frac{m \pi}{2} \sin \frac{n \pi}{2}}{m n \pi^{6}\left(\frac{m^{4}}{L^{4}} D_{x}+2 H \frac{m^{2} n^{2}}{L^{2} B^{2}}+\frac{n^{4}}{B^{4}} D_{y}\right)}
$$

\subsubsection{The Ratio of Deflections: Plate over T-beam}

Let the bending stiffness of the T-beam equal to the bending stiffness of the plate in the joist direction

$$
E I=D_{x} S
$$

Then the ratio of the maximum deflection of the plate and the beam is

$$
\begin{aligned}
\alpha & =\frac{w_{p} l}{w_{b}} \\
& =A \sum_{m=1}^{\infty} \sum_{n=1}^{\infty} \frac{(1-\cos m \pi)(1-\cos n \pi) \sin \frac{m \pi}{2} \sin \frac{n \pi}{2}}{m r\left[m^{4}+\beta_{1} m^{2} n^{2} \gamma^{2}+\beta_{2} n^{4} \gamma^{4}\right]}
\end{aligned}
$$

where

$$
\begin{aligned}
& A=\frac{1536}{5 \pi^{6}} \\
& \beta_{1}=\frac{2 H}{D_{x}}
\end{aligned}
$$




$$
\begin{aligned}
\beta_{2} & =\frac{D_{y}}{D_{x}} \\
\gamma & =\frac{L}{B}
\end{aligned}
$$

\subsubsection{Comparison and Discussion}

Assume that the bending stiffness of the plate in the direction of joists is the same as the bending stiffness of the corresponding T-beam, i.e. $E I=D_{x} S$. Assume the bending stiffness of the plate in the direction perpendicular to the joists $D_{y}$ and the torsional stiffness $H$ to be that of the plywood sheathing.

Neglecting Bending Stiffness in the y Direction and the Torsional Stifiness Let $D_{y}=H=0$, assume the load is uniformly distributed and compare equations 3.1 and 3.3.:

$$
\begin{aligned}
& E I \frac{d^{4} w_{b}}{d x^{4}}=q_{0} S \\
& D_{x} \frac{d^{4} w_{p l}}{d x^{4}}=q_{0}
\end{aligned}
$$

where $q_{0}$ is the uniformly distributed load acting on the floor. $q_{0} S$ is the load acting on the tributary area on the T-beam.

Notice that $D_{x} S=E I$. These two equations are identical. Then

$$
w_{p l \max }=w_{b \max }
$$

or

$$
a=1
$$

In other form

$$
a=A \sum_{m=1}^{\infty} \sum_{n=1}^{\infty} \frac{(1-\cos m \pi)(1-\cos n \pi) \sin \frac{m \pi}{2} \sin \frac{n \pi}{2}}{m^{5} n}=1
$$


Table 3.1: Rate of convergence

\begin{tabular}{|c|c|c|c|c|c|c|c|c|c|c|c|}
\hline \multicolumn{3}{|c|}{$\beta_{1}=\beta_{2}=0$} & \multicolumn{3}{|c|}{$\beta_{1}=\beta_{2}=0.01$} & \multicolumn{3}{|c|}{$\beta_{1}=\beta_{2}=0.1$} & \multicolumn{2}{|c|}{$\beta_{1}=\beta_{2}=1$} \\
\hline $\mathrm{M}$ & $\mathrm{N}$ & $\alpha$ & $\mathrm{M}$ & $\mathrm{N}$ & $\alpha$ & $\mathrm{M}$ & $\mathrm{N}$ & $\alpha$ & $\mathrm{M}$ & $\mathrm{N}$ & $a$ \\
\hline 1 & 1 & 1.2782 & 1 & 1 & 1.2531 & 1 & 1 & 1.0651 & 1 & 1 & .4261 \\
\hline 1 & 3 & 0.8521 & 1 & 3 & 1.0289 & 1 & 3 & 1.0225 & 1 & 3 & .4214 \\
\hline 1 & 5 & 1.1077 & 1 & 5 & 1.0629 & 1 & 5 & 1.0264 & 1 & 5 & .4218 \\
\hline 1 & 7 & 0.9251 & 1 & 7 & 1.0558 & 1 & 7 & 1.0257 & 1 & 7 & .4217 \\
\hline 1 & 9 & 1.0672 & 1 & 9 & 1.0579 & 1 & 9 & 1.0259 & 1 & 9 & .4217 \\
\hline 1 & 11 & 0.951 & 1 & 11 & 1.0571 & 1 & 11 & 1.0258 & 1 & 11 & .4217 \\
\hline 1 & 13 & 1.0493 & 1 & 13 & 1.0574 & 1 & 13 & 1.0258 & 1 & 13 & .4217 \\
\hline 1 & 15 & 0.9641 & 1 & 15 & 1.0573 & 1 & 15 & 1.0258 & 1 & 15 & .4217 \\
\hline 3 & 15 & 0.9601 & 3 & 15 & 1.0532 & 3 & 15 & 1.0217 & 3 & 15 & .4175 \\
\hline 5 & 15 & 0.9604 & 5 & 15 & 1.0535 & 5 & 15 & 1.022 & 5 & 15 & .4179 \\
\hline 7 & 15 & 0.9604 & 7 & 15 & 1.0534 & 7 & 15 & 1.0219 & 7 & 15 & .4178 \\
\hline 9 & 15 & 0.9604 & 9 & 15 & 1.0534 & 9 & 15 & 1.022 & 9 & 15 & .4178 \\
\hline \hline
\end{tabular}

\section{Rate of Convergence of the Series Solution}

The expression for the ratio $\alpha$ is in the form of a series (Equation 3.9). It is important to study the rate of convergence of the series. If it converges toos slow, the practical application of the formula will be limited. Fortunately, this is not thr casie. By examining equation 3.9 , it can be noticed that the $(m, n)$ th torm of thre suriess decreases in a rate of $m^{5} n, m^{3} n^{3}$ and $m n^{5}$. This characterises a fast convergonice. Table 3.1 shows the rate of convergence.

In Table 3.1, the ratio $\alpha$ is calculated to a certain number of terms of the series. $M$ and $N$ represent the number of terms in the series used. $\beta_{1}=\frac{2 \|}{D_{z}}$ and $\beta_{2}=\frac{\partial_{x}}{D_{x}}$ are the stiffness ratios. It can be observed that as the value of $\beta_{1}$ and $\beta_{2}$ increasiel, the rate of convergence of the ratio $\alpha$ is increased.

Therefore, for practical applications, only a limited number of terms in the serties needs to be used to achieve relatively accurate results. 


\section{Influences of Torsional and Transverse Bending Stiffess}

It has bren discussed that the results from plate theory are the same as the results dorived from beam theory when ignoring the torsional stiffness and transverse bending stiffness. In this case, $\alpha=1$, where $\alpha$ is the ratio of maximum deflection of the orthotropic plate and the maximum defication of the T-beam. The following is a discussion of the significance of ignoring torsional and transverse bending stiffness.

Figure 3.1 shows that for floors that are longer in the direction of the joist than the width of the floor, the T-beam theory cannot be used without incurring large errors. This can be explained by the fact that T-beam theory does not consider the influence in the transverse direction. For floors in such a configuration, the influence cannot be ignored.

It can be scen from Figure 3.2 that the trend is still the same. For floors with joist longer than the width of the floor, the errors caused by using $T$-beam theory is dramatic. However, it is more sensitive for the loose floors than the glued ones.

Figure 3.3 schematically shows the different layouts of floors. T-beam theory ignores the influence of the other dimension $B$ of the plate on its deflection. When the dimension ratio $L / B$ increases to $L$ certain point, deflection ratio increases dramatically. This is because of the influence of the supports in the transverse direction. The supports limit the deflection. The larger the ratio $\mathrm{L} / \mathrm{B}$, the larger the influence of the supports.

This result shows the necessity of limiting the application of $T$-beam formula in designing timber floors with high dimension ratio $L / B$.

Figure 3.4 shows the effects of the torsional and transverse bending siffness of the plywood. The thicker the plywood, the more severe the influence. This in turn proves that the transverse stiffness of the floor will have a drastic effect on floors with joists longer than the width of the floors.

The other obvious observation from the figures is that for a medium span floor, the deflertion calculated from plate theory is actually larger than that from the T-beam theory. The difference is as big as $10 \%$. This is shown as the segment of reverse curve. This is also due to the influence of supports in the transverse 
direction. except that this time the two sides tries to squeeze the plate and force the center point of the plate to go down even further and therefore yirld larger deflection than its T-beam counter-part. Imagine that the floor is not supported in the direction perpendicular to the joists. Ill the joists will have the same deflection curve which will be the same as the T-beam. Then try to push the unsupported sides up. This will actually push down the center joist of the floor. Bul this trond stops when the squeezing effect is offset or even overcome by the supporting effert. This supporting effect eventually reduced the deffection of the center peint of the floor when it becomes a long span floor from a medium one.

Figure 3.5 shows the short and medium span floors. It can be serell that for a typical floor (short or medium span with $2 \times 8$. $2 \times 10$ or $2 \times 12$ joist.s). the T Ixeam theory can predict the maximum deflection of floors without large discrepancy. 


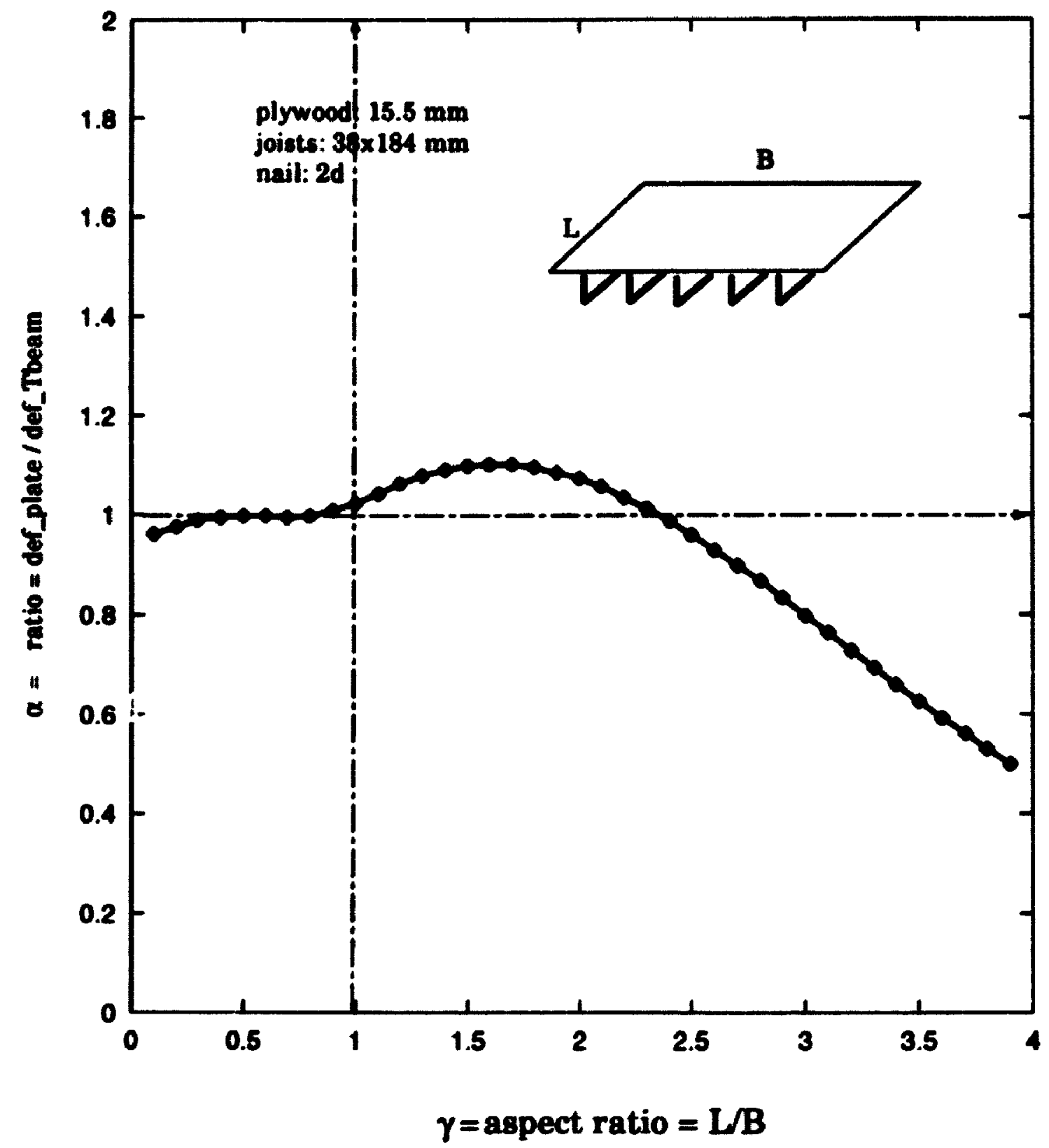

Figure 3.1: Effects of aspect ratios on floor deflections for a nailed floor 


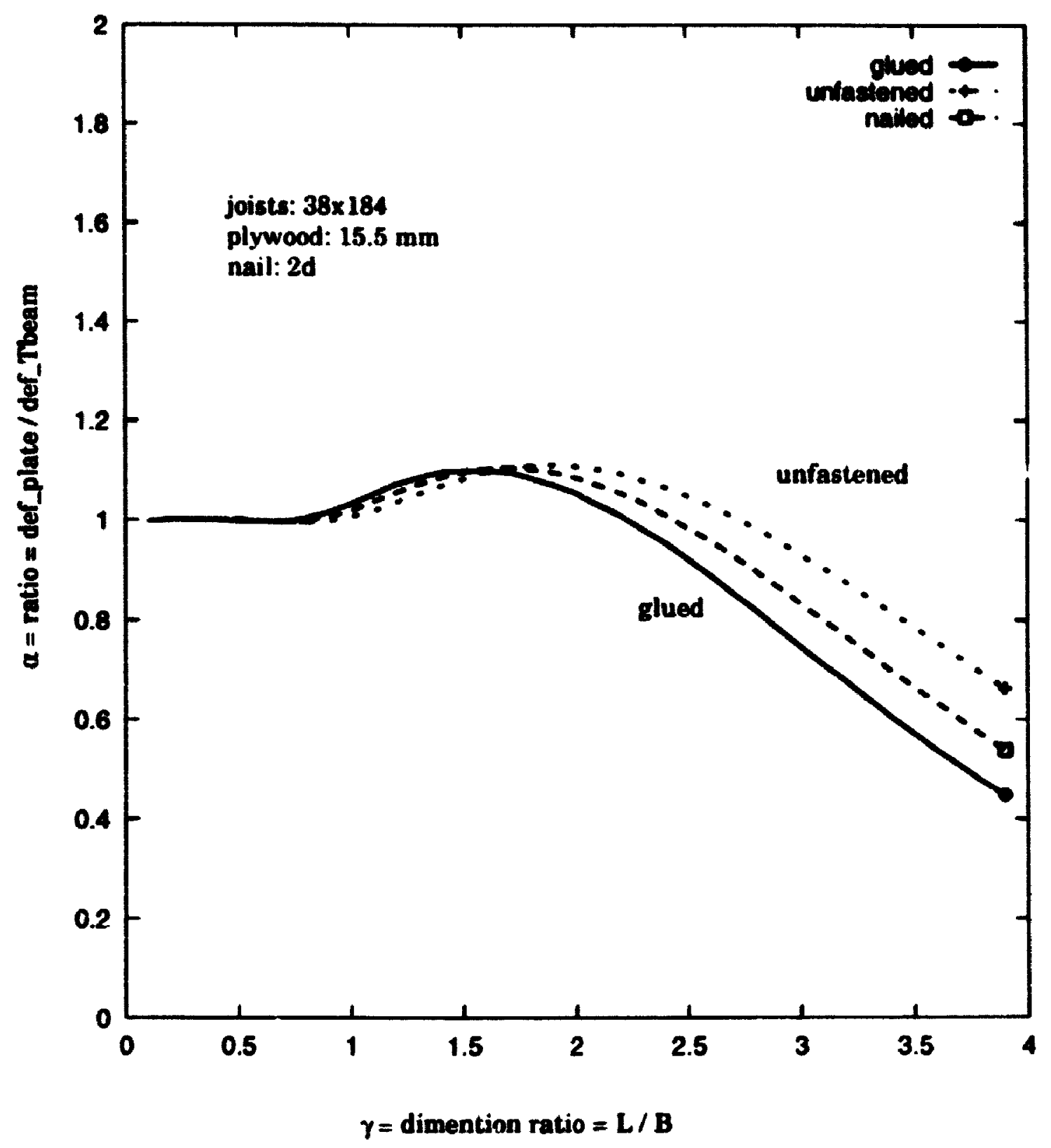

Figure 3.2: Effects of aspect ratios on deflections of floors with differront sizers af nails 


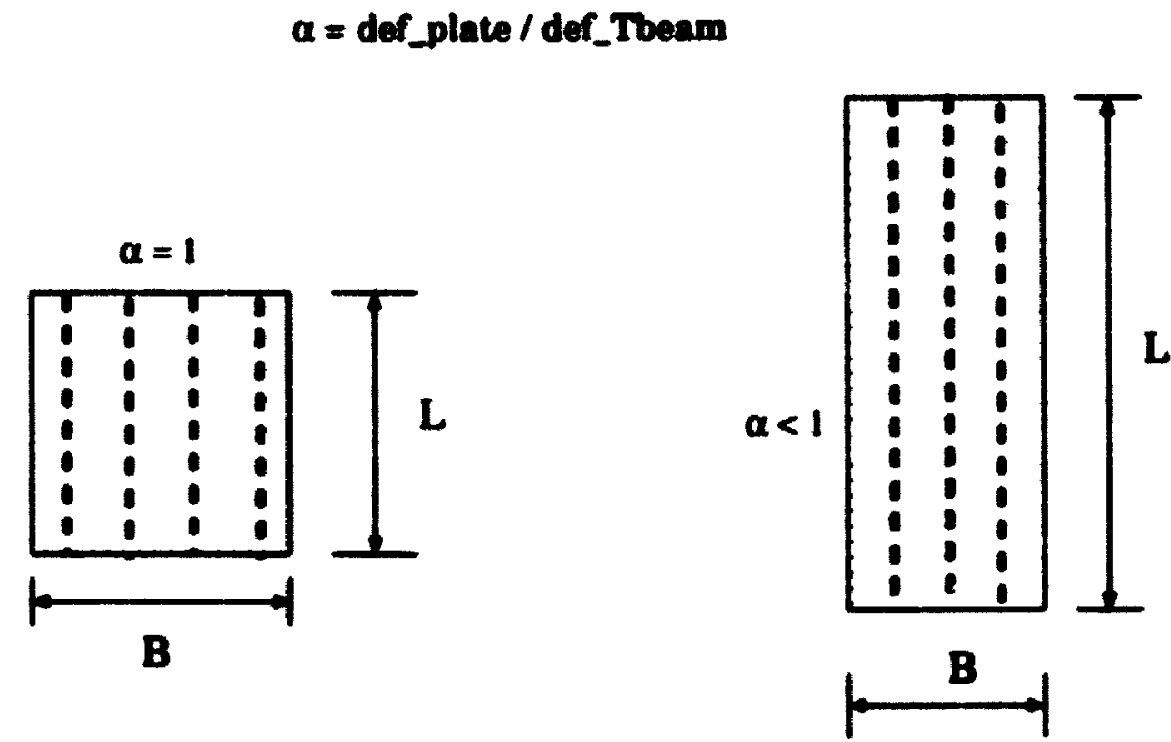

\section{Long span floor}

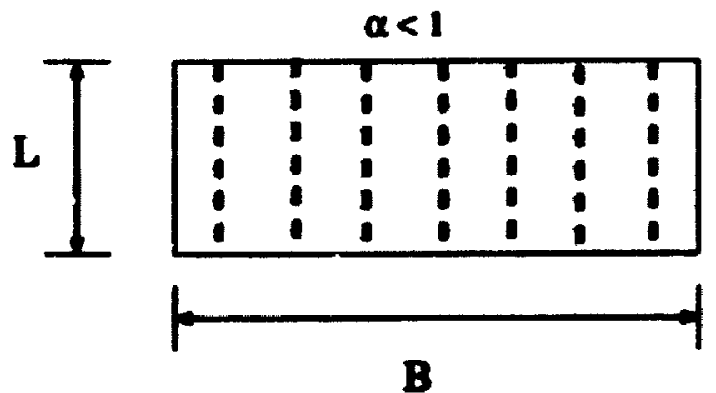

Short apan floor

Figure 3.3: Long span floor us short span flonr 


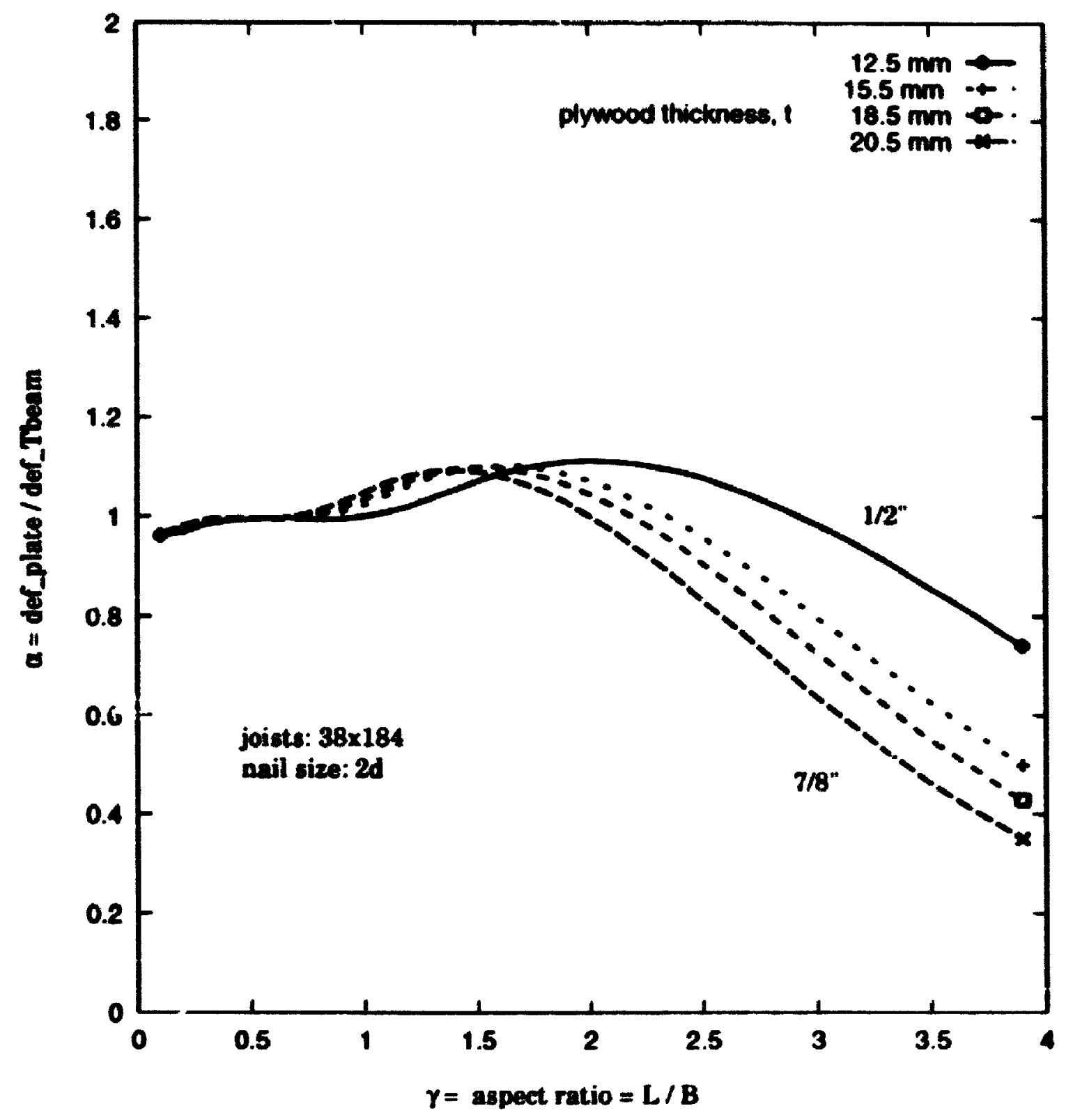

Figure 3.4: Effects of plywood thickness on flocor deffertions 


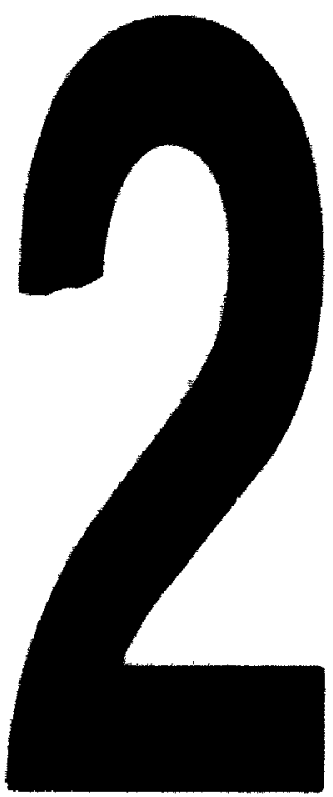

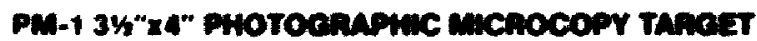

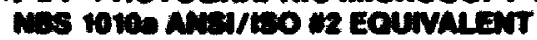

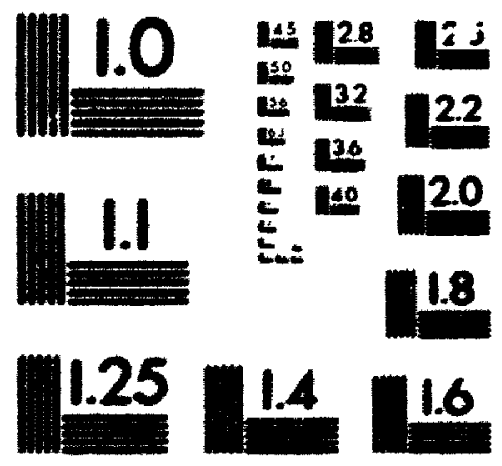

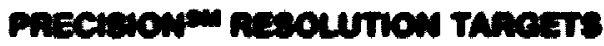




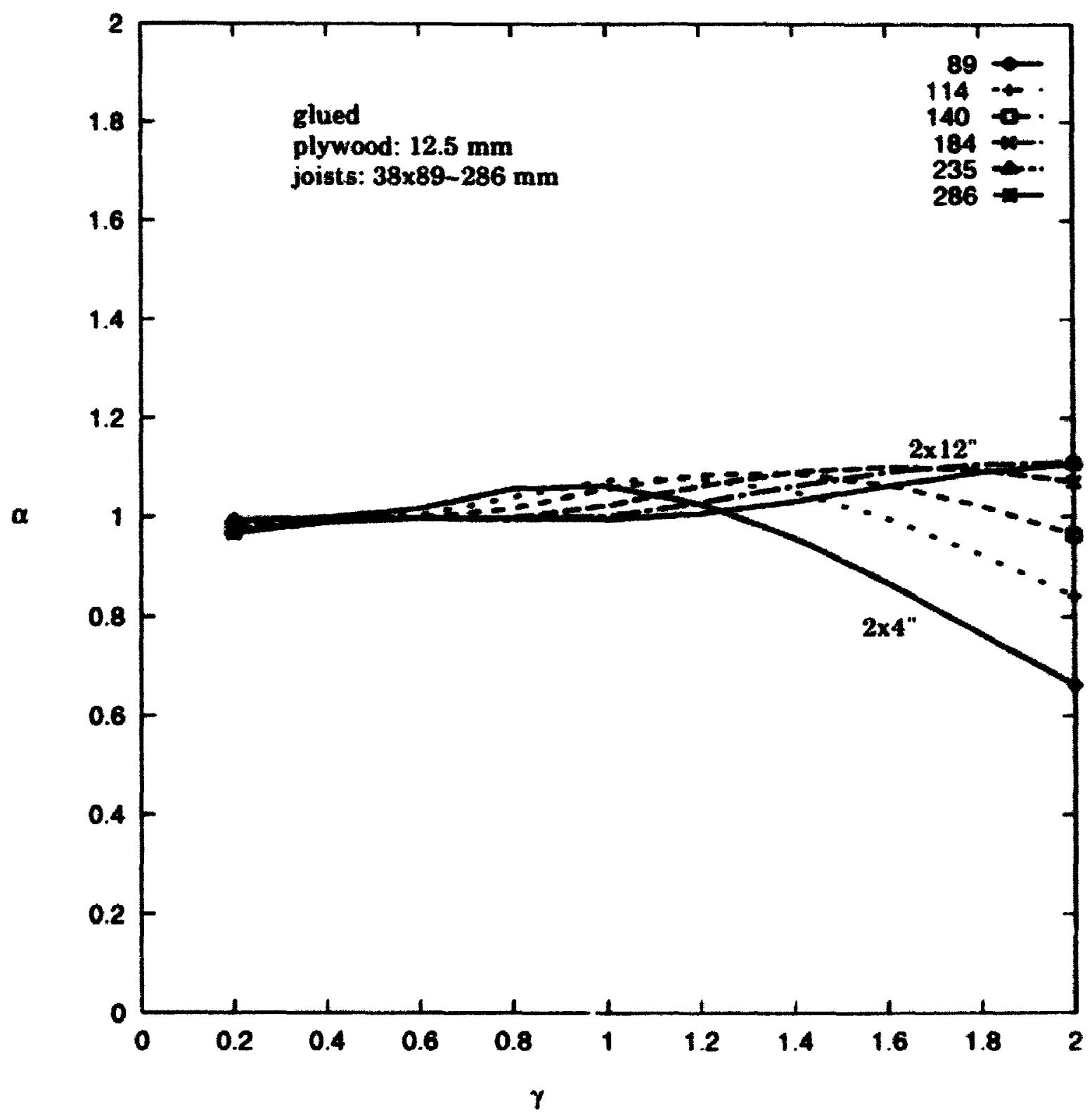

Figure 3.5: The most commonly used floor layouts,$<2$ 


\section{Chapter 4}

\section{Guidelines in Designing Medium and Long Span Floors}

For a long span floor, the T-beam theory may introduce significant errors. A long span floor is one that has joists longer than the width of the floor. The design for long span floors becomes an issue. which is investigated in the following section.

\subsection{Differences Between T-beam and Plate The- ory for Different Floors}

Let us cxamine the differences bet ween deflections calculated by the T-beam theory and the plate theory. The ratio of the maximum deflection of the plate and the beam. as described in last chapter. is

$$
\begin{aligned}
\alpha & =\frac{u_{p} l}{u_{b}} \\
& =1 \sum_{m=1}^{\infty} \sum_{n=1}^{\infty} \frac{(1-\cos m \pi)(1-\cos n \pi) \sin \frac{m r}{2} \sin \frac{n \pi}{2}}{m n\left[m^{4}+S_{1} m^{2} n^{2} \eta^{2}+S_{2} n^{4} p_{i}^{4}\right]}
\end{aligned}
$$

where

$$
A=\frac{1536}{5 \pi^{6}}
$$




$$
\begin{aligned}
j_{1} & =\frac{2 H}{D_{x}} \\
j_{2} & =\frac{D_{y}}{D_{r}} \\
\gamma & =\frac{a}{b}
\end{aligned}
$$

In order to calculate the floor deflection patterns. floors are modelled using the* existing range of sizes for all members. The minimum width of joists is $38 \mathrm{~mm}(2$ inches) while the maximum is $89 \mathrm{~mm}$ ( $t$ inches). The minimum height of joists are $89 \mathrm{~mm}$ ( 4 inches) and the maximum is 286 (12 inches). Four popular sizes for plywood are chosen with the thinnest as $12.5 \mathrm{~mm}$ and thickest as $20.5 \mathrm{~mm}$. Nails $20 \mathrm{~d}$ ( 1 inches) are chosen for the reason that any size bigger than $20 \mathrm{~d}$ doc's not make a significant difference. Calculations have been done for the following 11 floors:

- joists: $38 \times 89,38 \times 114.38 \times 140.38 \times 184,38 \times 235,38 \times 286,89 \times 114,89 \times 1.10,89 \times 1 \times 4$, $89 \times 235,89 \times 286$

- plywood: $12.5 \mathrm{~mm}, 4$ plies; $15.5 \mathrm{~mm} 5$ plies; $18.5 \mathrm{~mm}, 6$ plies: $20.5 \mathrm{~mm} 7$ plies

- nails: $20 \mathrm{~d}$

The results are illustrated in Figures 4.1, 4.2, 4.3, 4.4, 4.5, 1.6, 4.7, 1.8.

By examining these figures, the following observations can be found:

1. For short span floors, $\gamma=L / B<1$, the deflection ratio $\alpha=w_{p l} / w_{b}$ equals approximately to 1 . Therefore, the deflection of a short floor can be calculated using the T-beam formula.

2. For long span floors, $\gamma=L / B$ is bigger than 1 , the T-beam formula can beused but with modification (to be discussed later).

3. Floors with smaller joists, the $D_{x}$ is smaller and $\beta_{1}$ and $\beta_{2}$ is larger which leads to smaller $\alpha$. This suggests that floors with smaller joists tend to be more sensitive with the aspect ratio $\gamma$ (refer equation 4.1). Floors with thicker plywood which leads to larger $\beta_{1}$ and $\beta_{2}$ are also tend to be more sensitive to, aspect ratio. 
If a longer span floor is designed using the T-beam formula. which will design the floor as a single T-beam subject to load on the tributary area and ignore the influence of supports transferred through sheathing. the error can not be ignored. The supports at $y=0$ and $y=b$ limit the maximum deflections of the foor in the center. This supporting effect becomes larger with bigger rigidity ratio $\left(.3_{1}=2 H / D_{x}\right.$, $\left.x_{2}=D_{y} / D_{x}\right)$. The thicker the plywood. the more supporting effects from the sides are transferred to the center joists and thus the more it limit the maximum deflection. The smaller the joists, or the bigger the rigidity ratios, the less dominant the joists are in the floor system and thus the more influence from the sheat hing.

Only simply supported conditions are examined. Floors with fixed boundary conditions can also be examined. However, there are rarely fixed conditions in practice. If a floor is designed according to a simply supported boundary condition. the design is on the safe side since a floor with fixed sides deflects less than a floor with simply supported sides.

\subsection{Effects of Connections on the Deflection Ra- tio $\alpha$}

In last section. all the floors used in discussions are nailed with $20 \mathrm{~d}$ nails $(4$ inches in length). In order to examine the influence of connections on the deflection ratio, three kinds of connections are studied: unfastened, glued and nailed with $20 \mathrm{~d}$ nails.

It can be seen from Figure 4.9, 4.10, 4.11 and 4.12 that the influence of connections on the deflection ratio is not significant especially for floors with larger joists and thinner plywood.

\subsection{Design of Long Span Floors}

The following sections will be devoted to finding procedures to inrorporate the findings into design for long span floors. 


\subsubsection{Using Charts}

To design a long span floor. the $T$-bean formula can be userl to calculate the deflec tions $u_{b}$ of a $T$-beam subjected to the load on the tributary area. then multiplymg it by the $\alpha$ value taken from the appropriate igures as described fefore (Figure 1.1. 4.2. 4.3. 4.4. 4.5. 4.6. 4.. 1.5$)$

$$
w_{w}=w_{n}
$$

\subsubsection{Using Formula and Approximation}

The other way to design a long span floor is 10 use a formula. To calculate the deflection ratio from Equation 4.1 is too tedious because' of the serie's form. However. if the convergence of the series is fast. a formula of approximation can be deriverl.

Let us examine the convergence rate for varies floors. The eve'n terms ( $n=2.4$.6....: $\mathrm{m}=2.4 .6 \ldots$...) equals zero in equation 4.1 .

Let

$$
\alpha_{0}=A \sum_{m=1}^{M} \sum_{n=1}^{N} \frac{(1-\cos m \pi)(1-\cos n \pi) \sin \frac{m \pi}{2} \sin \frac{n \pi}{2}}{m n\left[m^{4}+3_{1} m^{2} n^{2} \gamma^{2}+\beta_{2} n^{4}-1\right]}
$$

In Figure 4.13, 4.14, 4.19 and 4.20 , $\alpha$ and $\alpha_{0}$ with $M=1.3 .5$ and $N=1$ are dis played. It can be seen that $\alpha$ converges very fast with $m$. There is megligible difference between $\mathrm{M}=1, \mathrm{M}=\mathbf{3}$ and $\mathrm{M}=\mathbf{5}$.

In Figure 4.15, 4.16. 4.17 and 4.18, $\alpha$ and $\alpha_{0}$ with $M=1$ and $N=1,3,5$ are displayed. It can be seen that $\alpha$ does not converge as fast with $n$ as with $\mathrm{m}$. However, when $\gamma>\gamma_{0}, \alpha_{0}$ and $\alpha$ are almost identical. yo represent a rritical value beyond which $\alpha_{0}$ and $\alpha$ are considered identical.

$\gamma_{0}$ can be calculated as follows:

Let

$$
\alpha_{m n}=\frac{4 A}{m n\left[m^{4}+\beta_{1} m^{2} n^{2} \gamma^{2}+\beta_{2} n^{4} \gamma^{4}\right]}
$$

From equation 4.1 , then after neglecting the in terms

$$
\alpha=\alpha_{11}-\alpha_{13}+\alpha_{15}-\ldots
$$




$$
a=a_{11}-1 a_{13}-a_{15}+\ldots \ldots t
$$

If

$$
a_{13}<k a_{11}
$$

then

$$
\left(a_{1}-a_{15}-\ldots .\right)<k a_{11}
$$

where $k$ is a value determined by the amount of error allowed.

('ombining tequation 1.5 and 1.6

$$
1+. f_{1} \eta^{2}+. \gamma_{2} \eta^{4}<3\left(1+9.3_{1} \eta^{2}+813_{2} \eta^{4}\right)
$$

assuming when $;=-i 0$

$$
1+H_{1} \eta^{2}+H_{2} \eta^{4}=3\left(1+93_{1} \eta^{2}+81 \beta_{2} \gamma^{4}\right)
$$

then

$$
\gamma_{\gamma}=\sqrt{\frac{(1-27 k) \cdot 3_{1}+\sqrt{(27 k-1) \cdot 3_{1}^{2}-\left(4(3 k-1)(243 k-1) 3_{2}\right.}}{2(243 k-1) 3_{2}}}
$$

70 is calculated for a list of different floors with $k=0.02$. The results are listed in Table 1.1 and 4.2 .

Cor floors with plywood glued to the joists. the $\gamma_{0}$ is listed in Table 4.3 and 4.4 .

\subsection{Summary}

When a designer wants to design for a long span floor with $\gamma=L / B>\gamma_{0}$. only the first term of equation 4.1 needs to be used. Then

$$
a=\alpha_{11}
$$


Table 4.1: $9,0, \alpha$ and $\alpha_{0}$ for different nailed floors. plywood thi kness: $12,5.15,5 \mathrm{~mm}$

\begin{tabular}{|c|c|c|c|c|c|c|c|}
\hline 1 & d & $\mathrm{h}$ & nail size & 90 & $n$ & $n_{0}$ & $\frac{1-20}{16}$ \\
\hline 12.5 & 38 & 89 & 20 & 1.71 & 1.02 & 1.06 & 0.0 .1 \\
\hline 12.5 & 38 & 114 & 20 & 2.00 & 1.04 & 1.08 & 0.0 .1 \\
\hline 12.5 & 38 & 140 & 20 & 2.29 & 1.05 & 1.10 & 0.0 .4 \\
\hline 12.5 & 38 & 184 & 20 & 2.74 & 1.07 & 1.11 & 0.04 \\
\hline 12.5 & 38 & 235 & 20 & 3.23 & 1.08 & 1.1 .2 & 0.0 .4 \\
\hline 12.5 & 38 & 286 & 20 & 3.70 & 1.08 & $1.1: 3$ & 0.0 .1 \\
\hline i2.3 & 89 & 114 & 20 & 2.33 & 1.06 & 1.10 & 0.01 \\
\hline 12.5 & 89 & 140 & 20 & 2.67 & 1.07 & 1.11 & 0.0 .4 \\
\hline 12.5 & 89 & 184 & 20 & 3.23 & 1.08 & 1.12 & 0.0 .1 \\
\hline 12.5 & 89 & 235 & 20 & 3.84 & 1.08 & 1.13 & 0.04 \\
\hline 12.5 & 89 & 286 & 20 & 4.42 & 1.09 & 1.13 & 0.04 \\
\hline 15.5 & 38 & 89 & 20 & 1.49 & 1.00 & 1.04 & 0.04 \\
\hline 15.5 & 38 & 114 & 20 & 1.74 & 1.02 & 1.06 & 0.04 \\
\hline 15.5 & 38 & 140 & 20 & 1.98 & 1.04 & 1.08 & 0.04 \\
\hline 15.5 & 38 & 184 & 20 & 2.37 & 1.06 & 1.10 & 0.04 \\
\hline 15.5 & 38 & 235 & 20 & 2.80 & 1.07 & 1.11 & 0.04 \\
\hline 15.5 & 38 & 286 & 20 & 3.20 & 1.08 & 1.12 & 0.04 \\
\hline 15.5 & 89 & 114 & 20 & 2.02 & 1.04 & 1.08 & 0.04 \\
\hline 15.5 & 89 & 140 & 20 & 2.32 & 1.05 & 1.10 & 0.04 \\
\hline 15.5 & 89 & 184 & 20 & 2.80 & 1.07 & 1.11 & 0.04 \\
\hline 15.5 & 89 & 235 & 20 & 3.33 & 1.08 & 1.12 & 0.04 \\
\hline 15.5 & 89 & 286 & 20 & 3.83 & 1.08 & 1.13 & 0.04 \\
\hline
\end{tabular}


Table 4.2: $\gamma_{0}, \alpha$ and $\alpha_{0}$ for different nailed floors plywood thickness: $18.5 .20 .5 \mathrm{~mm}$

\begin{tabular}{|c|c|c|c|c|c|c|c|}
\hline \hline & $d$ & $h$ & nail size & $\gamma_{0}$ & $\alpha$ & $\alpha_{0}$ & $\frac{a-\alpha o}{\alpha}$ \\
\hline 18.5 & 38 & 89 & 20 & 1.35 & 0.98 & 1.02 & 0.04 \\
\hline 18.5 & 38 & 114 & 20 & 1.57 & 1.01 & 1.05 & 0.04 \\
\hline 18.5 & 38 & 140 & 20 & 1.79 & 1.03 & 1.07 & 0.04 \\
\hline 18.5 & 38 & 184 & 20 & 2.14 & 1.05 & 1.09 & 0.04 \\
\hline 18.5 & 38 & 235 & 20 & 2.52 & 1.06 & 1.11 & 0.04 \\
\hline 18.5 & 38 & 286 & 20 & 2.88 & 1.07 & 1.12 & 0.04 \\
\hline 18.5 & 89 & 114 & 20 & 1.82 & 1.03 & 1.07 & 0.04 \\
\hline 18.5 & 89 & 140 & 20 & 2.09 & 1.05 & 1.09 & 0.04 \\
\hline 18.5 & 89 & 184 & 20 & 2.52 & 1.06 & 1.11 & 0.04 \\
\hline 18.5 & 89 & 235 & 20 & 3.00 & 1.07 & 1.12 & 0.04 \\
\hline 18.5 & 89 & 286 & 20 & 3.45 & 1.08 & 1.12 & 0.04 \\
\hline 20.5 & 38 & 89 & 20 & 1.30 & 0.97 & 1.01 & 0.04 \\
\hline 20.5 & 38 & 114 & 20 & 1.50 & 1.00 & 1.04 & 0.04 \\
\hline 20.5 & 38 & 140 & 20 & 1.70 & 1.02 & 1.06 & 0.04 \\
\hline 20.5 & 38 & 184 & 20 & 2.03 & 1.04 & 1.09 & 0.04 \\
\hline 20.5 & 38 & 235 & 20 & 2.38 & 1.06 & 1.10 & 0.04 \\
\hline 20.5 & 38 & 286 & 20 & 2.72 & 1.07 & 1.11 & 0.04 \\
\hline 20.5 & 89 & 114 & 20 & 1.73 & 1.02 & 1.06 & 0.04 \\
\hline 20.5 & 89 & 140 & 20 & 1.97 & 1.04 & 1.08 & 0.04 \\
\hline 20.5 & 89 & 184 & 20 & 2.37 & 1.06 & 1.10 & 0.04 \\
\hline 20.5 & 89 & 235 & 20 & 2.81 & 1.07 & 1.11 & 0.04 \\
\hline 20.5 & 89 & 286 & 20 & 3.23 & 1.08 & 1.12 & 0.04 \\
\hline \hline
\end{tabular}


Table 4.3: 9o. $a_{0}$ and $a$ for different glued floors.plywood thickness: 13.5. 15.i mm

\begin{tabular}{|c|c|c|c|c|c|c|}
\hline $\mathrm{t}$ & $\mathrm{d}$ & $\mathrm{h}$ & $\gamma \mathrm{r}$ & $\alpha$ & $\alpha_{0}$ & $\frac{1}{10}$ \\
\hline 12.5 & 38 & 89 & 1.82 & 1.03 & 1.07 & 0.04 \\
\hline 12.5 & 38 & 114 & 2.12 & 1.05 & 1.09 & 0.01 \\
\hline 12.5 & 38 & 140 & 2.42 & 1.06 & 1.10 & 0.01 \\
\hline 12.5 & 38 & 184 & 2.88 & 1.07 & 1.12 & 0.01 \\
\hline 12.5 & 38 & 235 & 3.38 & 1.08 & 1.12 & 0.01 \\
\hline 12.5 & 38 & 286 & 3.85 & 1.08 & 1.13 & 0.01 \\
\hline 12.5 & 89 & 114 & 2.44 & 1.06 & 1.10 & 0.01 \\
\hline 12.5 & 89 & 140 & 2.79 & 1.07 & 1.11 & 0.01 \\
\hline 12.5 & 89 & 184 & 3.34 & 1.08 & 1.12 & 0.04 \\
\hline 12.5 & 89 & 235 & 3.95 & 1.08 & 1.13 & 0.04 \\
\hline 12.5 & 89 & 286 & 4.53 & 1.09 & 1.13 & 0.01 \\
\hline 15.5 & 38 & 89 & 1.57 & 1.01 & 1.05 & 0.04 \\
\hline 15.5 & 38 & 114 & 1.82 & 1.03 & 1.07 & 0.04 \\
\hline 15.5 & 38 & 140 & 2.07 & 1.04 & 1.09 & 0.04 \\
\hline 15.5 & 38 & 184 & 2.47 & 1.06 & 1.10 & 0.04 \\
\hline 15.5 & 38 & 235 & 2.90 & 1.07 & 1.12 & 0.04 \\
\hline 15.5 & 38 & 286 & 3.31 & 1.08 & 1.12 & 0.04 \\
\hline 15.5 & 89 & 114 & 2.09 & 1.05 & 1.09 & 0.04 \\
\hline 15.5 & 89 & 140 & 2.39 & 1.06 & 1.10 & 0.04 \\
\hline 15.5 & 89 & 184 & 2.88 & 1.07 & 1.11 & 0.04 \\
\hline 15.5 & 89 & 235 & 3.40 & 1.08 & 1.12 & 0.04 \\
\hline 15.5 & 89 & 286 & 3.90 & 1.08 & 1.13 & 0.04 \\
\hline
\end{tabular}


Table 1.4: $\%, \alpha$ and $\alpha_{0}$ for different glued floors.plywood thickness: $18.5 .20 .5 \mathrm{~mm}$

\begin{tabular}{|c|c|c|c|c|c|c|}
\hline \hline & $d$ & $h$ & $\gamma_{0}$ & $\alpha$ & $\alpha_{0}$ & $\frac{a-a n}{a}$ \\
\hline 18.5 & 38 & 89 & 1.43 & 0.99 & 1.03 & 0.04 \\
\hline 18.5 & 38 & 11. & 1.65 & 1.01 & 1.06 & 0.04 \\
\hline 18.5 & 38 & 140 & 1.87 & 1.03 & 1.08 & 0.04 \\
\hline 18.5 & 38 & 184 & 2.23 & 1.05 & 1.10 & 0.04 \\
\hline 18.5 & 38 & 235 & 2.61 & 1.06 & 1.11 & 0.04 \\
\hline 18.5 & 38 & 286 & 2.98 & 1.07 & 1.12 & 0.04 \\
\hline 18.5 & 89 & 114 & 1.89 & 1.03 & 1.08 & 0.04 \\
\hline 18.5 & 89 & 140 & 2.16 & 1.05 & 1.09 & 0.04 \\
\hline 18.5 & 89 & 184 & 2.59 & 1.06 & 1.11 & 0.04 \\
\hline 18.5 & 89 & 235 & 3.06 & 1.07 & 1.12 & 0.04 \\
\hline 18.5 & 89 & 286 & 3.51 & 1.08 & 1.12 & 0.04 \\
\hline 20.5 & 38 & 89 & 1.39 & 0.98 & 1.02 & 0.04 \\
\hline 20.5 & 38 & 114 & 1.60 & 1.01 & 1.05 & 0.04 \\
\hline 20.5 & 38 & 140 & 1.82 & 1.03 & 1.07 & 0.04 \\
\hline 20.5 & 38 & 184 & 2.15 & 1.05 & 1.09 & 0.04 \\
\hline 20.5 & 38 & 235 & 2.51 & 1.06 & 1.11 & 0.04 \\
\hline 20.5 & 38 & 286 & 2.85 & 1.07 & 1.11 & 0.04 \\
\hline 20.5 & 89 & 114 & 1.82 & 1.03 & 1.07 & 0.04 \\
\hline 20.5 & 89 & 140 & 2.07 & 1.04 & 1.09 & 0.04 \\
\hline 20.5 & 89 & 184 & 2.48 & 1.06 & 1.10 & 0.04 \\
\hline 20.5 & 89 & 235 & 2.91 & 1.07 & 1.12 & 0.04 \\
\hline 20.5 & 89 & 286 & 3.33 & 1.08 & 1.12 & 0.04 \\
\hline \hline
\end{tabular}




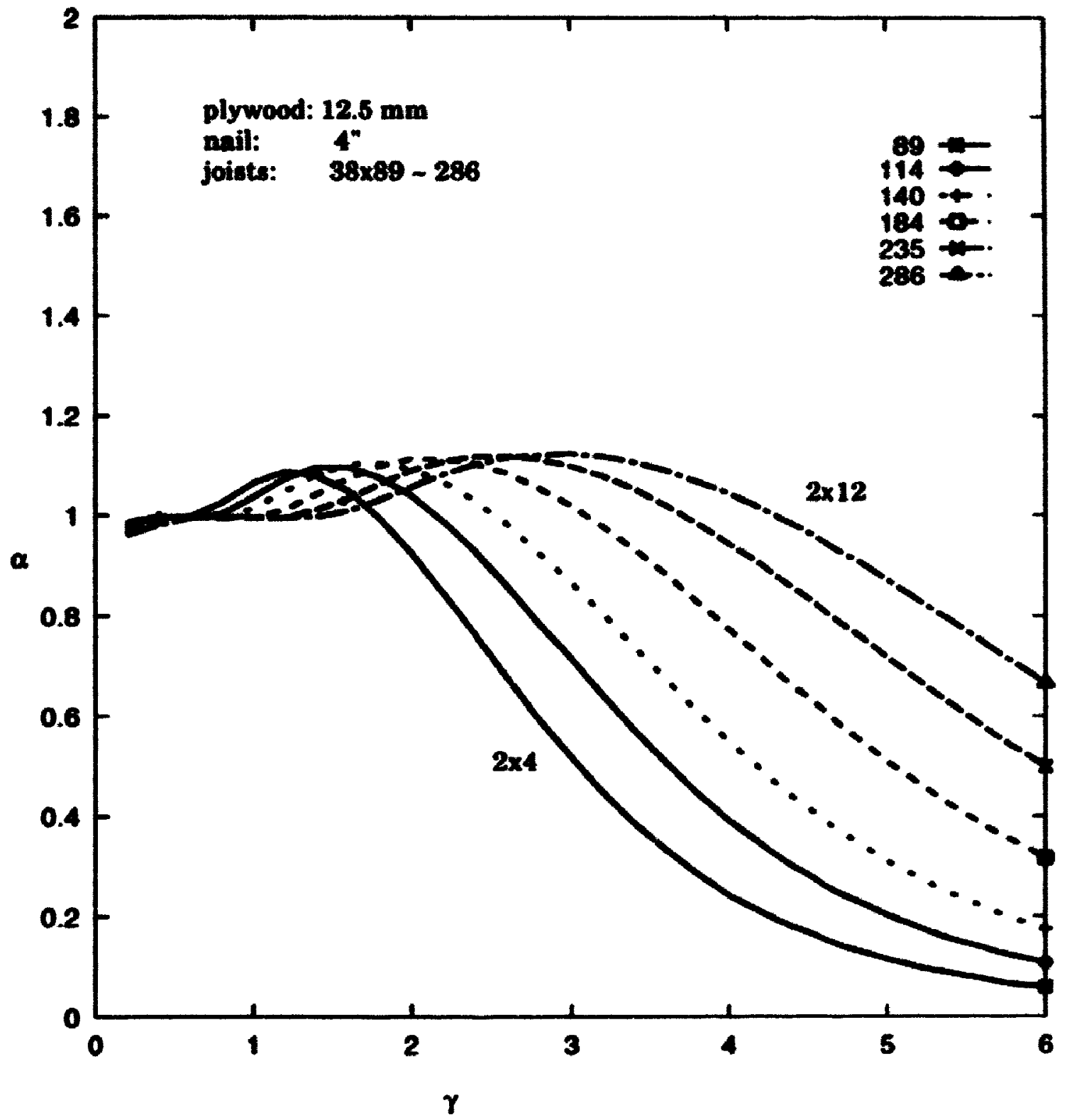

Figure 4.1: Deflection ratio vs aspect ratio. Joist sizes: $38 \times 89$ to $38 \times 2 \times 6$. Plywend thickness: $12.5 \mathrm{~mm}$. 


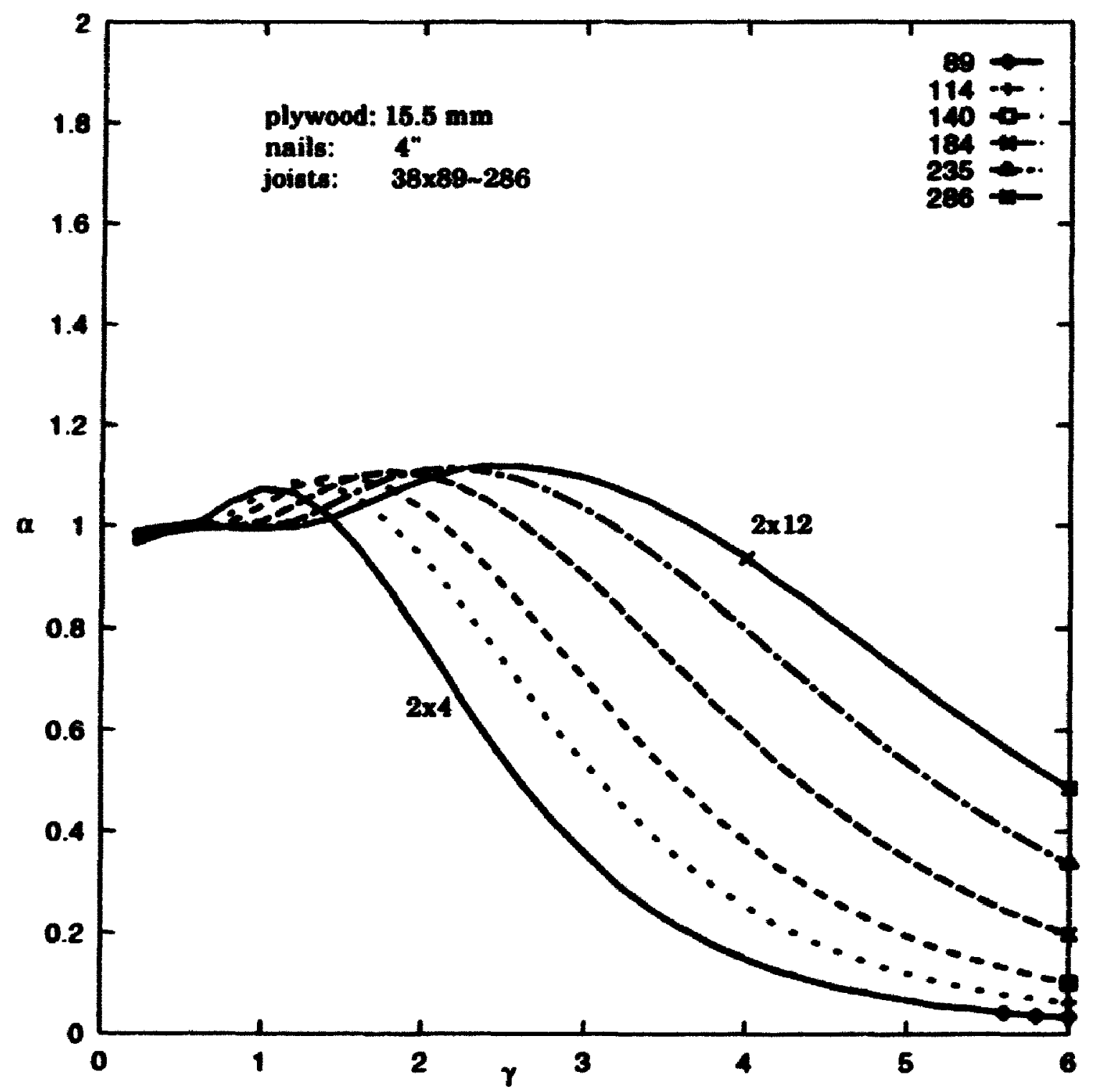

Fig.ure 4.2: Deflection ratio vs aspect ratio. Joist sizes: $38 \times 89$ to $38 \times 286$. Plywood thickness: $15.5 \mathrm{~mm}$. 


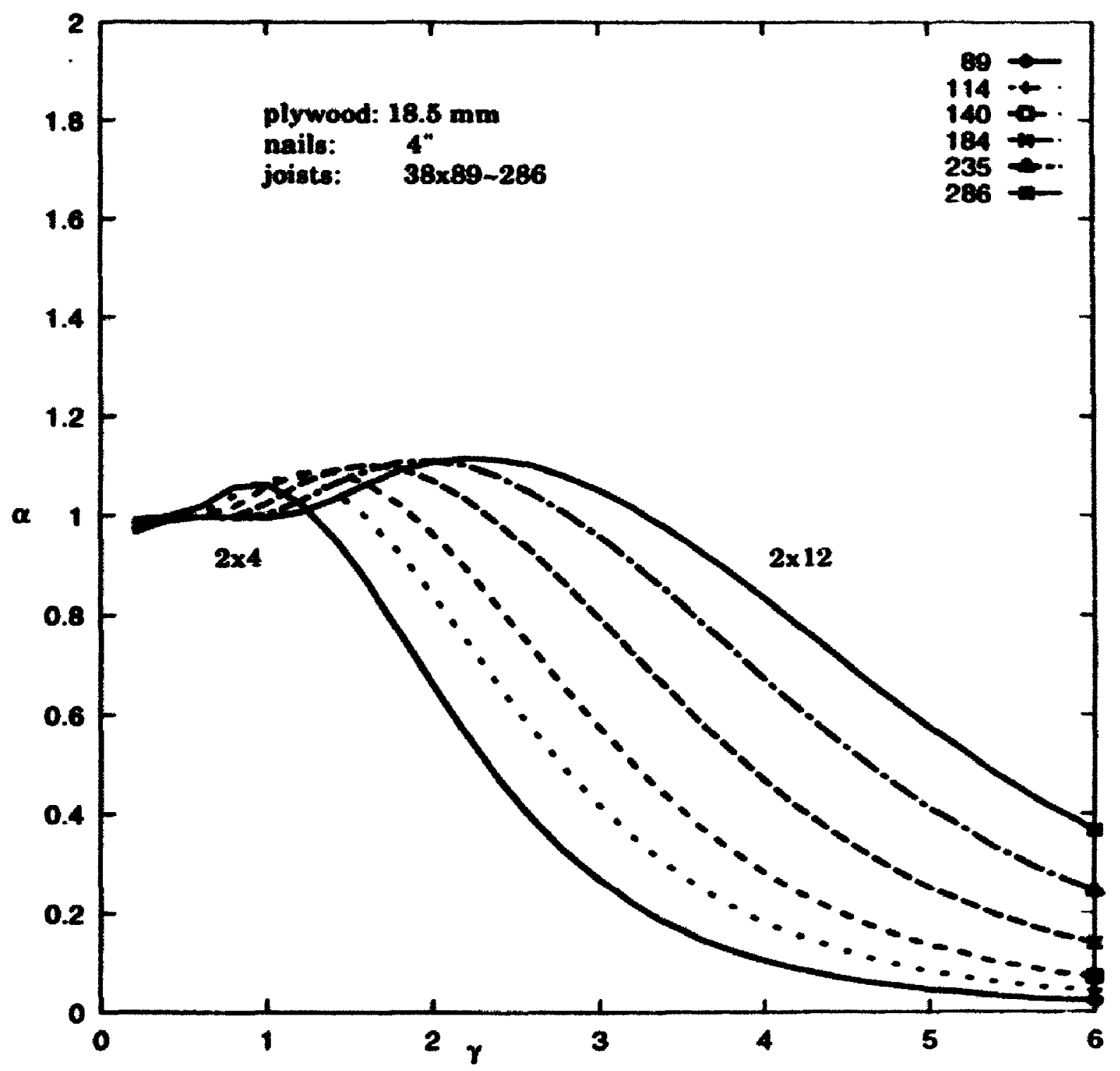

Figure 4.3: Deflection ratio vs aspect ratio. Joist sizes: $38 \times 89$ to $3 \times \times 2 \times 6$. Plywored thickness: $18.5 \mathrm{~mm}$ 


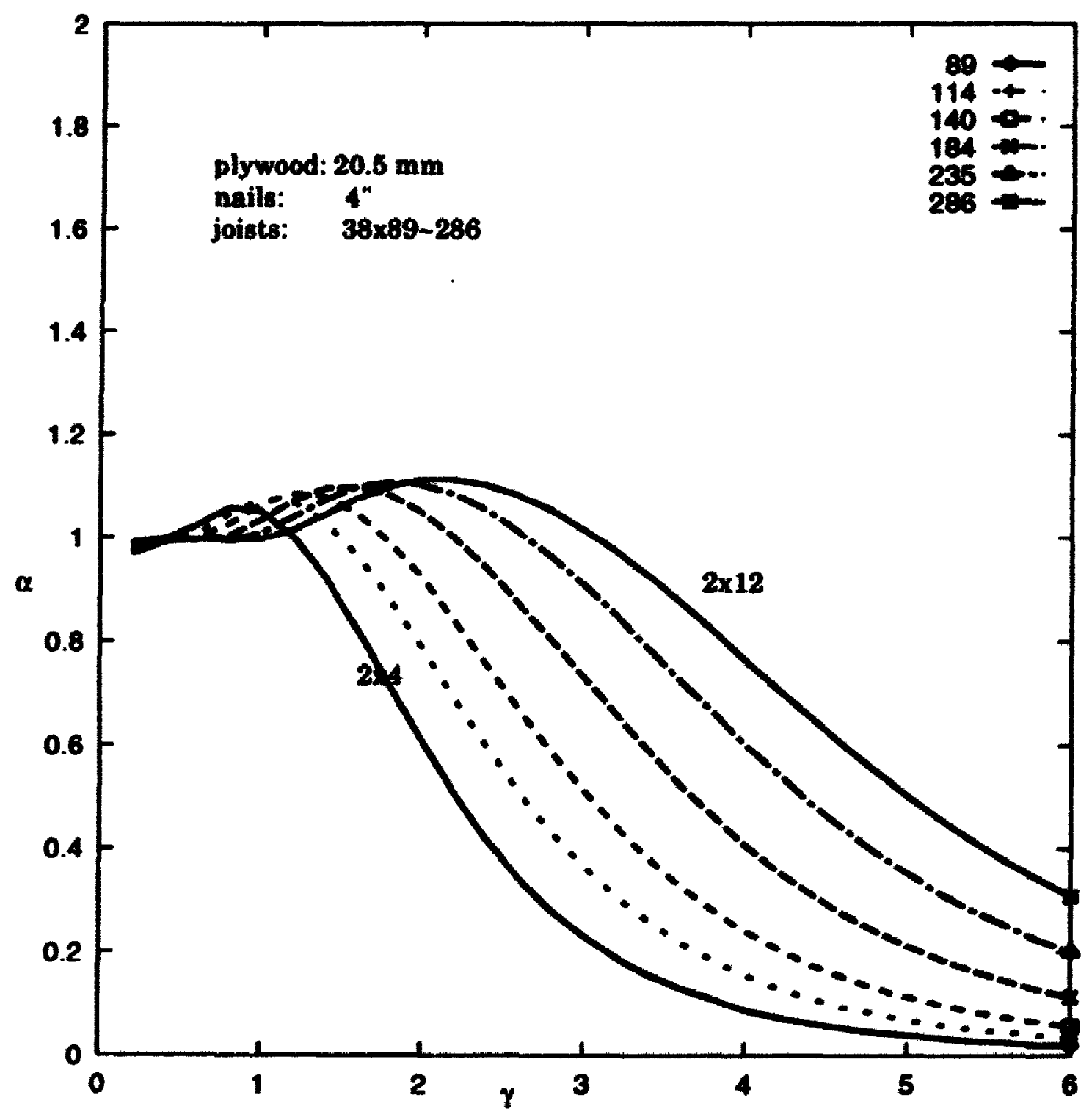

Figure 4.4: Deflection ratio vs aspect ratio. Joist sizes: $38 \times 89$ to $38 \times 286$. Plywood thicktess: $20.5 \mathrm{~mm}$ 


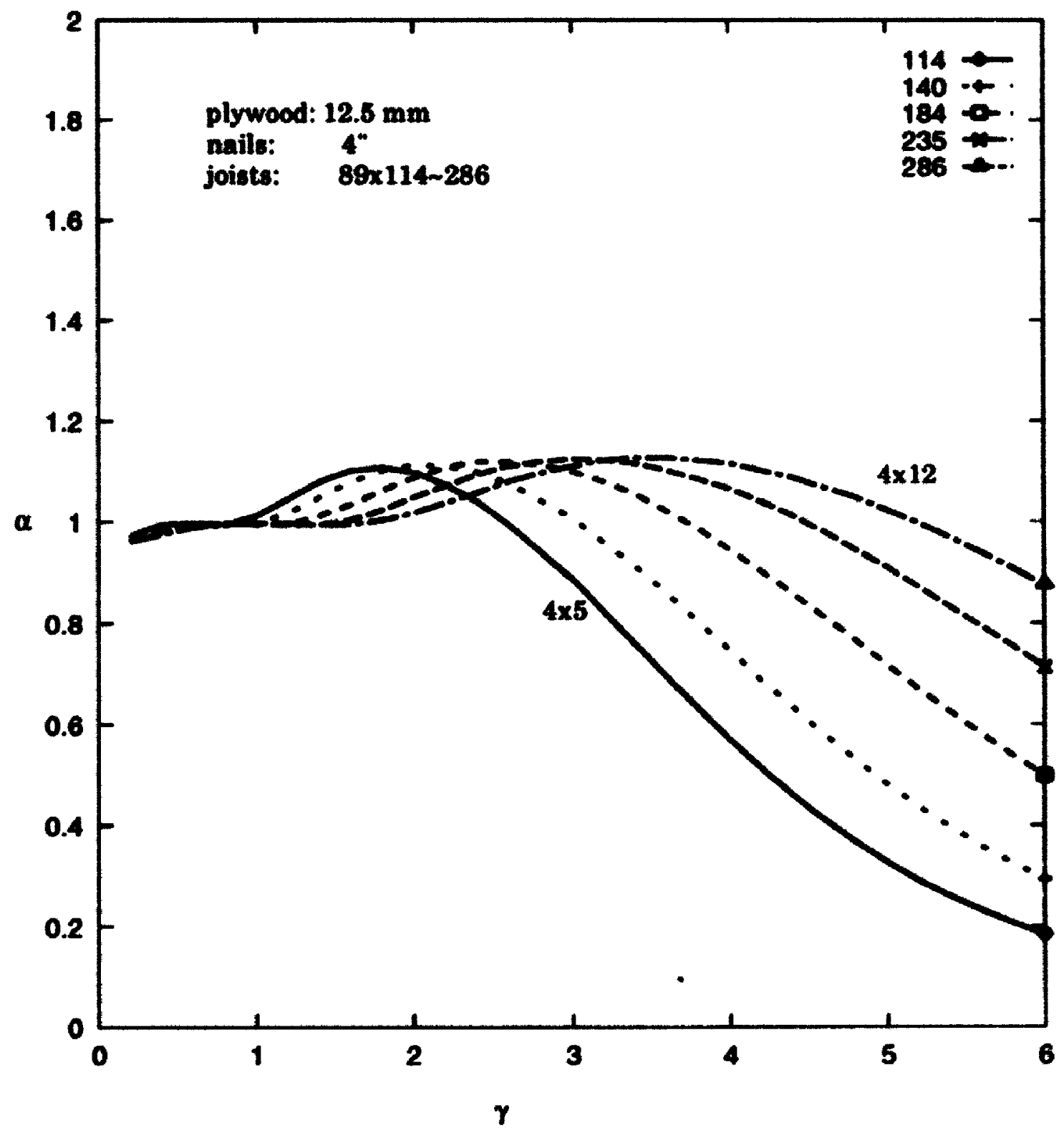

Figure 4.5: Deflection ratio vs aspect ratio. Joist sizes: $89 \times 114$ to 89x28fi. Plywood thickness: $12.5 \mathrm{~mm}$ 


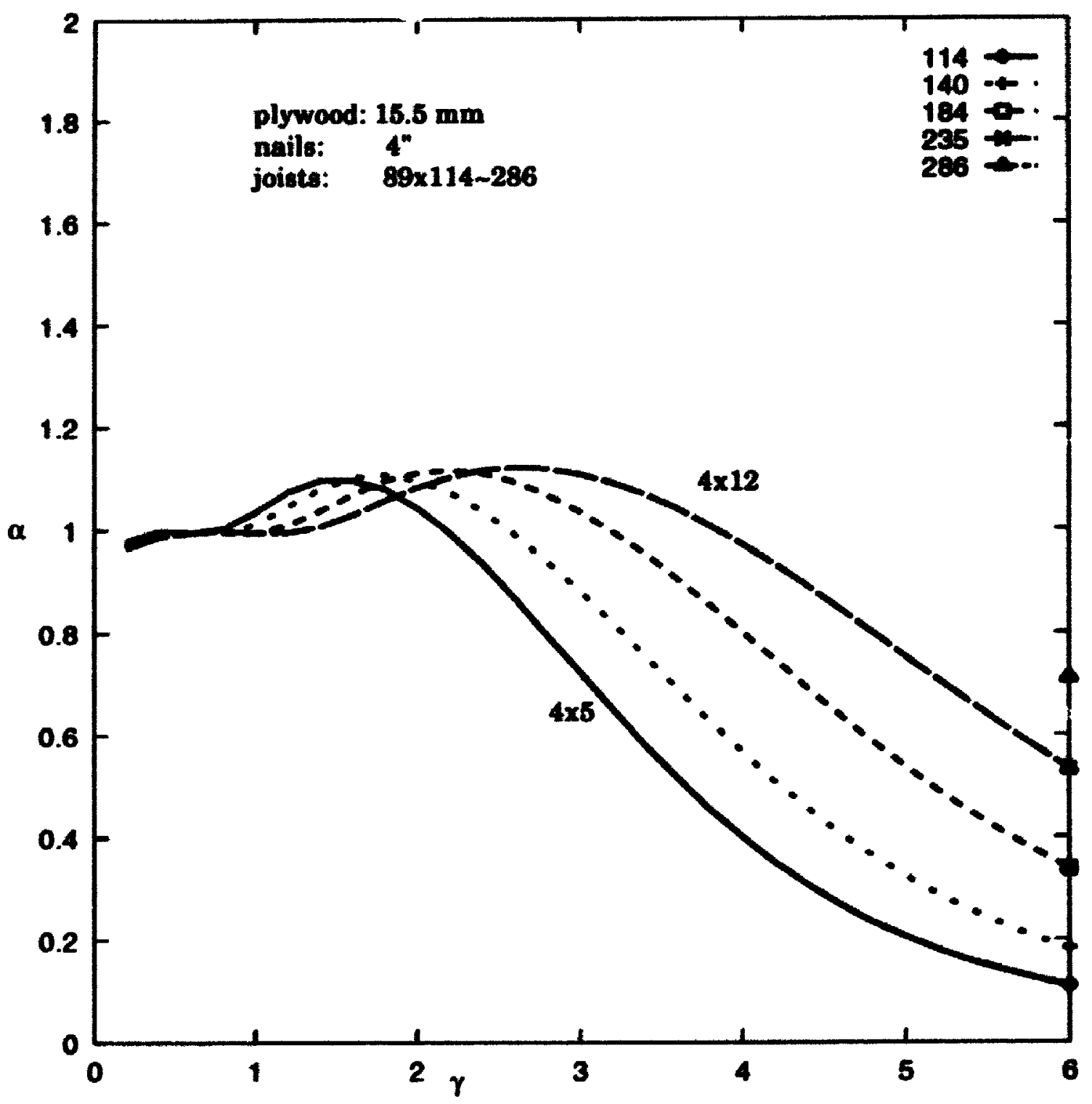

Figure 4.6: Deflection ratio vs aspect ratio. Joist sizes: $89 \times 114$ to $89 \times 286$. Plywood thickness: $15.5 \mathrm{~mm}$ 


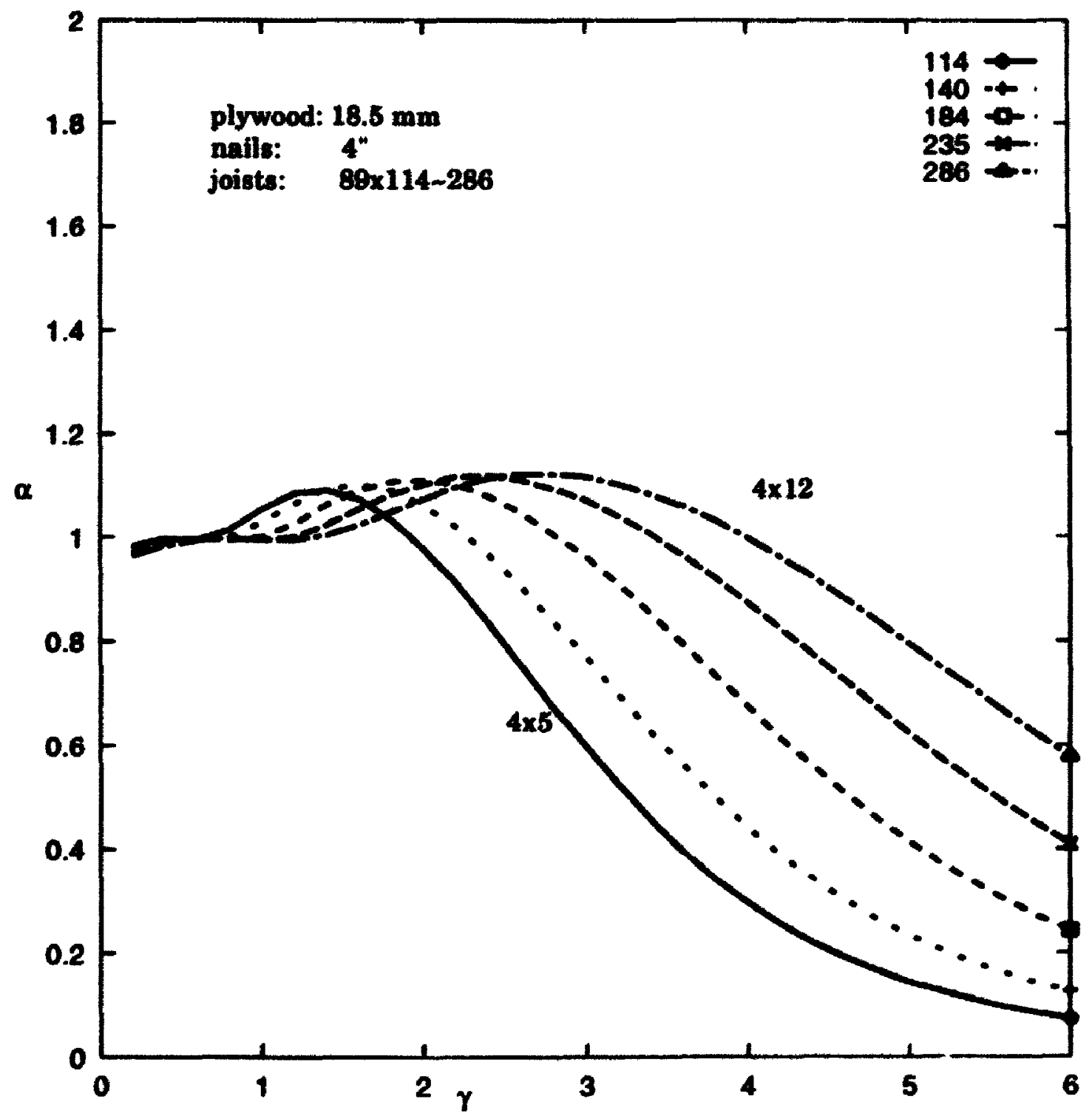

Figure 4.7: Deflection ratio vs aspect ratio. Joist sizes: 89x114 to 89x28fi. Plyworod thickness: $18.5 \mathrm{~mm}$ 


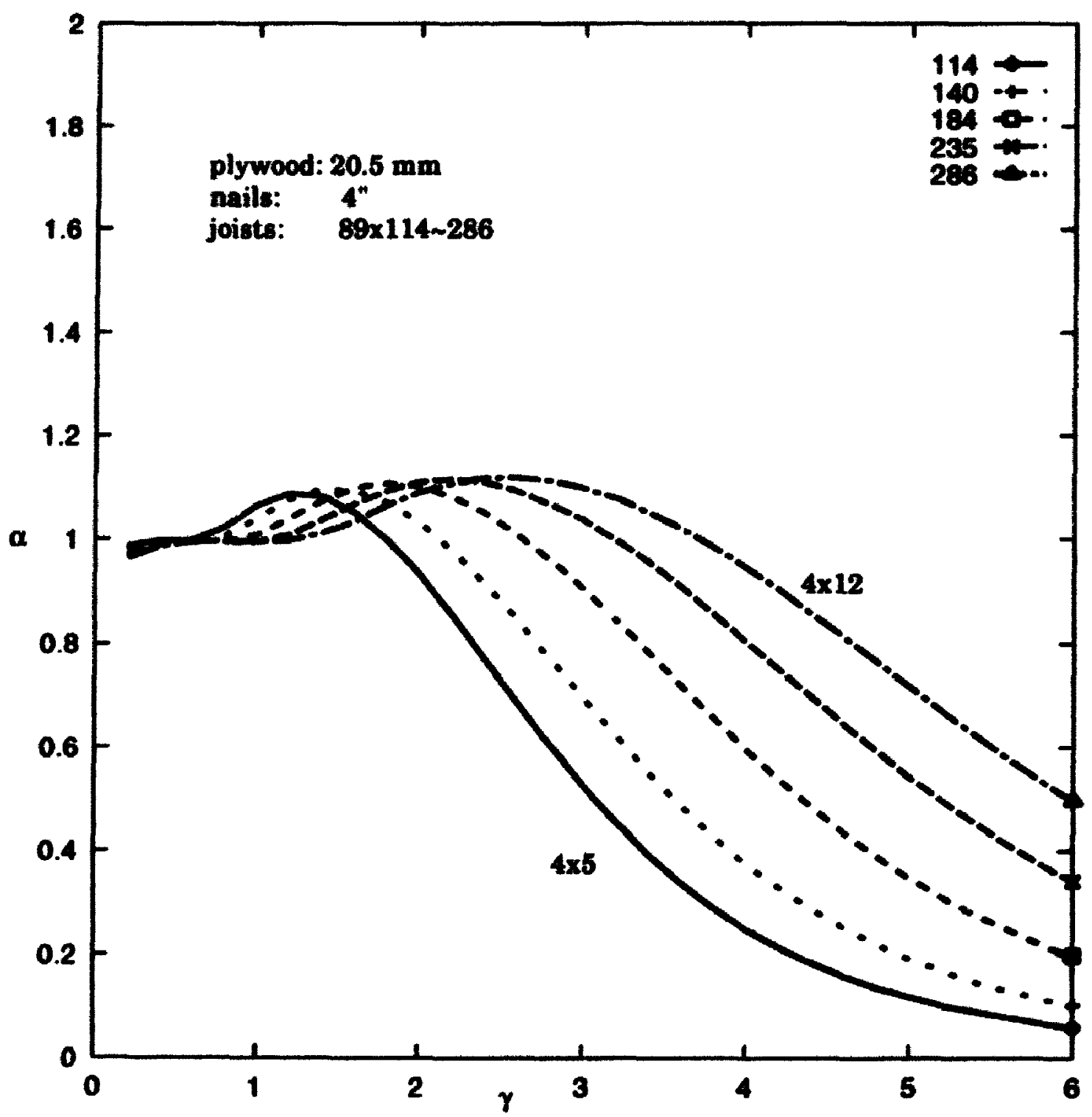

Figure 4.8: Deflertion ratio vs aspect ratio. Joist sizes: $89 \times 114$ to 89x286. Plywood thickness: $20.5 \mathrm{~mm}$ 


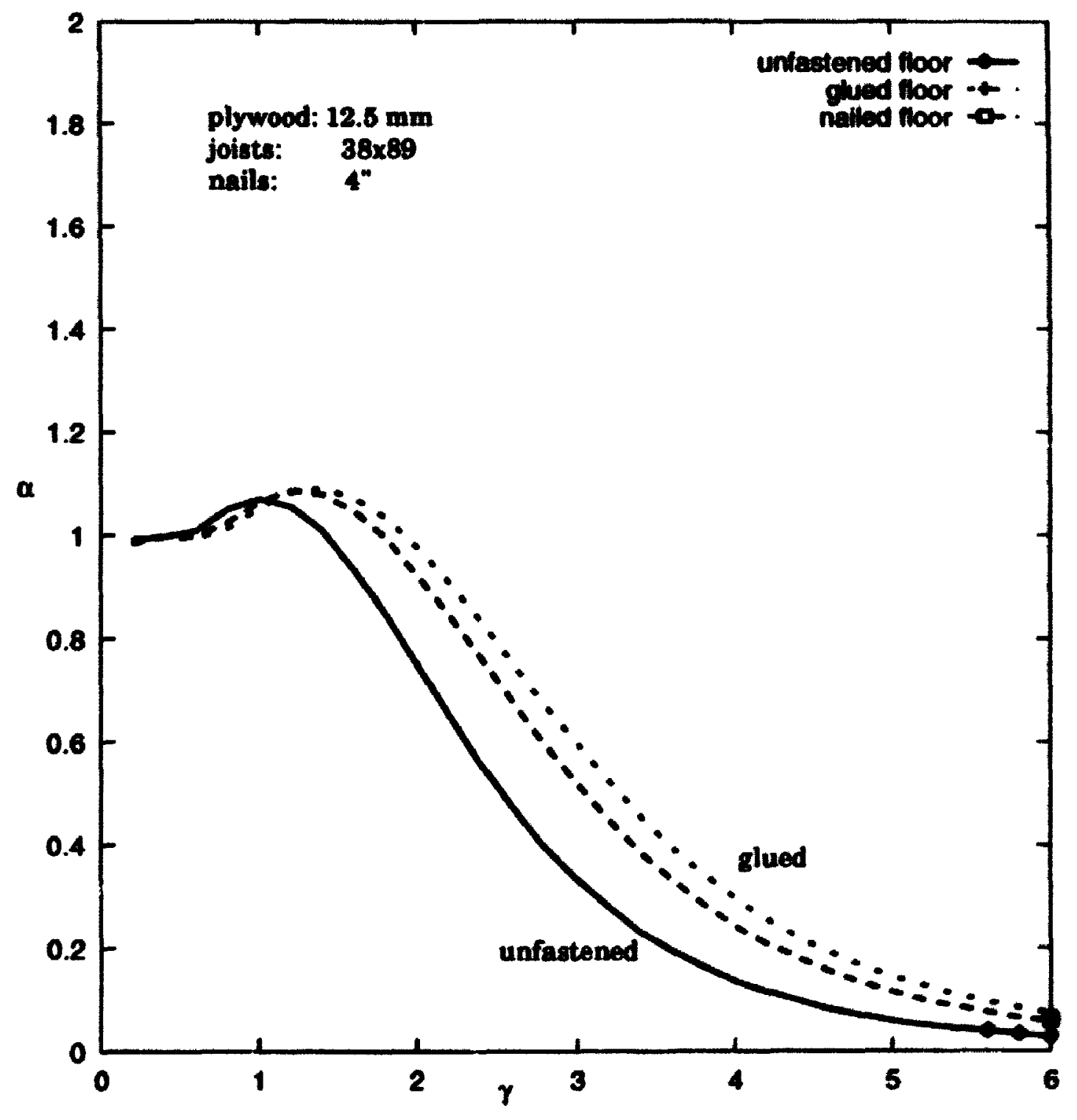

Figure 4.9: Influence of connections on deflection ratio, $38 \times 89$ 


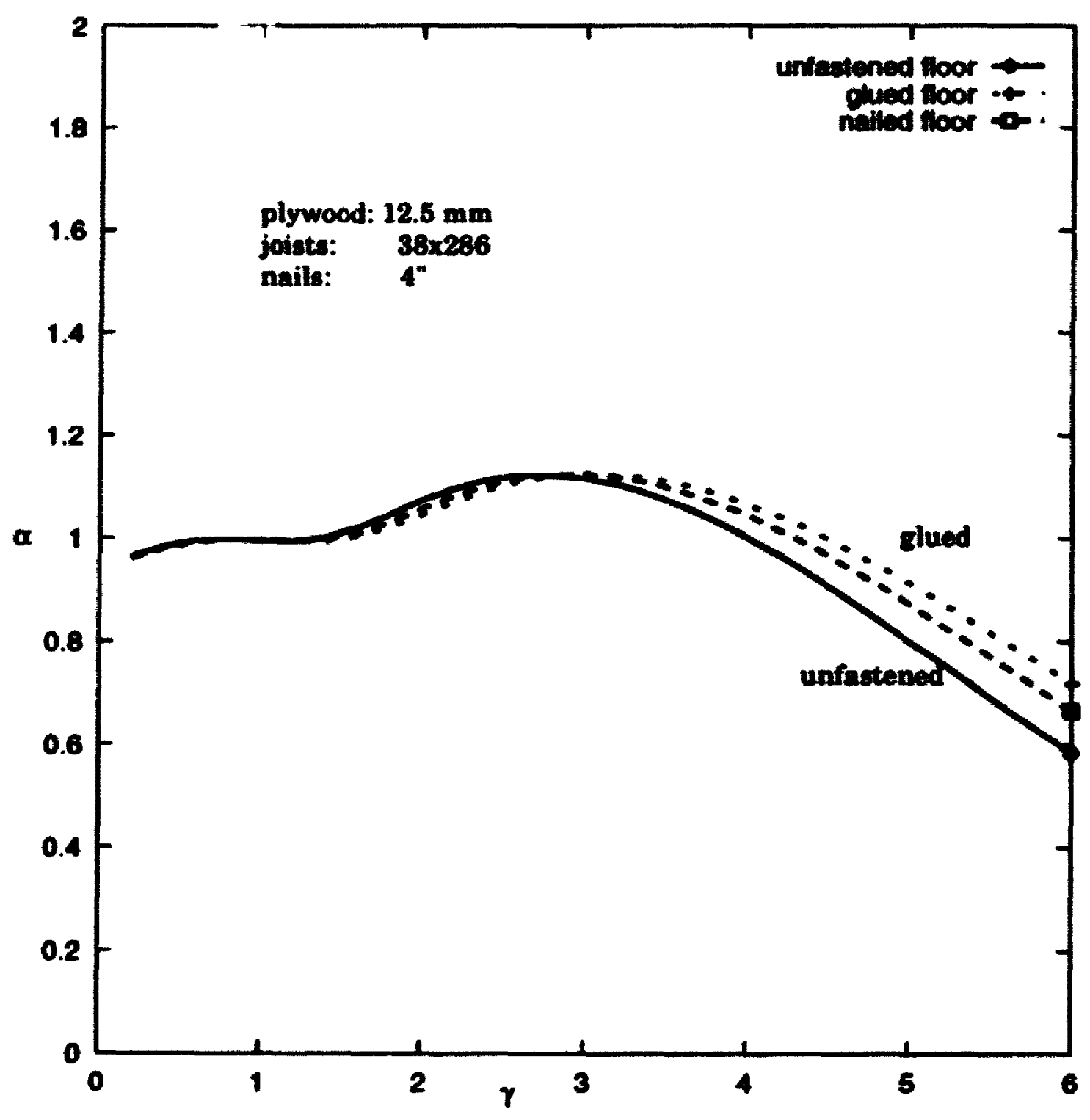

Figure 4.10: Influence of connections on deflection ratio, $38 \times 286$ 


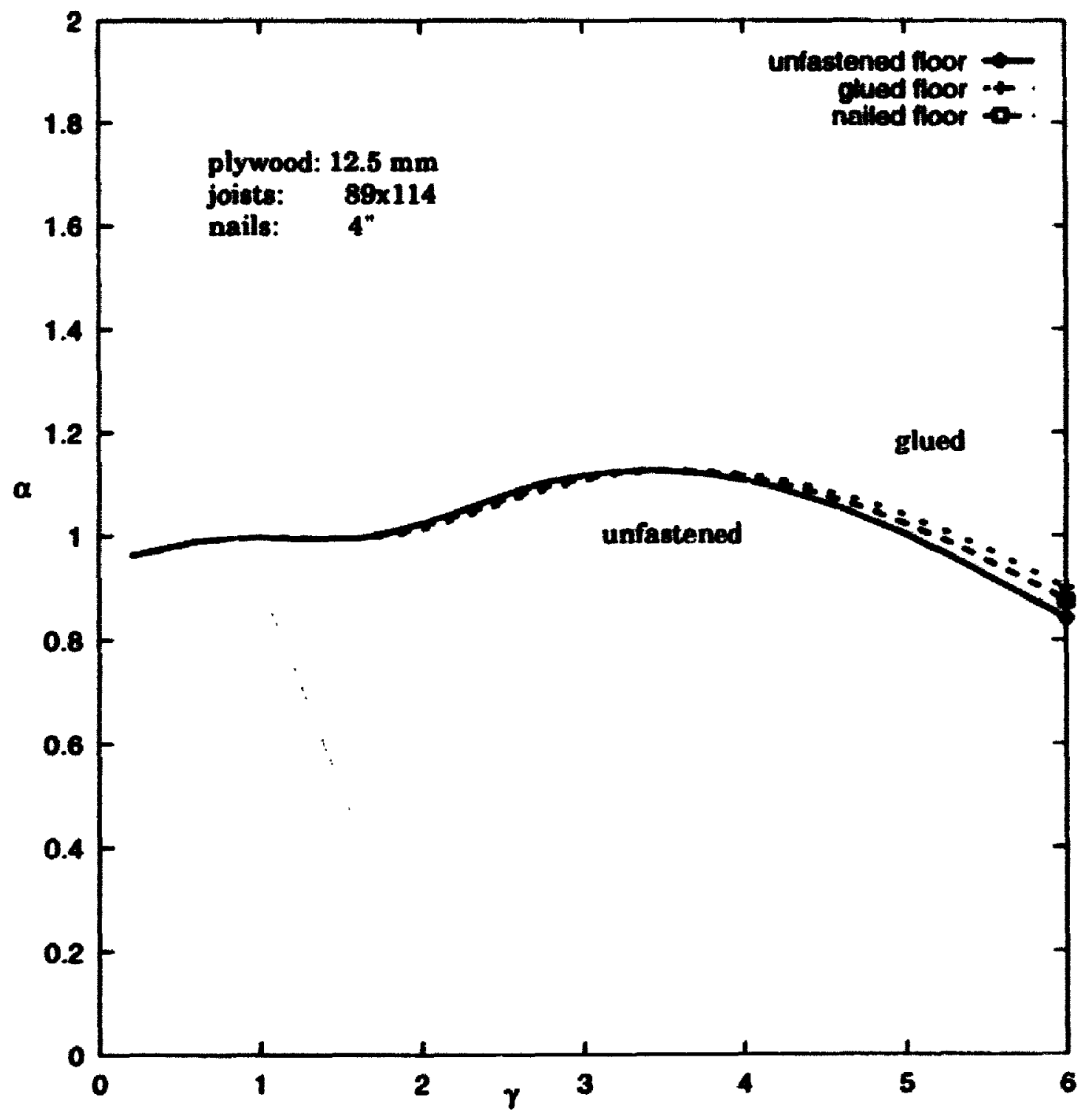

Figure 4.11: Influence of connections on deffection ratio, $89 \times 114$ 


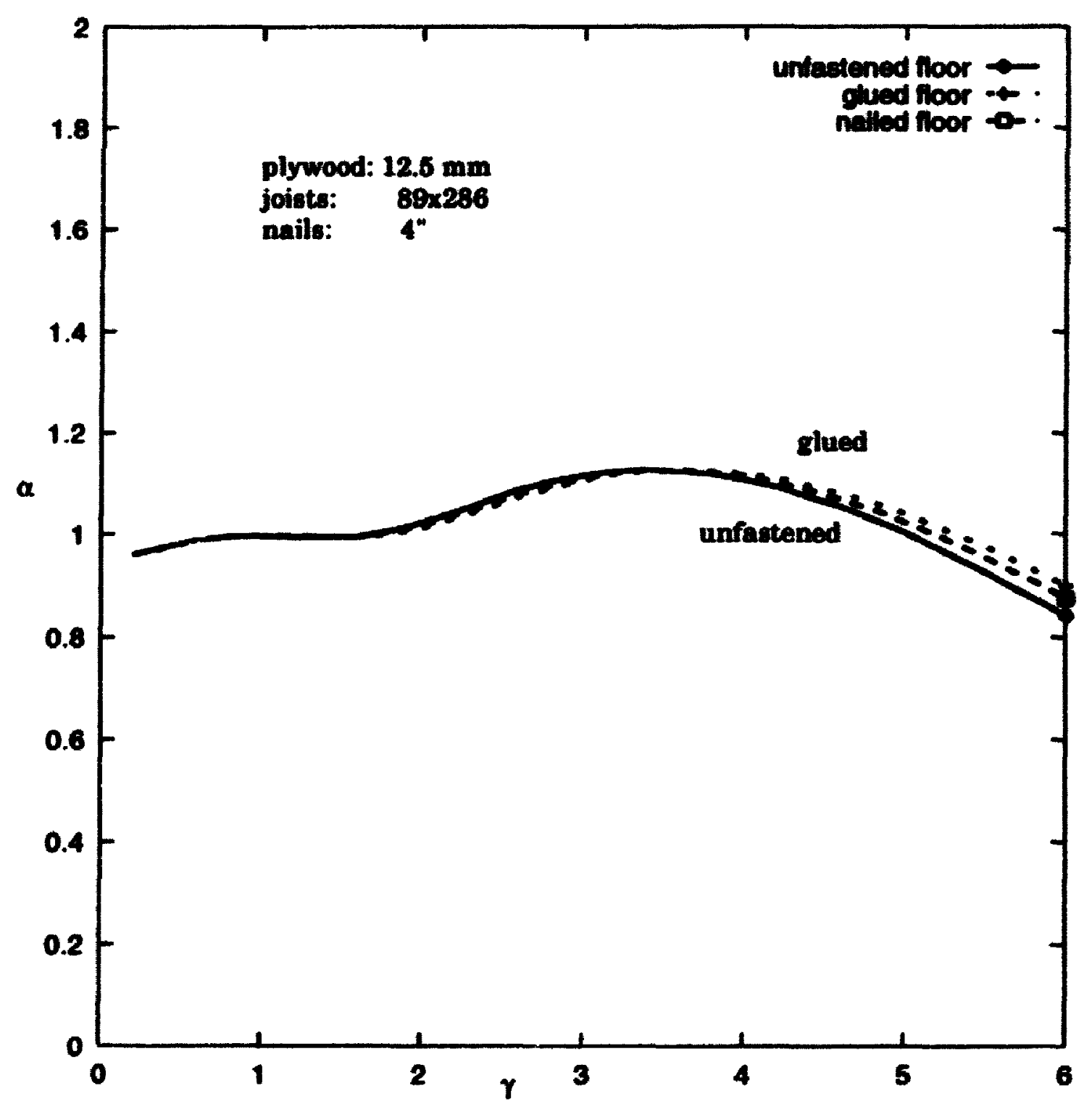

Figure 4.12: Influence of connections on deflection ratio, $89 \times 286$ 


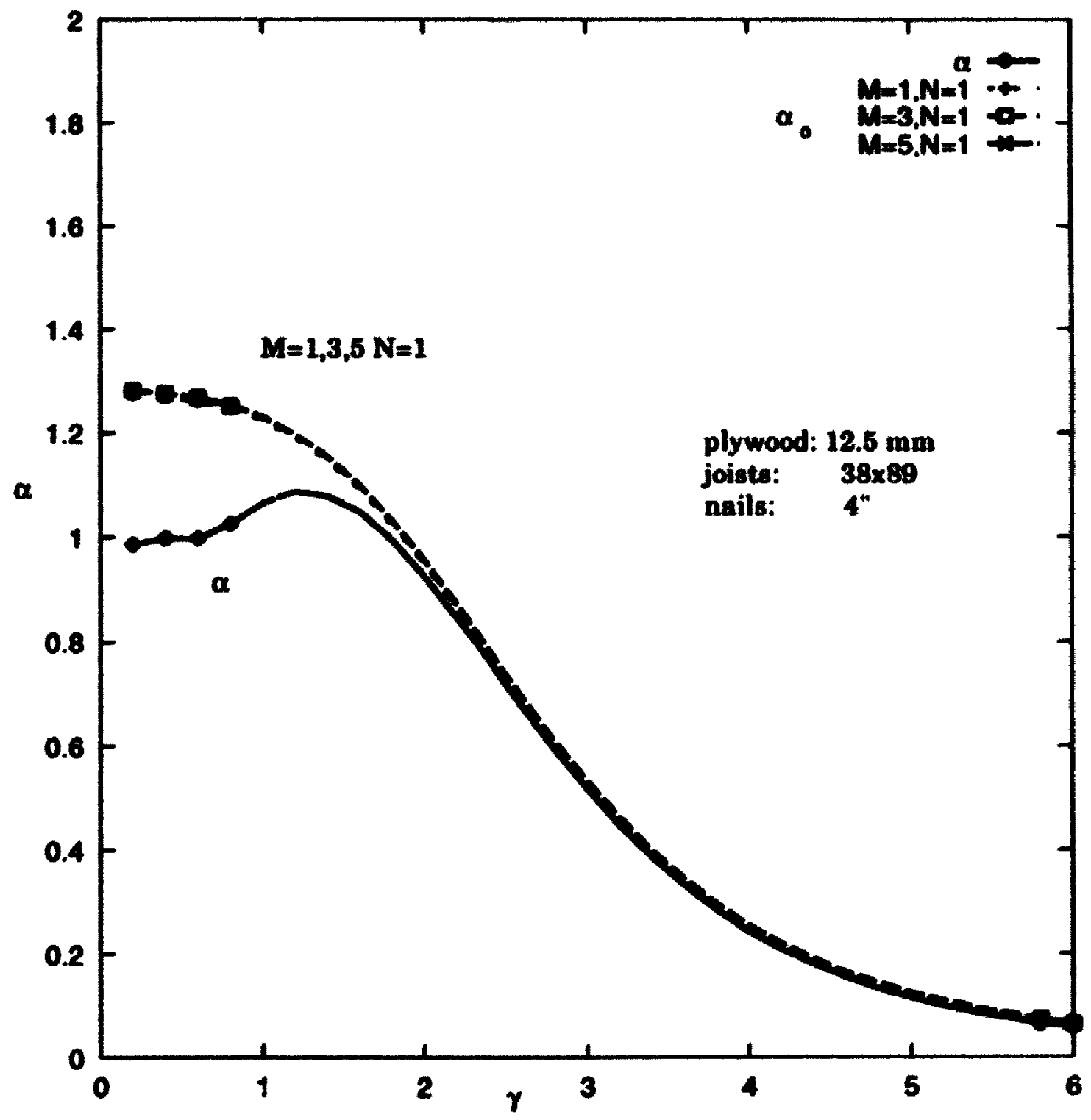

Figure 4.13: Convergence of $\mathrm{m}$ terms, $38 \times 89,12.5 \mathrm{~mm}$ 


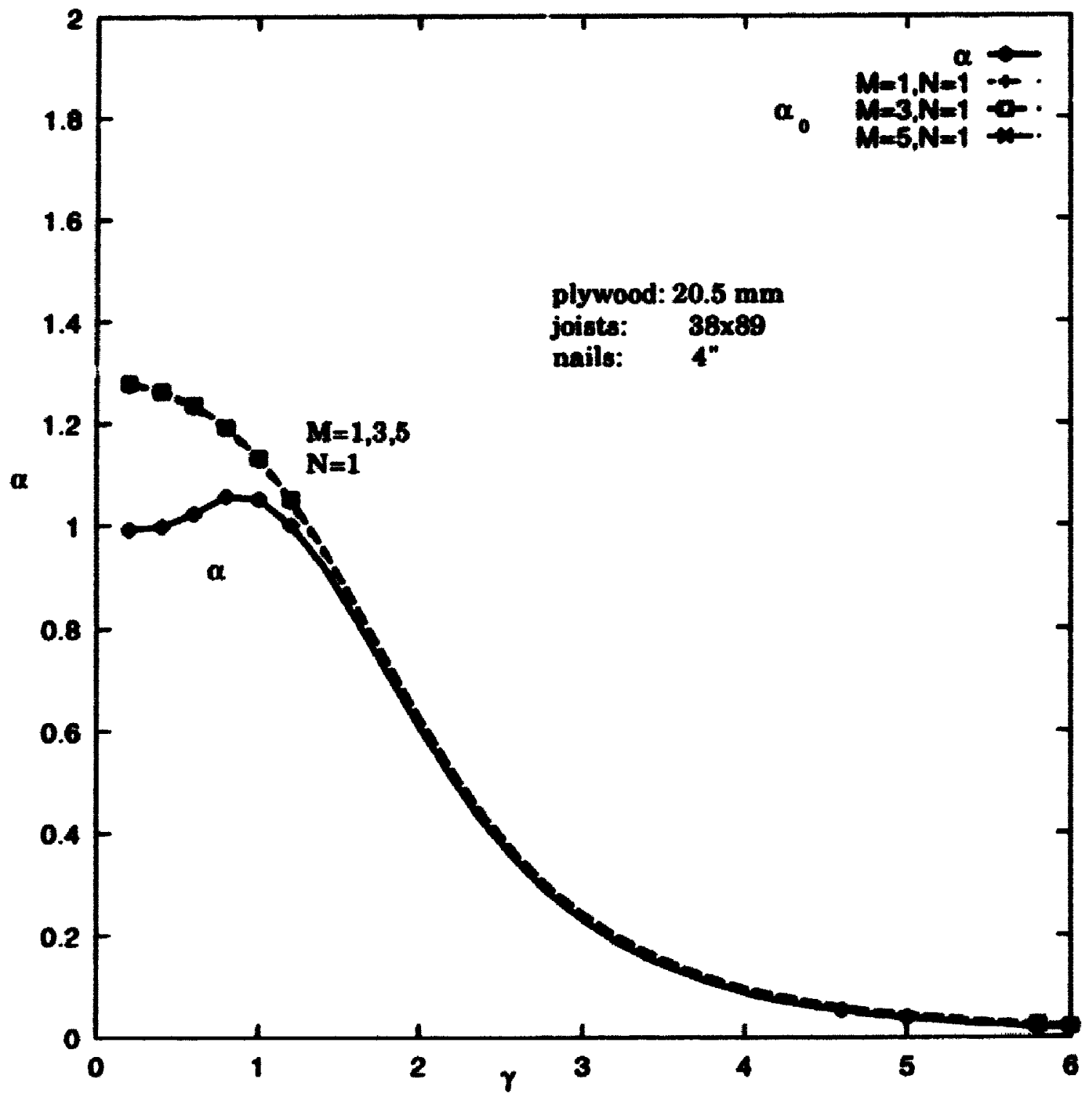

Figure 4.14: Convergence of $\mathrm{m}$ terms, 38x89, $20.5 \mathrm{~mm}$ 
and

$$
w_{p l}=w_{b} n=w_{b} a_{11}
$$

The errors are negligible.

If $1<\gamma<\gamma_{0}$, errors arise. These floors can be describerl as urvium span floors. For a medium span, floor deflection can be calculated using T-Ixatu therory and adjusted upward a maximum of 104.22 and Figure 4.23 illust rate mudium spant floors with the most commonly used joist sizes: $2 \times 8,2 \times 10$ and $2 \times 12$.

It, therefore, can be concluded that to design for a floor subjert to uniformuly distributed load, the following procedures can be followed:

1. Calculate $\gamma=L / B$.

2. If $\gamma<=1$, short span floor, use $T$-beam formula. This is the moxt conmmon case.

3. Otherwise, calculate $\gamma_{0}$ according to Equation 4.7.

4. If $\gamma<\gamma_{0}$, medium span floor, use $T$-beam formula. The maximum deflectien thus calculated is multiplied by an adjustment factor of 1.1 .

5. Otherwise, long span floor, use T-beam formula. The maximum deflertion is multiplied by a different adjustment factor of $\alpha=\alpha_{11}$ as in Fyuation 4.X. 


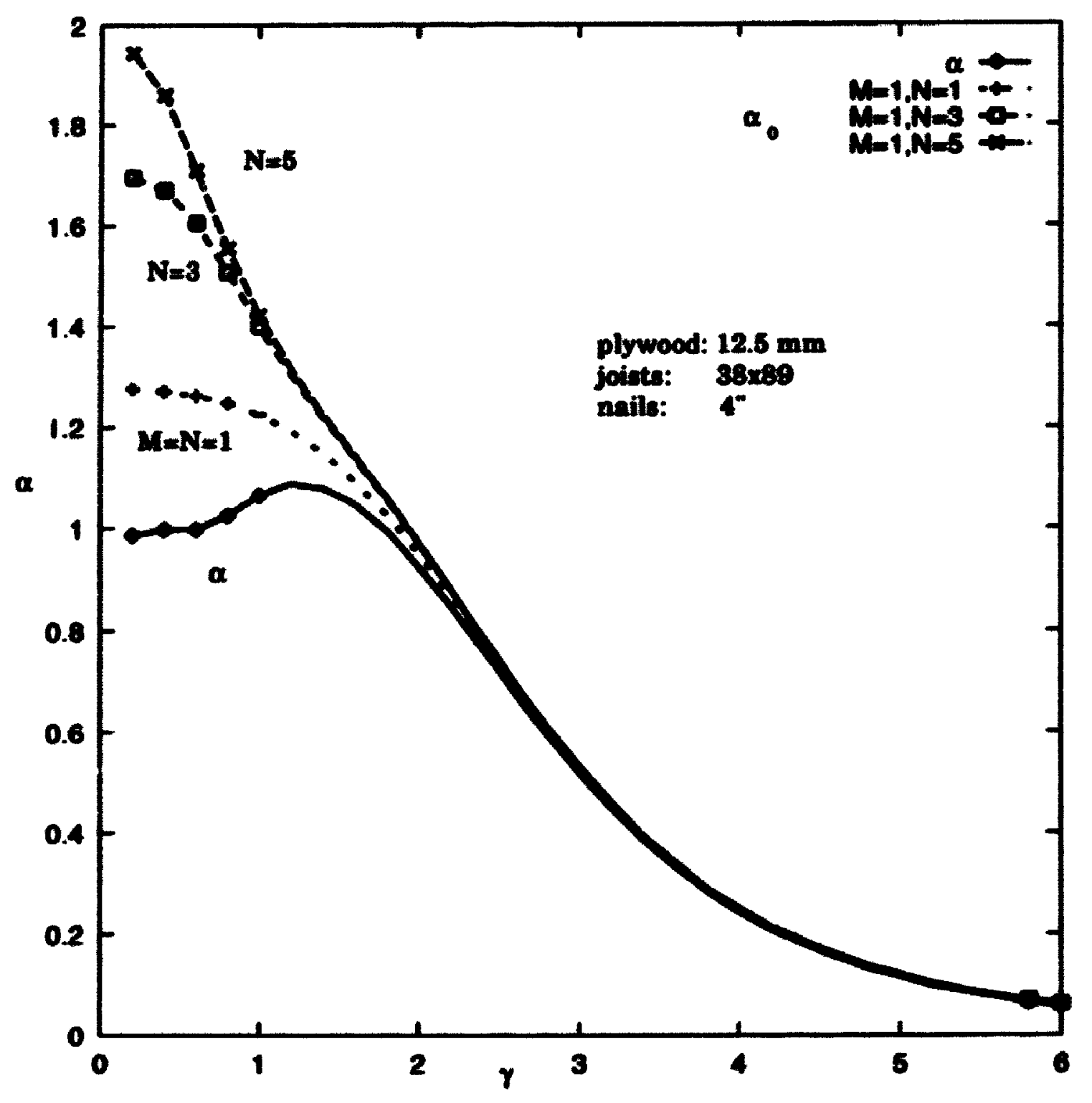

Figure 4.15: Convergence of $\mathrm{n}$ terms, $38 \times 89,12.5 \mathrm{~mm}$ 


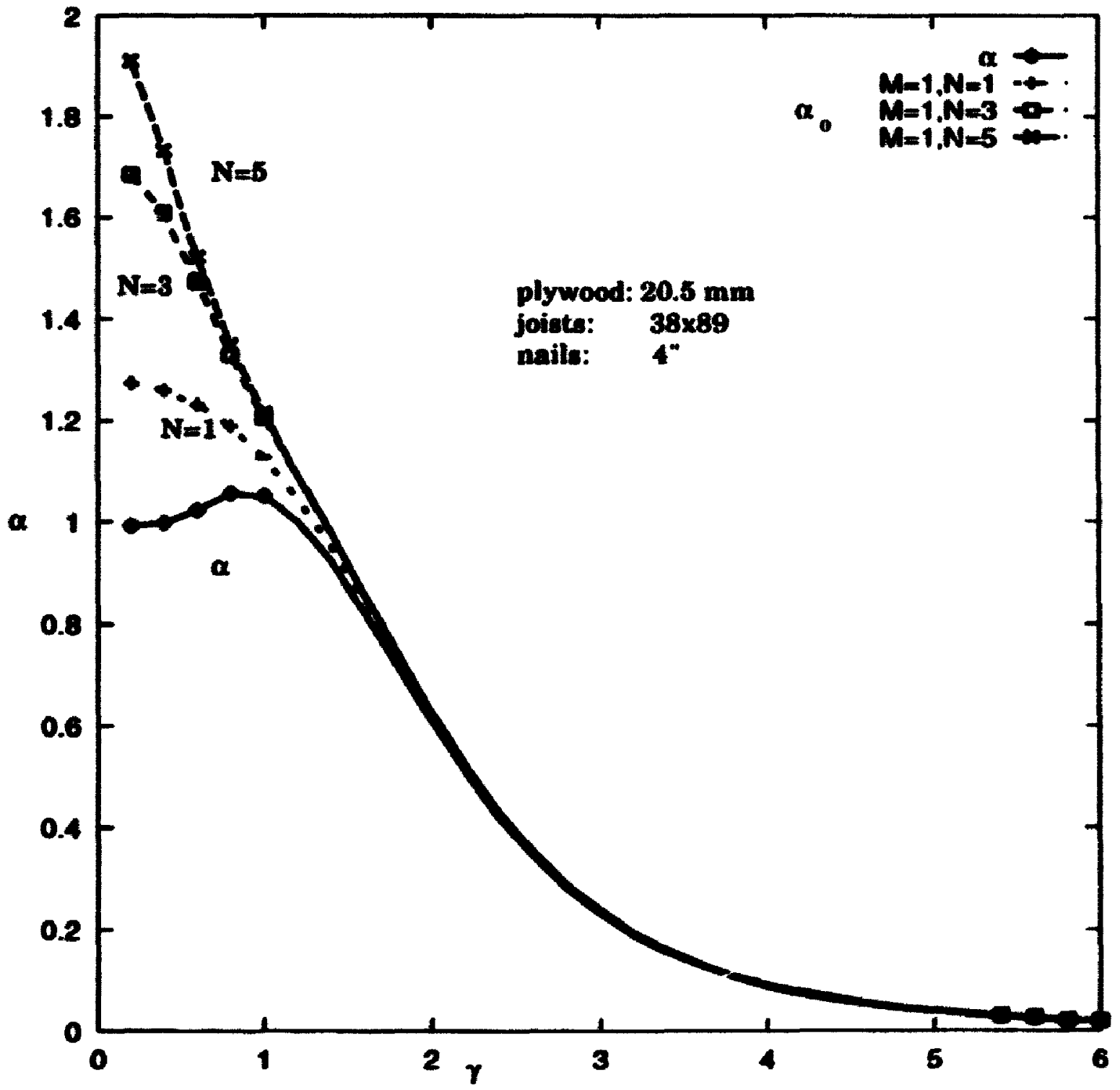

Figure 4.16: Convergence of $n$ terms, 38x89, $20.5 \mathrm{~mm}$ 


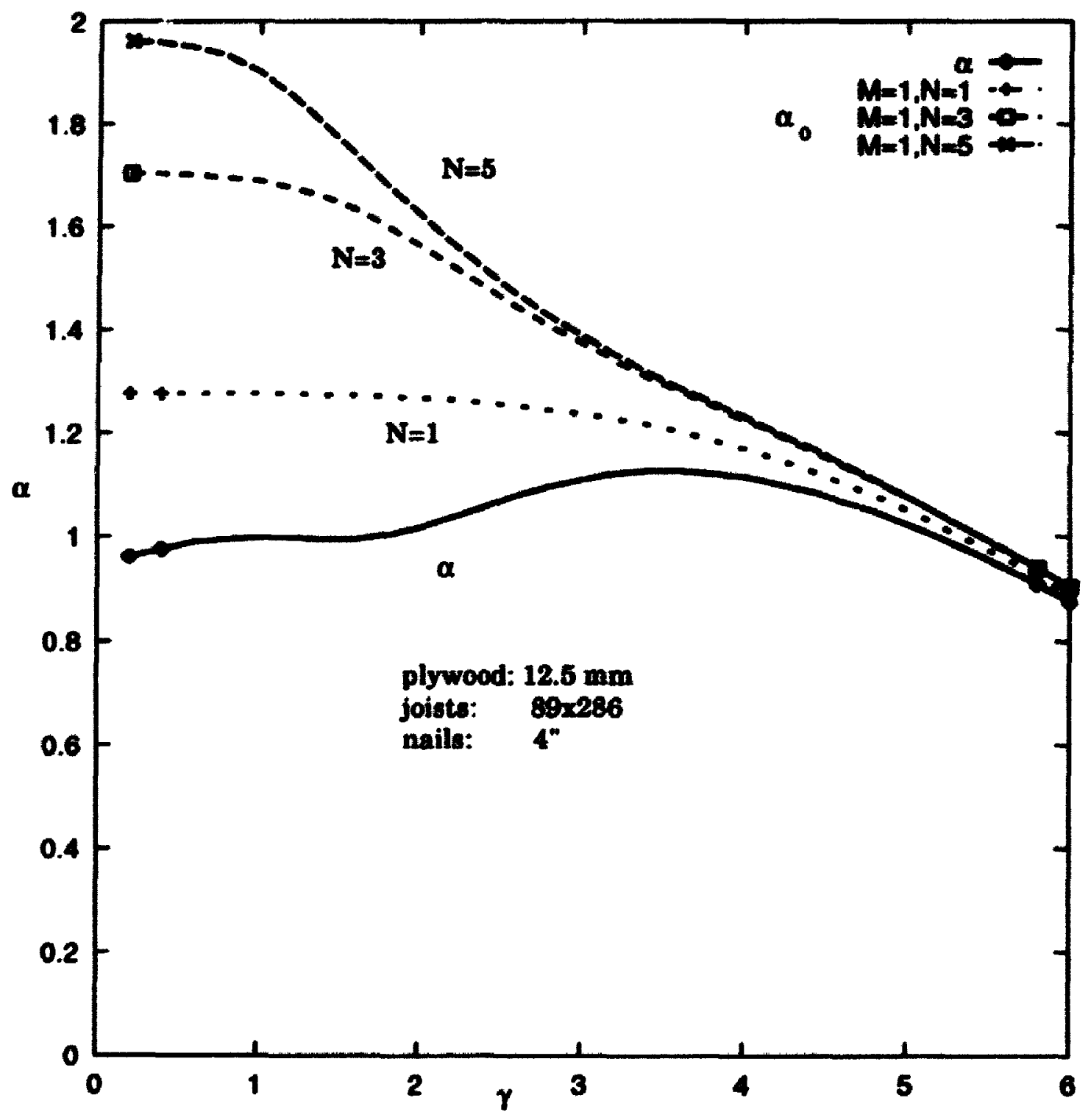

Figure 4.17: Convergence of $\mathrm{n}$ terms, $89 \times 286,12.5 \mathrm{~mm}$ 


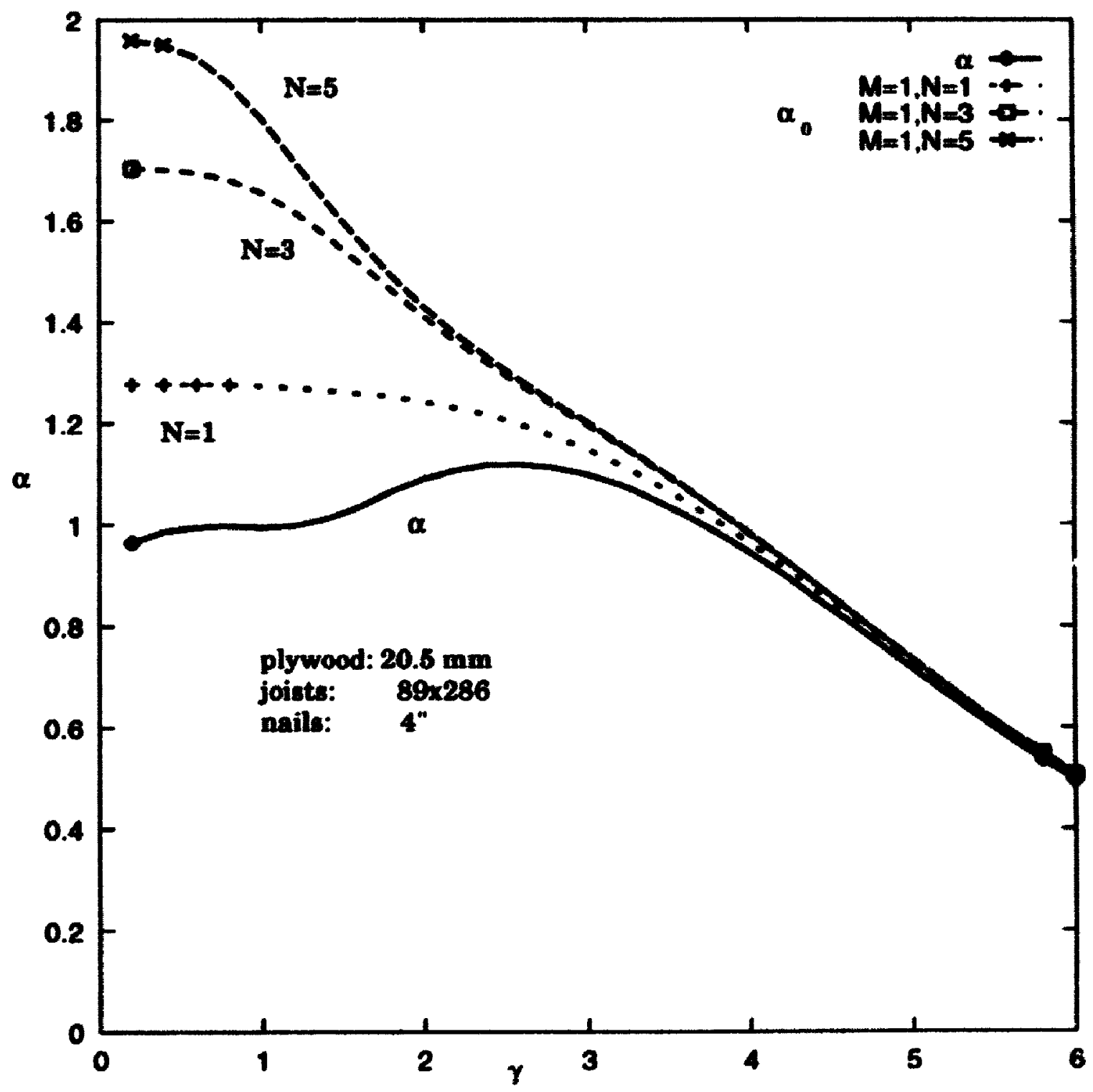

Figure 4.18: Convergence of $\mathrm{n}$ terms, $89 \times 286,20.5 \mathrm{~mm}$ 


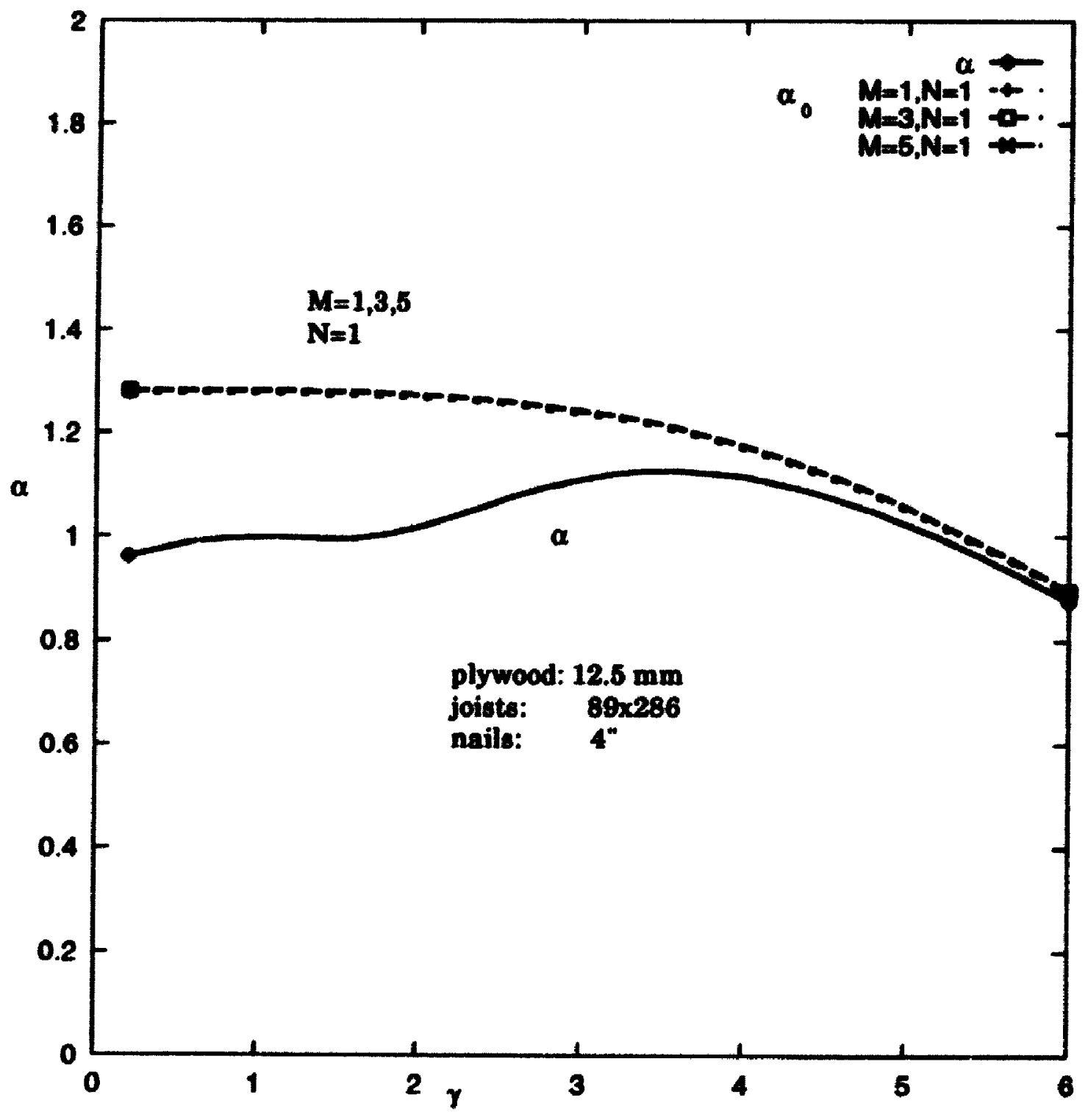

Figure 4.19: Convergence of $\mathrm{m}$ terms, $89 \times 286,12.5 \mathrm{~mm}$ 


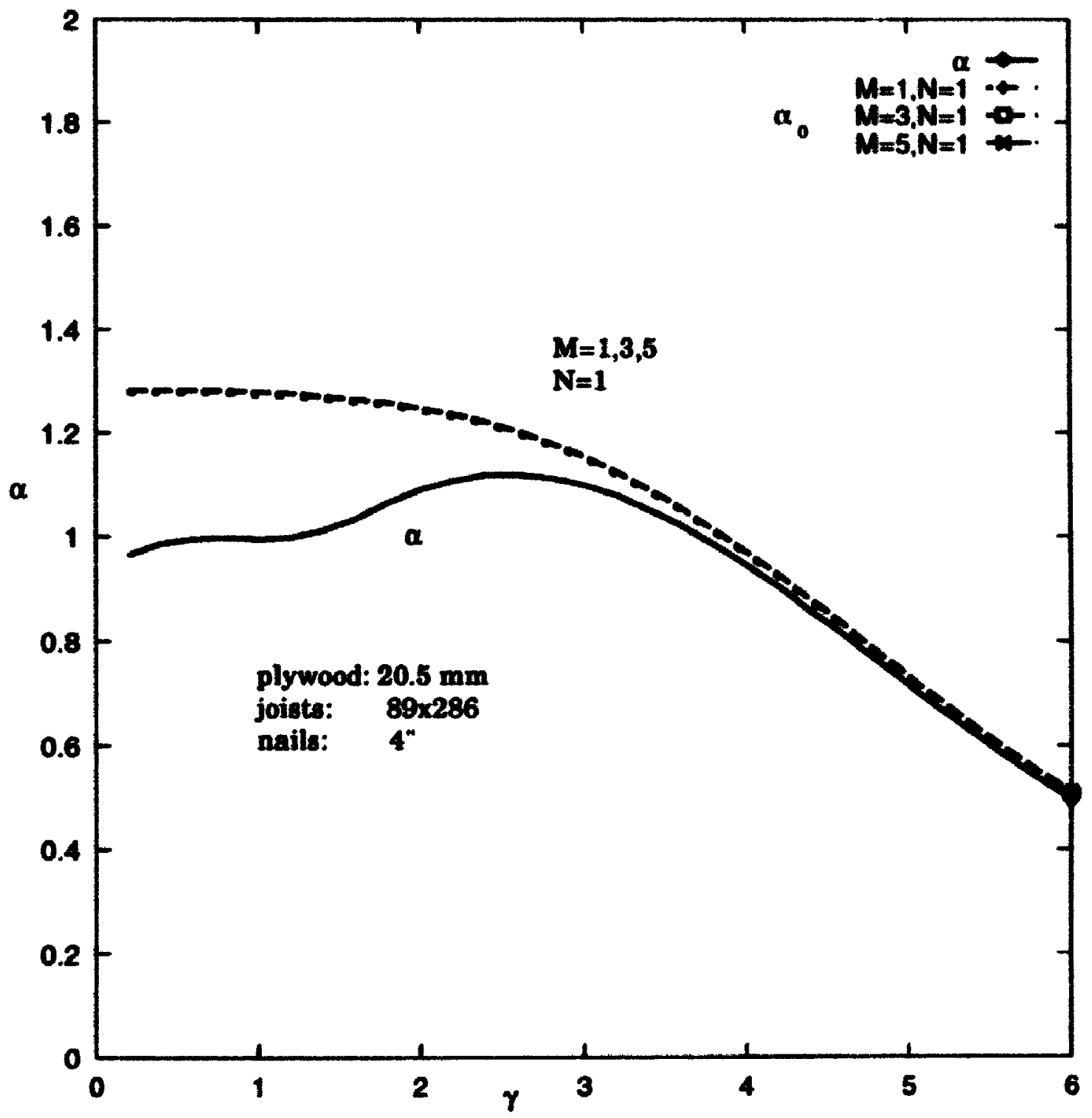

Figure 4.20: Convergence of $\mathrm{m}$ terms, $89 \times 286,20.5 \mathrm{~mm}$ 


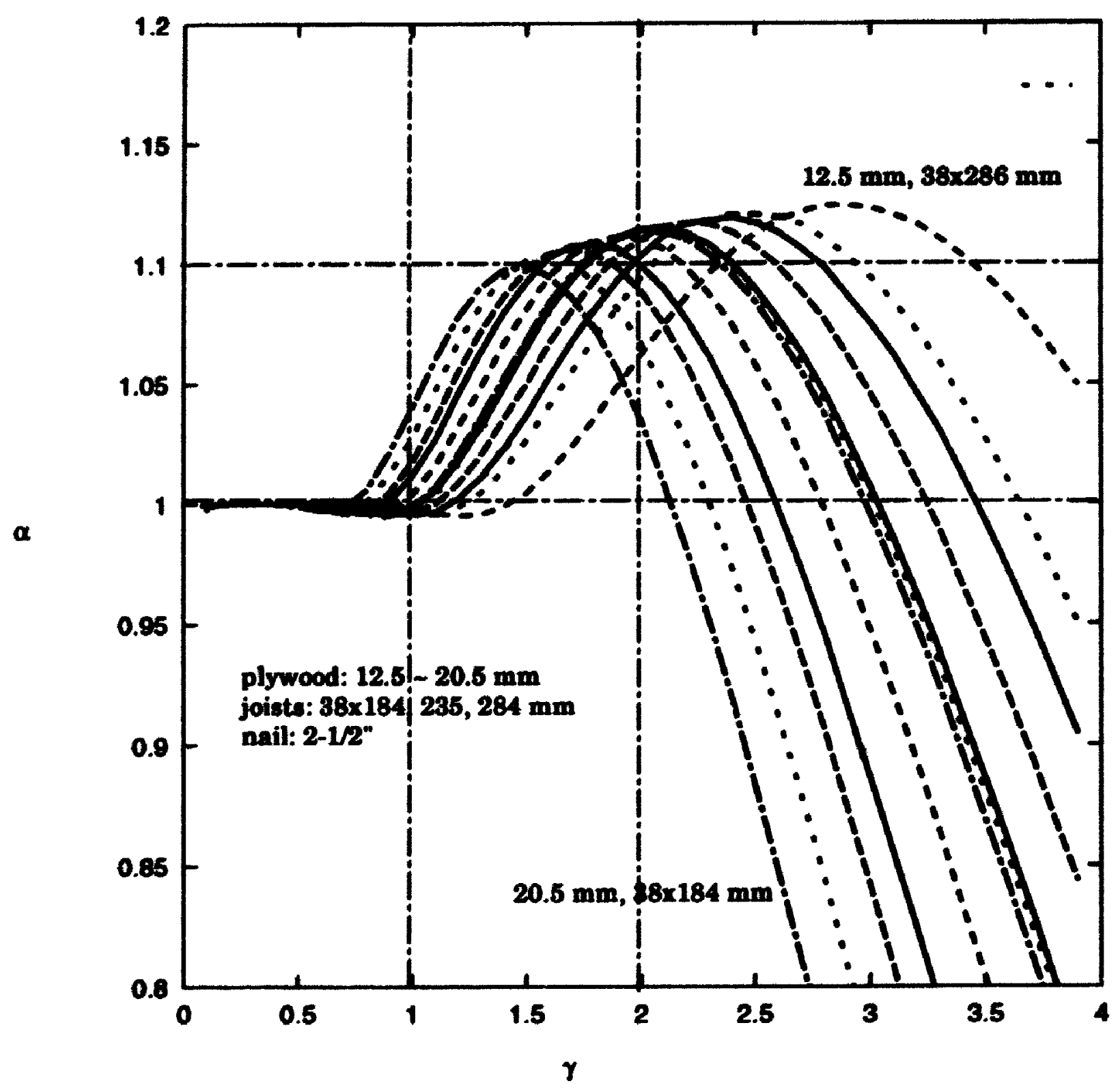

Figure 4.21: Medium span floors, joists: $2 \times 8,2 \times 10,2 \times 12,2-1 / 2^{\text {" nails }}$ 


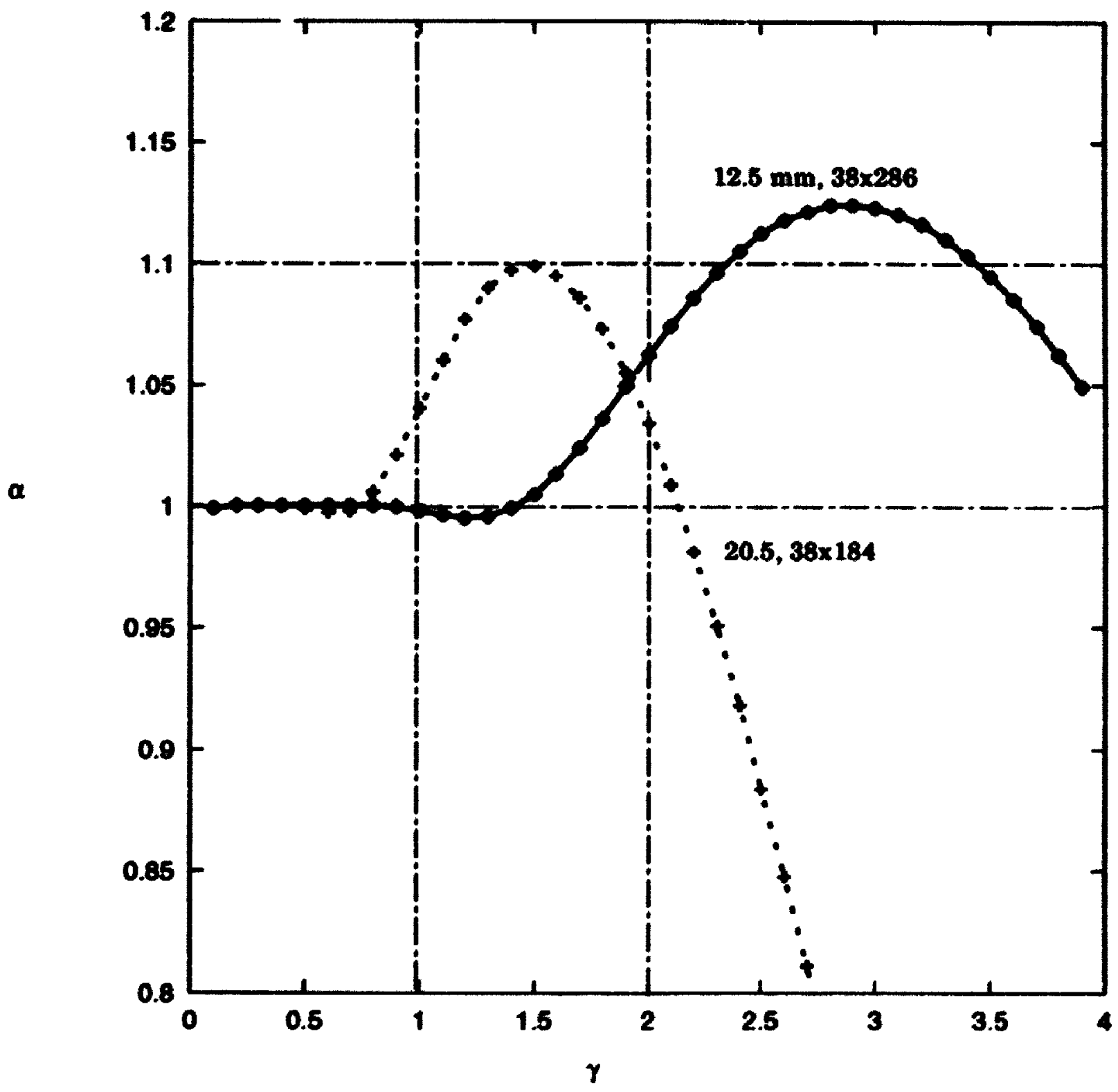

Figure 4.22: Extreme cases, medium span, $12.5 \mathrm{~mm}, 2 \times 12$ and $20.5 \mathrm{~mm}, 2 \times 8 ; 2 \cdot 1 / 2$ " nails 


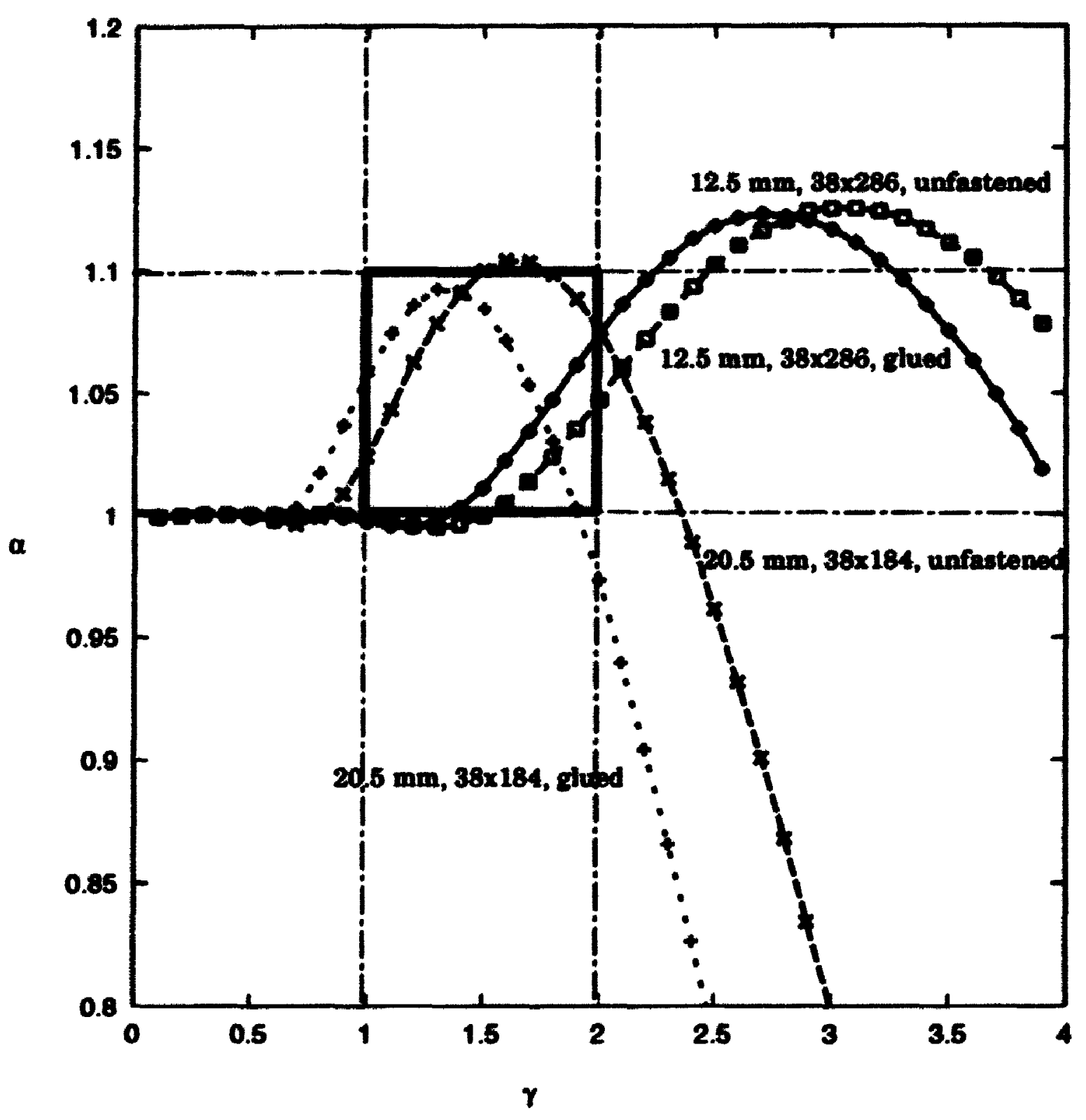

Figure 4.23: Upper and lower limit, medium span 


\section{Chapter 5}

\section{Design of Plywood Sheathed Floors Subject to Concentrated Load}

\subsection{Introduction}

In many cases, concentrated loads such as heavy machinery in industrial buildings and refrigerators in residential dwellings, have to be to be considerry in the donign of floor systems. T-beam theory can not be used to design for concentrated loads acting on plywood sheathed floors. Without sheathing, one of the bare joists will sustain the point load acting on it. If the sheathing is provided to cover the joists, the sheathing becomes a load distribution element. It transfers load from the point of loading to adjacent joists. In addition to the composite action of a $T$-beam, two-way action becomes an important factor in designing foors subjected to a concentrated load. The thickness of the sheathing and the size of the joists will determine thr: magnitude of the two-way action. It has been reported (Vanderbilt et al., 1974, [91]) that the load will be distributed to a few neighbouring joists. The joists far from the point of loading will share only a negligible portion of the load.

In this chapter, the defection of foors subject to a concentrated load is coxamined using orthotropic plate theory. Results are compared against the T-beam approach and the experimental results. A simple design procedure for wood joist foors subjected to concentrated loads will be proposed. 


\subsection{Test Results from Forest Product Lab. USDA, McCutcheon}

Tests have been done at Forest Products Labrsratory, U.S. Department of Agriculture, on floors subject to concentrated loads (McCutcheon 1977, [62]). Four floors (designated N-1 to N-4) used standard grade 5/8-inch plywood nailed to the joists with face grain perpendicular to the span. Nails were $2-1 / 2^{n}$ at 6 inches along the edges and 8 inches over the intermediate joists. Another 3 floors (G-1 to G-3) had the plywood nail-glued in place using a rigid adhesive. These used tongueand-groove plywood with the edges glued to give a continuous sub-floor. The joist stiffness was determined using nondestrutive static bending tests before the foors were assembled.

The concentrated point loads were applied by means of a hydraulic jack placed over the center joist at midspan. The concentrated load was twice applied in increments of 100 pounds to a total load of 500 pounds.

The test results are listed below: Concentrated load 500 pounds

\begin{tabular}{|c|c|c|}
\hline \multirow{2}{*}{ Floor No. } & Average E, Modulus of Elasticity & $500 \mathrm{lbs} *$ \\
\cline { 2 - 3 } & $10^{6} \mathrm{lbs} / \mathrm{in}^{2}\left(10^{3} \mathrm{MPa}\right)$ & inch $(\mathrm{mm})$ \\
\hline $\mathrm{N}-1$ & $1.57(10.82)$ & $0.16(3.94)$ \\
\hline $\mathrm{N}-2$ & $2.20(15.17)$ & $0.13(3.20)$ \\
\hline $\mathrm{N}-3$ & $2.00(13.79)$ & $0.12(2.92)$ \\
\hline $\mathrm{N}-4$ & $1.49(10.27)$ & $0.15(3.86)$ \\
\hline G-1 & $1.53(10.55)$ & $0.10(2.64)$ \\
\hline G-2 & $2.20(15.17)$ & $0.09(2.21)$ \\
\hline G-3 & $2.00(13.79)$ & $0.10(2.36)$ \\
\hline \multicolumn{2}{|c|}{ * Deflection at midspan of loaded joist. Concentrated load. } \\
\hline \multicolumn{2}{|c}{} \\
\hline
\end{tabular}




\subsection{An Example Using the T-beam Theory}

As an example to illustrate the results from T-beam theory, let us consider the following floor.

plywood:

$\begin{array}{rlrl}5 / 8^{n} & \text { standard grade } & & 15.5 \mathrm{~m} \\ \mathrm{Ba}= & 110,000 \mathrm{~N} / \mathrm{mm} & & 90^{\circ} \\ & 75,000 & & 90^{\circ} \\ \mathrm{Bb}= & 3,700,000 \mathrm{~N} \cdot \frac{\mathrm{mm}^{2}}{\mathrm{~mm}} & & 90^{\circ} \\ 430,000 & & 99^{\circ}\end{array}$

joists:

$$
\begin{aligned}
& \text { bxd }=38 \times 184 \mathrm{~mm} \\
& E=13,000 \mathrm{MPa}
\end{aligned}
$$

spacing of joists:

$$
406 \mathrm{~mm}
$$

floor layout:

$$
\begin{aligned}
& L=3660 \mathrm{~mm} \\
& B=4060 \mathrm{~mm}
\end{aligned}
$$

load:

$$
\mathrm{P}=2250 \mathrm{~N}
$$

Using T-beam theory, recall equation 2.23 and 2.26 in chapter 2:

$$
\begin{aligned}
y_{0} & =\frac{d}{2}+\delta \\
\delta & =\frac{d+t}{2} \frac{(E A)_{2}}{(E A)_{2}+(E A)_{1}} \\
& =\frac{d+t}{2} \frac{B_{a} S}{B_{a} S+E b d} \\
& =25 \mathrm{~mm} \\
y_{0} & =\frac{184}{2}+\delta \\
& =92+\delta \\
& =117 \mathrm{~mm}
\end{aligned}
$$


The upper limit of the effective rigidity of the T-beam (referring chapter 2):

$$
\begin{aligned}
(E I)_{e} & =(E I)_{1}+(E A)_{1} \delta^{2}+(E I)_{2}+(E A)_{2}\left(\frac{d+t}{2}-\delta\right)^{2} \\
& =\frac{E b d^{3}}{12}+E b d \delta^{2}+B_{b} S+B_{a} S\left(\frac{d+t}{2}-\delta\right)^{2} \\
& =482.810^{9}\left(N . \mathrm{mm}^{2}\right)
\end{aligned}
$$

The lower limit of the maximum deflection is therefore:

$$
\begin{aligned}
f_{\max } & =\frac{P L^{3}}{48(E I)_{e}} \\
& =4.75 \mathrm{~mm}
\end{aligned}
$$

The lower limit of the effective rigidity:

$$
\begin{aligned}
(E I)_{e} & =(E I)_{1}+(E I)_{2} \\
& =25610^{\circ}\left(\mathrm{N} \cdot \mathrm{mm}^{2}\right)
\end{aligned}
$$

The upper limit of the maximum deflection:

$$
\begin{aligned}
f_{\max } & =\frac{P L^{3}}{48(E I)_{e}} \\
& =8.96 \mathrm{~mm}
\end{aligned}
$$

Comparing the test results, the maximum deflections are between $2.21 \mathrm{~mm}$ and $3.937 \mathrm{~mm}$ which is much lower than what is predicted by the T-beam theory. This indicates that using the T-beam approach will lead to conservative designs. The T-beam approach ignores the load sharing by adjacent joists and lets the single joist under point load sustain the whole point load. This obviously results in overly conservative design. It is, therefore, necessary to examine the floor using orthotropic plate theory. 


\subsection{Result From Orthotropic Plate Theory}

Assume that the fivor is subjected to a concent rated load acting at location $(\xi L, \eta B)$ as shown in figure 5.2, then treat the floor as an orthotropic plate.

$$
\begin{gathered}
D_{x}\left(\frac{\partial^{4}}{\partial x^{4}}+2 H \frac{\partial^{4}}{\partial x^{2} \partial y^{2}}+D_{x} \frac{\partial}{\partial y^{4}}\right) w(x, y)=q(x, y) \\
q(x, y)=\left\{\begin{aligned}
\frac{p}{d d^{2}} & x=\xi L, y=\eta B \\
0 & \text { else }
\end{aligned}\right.
\end{gathered}
$$

Assume

$$
\begin{aligned}
& w(x, y)=\sum_{m=1}^{\infty} \sum_{n=1}^{\infty} w_{m n} \sin \frac{m \pi x}{L} \sin \frac{n \pi y}{B} \\
& q(x, y)=\sum_{m=1}^{\infty} \sum_{n=1}^{\infty} q_{m n} \sin \frac{m \pi x}{L} \sin \frac{n \pi y}{B}
\end{aligned}
$$

where

$$
q_{m n}=\frac{4}{L B} \int_{0}^{L} \int_{0}^{B} q(x, y) \sin m \pi \xi \sin n \pi \eta
$$

substitute equation 5.7 into equation 5.10 :

$$
q_{m n}=\frac{4 P}{L B} \sin m \pi \xi \sin n \pi \eta
$$

solve the above equation, the result is reached as follows:

$$
\begin{aligned}
w_{m n} & =\frac{q_{m n}}{D_{m n}} \\
q_{m n} & =\frac{4 P}{L B} \sin m \pi \xi \sin n \pi \eta \\
D_{m n} & =D_{x}\left(\frac{m \pi}{L}\right)^{4}+2 H\left(\frac{m \pi}{L}\right)^{2}\left(\frac{n \pi}{B}\right)^{2}+D_{y}\left(\frac{n \pi}{B}\right)^{4} \\
w(x, y) & =\sum_{m=1}^{\infty} \sum_{n=1}^{\infty} w_{m n} \sin \frac{m \pi x}{L} \sin \frac{n \pi y}{B}
\end{aligned}
$$

Assume that the concentrated load $P$ is acting at the center of the plate $(\xi=$ $0.5, \eta=0.5)$. The deflection at $\left(x=\frac{L}{2}, y=\frac{\theta}{2}\right)$ is then 


$$
\left.w(x, y)\right|_{x=L / 2, y=B / 2}=\sum_{m=1}^{\infty} \sum_{n=1}^{\infty} \frac{4 P}{L B} \frac{\sin ^{2} \frac{m z}{2} \sin ^{2} \frac{n x}{2}}{D_{m n}}
$$

From McCutcheon's data:

$$
\begin{aligned}
& P=2250 \mathrm{~N}(500 \mathrm{lbs}) \\
& \mathrm{L}=3660 \mathrm{~mm} \\
& B=4060 \mathrm{~mm} \\
& D_{2}=3,700,00 \frac{\mathrm{Nmm}}{\mathrm{mm}} \\
& D_{1}=482.8 \times 10^{\circ} / 406 \frac{\mathrm{Nmm}}{\mathrm{mm}} \\
& \quad\left(482.8 \times 10^{\circ} \text { is the effective rigidity of the T-beam }\right) \\
& 2 \mathrm{H}=D_{2}
\end{aligned}
$$

The result of calculation: maximum deflection is $2.538 \mathrm{~mm}$ which falls within the range of 2.362 to $2.642 \mathrm{~mm}$ from McCutcheon's tests of floors with plywood sheathing glued to the joists. This indicates that the orthotropic plate theory describes well the test results on floors subject to a concentrated load.

\subsection{Comparison}

The following table lists the results from the $\mathrm{T}$-beam theory, orthotropic plate theory and the teats (McCutcheon 1977, [62]). For nailed floors, it was assumed that there are no gaps. 


\begin{tabular}{|c|c|c|c|c|c|}
\hline \multirow{2}{*}{ Floor No. } & Average MOE & $500 \mathrm{lbs}$ & plate & error \% & Tbeam \\
\cline { 2 - 6 } & $10^{3} \mathrm{MPa}$ & $\mathrm{mm}$ & $\mathrm{mm}$ & $\%$ & $\mathrm{~mm}$ \\
\hline $\mathrm{N}-1$ & 10.82 & 3.937 & 3.73 & $-5 \%$ & 8.01 \\
\hline N-2 & 15.17 & 3.200 & 3.06 & $-4 \%$ & 6.17 \\
\hline N-3 & 13.79 & 2.921 & 3.28 & $4 \%$ & 6.67 \\
\hline N-4 & 10.27 & 3.861 & 3.88 & $0.5 \%$ & 8.44 \\
\hline G-1 & 10.55 & 2.642 & 2.99 & $13 \%$ & 5.99 \\
\hline G-2 & 15.17 & 2.210 & 2.49 & $12 \%$ & 4.70 \\
\hline G-3 & 13.79 & 2.362 & 2.61 & $10 \%$ & 5.02 \\
\hline Deflection at midspan of loaded joist. Concent rated load. \\
\hline
\end{tabular}

It can be seen from this table that orthotropic plate theory explains the towt results well, especially for the nailed floors which resulted in less than $1 \%$ error. Even for the glued floors, and that it is much closer to the test results thall what is obtained from T-beam approach. In the next section, detailed investigation on the effects of different parameters on the floor deflections will be conducturd.

\subsection{Parametric Study}

In this section, investigation is made to determine if the discrepancy lyetwern the orthotropic plate theory and the T-beam approach is consistent for floors with other joist, nail sizes, connection types and plywood thicknesses. The results are listed in Table 5.1, 5.2 and are also plotted in Figure 5.3, 5.4, 5.5, 5.6 and 5.7. The ratios is obtained by dividing deflections achieved from T-beam approach with deflecticus from the orthotropic plate theory.

Figure 5.3 shows that for floors with joists of larger sizes the difference lends $\mathrm{t}$, be smaller. Figure 5.4 and 5.6 shows that errors caused by using the T-beam formula far out-weigh the differences of using different connections. Figure 5.5 displays the ratio of the deflections computed from $T$-beam theory and the plate therory. It ran be seen that even for the largest size of joists, the difference is more than $50 \%$. Thelast one, Figure 5.7 shows that even thinner plywood sheathing will not reduce the 
Table 5.1: Deflection of different floors calculated using both orthot ropic plate theory and T-beam formula with different joist sizes. Joist sizes: $38 \times 89$ to $38 \times 286$. Plywood thickness: $12.5 \mathrm{~mm}$. $2 \mathrm{~d}$ nail.

\begin{tabular}{|c|c|c|c|c|c|c|c|c|c||}
\hline \multicolumn{9}{|c|}{ Deflections (mm); plywood: $12.3 \mathrm{~mm}$, nail: $2 \mathrm{~d}$, joist 38xh } \\
\hline \multirow{2}{*}{ h } & \multicolumn{2}{|c|}{ unfastened floors } & \multicolumn{3}{|c|}{ glued floors } & \multicolumn{3}{|c|}{ nailed floors } \\
\cline { 2 - 10 } & plate & Tbeam & ratio & plate & Tbeam & ratio & plate & Tbeam & ratio \\
\hline 89 & 26.93 & 93.11 & 3.46 & 13.87 & 37.36 & 2.69 & 20.92 & 65.71 & 3.14 \\
\hline 114 & 15.73 & 44.38 & 2.82 & 8.81 & 20.11 & 2.28 & 12.87 & 33.72 & 2.62 \\
\hline 110 & 10.03 & 23.98 & 2.39 & 5.98 & 11.94 & 2.00 & 8.49 & 19.15 & 2.25 \\
\hline 184 & 5.46 & 10.57 & 1.94 & 3.53 & 5.90 & 1.67 & 4.80 & 8.90 & 1.85 \\
\hline 235 & 3.15 & 5.07 & 1.61 & 2.17 & 3.10 & 1.43 & 2.84 & 4.43 & 1.56 \\
\hline 286 & 2.01 & 2.81 & 1.40 & 1.45 & 1.84 & 1.27 & 1.85 & 2.52 & 1.36 \\
\hline \hline
\end{tabular}

error raused by using the $T$-beam formula.

Therefore, a wood joist floor with sheathing subjected to concentrated load has to be designed as an orthotropic plate instead of a T-beam. The errors caused by using $T$-beam approach are not negligible for any floor configuration.

\subsection{Location of Maximum Deflections, $\left(x_{0}, y_{0}\right)$}

It is now established that plywood sheathed joist floors can not be designed using T-beam theory: This section will examine the issues involved in designing floors subjected to concent rated loading.

\subsubsection{In the Direction Perpendicular to Joists, $y_{0}$}

Rewrite equation $\mathbf{5 . 1 5}$

$$
w(x, y)=\sum_{m=1}^{\infty} \sum_{n=1}^{x} w_{m n} \sin \frac{m \pi x}{L} \sin \frac{n \pi y}{B}
$$

where 
Table 3.2: Deflection of different floors calculated using both ort hot ropic plate theory and T-beam formula with different nail sizes. Joist sizes: 38x89. Plywood thirkness: $12.5 \mathrm{~mm}$. Nails: $2 \mathrm{~d}$ to $60 \mathrm{~d}$.

\begin{tabular}{|c|c|c||}
\hline \hline \multicolumn{2}{|c|}{ Deflection of floors: plywood: $12.5 \mathrm{~mm}$ : nail size: $2 \mathrm{~d}$ - 60d; joist: $38 \times 89$} \\
\hline plate & Tbeam & ratio \\
\hline 10.92 & 65.71 & 3.14 \\
\hline 19.44 & 59.39 & 3.06 \\
\hline 19.44 & 59.39 & 3.06 \\
\hline 18.84 & 56.90 & 3.02 \\
\hline 18.19 & 54.21 & 2.98 \\
\hline 17.64 & 51.96 & 2.95 \\
\hline 17.27 & 50.48 & 2.92 \\
\hline 16.61 & 47.83 & 2.88 \\
\hline 16.35 & 46.79 & 2.86 \\
\hline 16.05 & 45.62 & 2.84 \\
\hline 15.62 & 43.94 & 2.81 \\
\hline
\end{tabular}




$$
\begin{aligned}
w_{m n} & =C \frac{\sin m \pi \xi \sin n \pi \eta}{m^{4}+\beta_{1} m^{2} n^{2} \gamma^{2}+\beta_{2} n^{4} \gamma^{4}} \\
C & =\frac{4 P L^{3}}{B \pi^{4} D_{x}} \\
\beta_{1} & =\frac{2 H}{D_{x}} \\
\beta_{2} & =\frac{D_{y}}{D_{x}} \\
\gamma & =\frac{L}{B}
\end{aligned}
$$

In order to design for the serviceability of a floor, it is necessary to find the maximum deflection. Since equation 5.17 is in series form, it is difficult to find a simple closed form solution for the maximum deflection. Instead of finding the exact location of the maximum deflections, a numerical method was employed with a simple algorithm. By calculating the deflection of a sufficient number of points on the floor, the maximum deflection and its location can be found with satisfactory accuracy. This algorithm is by no means the best one. There are a number of alternative ways to achieve the same result. But, for the purpose of illustrating the discussion herein, this simple algorithm will be used.

Denote $\left(x_{0}, y_{0}\right)$ as the location of the maximum deflection. The point load is acting at $(\xi L, \eta B)$.

Let us examine the following floor:

\begin{tabular}{ccc}
\hline joists: & & \\
size & $38 \times 184$ & $2^{\prime \prime} \times 8^{\prime \prime}$ \\
L & $3660 \mathrm{~mm}$ & $12^{\prime}$, joist span \\
B & $4060 \mathrm{~mm}$ & 9 joists \\
S & $406 \mathrm{~mm}$ & $16^{\prime \prime}$, joist spacing \\
\hline plywood: & 4 plies & \\
t & $15.5 \mathrm{~mm}$ & $5 / 8 "$ \\
\hline load: & concentrated load & \\
P & $2250 \mathrm{~N}$ & $500 \mathrm{lbs}$ \\
\hline \hline
\end{tabular}


Table 5.3: Location of maximum deflections of floors subject to point load.

\begin{tabular}{|c|c|c|c|c|c|c|c|c|c|c|}
\hline$\eta \rightarrow$ & \multicolumn{2}{|c|}{0.1} & \multicolumn{2}{c|}{0.2} & \multicolumn{2}{c|}{0.3} & \multicolumn{2}{c|}{0.4} & \multicolumn{2}{c|}{0.5} \\
\hline$\xi$ & $x_{0}$ & $y_{0}$ & $x_{0}$ & $y_{0}$ & $x_{0}$ & $y_{0}$ & $x_{0}$ & $y_{0}$ & $x_{0}$ & $y_{0}$ \\
\hline 0.1 & 0.3 & 0.1 & 0.35 & 0.2 & 0.35 & 0.3 & 0.35 & 0.4 & 0.35 & 0.5 \\
\hline 0.2 & 0.35 & 0.1 & 0.35 & 0.2 & 0.35 & 0.3 & 0.35 & 0.4 & 0.35 & 0.5 \\
\hline 0.3 & 0.4 & 0.1 & 0.4 & 0.2 & 0.4 & 0.3 & 0.4 & 0.4 & 0.4 & 0.5 \\
\hline 0.4 & 0.45 & 0.1 & 0.45 & 0.2 & 0.45 & 0.3 & 0.45 & 0.4 & 0.45 & 0.5 \\
\hline 0.5 & 0.5 & 0.1 & 0.5 & 0.2 & 0.5 & 0.3 & 0.5 & 0.4 & 0.5 & 0.5 \\
\hline
\end{tabular}

Table 5.4: Maximum deflections ( $\mathrm{mm}$ )

\begin{tabular}{|c|c|c|c|c|c|c|c|c|c|c|}
\hline$\eta \rightarrow$ & \multicolumn{2}{|c|}{0.1} & \multicolumn{2}{c|}{0.2} & \multicolumn{2}{c|}{0.3} & \multicolumn{2}{c|}{0.4} & \multicolumn{2}{c|}{0.5} \\
\hline$\xi$ & glued & nailed & glued & nailed & glued & naile $\mid$ & glued & nailed & glued & nailed \\
\hline 0.1 & 0.77 & 0.96 & 0.83 & 1.09 & 0.81 & 1.06 & 0.81 & 1.06 & 0.81 & 1.06 \\
\hline 0.2 & 1.46 & 1.82 & 1.59 & 2.08 & 1.56 & 2.03 & 1.56 & 2.03 & 1.56 & 2.03 \\
\hline 0.3 & 2.02 & 2.51 & 2.21 & 2.89 & 2.16 & 2.82 & 2.16 & 2.18 & 2.16 & 2.82 \\
\hline 0.4 & 2.39 & 2.95 & 2.62 & 3.43 & 2.56 & 3.34 & 2.56 & 3.33 & 2.56 & 3.34 \\
\hline 0.5 & 2.51 & 3.11 & 2.76 & 3.62 & 2.70 & 3.52 & 2.70 & 3.52 & 2.70 & 3.52 \\
\hline
\end{tabular}

From Table 5.3, it can be seen that $y_{0}=\eta B$ which indicates that the maximum deflection occurs along the line $y=y_{0}$. This line is parallel to the joists and underneath the point load. This conclusion can be further illustrated by Figure 5.11. Deflections of the floor subjected to point load at varies $(\xi L, \eta B)$ are illustrated in Figure 5.8, 5.9, 5.10 and 5.11.

Figure 5.8 shows that when the point load is applied at varies points along the span of the joists and not at the mid-width, the maximum deflection is not. at the point of loading. It resembles a single beam subjected to concentrated load. The only exception is that when the load $P$ is applied at mid-span, the maximum deflection is also at mid-span.

Figure 5.9 is the same as Figure 5.8 except that $P$ is acting at the mid.width. 
The result is identical in both cases.

Figure 5.10 describes the deflections of a floor along the span when the point load acts at varies points along the width at mid-span of the joists. It implies that there is not much difference among the deflection curves along the span under load point when point load is applied in the central part of the floor. As an example, let us assume a floor with 11 joists numbered from 1 to 11 . Joist No.1 and No.11 are supported. Joist No.6 is at the center of the floor. The deflection curve of joist No.6, when load is applied at the mid-span of joist No.6, is almost the same as the deflection curve of joist No.5, when the point load is applied to the mid-span of joist No.5.

Figure 5.11 illustrates the deflection curve of the floor at mid-span when a point load is applied to the mid-span. It can be seen that the maximum deflection is under the point of loading for the central joists. It can also be seen that only a few neighboring joists are affected by the point load. It is therefore a local effect. The implication is that for a building built for a special purpose and when the location of the point load is known beforehand, local reinforcement can be applied underneath the point load.

In order to show that $y_{0}=\eta B$ is also true for other floors of different joist sizes and plywood thicknesses, let's exs mine the following floors.

\begin{tabular}{ccc}
\hline \hline load: $\mathrm{P}$ & $2250 \mathrm{~N}$ & $500 \mathrm{lbs}$ \\
\hline joist span, $\mathrm{L}$ & $3660 \mathrm{~mm}$ & 12 ' \\
floor width, $\mathrm{B}$ & $4060 \mathrm{~mm}$ & 9 joists \\
joist sparing, $\mathrm{S}$ & $406 \mathrm{~mm}$ & $16^{\prime \prime}$ \\
\hline floor 1 & joists: $38 \times 89$ & plywood: $\mathrm{t}=12.5 \mathrm{~mm}, 4$ plies \\
\hline floor 2 & joists: $38 \times 89$ & plywood: $\mathrm{t}=20.5 \mathrm{~mm}, 7$ plies \\
\hline floor 3 & joists: $89 \times 286$ & plywood: $\mathrm{t}=12.5 \mathrm{~mm}, 4$ plies \\
\hline floor 4 & joists: $89 \times 286$ & plywood: $\mathrm{t}=20.5 \mathrm{~mm}, 7$ plies \\
\hline \hline
\end{tabular}

The results are illustrated in Figure 5.12, 5.13, 5.14, and 5.15. This group of 4 floors represent the combinations of thinnest and thickest plywood, smallest and 


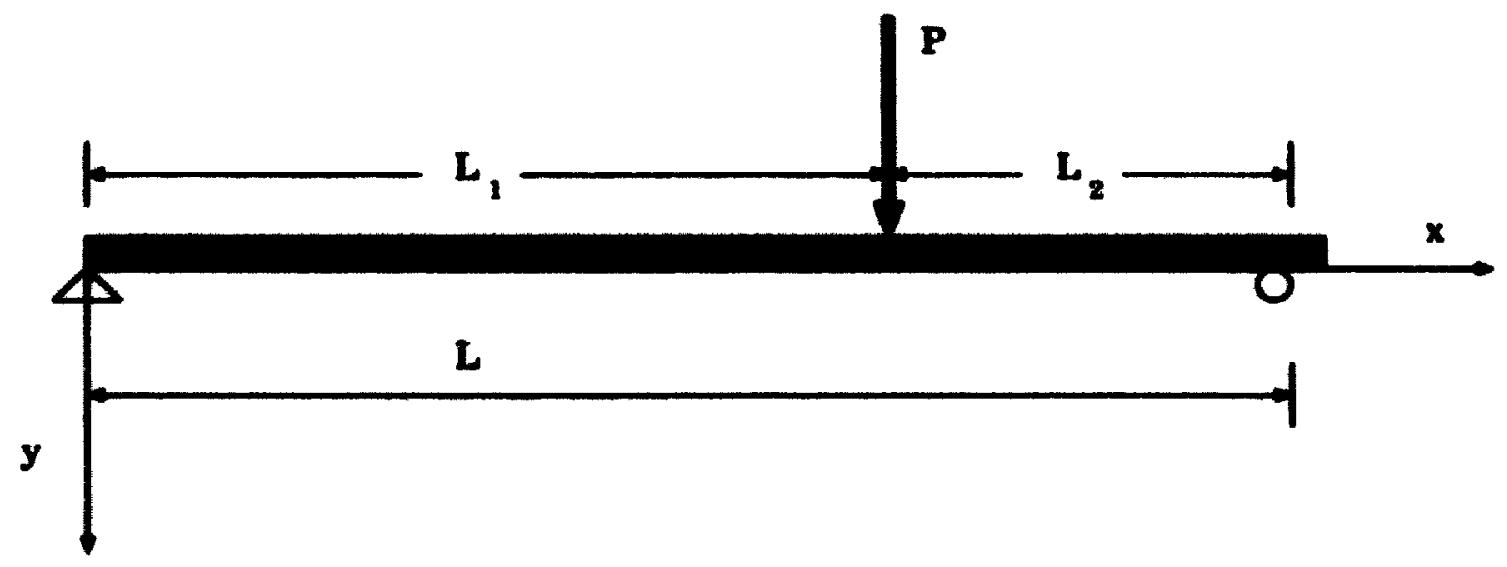

Figure 5.1: Simply supported beams subject to point load

largest joists. A few observations can be made. First of all, it can be sern that $y_{0}=\eta B$. Second, thicker plywood transfers load to other joists further away from point of loading while larger joist will do the opposite. This is apparent by comparing Figure 5.13, which has smaller joists covered by thicker plywood, with Figure 5.14 which has a thinner plywood and larger joists.

Figure 5.16 and 5.12 shows the deflection curves computed by using 3 termx and 15 terms in the joist direction. It is obvious that they are identical. This further shows that the solution converges very fast.

\subsubsection{In the Direction of Joists, $x_{0}$}

It has been observed that the deflection curve of the floor in the diruction of the joists is similar to the deflection curve of a simply supported beam subjerted to point load, Figure 5.17. The following steps are taken to show that thr maximum deflection of the plate can be found by calculating the deflection of the plate at the. point where the maximum deflection of the beam orcurs.

For a simply supported beam subjected to point load as shown in Figure 5.1, the location of the maximum deflection is at

$$
x_{6}=\sqrt{\frac{L^{2}-L_{2}^{2}}{3}} \quad L_{1}>L_{2}
$$

The deflection of a floor at point $\left(x_{b} L, \eta B\right)$ is 


$$
\begin{aligned}
w\left(x_{b}, \eta\right) & =\sum_{m=1}^{\infty} \sum_{n=1}^{\infty} w_{m n} \sin m \pi x_{b} \sin n \pi \eta \\
w_{m n} & =\frac{q_{m n}}{D_{m n}} \\
q_{m n} & =\frac{4 P}{L B} \sin m \pi \xi \sin n \pi \eta \\
D_{m n} & =\pi^{4}\left[D_{x}\left(\frac{m}{L}\right)^{4}+2 H\left(\frac{m n}{L B}\right)^{2}+D_{v}\left(\frac{n}{B}\right)^{4}\right]
\end{aligned}
$$

Using above equations, the maximum deflection for floors with plywood $12.5 \rightarrow$ $20.5 \mathrm{~mm}$, joists $(38,64,89) \times(89 \rightarrow 286)$ are calculated. The result is shown in Figure 5.18. It can be seen that they are almost identical. Therefore, the maximum deflection of a floor can be calculated as the deflection of the floor at point $\left(x_{b}, \eta B\right)$.

\subsection{Guidelines in Designing Floors Subject to Point Load}

In order to design for a wood joist floors subject to concentrated load, the following procedures can be followed:

1. Deflection of floors at any point $(x, y)$

$$
\begin{aligned}
w(x, y) & =\sum_{m=1}^{\infty} \sum_{n=1}^{\infty} w_{m n} \sin \frac{m \pi x}{L} \sin \frac{n \pi y}{B} \\
w_{m n} & =\frac{q_{m n}}{D_{m n}} \\
q_{m n} & =\frac{4 P}{L B} \sin m \pi \xi \sin n \pi \eta \\
D_{m n} & =D_{x}\left(\frac{m \pi}{L}\right)^{4}+2 H\left(\frac{m \pi}{L}\right)^{2}\left(\frac{n \pi}{B}\right)^{2}+D_{v}\left(\frac{n \pi}{B}\right)^{4}
\end{aligned}
$$

2. Find the location of the maximum deflection of a beam subjected to concentrated load: $x_{b}$

$$
x_{b}=\sqrt{\frac{L^{2}-L_{2}^{2}}{3}} \quad L_{1}>L_{2}
$$


3. Calculate the deflection of the floor at point $\left(x_{b}, \eta B\right)$. This deflection will be the approximate maximum deflection.

$$
w(x, y)=\sum_{m=1}^{\infty} \sum_{n=1}^{\infty} w_{m n} \sin m \pi \frac{x_{b}}{L} \sin n \pi \eta
$$

$w_{m n}$ can also be written as

$$
\begin{aligned}
w_{m n} & =C \frac{\sin m \pi \xi \sin n \pi \eta}{L_{m n}} \\
C & =\frac{4 P L^{3}}{B D_{x} \pi^{4}} \\
L_{m n} & =m^{4}+\beta_{1} m^{2} n^{2} \gamma^{2}+\beta_{2} n^{4} \gamma^{4} \\
\beta_{1} & =\frac{2 H}{D_{x}} \\
\beta_{2} & =\frac{D_{y}}{D_{x}} \\
\gamma & =\frac{L}{B}
\end{aligned}
$$

Where $(\xi L, \eta B)$ is the point of loading, $P$ is the point load, $L$ and $B$ is the span and width of the floor, $D_{x}$ is the bending rigidity of the T-beam and II and $D_{y}$ the torsional rigidity and bending rigidity of plywood perpendicular to the joists. The. convergence of the series is fast. 

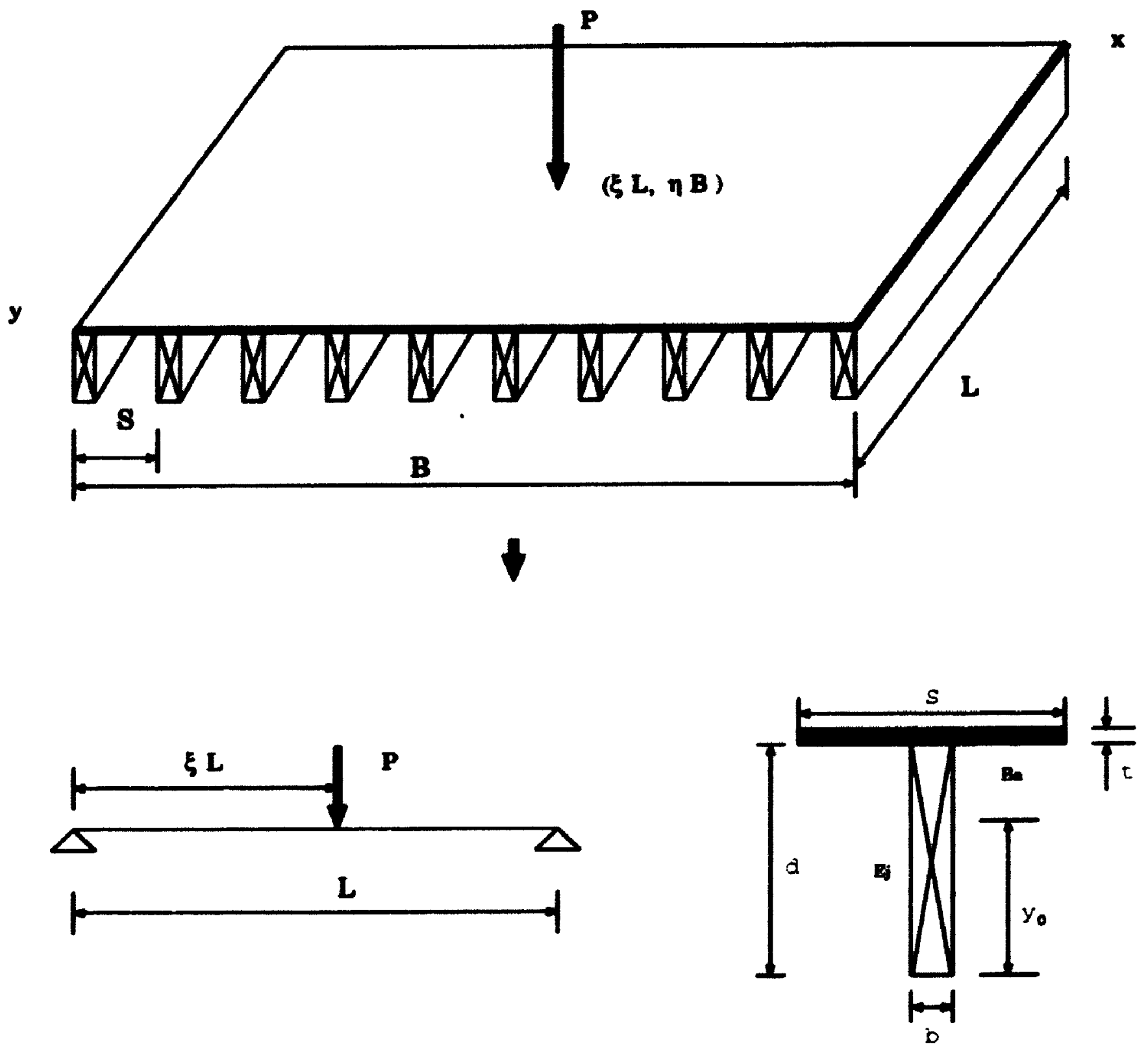

Figure 5.2: A plywood sheathed floor subjects to concentrated load. 


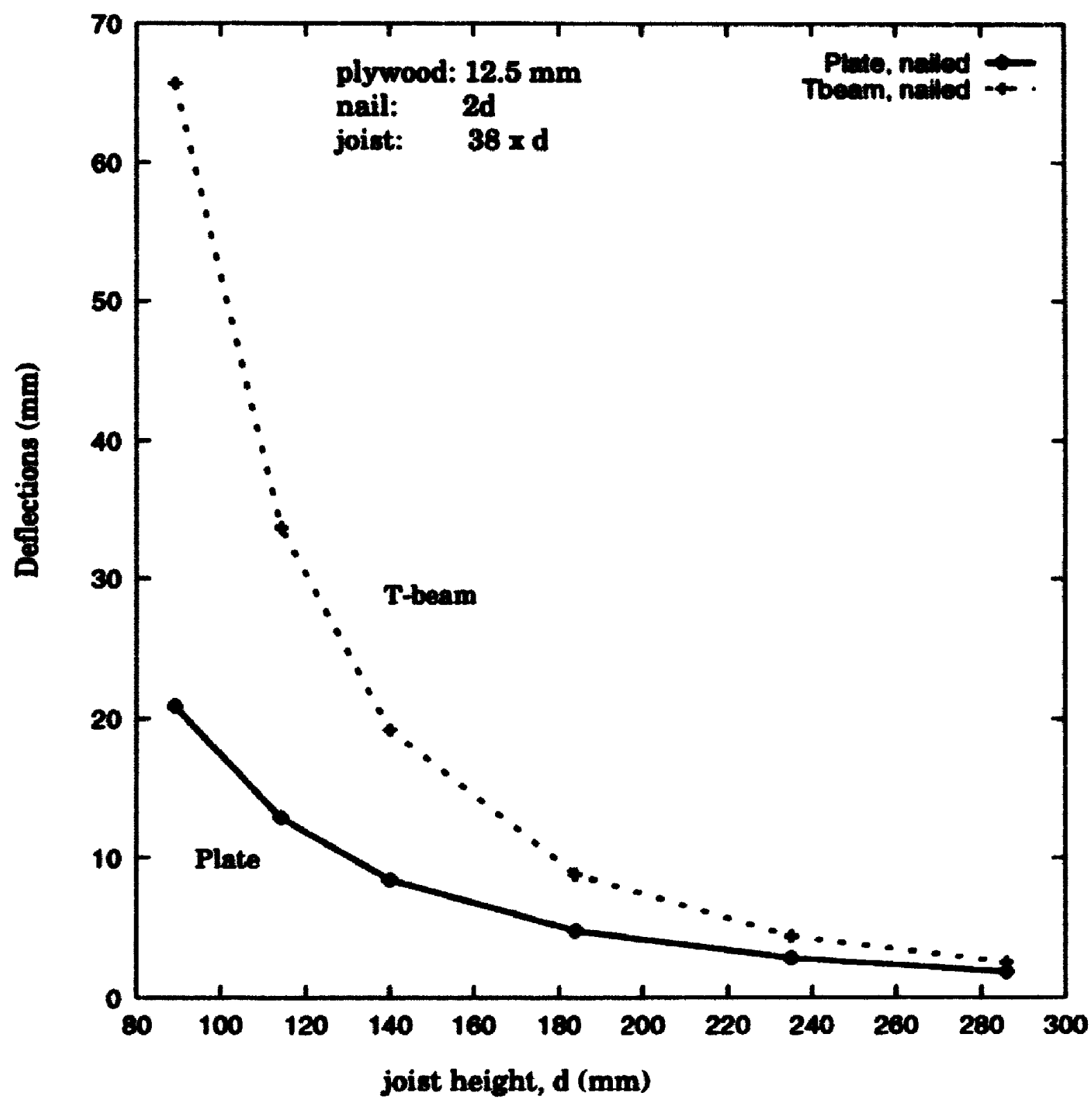

Figure 5.3: Deflection of different floors calculated using both orthotropir plate theory and T-beam formula with different joist sizes. Joist sizes: $38 \times 89$ to $38 \times 286$. Plywood thickness: $12.5 \mathrm{~mm}$. 2d nail. 


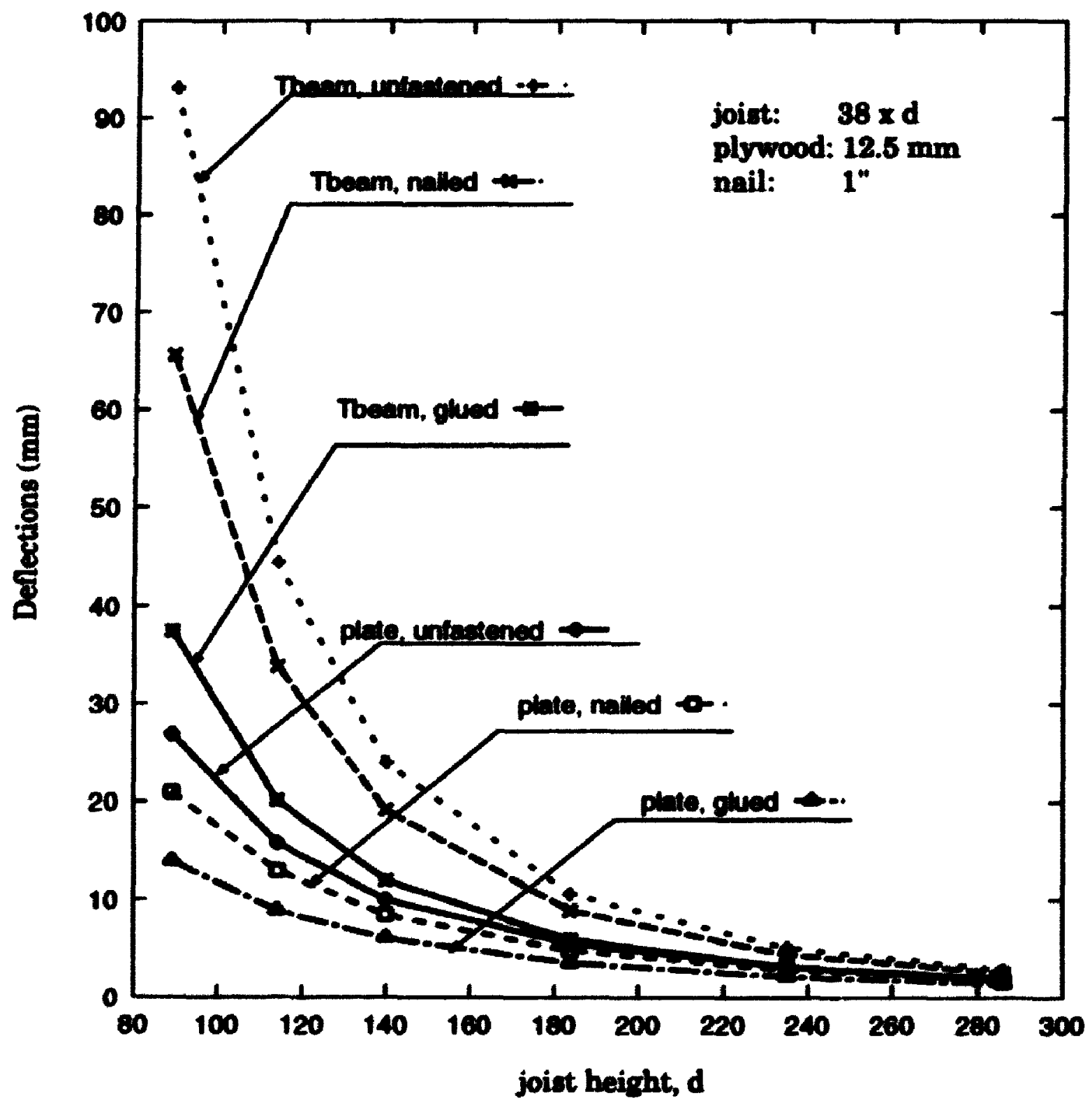

Figure 5.4: Deflection of different floors calculated using both orthotropic plate theory and T-beam formula with different joist sizes, upper bound, lower bound and naiked. Joist sizes: $38 \times 89$ to $38 \times 286$. Plywood thickness: $12.5 \mathrm{~mm}$. $2 \mathrm{~d}$ nail. 


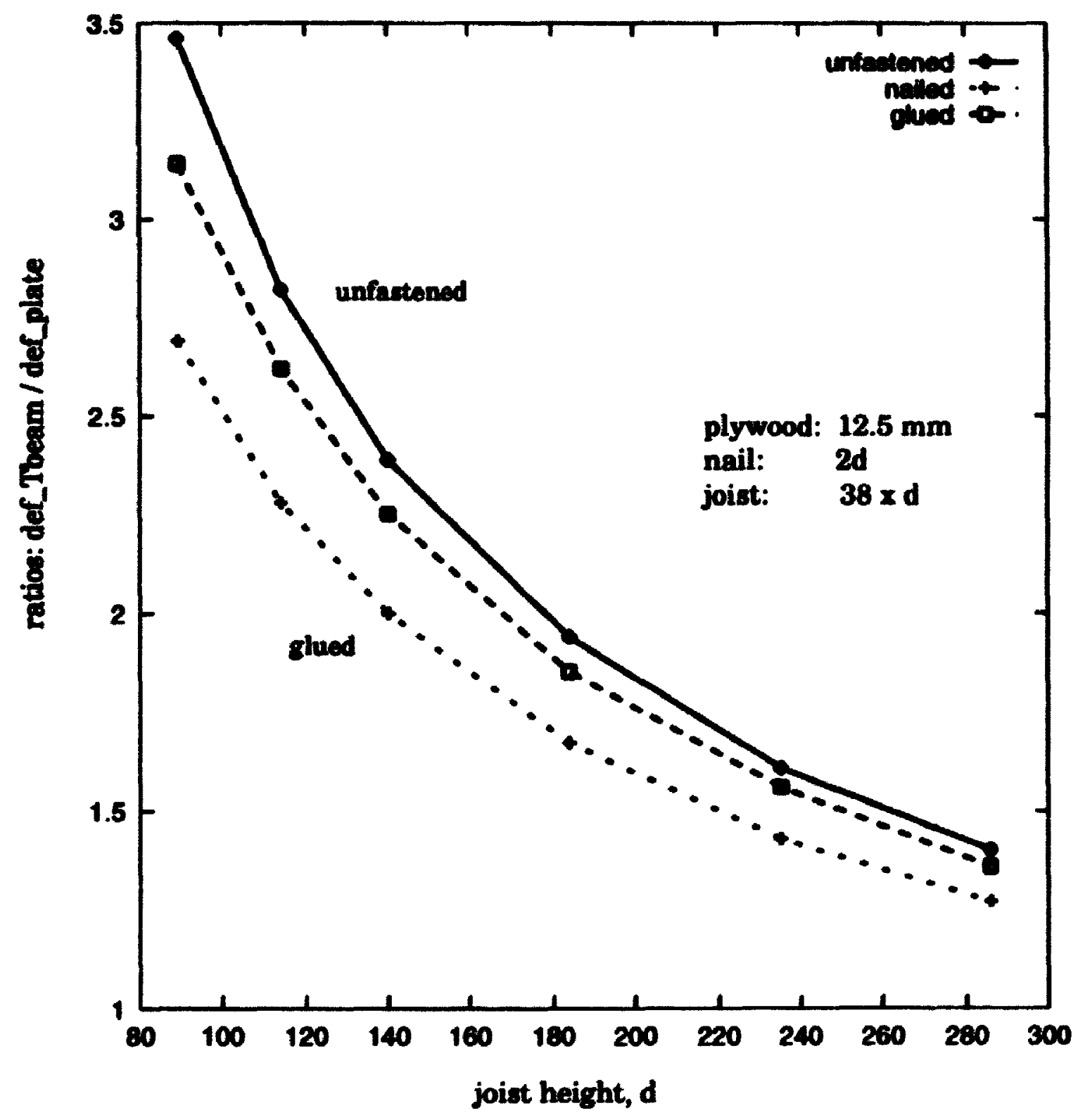

Figure 5.5: Ratio of deflections obtained from Tbeam formula and orthot ropic plate theory. Joist sizes: $38 \times 89$ to $38 \times 286$, Plywood thickness: $12.5 \mathrm{~mm}$, nail size: $2 d$. 


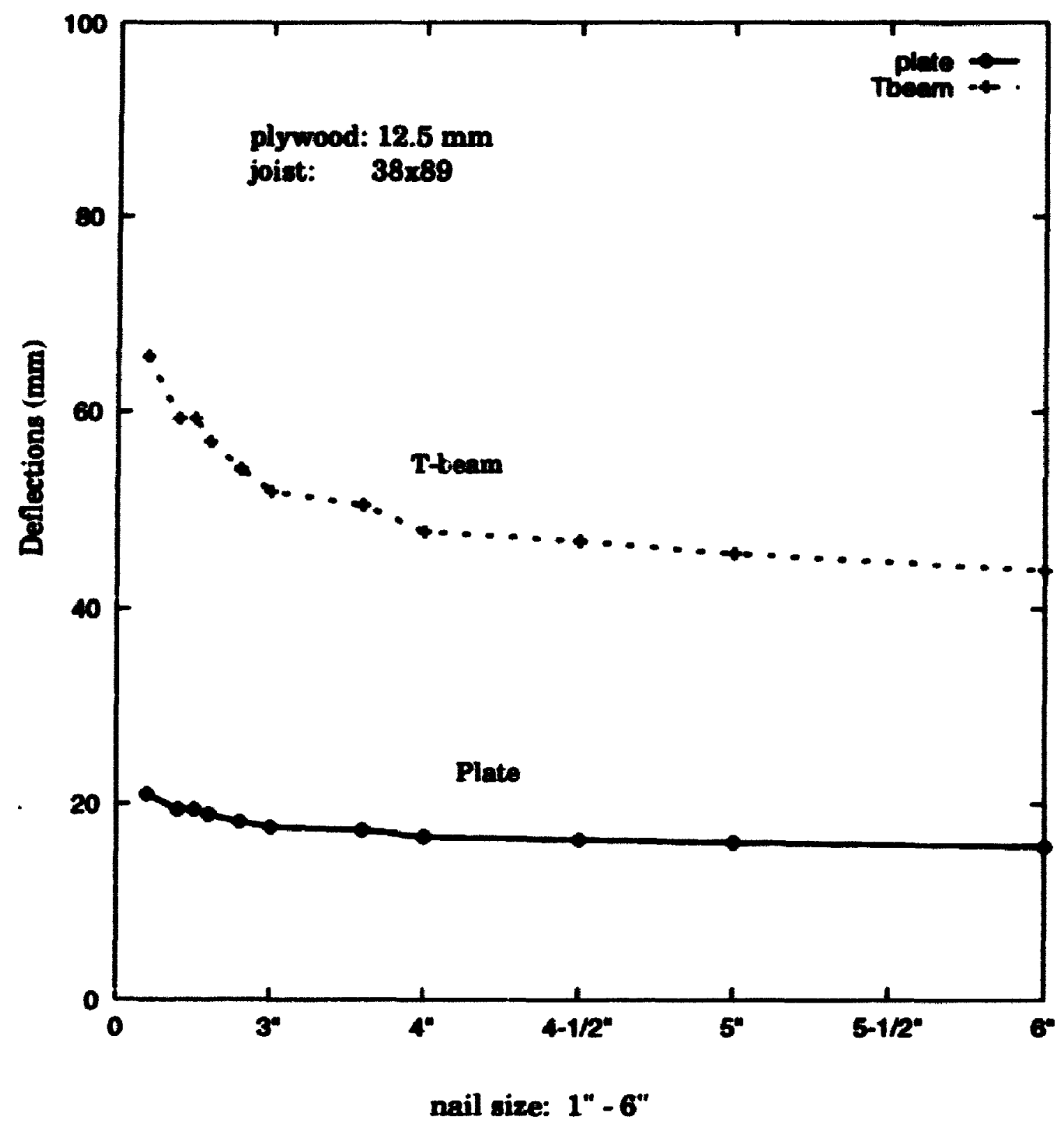

Figure 5.6: Deflection of different floors calculated using both orthotropic plate theory and T-beam formula with different nail sizes. Joist sizes: 38x89. Plywood thickness: $12.5 \mathrm{~mm}$. Nails: $2 \mathrm{~d}$ to $60 \mathrm{~d}$. 


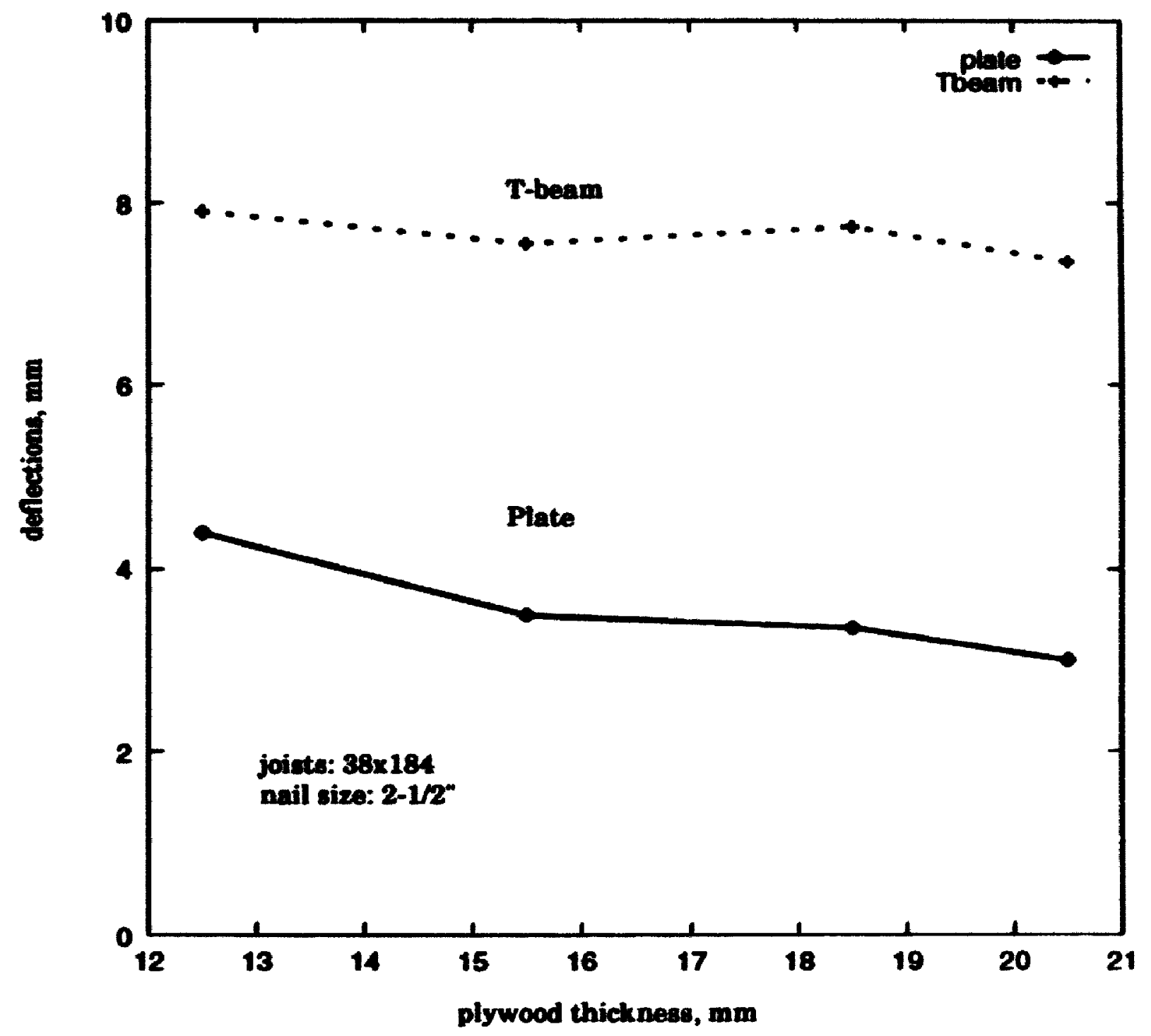

Figure 5.7: Deflection of different floors calculated using both orthotropic plate theory and T-beam formula with different plywood thicknesses. Joist sizes: $3 \times \times \mid \times 4$. Plywood thickness: 12.5 to $20.5 \mathrm{~mm}$. Nails: $8 d$. 


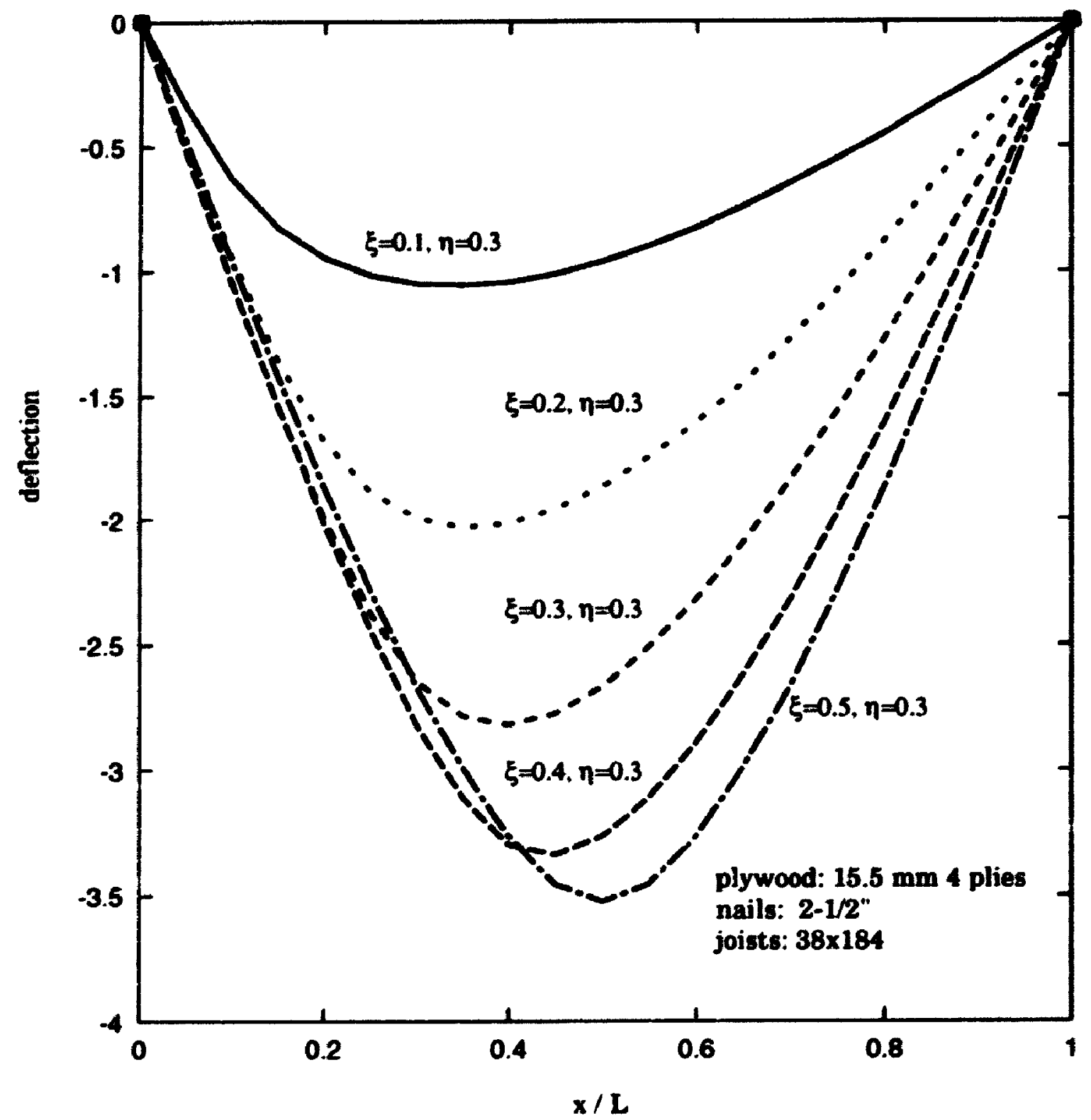

Figure 5.8: Deflections along the span when $P$ acts at varies points along the span at $\eta=0.3$ 


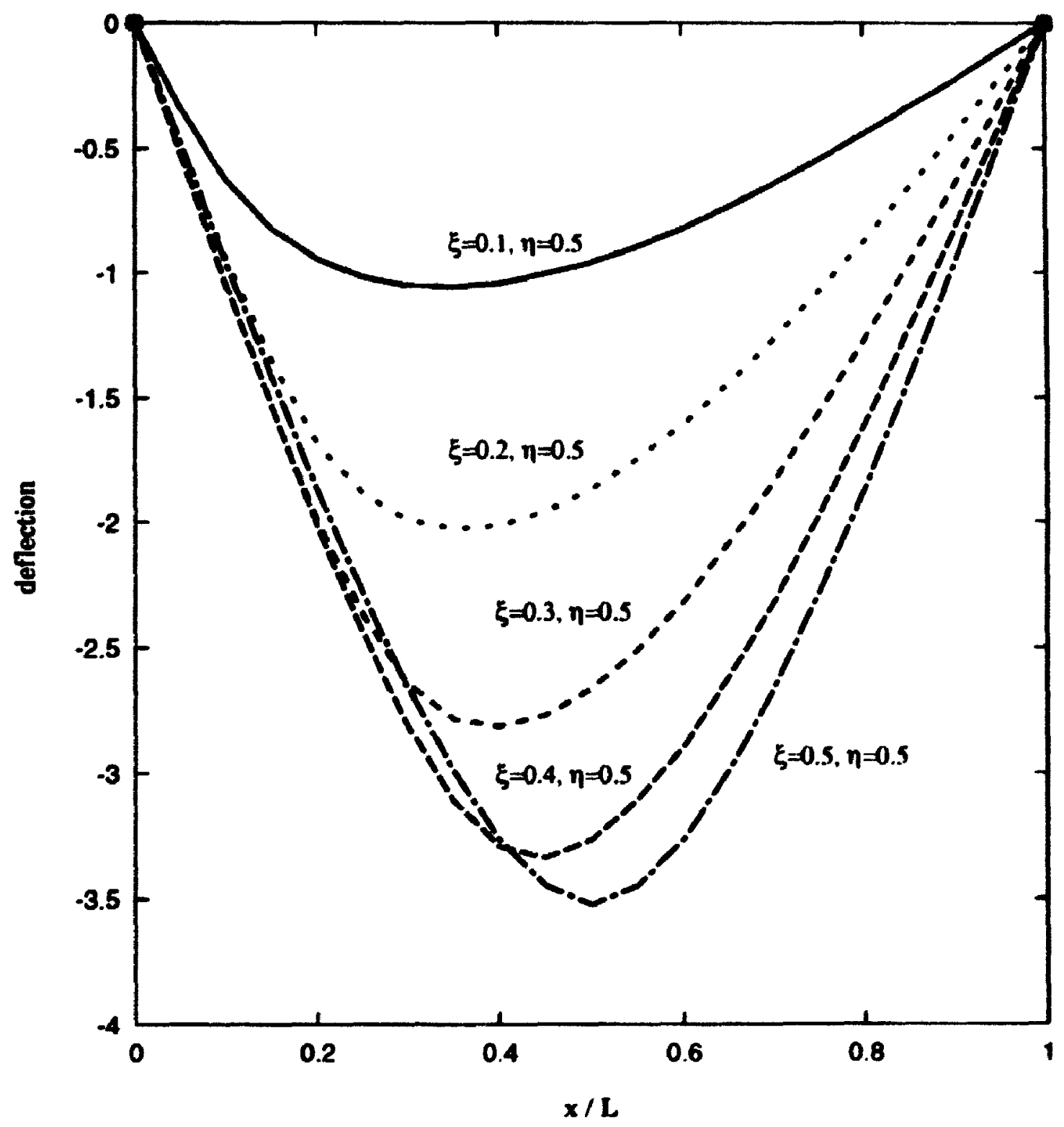

Figure 5.9: Deflections along the span when $P$ acts at varies points alesig the span at mid-width $\eta=0.5$ 


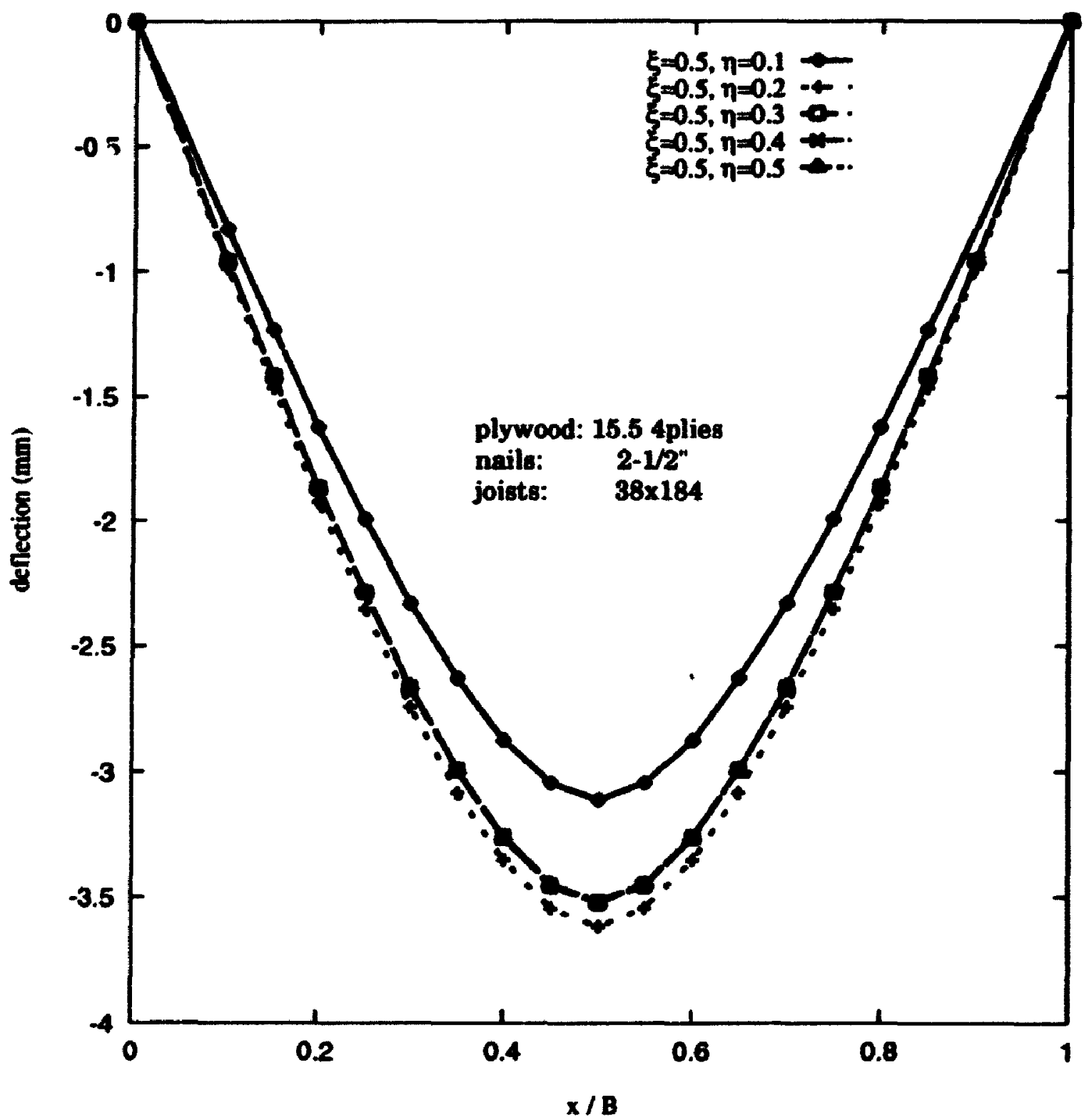

Figure 5.10: Deflections along the span when $P$ acts at mid-span 


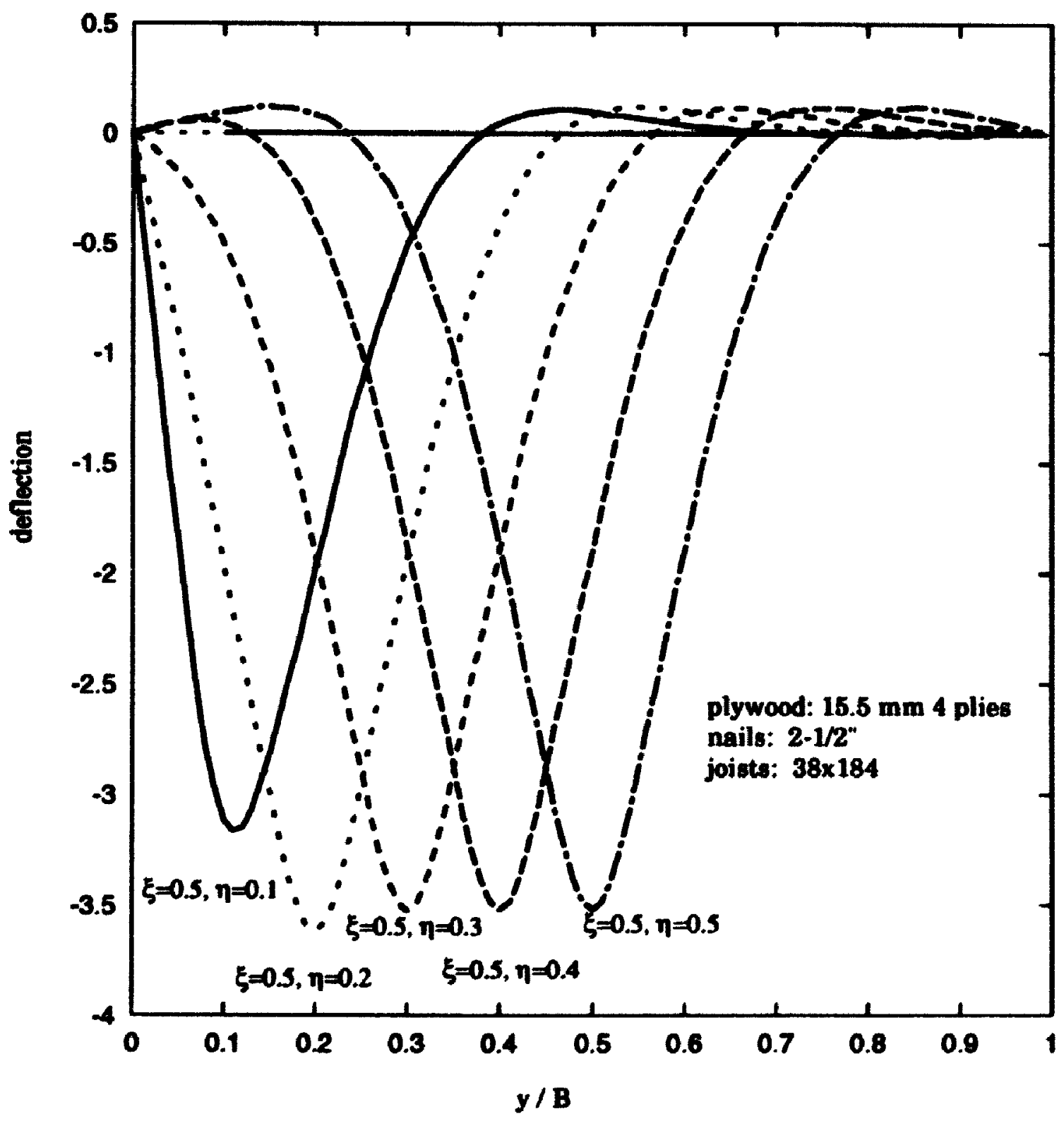

Figure 5.11: Deflections along the width when $P$ acts at mid-span 


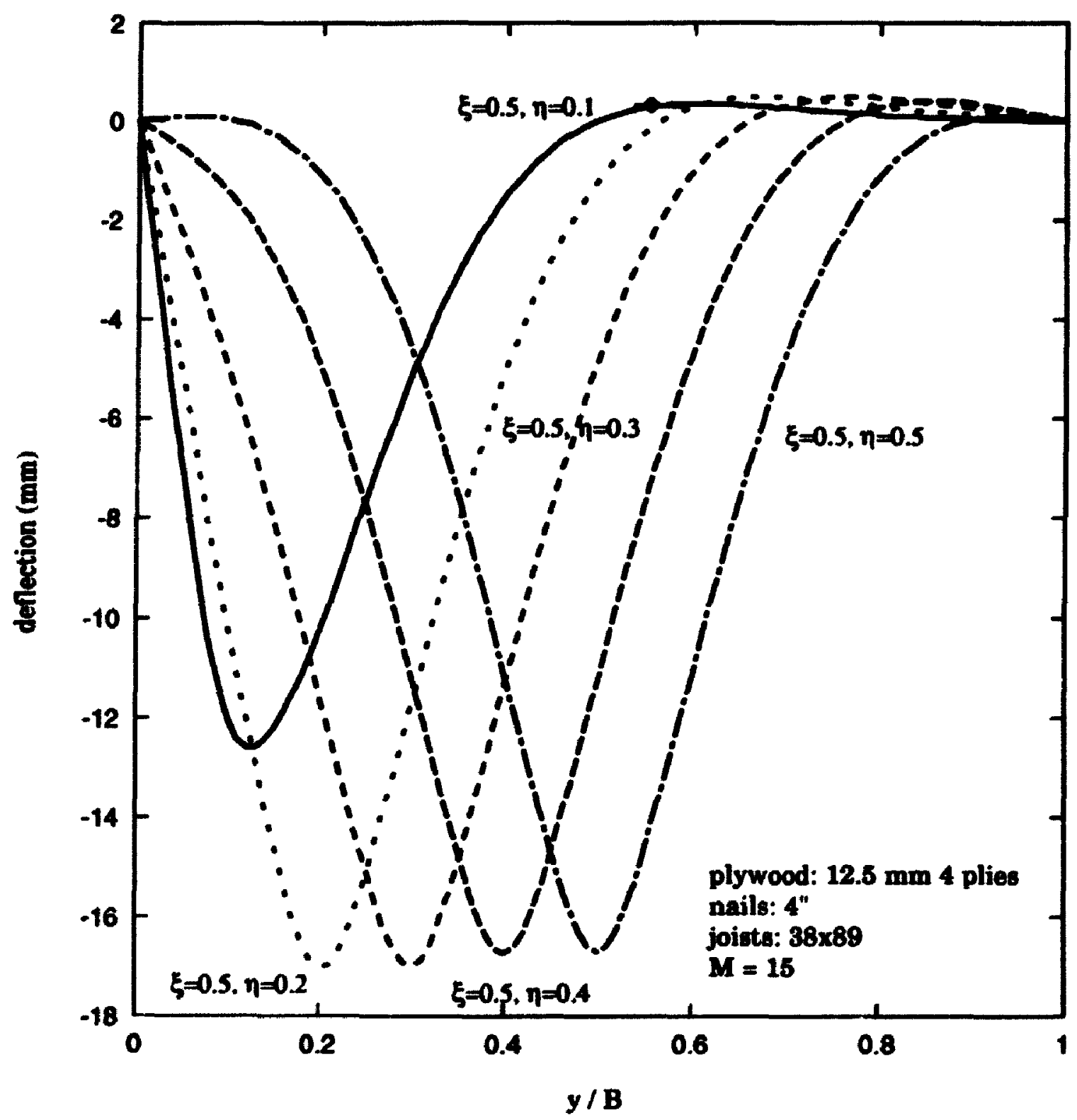

Figure 5.12: Deflections along the width when $P$ acts at mid-span, $38 \times 89,12.5 \mathrm{~mm}$ 


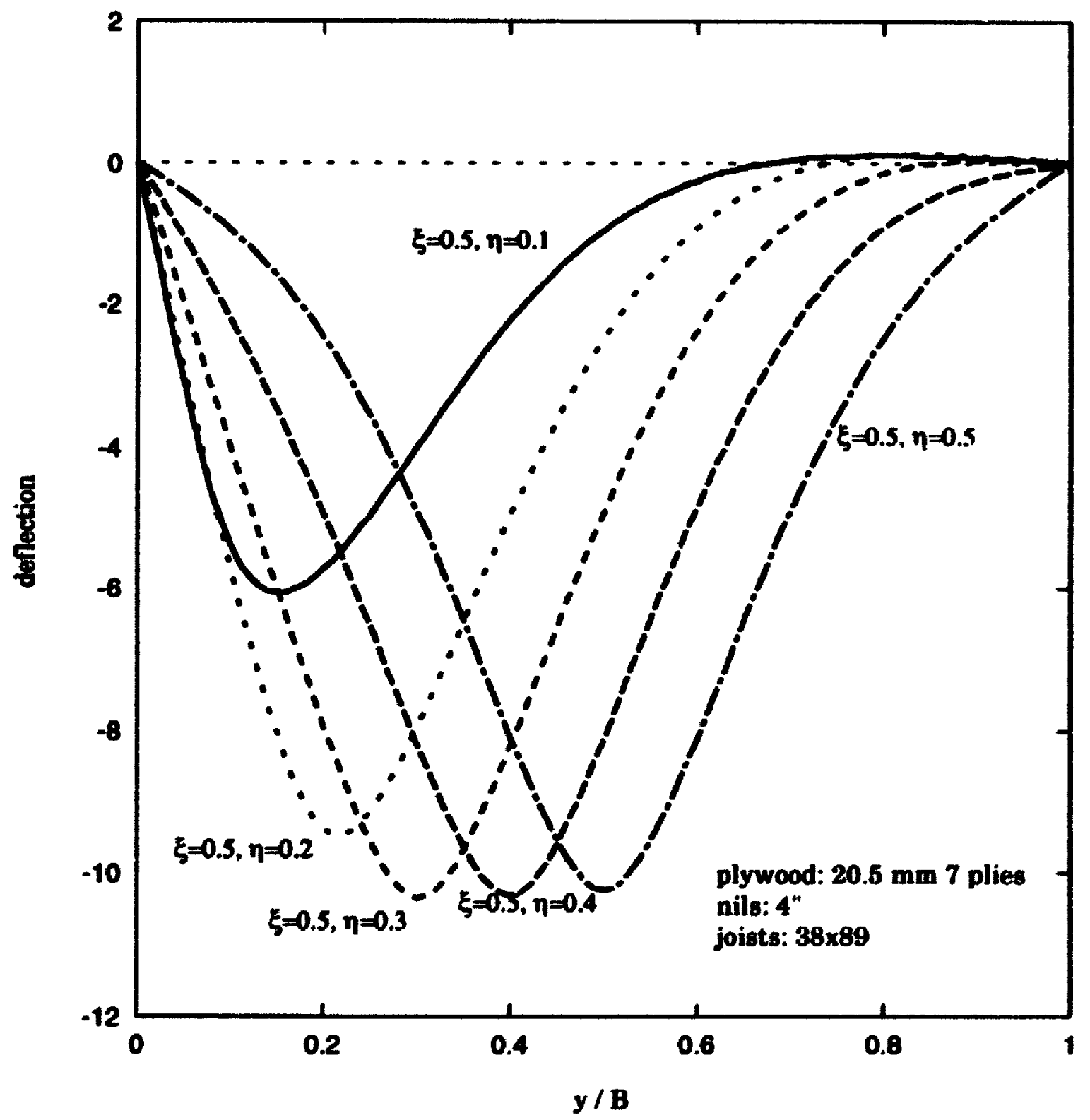

Figure 5.13: Deflections along the width when $P$ acts at mid-span, 38x89, $20.5 \mathrm{~mm}$ 


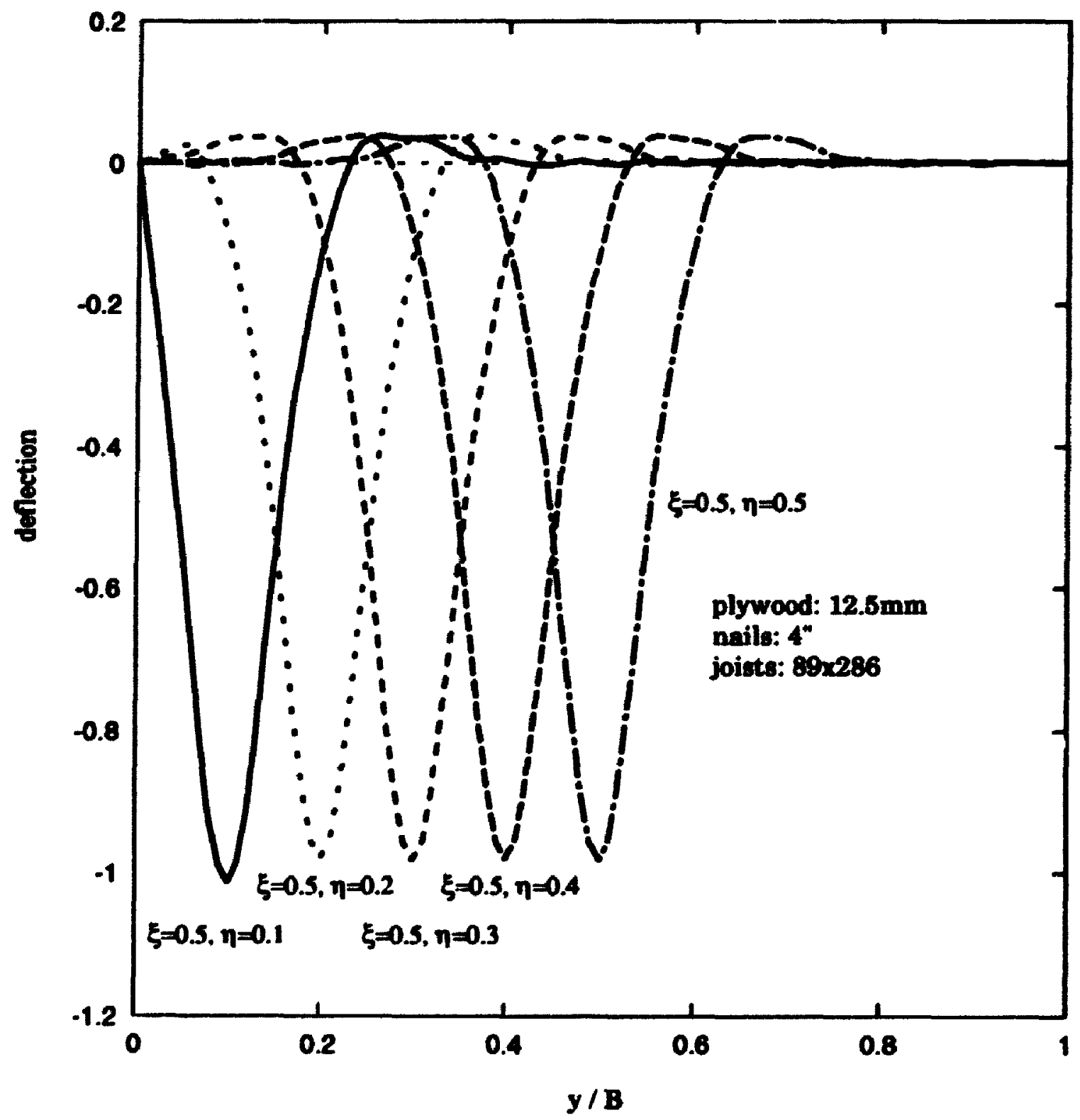

Figure 5.14: Deflections along the width when $P$ acts at mid-span, $89 \times 286,12.5 \mathrm{~mm}$ 


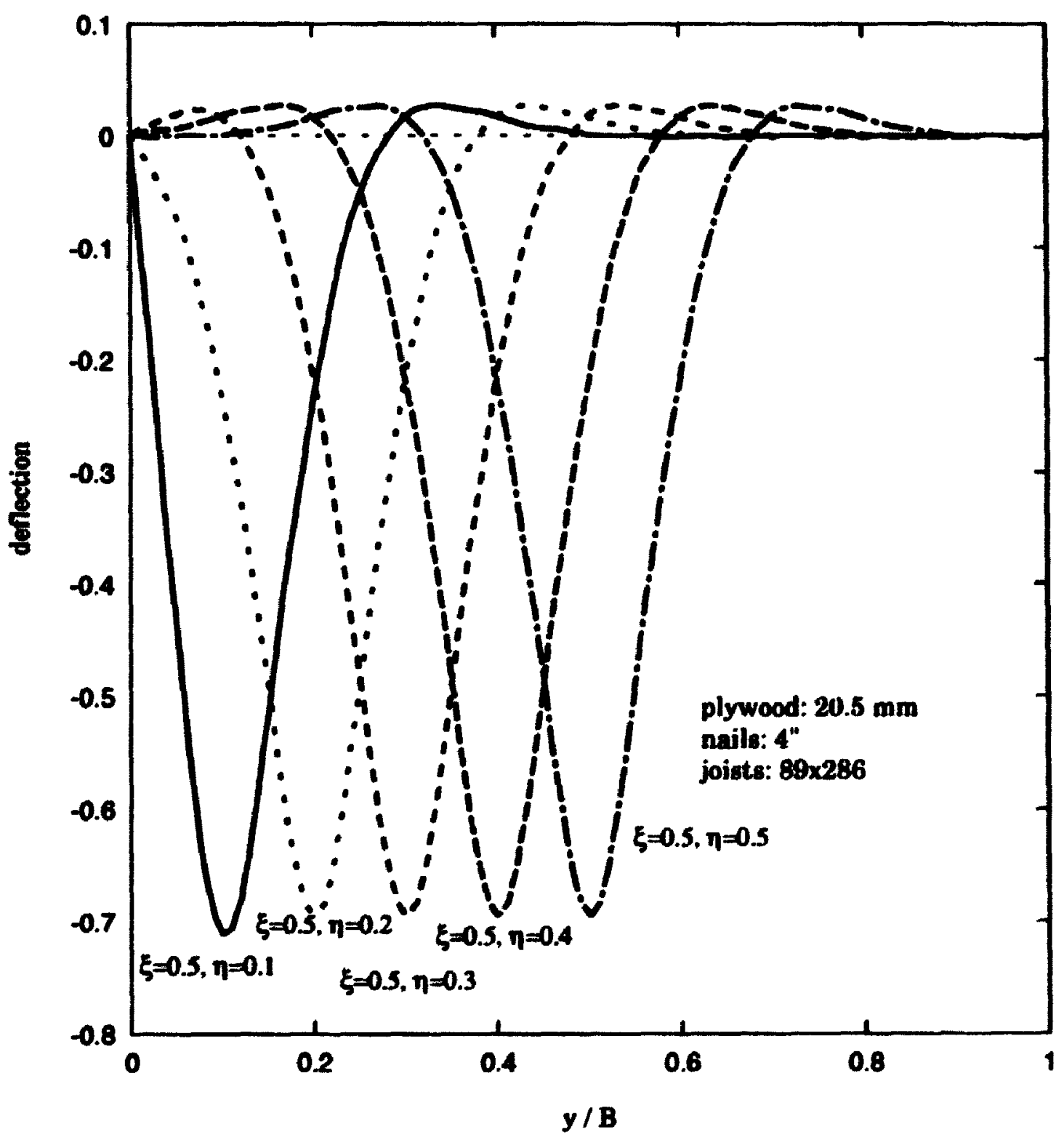

Figure 5.15: Deflections along the width when $P$ acts at mid-span, $89 \times 2 \times 6,20.5$ mm! 


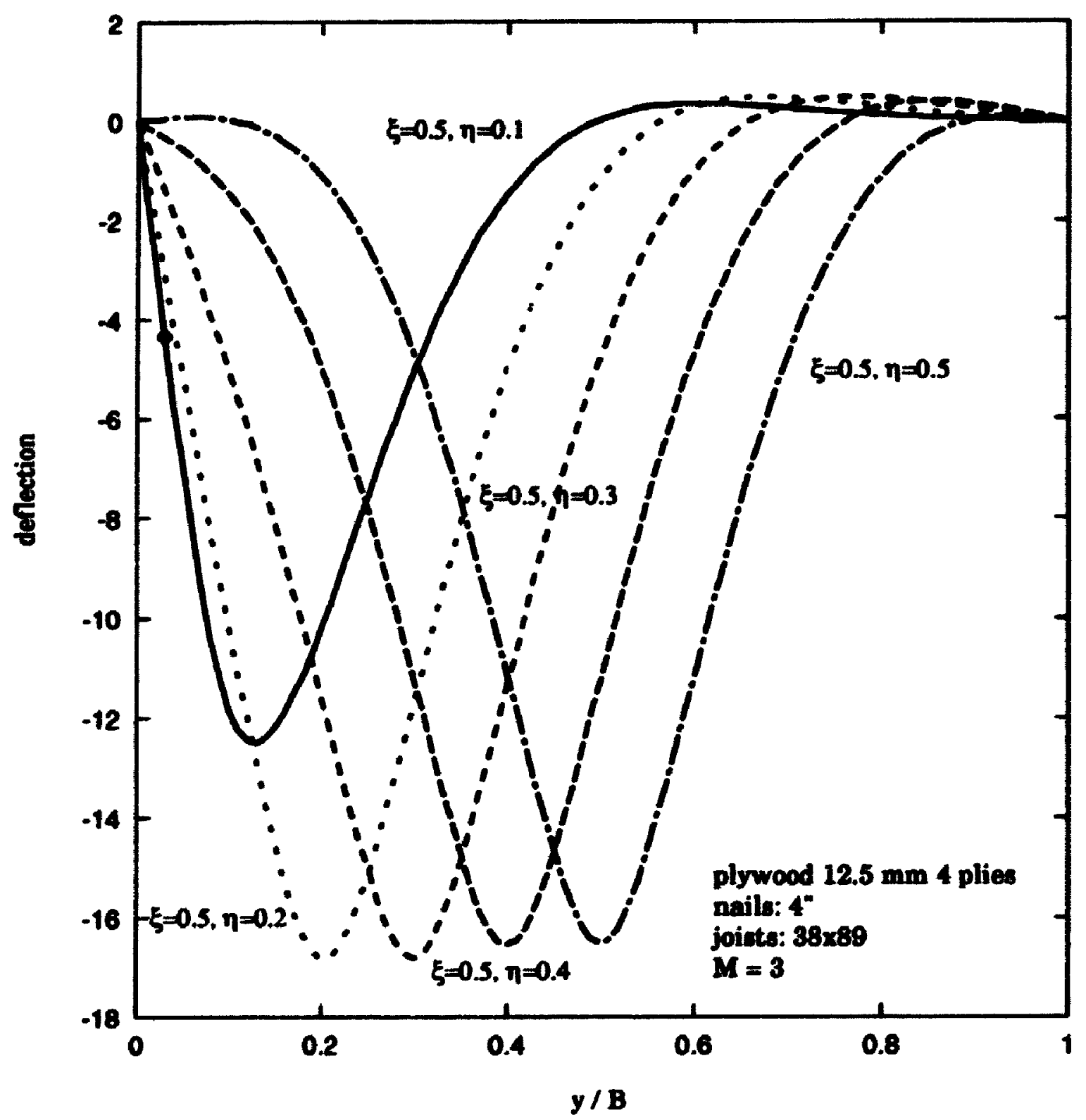

Figure 5.16: Deflections along the width when $P$ acts at mid-span, $38 \times 89,12.5 \mathrm{~mm}$, $\mathbf{M}=\mathbf{3}$ 


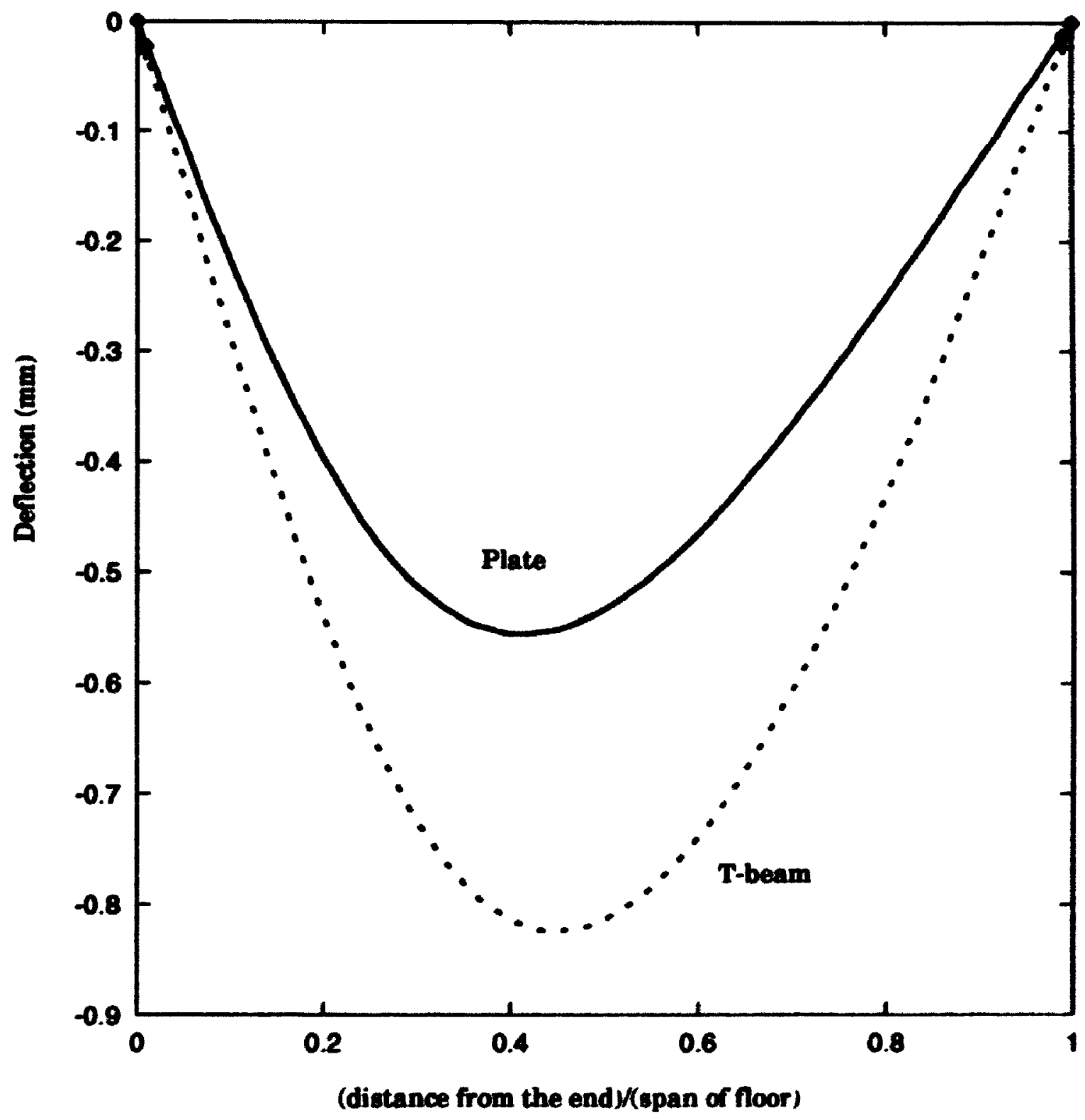

Figure 5.17: Deflections along the span when $P$ acts at $(0.3 \mathrm{~L}$. $0.5 \mathrm{~B})$ 


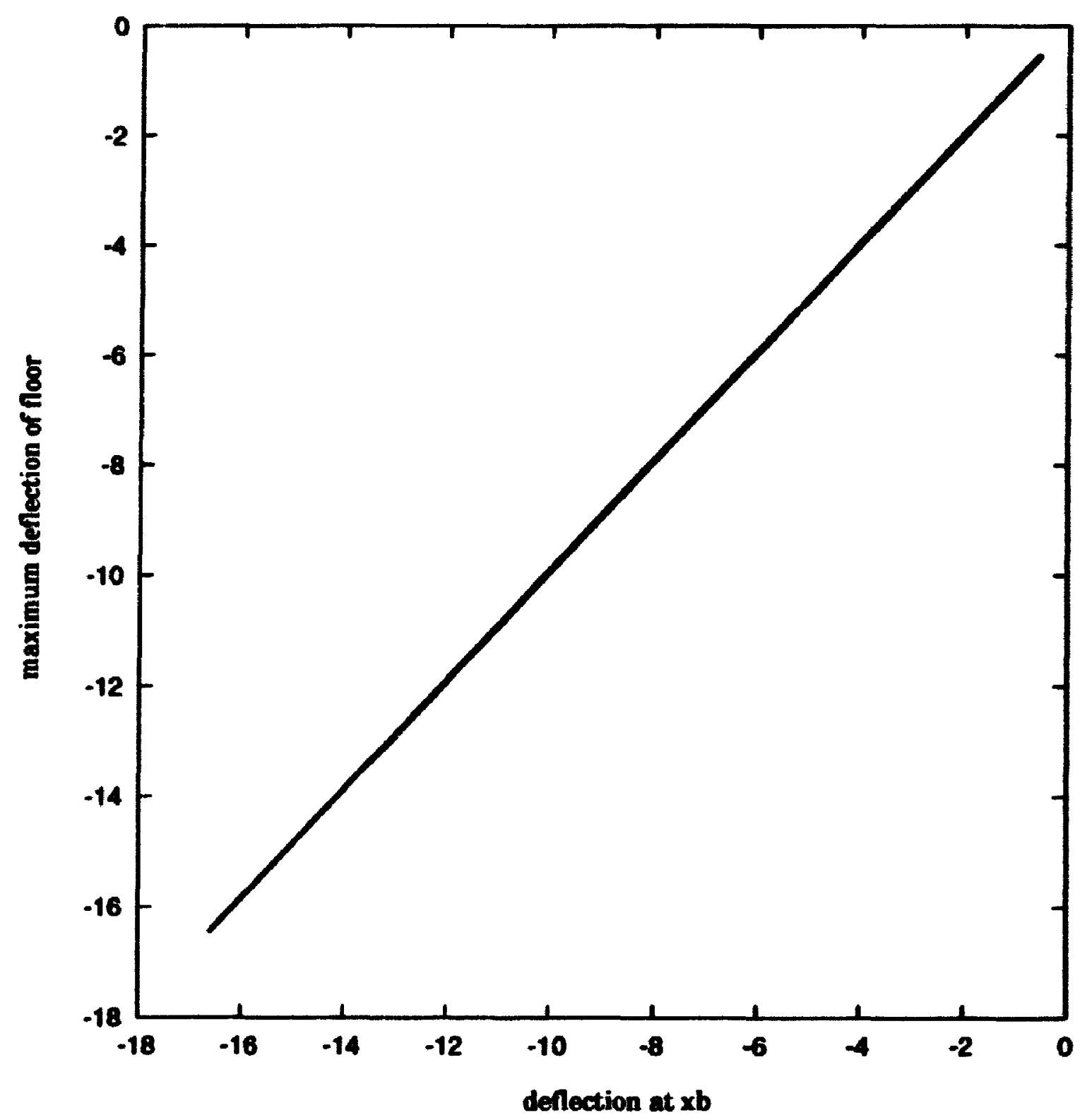

Figure 5.18: Deflections at $\left(x_{b}, \eta B\right)$ and maximum deflection when $P$ acts at $(0.3$ I. 0.5 B). plywood 12.5, 15.u. 18.5, $20.5 \mathrm{~mm}$; joists $38,64,89 \times 89 \rightarrow 284$ 


\section{Chapter 6}

\section{Failure Criteria for Flat Roofs Subject to Ponding}

\subsection{Introduction}

Flat roofs may fail due to ponding of rainwater as evidencenl ly repurts of fail ures of flat ru ofs in rain storms. Ponding load initiates and increases the deflertiun of flat roofs. Increased deflection in turn increases the ponding load. 'This cycle* of deflection-ponding-more deflection- more ponding continu's until the st ructure reaches equilibrium. The roof may stand at equilibrium and the extra water run of the edge. or the roof may experience large deflections before roarling apuilil, rium which could mean collapse. The roofs which can stand the ponding load with enough stiffness are considered stable structures whike those which ran unt stuml the ponding load are called unstable structures as far as ponding is concormed. The question is. what are the criteria that govern this pheriomermu (1,iu al al. IM)2, [42]).

The amplifying effects of the ponding load were studied by Haussler H.W. [333] These studies were motivated by reports of failures caused by instatility in woul. steel and aluminum roofs. In this study, the roof was modeled as a |manil deffested in a sine curve subjected to ponding load which is proportional to the drefler tions of the beam. Kuenzi and Bohannan [39] in 1364 performed 1asts 16 verify the* theory. Significant ponding effects were observed. More investigations isy w'veral 
other authors followed. Salama and Moody [70] extended the study of the poncing -ffects using isot ropir plates theory and by treating the roofs as isotropic plates. They derived the critical stiffness of such a plate. Folz and Foschi [16] studied the structural reliability of lumber joists of roofs that are subjected to ponding loads. Rools were modeled as a beam of sine curve.

However. most rooks arr not ronstructed in a manner that they can be treated as isotropic plates. For example. timber roofs are constructed using plywood. which itself is an orthot ropic material. and supported with joists. The roof structure as a whole has to be trealed as an orthotropic plate. This kind of structure also has its own charactcoristics such as having high bending stiffness in one direction and weak in the other.

In this study. the critotia of the instability of orthotropic plates are derived. The criteria are expressed in terms of dimensions and rigidity of the plates and the density of the ponding liquid.

The results can be used to provide provisions for the dimensions and clear spans of flat roofs. Any flat roof which can be treated as an orthotropic plate such as corrugated steel plates can be analyzed by using the derived results.

\subsection{Governing Equations for Orthotropic Plates}

An orthotropic rertangular plate is considered as shown in Figure 6.1. Small deformation and a linear stress-st rain relationship are assumed.

The governing equation is :

$$
\left(D_{r} \frac{\partial^{4}}{\partial x^{4}}+2 H \frac{\partial^{4}}{\partial x^{2} \partial y^{2}}+D_{y} \frac{\partial^{4}}{\partial y^{4}}\right) w(x, y)=p(x, y)
$$

Where

$$
\begin{gathered}
H=D_{12}+2 D_{k} \\
D_{2}=\frac{t^{3}}{12}\left(\frac{E_{1}}{1-\mu_{1} \mu_{2}}\right)
\end{gathered}
$$




$$
\begin{gathered}
\left.D_{2}=\frac{t^{3}}{12}\left(\frac{E_{2}}{1-\mu_{1} \mu_{2}}\right)=\frac{E_{2}}{E_{1}}\right)_{x} \\
D_{12}=\frac{t^{\prime}}{1 ! !}\left(\frac{E_{1} \mu_{2}}{1-\mu_{1} \mu_{2}}\right)=\left(\frac{t^{3}}{12} \frac{E_{2} \mu_{2}}{1-\mu_{1} \mu_{2}}\right) \\
D_{k}=\frac{t^{3}}{1 \cdot 2} C_{i}
\end{gathered}
$$

w

$\mathbf{p}$

$E_{1} \cdot E_{2}$

$\mu_{1} \cdot \mu_{2}$

C:

$t$ aleflection of the plate (min)

loads $\left(\frac{y}{m m^{2}}\right)$

effertive modulus of elast icity in the $x$. y direetion $\left(\frac{y}{m+m^{\circ}}\right)$

Poisson's ratios

hlicar modulus $\left(\frac{y}{\mathrm{~mm}^{2}}\right)$

plate thickness (min)

\subsection{Ponding of Orthotropic Plate Simply Sup- ported on Four Sides}

Ponding load can be described as $k w$. Then the total load on the str ing is

$$
p(r \cdot y)=q(r \cdot y)+h u(r \cdot y)
$$

where $q$ is the load without ponding, $k$ is water density. $w$ is the devlectiun of the plate.

Ising the classical Navier method and assuming:

$$
\begin{aligned}
& u(x, y)=\sum_{m=1}^{x} \sum_{n=1}^{x} w_{m n} \sin \frac{m \pi x}{L} \sin \frac{n \pi y}{b} \\
& q(x, y)=\sum_{m=1}^{x} \sum_{n=1}^{x} q_{m n} \sin \frac{m \pi x}{l} \sin \frac{n \pi y}{b}
\end{aligned}
$$

where

$$
q_{m \pi}=\frac{1}{L \cdot B} \int_{0}^{L} \int_{0}^{B} q(r \cdot y) \sin \frac{m \pi r}{L} \sin \frac{m \pi y}{B} d r d y
$$


For constant load:

$$
q=q_{0}
$$

The'll

$$
y_{m n}=\frac{1 q_{0}}{m n \pi^{2}}(1-\cos m \pi)(1-\cos n \pi)
$$

From expation 6.1 6.2. 6.3 and 6.4. we get

$$
\begin{aligned}
& \sum_{m=1}^{\infty} \sum_{n=1}^{\infty} u_{m n}\left(D_{m n}-k\right) \sin \frac{m \pi x}{L} \sin \frac{n \pi y}{B} \\
= & \sum_{m=1}^{\infty} \sum_{n=1}^{x} q_{m n} \sin \frac{m \pi x}{L} \sin \frac{n \pi y}{B}
\end{aligned}
$$

where

$$
D_{m n}=\frac{m^{4} \pi^{4}}{L^{4}} D_{x}+2 H \frac{m^{2} n^{2} \pi^{4}}{L^{2} B^{2}}+\frac{n^{4} \pi^{4}}{B^{4}} D_{y}
$$

Since the equation $6 . i$ is true for all $x$ and $y$. therefore

$$
u_{m n}\left(D_{m n}-k\right)=q_{m n}
$$

the':

$$
w_{m n}=\frac{q_{m n}}{D_{m n}-k}
$$

or

$$
u_{m n}=A_{m n} \frac{q_{m n}}{D_{m n}}
$$

where

$$
A_{m n}=\frac{1}{1-\frac{k}{D_{m n}}}
$$

$A_{n, n}$ is called the amplification factor and it is function of the dimension of plate (1..B). the rigidity $\left(D_{x} D_{y} H\right)$, and the density of the liquid or water (k). 
It should be noted that in the Equation 6.11. if $q_{m n}=0$. then $\|_{m n}=0$. This is true because if there is no other external load to develop initial deffertion. ponding will not occur. In other words. un-deformed plate will not hold liquid. Therefore ponding can only exist with initial deflection or co-exist with other external loads.

\subsection{Critical Dimensions to Develop Instability}

Consider the first order of $w_{m n}$ or $u_{11}$.

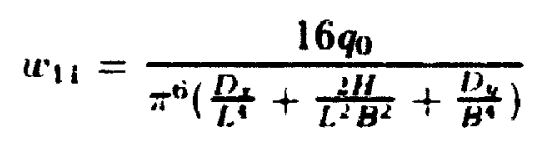

(1) For a square plate. i.e.. $L=B$. so that

$$
\begin{gathered}
\frac{\pi^{4}}{L^{4}}\left(D_{x}+2 H+D_{y}\right)-k=0 \\
A_{11}=\infty, w_{11}=\infty
\end{gathered}
$$

This means that when $L$ approaches a critical dimension the deflection is infinite. In other words. the plate is unstable. The critical dimension is

$$
L=\pi\left(\frac{D_{r}+2 H+D_{v}}{k}\right)^{\frac{1}{4}}
$$

(2) For a rectangular plate with unequal sides, $L \neq B$,

To make $w_{11}=\boldsymbol{x}$. let

$$
\pi^{4}\left(\frac{D_{x}}{L^{4}}+\frac{2 H}{L^{2} B^{2}}+\frac{D_{y}}{B^{4}}\right)-k=0
$$

Now solve for $L$ in terms of $B$, the only real solution is:

$$
\begin{aligned}
& L=f_{11}(B)=B \sqrt{\frac{H+\sqrt{H^{2}-D_{x}\left(D_{y}-\frac{k B^{4}}{x^{4}}\right)}}{-D_{y}+\frac{k B^{4}}{r^{4}}}} \\
& B=B_{11}=\pi\left(\frac{D_{y}}{k}\right)^{\frac{1}{4}}
\end{aligned}
$$


where $B_{11}$ is the critical value of width $B$. It can be seen from equation 6.18 that

$$
\lim _{b \rightarrow x} L=L_{11}=\pi\left(\frac{D_{x}}{k}\right)^{\frac{1}{t}}
$$

Similarly, $L_{11}$ is the critical length as shown in figure 6.2.

Define function $f(I . . B)$ :

$$
f(a, b)=\pi^{4}\left(\frac{D_{x}}{L^{4}}+\frac{2 H}{L^{2} B^{2}}+\frac{D_{y}}{B^{4}}\right)-k
$$

When $f(L, B)>0$. plate is stable: when $f(L, B)<0$, the plate is unstable; while $f(L . B) \rightarrow 0$. deflection approaches infinite.

\subsection{Discussion}

\subsubsection{Stable and unstable regions.}

In Figure 6.2, the region is divided into two sub-regions by the curve $L=f_{11}(B)$. equation 6.18 .

Any point (L.B) represents the dimensions of a plate of width $B$ and length $L$. If a point (L,B) falls within the stable region. such a plate will not deflect infinitely, as shown in Figure 6.5 and 6.6. If a point falls in the unstable region. the deflection of such a plate could be infinite. In other words, the plate may collapse suddenly, as shown in Figure 6.6 and 6.7. Figure 6.5. 6.6 and 6.7 will be discussed in detail in later examples.

\subsubsection{Higher order approximation of roof deflection, $w$}

The discussions so far are concerned with the first order of $w$, or $w_{11}$. What is the effect of higher order terms. How many terms should one choose for a practical and accurate approximation? From equation 6.6 we find that $q_{m n}=0$ when $m$ or $n$ is an even number. Therefore the second non-zero term of $w$ is $w_{13}$ and $w_{31}$ followed by $u_{33}$.

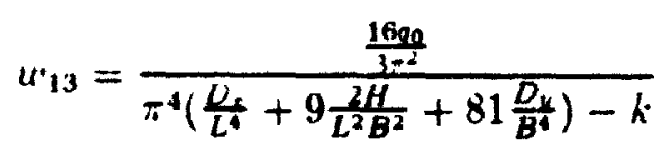


By comparing $w_{13} \cdot w_{11} \cdot u_{13}$ with $w_{11}$, it can be seen that $w_{13}$. $w_{31}$ are not negli gible while $u_{33}$ can be neglected. For instance, when $k=0$. $\frac{1 w}{w_{n}}=\frac{1}{32}=0.0013 \pi$.

$$
\begin{aligned}
& u_{* 1}=\frac{\frac{16 q_{0}}{L^{2}}}{\pi^{4}\left(81 \frac{D_{4}}{L^{4}}+9 \frac{2 H}{L^{2} B^{2}}+\frac{D_{4}}{B^{4}}\right)-k} \\
& u_{* 3}=\frac{\frac{16 q 0}{9^{2}}}{s 1 \pi^{4}\left(\frac{D_{4}}{L^{4}}+\frac{2 H}{L^{2} B^{2}}+\frac{D_{y}}{B^{4}}\right)-k}
\end{aligned}
$$

To study the stable and unstable regions for $w_{13}, u^{\prime} 3$ and $w^{\prime}, w_{3}$. follow the same procedure used for $w_{11}$. The conclusions are shown in Figure 6.3 .

The critical curves

for $u_{31}$ is

$$
\begin{aligned}
& L=f_{31}(B)=3 \int_{11}(B) \\
& L_{31}=3 L_{11}
\end{aligned}
$$

for $w_{13}$ is

$$
\begin{aligned}
L & =f_{13}(B)=\frac{B}{3} \sqrt{\frac{H+\sqrt{H^{2}-D_{x}\left(D_{y}-\frac{k b^{4}}{81 x^{4}}\right)}}{-D_{y}+\frac{k b^{4}}{B 1 x^{4}}}} \\
B_{13} & =3 B_{11}
\end{aligned}
$$

for $w_{33}$ is

$$
\begin{aligned}
L & =f_{33}(B)=3 B \sqrt{\frac{H+\sqrt{H^{2}-D_{x}\left(D_{y}-\frac{k H^{3}}{K 1 \pi^{4}}\right)}}{-D_{y}+\frac{k B^{4}}{81 \pi^{4}}}} \\
L_{33} & =L_{31}=3 L_{11} \\
B_{33} & =B_{13}=3 B_{11}
\end{aligned}
$$

It is proved that the stable region of $u_{11}$ is within the stable region of higher order terms. Therefore the criterion of stability of $w_{11}$ governs. In other words. as long as the width $B$ and length $L$ of a plate are smaller than the critical dimensions $B_{11}$ and $L_{11}$ respectively by a finite amount, the deflection of the plate will be finite. 


\subsection{Practical Applications}

Consider a flat roof ronsisting of plywood sheathing of thickness $t$. width $B$ and length $\mathrm{L}$. and $\mathrm{X}$ joists of size $\mathrm{b} x \mathrm{~d}$. as shown in Figure 6.4. Issume that the sheathing and joists are rigidly attached to each other. i.e. no slippage between the'm.

This roof system "an be analyzed as an orthotropic plate. It can be reasonably assumed that the bending stiffuess along the $y$ direction. $D_{y}$, is the bending stiffness of the plywood sheathing. The Iwisting stiffness $\mathrm{H}$ is also the twisting stiffness of plywood. The bending stiffuess along the $\mathrm{x}$ direction can be calculated as following:

Take a T-beam rection as shown in Figure 6.4.

where

$$
\begin{array}{ll}
S & \text { sparing of joists } \\
1 & \text { thickness of plywood }
\end{array}
$$

Then the bending stiffness of this cross-section is

$$
D_{x}=B_{b}+B_{a}\left(d+\frac{t}{2}-y_{0}\right)^{2}+\frac{E_{b} b d^{3}}{12 S}+\frac{E_{b} b d}{S}\left(\frac{d}{2}-y_{0}\right)^{2}
$$

where

$$
\begin{aligned}
& \text { Bb bending stiffness of plywood }(\mathrm{N} \mathrm{mm}) \\
& \mathrm{Ba} \text { axial stiffness of plywood }(\mathrm{N} / \mathrm{mm}) \\
& \mathrm{Eb} \text { modulus of elasticity of joists }\left(\mathrm{N} / \mathrm{mm}^{2}\right) \\
& y_{0} \text { distance between the bottom of joist and the neutral } \\
& \text { axis of the T-beam } \\
& y_{0}=\frac{B_{a} S\left(\frac{1}{2}+d\right)+E_{b} b d \frac{d}{2}}{B_{3} S+E_{b} b d}
\end{aligned}
$$

The boundary conditions are assumed to be simply supported on four sides. It $y=0$. $\mathrm{h}$. the sheathing is attached to a joist. Rotation about the $\mathrm{x}$ axis is usually not restrained. At $x=0$, L. joists are the dominant members. They are 
simply supported. The assumption of a simply supported boundary condition is reasonable.

Example:

$$
\begin{aligned}
& \therefore \quad=12 \text { joist } \mathrm{s} \\
& \text { L } \quad=3657.6(\mathrm{~mm}) \\
& \text { B } \quad=3657.6(\mathrm{~mm}) \\
& \text { b } \quad=38(\mathrm{~mm}) \\
& \text { d } \quad=184(\mathrm{~mm}) \\
& \text { Eb } \quad=11000\left(\frac{v}{m m^{2}}\right) \\
& \mathrm{S}=106.4(\mathrm{~mm}) \\
& \mathrm{t}=1.5 .5(\mathrm{~mm}) \\
& \mathrm{Ba}=7.5000\left(\frac{\hat{\nu}}{\mathrm{mm}}\right) \\
& \mathrm{Bb} \quad=630000(N \mathrm{~mm}) \\
& \text { Dy } \quad=3000000(\mathrm{Nmm}) \\
& \text { H } \quad=3000000(\mathrm{~N} \mathrm{~mm}) \\
& \mathrm{k} \quad=9.81 \times 10^{-6}\left(\frac{\mathrm{N}}{\mathrm{mm}^{3}}\right) \\
& q_{0} \quad=1.9\left(\mathrm{kPa}, 40 \mathrm{lb} f / f t^{2}\right)
\end{aligned}
$$

\section{(1) Stable Region}

For such a structure. Figure 6.5 shows the deflection vs width $B$ of the plate when $L$ is in the stable region. It can be seen that the deflection stabilizad aftur it reaches finite value with the increase of width B. One of the dimensions. I, in this case, controls. It is also shown that ponding effect is not dramatir.

This situation is represented by line $L=5601$ in Figure 6.6 which shows that since value of $\mathrm{L}$ is below $L_{11}$ the line stays in the stable region.

(2) Unstable Region

In Figure 6.7, on the other hand. $B$ is larger than $B_{11}$. In this case. when $I$ approaches the critical value $L_{11}$, deflection approaches infinity. Ponding effert is dramatic.

This situation car. be represented by hline 2 in Figure 6.6. Since $B$ is larger than $B_{11}, L$ is limited by the curve $L=f_{11}(B)$ which is the boundary between stable and 
Table 6.1: Efferts of sheathing thickness on floor deflection.

\begin{tabular}{|c|c|c|c|c|c|c|c|c||}
\hline \hline & Ba & Bb & $11 \times 1000$ & Dy $\times 1000$ & Dx $10^{6}$ & $z_{0}$ & $u_{0}$ & w ponding \\
\hline 7.5 & 47 & 300 & 3.4 & 17 & 984 & 109 & 7.08 & 7.33 \\
\hline 9.5 & 47 & 570 & 6.6 & 33 & 992 & 109 & 7.03 & 7.28 \\
\hline 12.5 & 59 & 1300 & 38 & 190 & 1080 & 113 & 6.49 & 6.71 \\
\hline 15.5 & 75 & 2500 & 86 & 430 & 1190 & 117 & 5.94 & 6.12 \\
\hline 18.5 & 95 & 3400 & 260 & 1300 & 1310 & 122 & 5.49 & 5.64 \\
\hline 20.5 & 100 & 1300 & 520 & 2600 & 1350 & 124 & 5.18 & 5.63 \\
\hline \hline
\end{tabular}

unstable region.

(3) Influence of plywood thickness Figure 6.8 shows the influence of the thickness of plywood. Deflection derreases hlinearly as thickness of plywood sheathing increases. This shows that the composite action of plywood is not negligible. However, The ponding effect remains the same for different thickness evidenced by the almost constant difference between the two curves.

(4) Influence of joist spacing

Figure 6.9 shows the effects of joist spacing. It is drawn by placing different number of joists under the sheathing. The data is concluded in Table 6.2. It can be seen that the deflection increases almost hlinearly when spacing increases. There is a slight increase in the effect of ponding with the increase of spacing.

(5) Implications in timber code:

The limit state design equation for the ultimate strength of timber can be expressed in the following format:

$$
1.25 E\left(D_{n}\right)+1.50 E\left(Q_{n}\right)=\Phi R_{0.05}
$$

where

$$
\begin{array}{ll}
E\left(D_{n}\right), E\left(Q_{n}\right) & \text { design dead and live load effects } \\
\Phi & \text { performance factor } \\
R_{0.05} & \text { characteristic strength }
\end{array}
$$


Table 6.2: Effects of joist sparing on flour deflertion

\begin{tabular}{|c|c|c|c|c|c|}
\hline No of joists & spacing & $\therefore$ & $D_{r} 10^{6}$ & $w_{0}$ & $w$ \\
\hline 1 & 2133 & 172 & 107 & 18.6 & 20.39 \\
\hline 2 & 1423 & 16.5 &.$j 68$ & 13.1 & 13.92 \\
\hline 3 & 1068 & 150 & ;2!2 & 10.3 & 10.81 \\
\hline$t$ & 854 & 154 & 842 & 8.65 & 9.02 \\
\hline 5 & 712 & 150 & 962 & 7.54 & 7.82 \\
\hline 6 & 610 & 146 & 1070 & 6.14 & 6.95 \\
\hline$i$ & 534 & 113 & 1180 & 6.13 & 6.31 \\
\hline 8 & 174 & 140 & 1270 & 5.65 & 5.80 \\
\hline 9 & $12 T$ & 137 & 1370 & 5.25 & 5.39 \\
\hline 10 & 388 & 135 & 1150 & 4.93 & .05 \\
\hline 11 & 356 & 133 & 1540 & 4.65 & 4.76 \\
\hline 12 & 329 & 131 & 1620 & 4.41 & 4.50 \\
\hline 13 & 305 & 129 & 1700 & 1.20 & 4.29 \\
\hline 14 & 28.5 & 127 & 1780 & 4.01 & 4.09 \\
\hline
\end{tabular}


Table 6.3: Maximum width for different plywood thickness

\begin{tabular}{|c|c|c|c|c||}
\hline plywood thickness. 1. mm & 12.5 & 15.5 & 18.5 & 20.5 \\
\hline Maximum widh $B_{11}$ of a st able roof. $\mathrm{mm}$ & 2027 & 2462 & 2600 & 2801 \\
\hline
\end{tabular}

The amplification factor $A_{m n}$ will appear in the above equation. For ponding stable structures. a different performance factor has to be calibrated using reliability antysis account ing for the variability of the material properties.

\subsection{Critical Dimensions That Define Stable and Unstable Roofs}

Table 6.3 shows the maximum width a roof can have for a given plywood thickness without incurring ponding instability. i.e. the critical width $B_{11}$. In Table 6.4, 6.i. 6.6 and 6.7. the upper and lower bound of the maximum length and width a roof can have without incurring ponding instability are listed. The upper bound corresponding to a loose roof in which the plywood sheathing is not connected to the joists by either nail or glued. The lower bound. on the other hand. corresponds to the gitued roofs with plywood glued to the joists. It can be seen from the tables that the upper and lower bounds are close .

\subsection{Comparison with Other Research}

It has been proposed that the following amplifying factor be used in timber design code to design for ponding (B. Folz. R. Foschi. 1990. [16]) :

$$
A_{p}=\frac{1}{1-\frac{k S L^{4}}{E I \pi^{4}}}
$$

This formula is derived by simplifying the roof as a $T$-beam and assume that the T-beatu deflects into a sine curve. The critical length of the roof is therefore 
Table 6.4: Maximum length for different joists. plywood thickuess: $12.5 \mathrm{~mm}$

\begin{tabular}{|c|c|c|c|}
\hline joist width, b & height. d & Max. length.lower bound & upper loound \\
\hline 38 & 89 & 49.53 & 58.51 \\
\hline 38 & 114 & 5961 & (ixiti \\
\hline 38 & 140 & 69.53 & i \\
\hline 38 & 184 & 85.34 & 9381 \\
\hline 38 & 235 & 10252 & 1107. \\
\hline 38 & 286 & 11879 & 12678 \\
\hline 64 & 114 & 6730 & 7.488 \\
\hline 64 & 140 & 7920 & 8592 \\
\hline 64 & 184 & $972 \mathrm{i}$ & 103599 \\
\hline 64 & 235 & 11679 & $12: 285$ \\
\hline 64 & 286 & 135.32 & 11111 \\
\hline 89 & 114 & 7373 & 79.58 \\
\hline 89 & 140 & 8601 & 9158 \\
\hline 89 & 184 & 105.57 & 11079 \\
\hline 89 & 235 & 12682 & 1317: \\
\hline 89 & 286 & 14695 & 15164 \\
\hline
\end{tabular}


Table 6.5: Maximum length for different joists. plywood thickness: $13.5 \mathrm{~mm}$

\begin{tabular}{|c|c|c|c||}
\hline joist width. $b$ & hright. $d$ & Max. length.lower bound & upper bound \\
\hline 38 & 89 & 4958 & 5980 \\
\hline 38 & 111 & 7964 & 6973 \\
\hline 38 & 110 & 6955 & 7952 \\
\hline 38 & 184 & 8535 & 9506 \\
\hline 38 & 235 & 10253 & 11196 \\
\hline 38 & 286 & 11879 & 12798 \\
\hline 64 & 114 & 6792 & 7603 \\
\hline 64 & 140 & 7921 & 8703 \\
\hline 64 & 184 & 9722 & 10463 \\
\hline 64 & 235 & 11679 & 12384 \\
\hline 64 & 286 & 13533 & 14208 \\
\hline 89 & 114 & 7374 & 8061 \\
\hline 89 & 140 & 8602 & 9255 \\
\hline 89 & 184 & 105.57 & 11168 \\
\hline 89 & 235 & 12683 & 13258 \\
\hline 89 & 286 & 14695 & 15243 \\
\hline \hline
\end{tabular}


Table 6.6: Maximum length for different joists. plywood thickne'ss: IS.j mun

\begin{tabular}{|c|c|c|c|}
\hline joist width. $b$ & height. d & Max. length.Jower bound & upper hound \\
\hline 38 & 39 & 1976 & 5411 \\
\hline 38 & 111 & 5974 & $6 \times 81$ \\
\hline 38 & 110 & 6961 & 7846 \\
\hline 38 & 184 & 8538 & 9387 \\
\hline 38 & 235 & 10255 & 110.5 \\
\hline 38 & 286 & 11881 & 12661 \\
\hline 64 & 114 & 6799 & 7515 \\
\hline 64 & 140 & 7926 & 8607 \\
\hline 64 & 184 & 9724 & 10361 \\
\hline 64 & 235 & 11681 & 12279 \\
\hline 64 & 286 & 13533 & 14102 \\
\hline 89 & 114 & 7380 & 7981 \\
\hline 89 & 140 & 8605 & 9170 \\
\hline 89 & 184 & 10559 & 11080 \\
\hline 89 & 235 & 12684 & 13169 \\
\hline 89 & 286 & 14696 & 15154 \\
\hline
\end{tabular}


Table 6.7: Maximum length for different joists. plywood thickness: $20.5 \mathrm{~mm}$

\begin{tabular}{|c|c|c|c|}
\hline joist. width. $b$ & hright. $d$ & Max. length.lower bound & upper bound \\
\hline 38 & 89 & 4990 & 6098 \\
\hline 38 & 114 & 5982 & 707 \\
\hline 38 & 140 & 6966 & 8041 \\
\hline 38 & 184 & 8541 & 9583 \\
\hline 38 & 235 & 10256 & 11264 \\
\hline 38 & 286 & 11882 & 12859 \\
\hline 64 & 114 & 6804 & 7691 \\
\hline 64 & 140 & 7929 & 8779 \\
\hline 64 & 184 & 9726 & 10526 \\
\hline 64 & 235 & 11682 & 12438 \\
\hline 64 & 286 & 13534 & 14256 \\
\hline 89 & 114 & 7344 & 8139 \\
\hline 89 & 140 & 8608 & 9321 \\
\hline 89 & 184 & 10560 & 11222 \\
\hline 89 & 235 & 12685 & 13303 \\
\hline 89 & 286 & 14697 & 15283 \\
\hline \hline
\end{tabular}




$$
L=\pi\left(\frac{E I}{R \cdot S}\right)^{\frac{1}{4}}
$$

Since $D_{x}=E I / S$. the above critical equation is identical to $L_{11}$.

By examining Figure 6.2 and 6.6. it can be seen that $L_{11}$ is the asymptote of $L$. :$f_{11}(B)$ when $B$ approaches infinity. It is true that for a very wide ruf. the $I$ beam formula can be used with sufficint accurary since Imundary anditions in the transverse direction is negligible. For a roof with regular size. i.e. the width is close the the span. there will be a difference betwern the critical dimunsions clerived from orthotropic plate theory and simplified $T$-beam of sinc curve. However, the asymptote and. hence. the result from simplified T.lxanl therry all In Inwel In define the critical dimension on a conservative side. Thus defined critical dimusium will be simpler than using the act ual critical dimension defined by curve* $t=f_{\perp 1}(B)$.

The other point to be made is that for a wood joist roof. the critical width is much smaller than the critical span as can be seen in Table 6.3 and (i.j). Thereforr. the governing dimension ior a wood joist roof is the span. If the critical span is exceeded, the roof is ponding unstable since the critical width is usually smaller than the actual width of roofs. Therefore. equation 6.12 call be used lo deline the critical span of wood joist roofs. This coincides with the result of simplifienl leasu theory.

\subsection{Conclusions}

The findings and implications of this study can be summarizerl as follows:

1. An amplification factor which describes the ponding efferts is derivied. It is a function of bending rigidity, dimensions of orthot ropic plates and the density of water.

2. Critical dimensions $L_{11}$ and $B_{11}$ governing the stability of structures suljectrod to ponding load are derived. The $L_{11}, B_{11}$ are the maximum width and longth of a stable ort hot ropic plate subjected to ponding respertivels. $A$, kng as ance of the dimensions is kept smalker than its maximum. the structure will uot 
deflect infinitely: Ponding effect is not dramatic. However. keeping $L<L_{11}$ or $B<B_{11}$ does not guarantee that it will not develop large deflection due to normal load. 1 limit of the dimensions has to be furt her est ablished to rest rict the bending stresses from exceeding the strength of the material.

3. Results can be used to calibrate the formulation in the timber code to account for the ponding effects.

1. The procedure developed in this study can be used to analyze floor and roof systems. esperially in timber structures. The effects of connections between the plywood shoathing and joists can be found by incorporating the effective rigidity of the T-beam. as described in previous chapters. into the formula.

It should be pointed out that the criterion derived are within the range of small deflection. Roofs may yield large deflection before failure. The behaviour of roofs with large deflection has to be examined using the theory of nonlinear orthotropir plate theory which is beyond the scope of this thesis. 

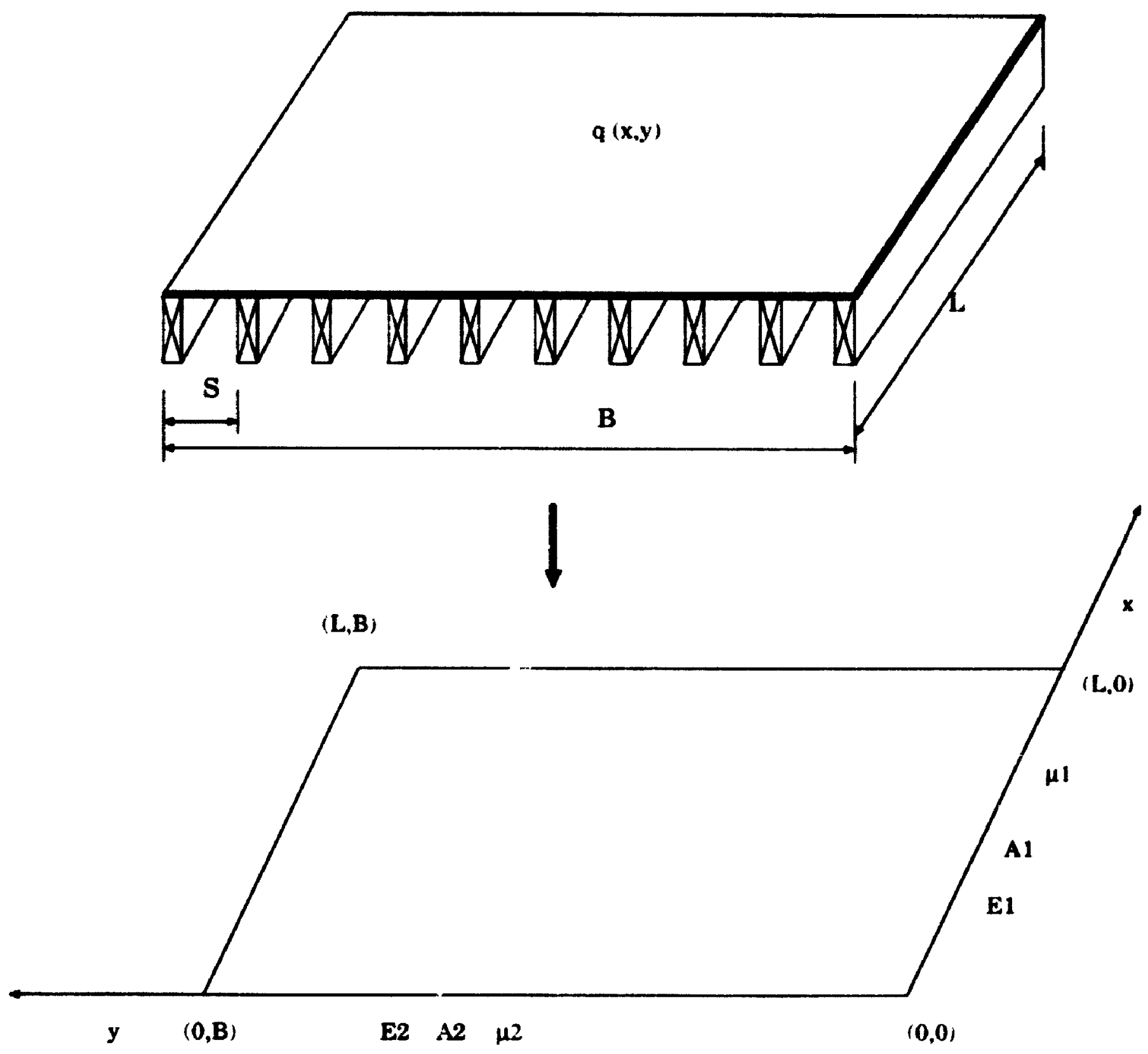

Figure 6.1: An orthot ropic plats 


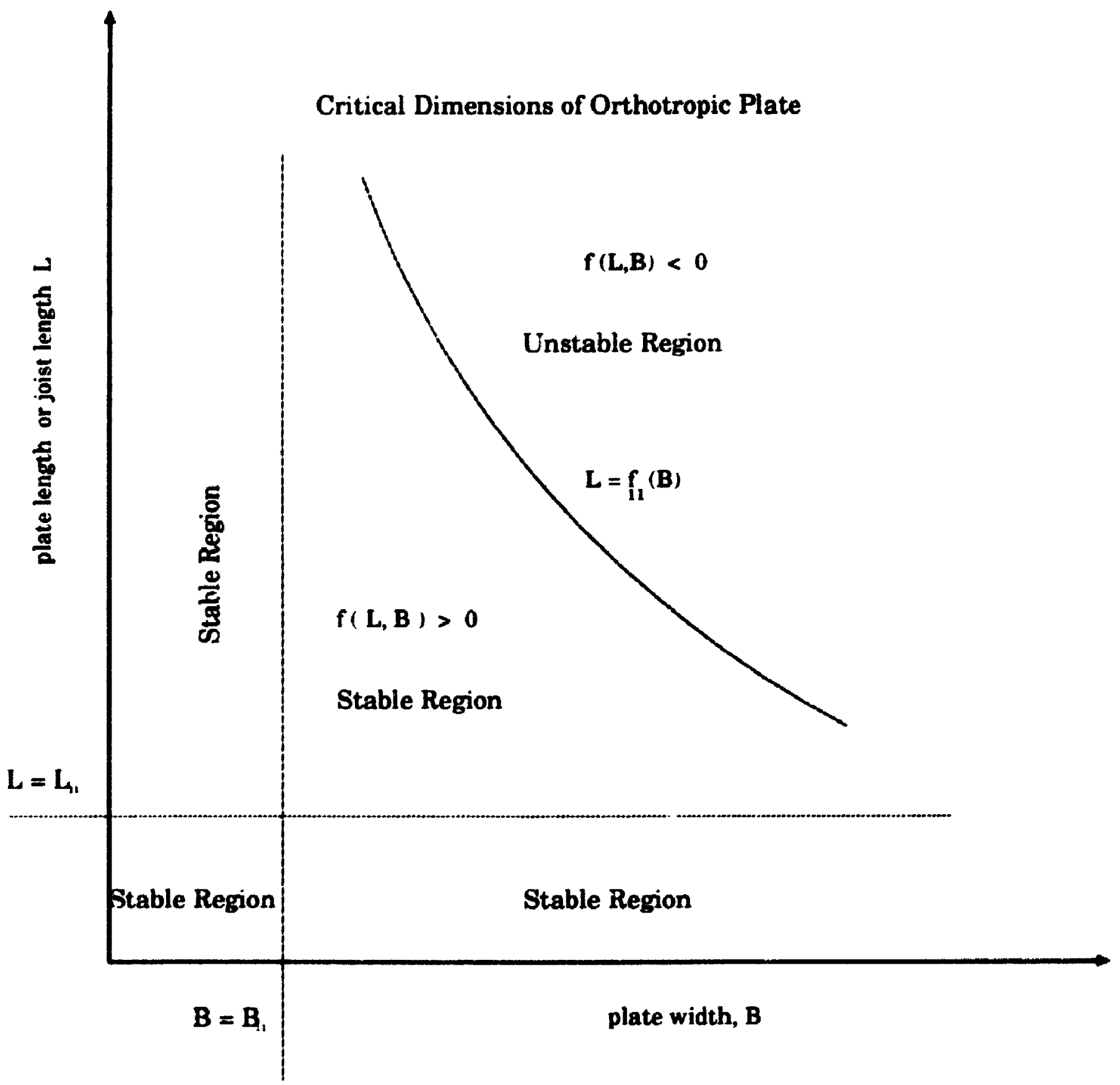

Figure 6.2: Critical dimensions of roofs subject to ponding 


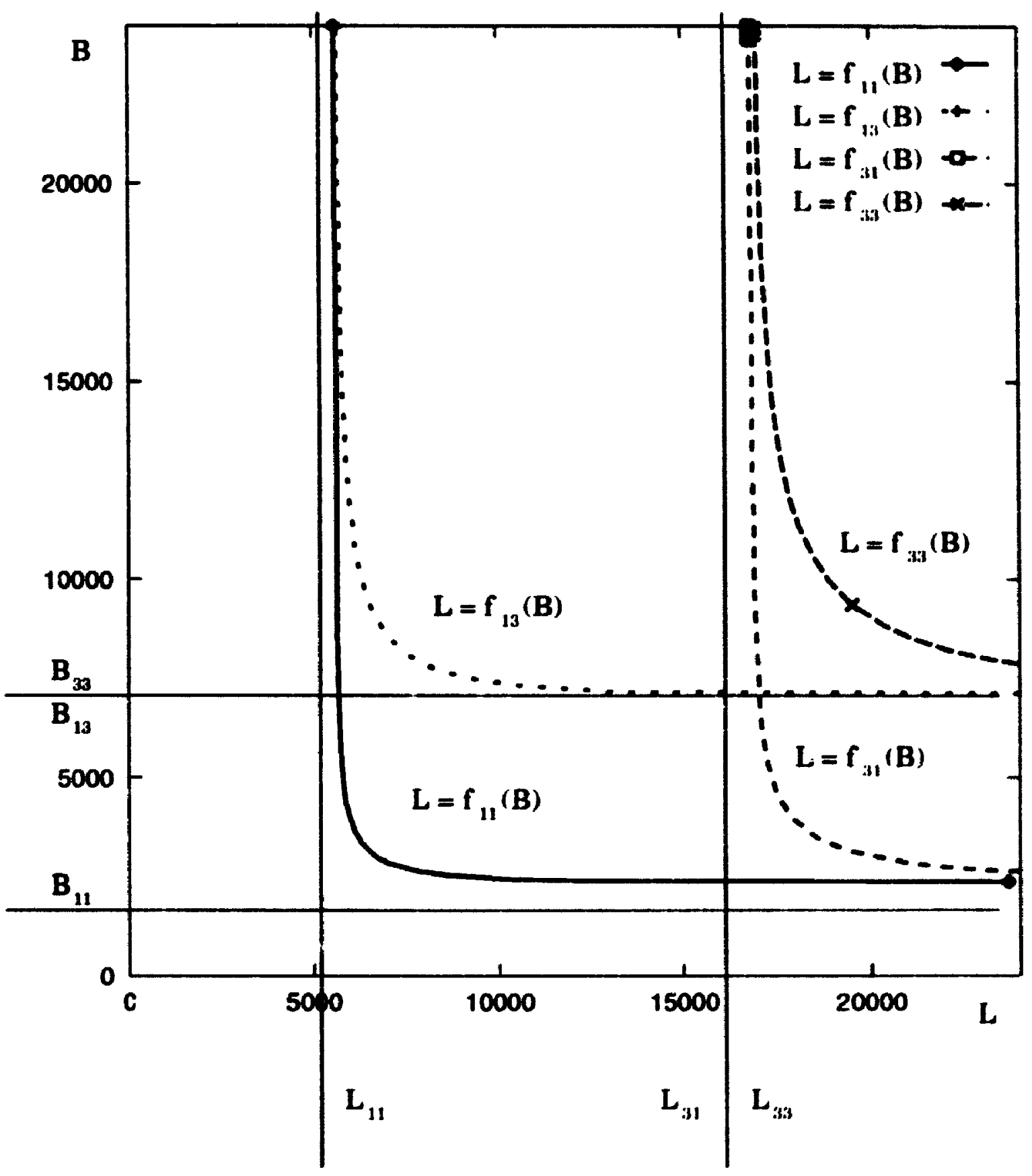

Figure 6.3: Higher order critical dimensions 

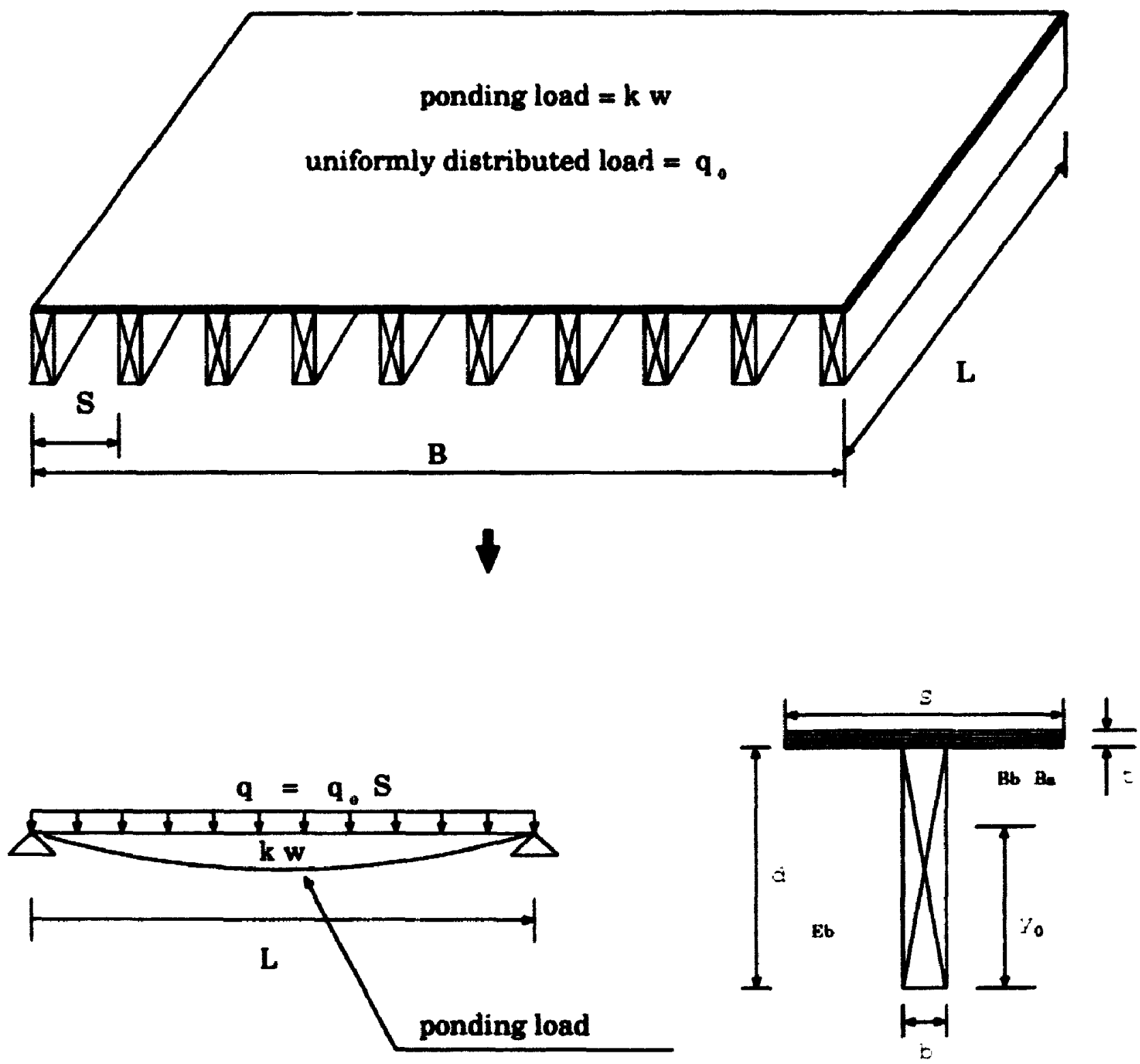

Figure 6.4: Plywood sneathed roofs subject to ponding load 


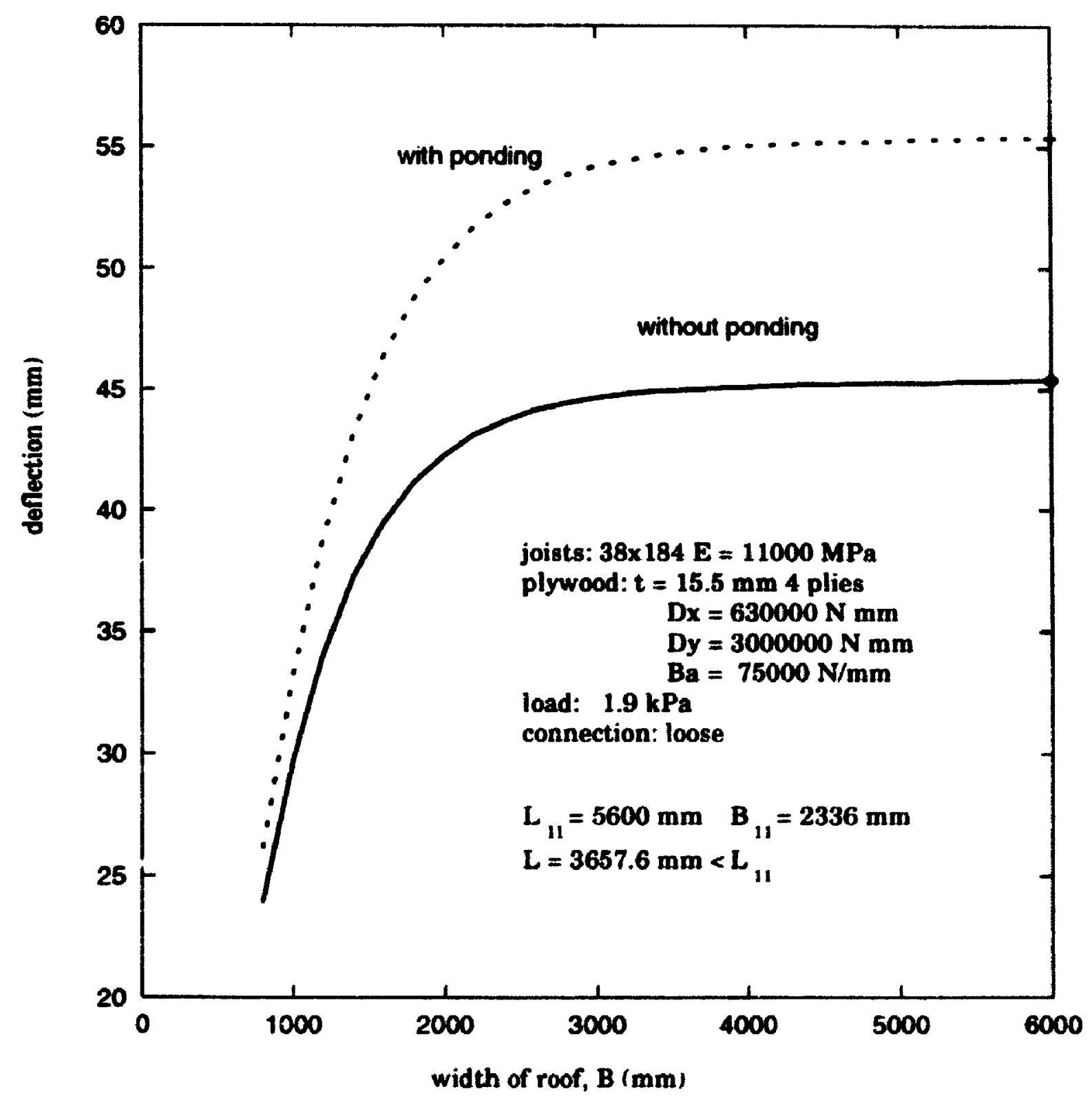

Figure 6.5: Deflection in a stable region 


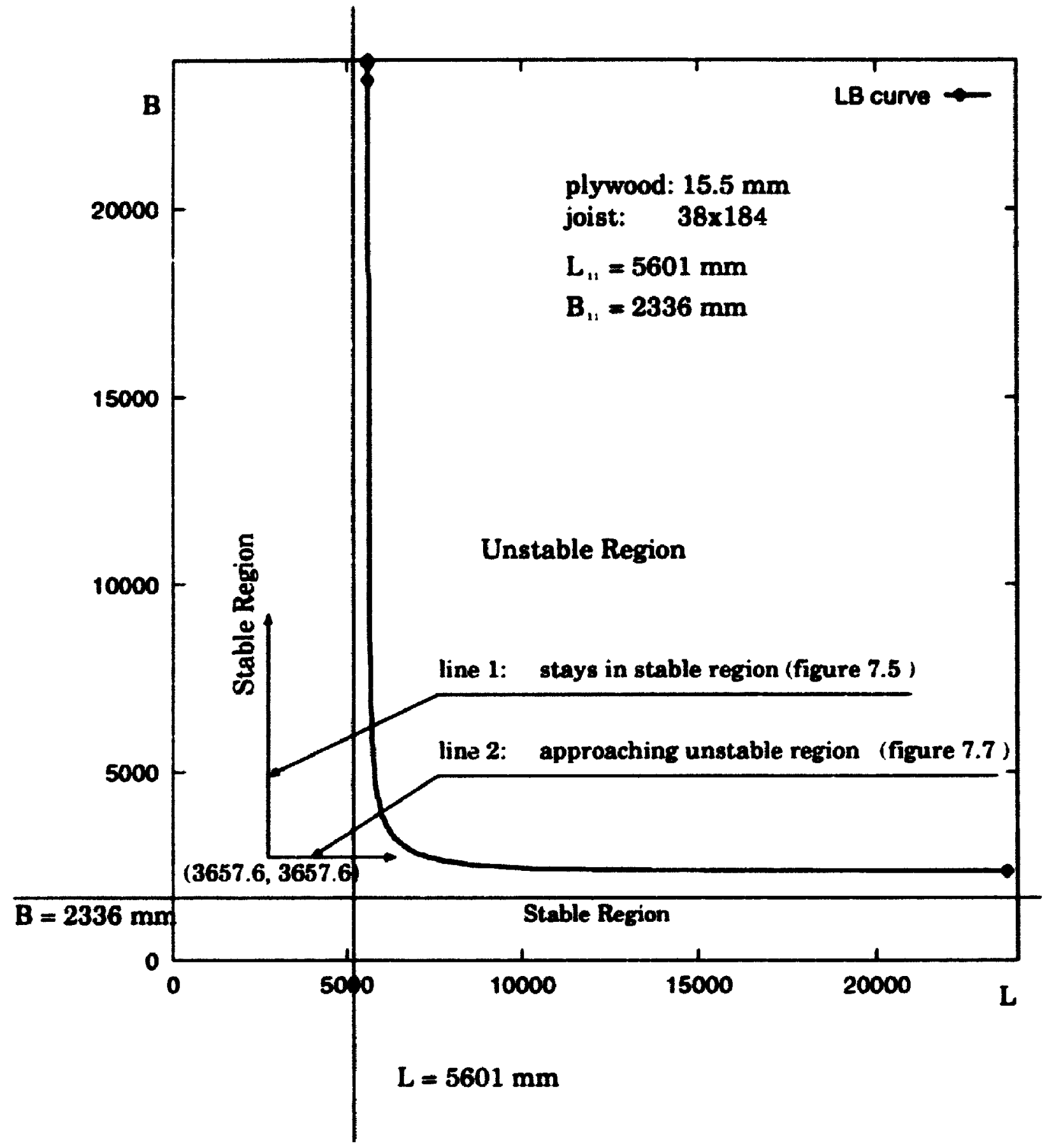

Figure 6.6: Regions 


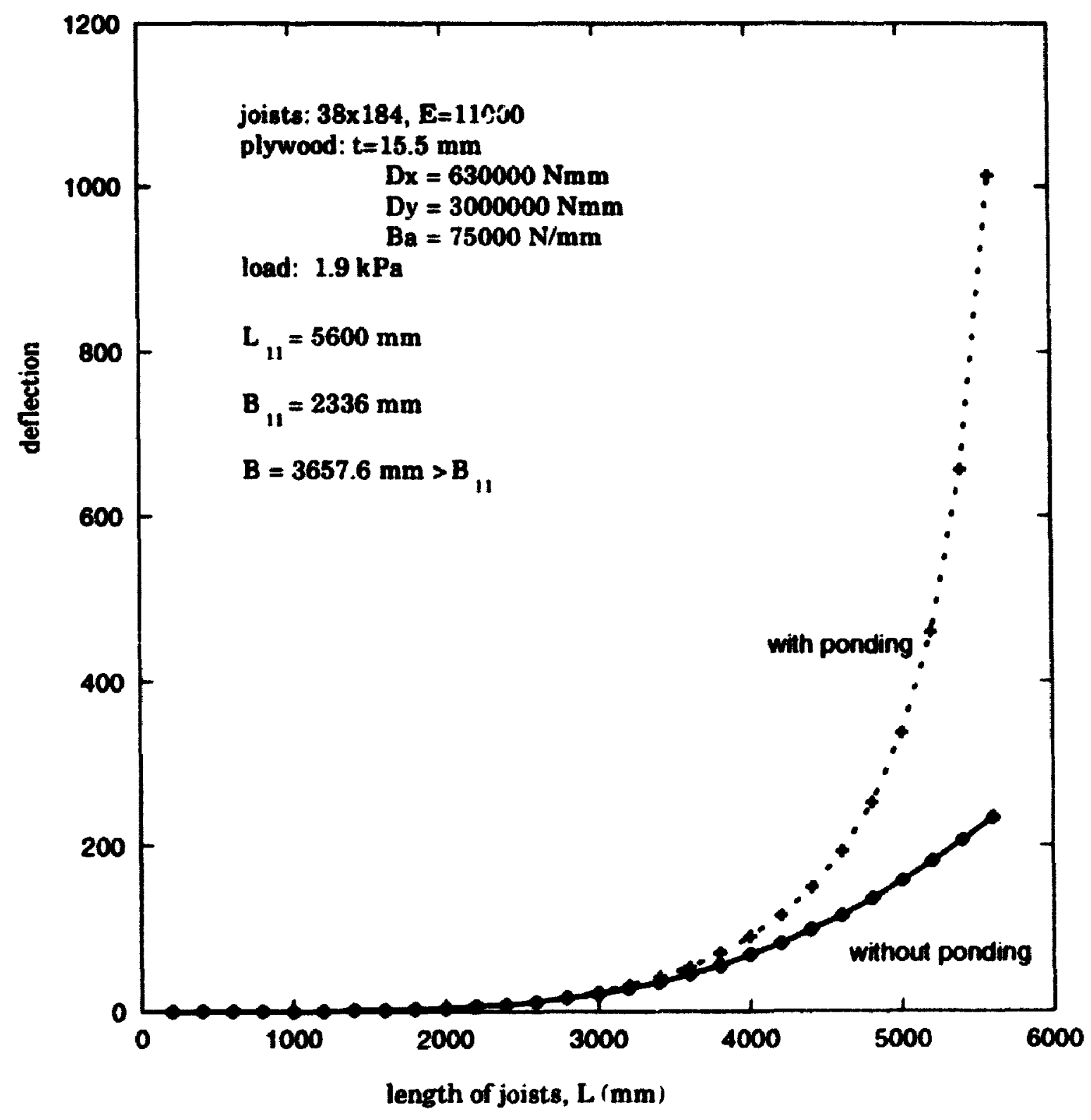

Figure 6.7: Deflections when span. $L$, approaching unstable region 


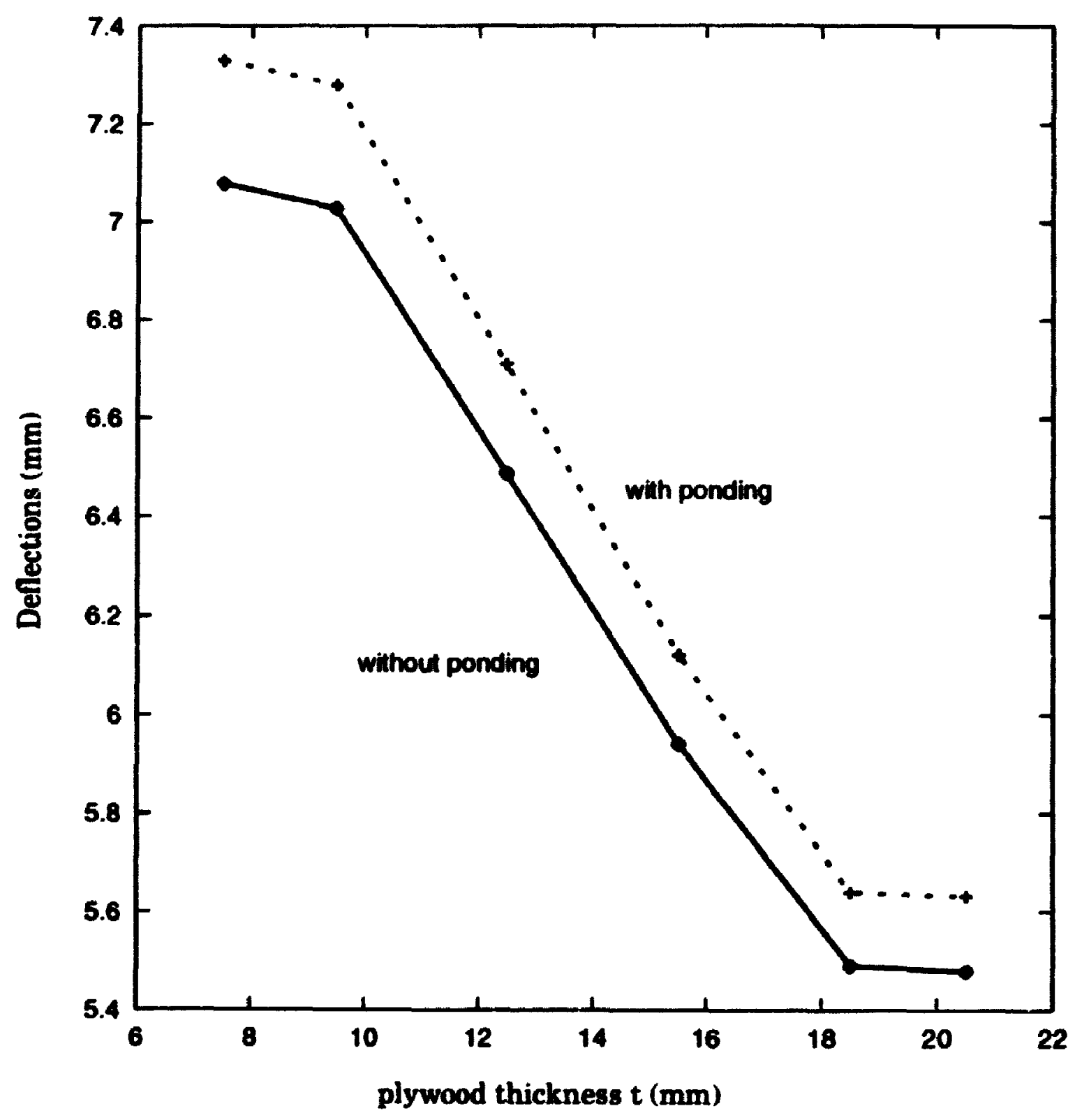

Figure 6.8: Deflection vs plywood thickness 


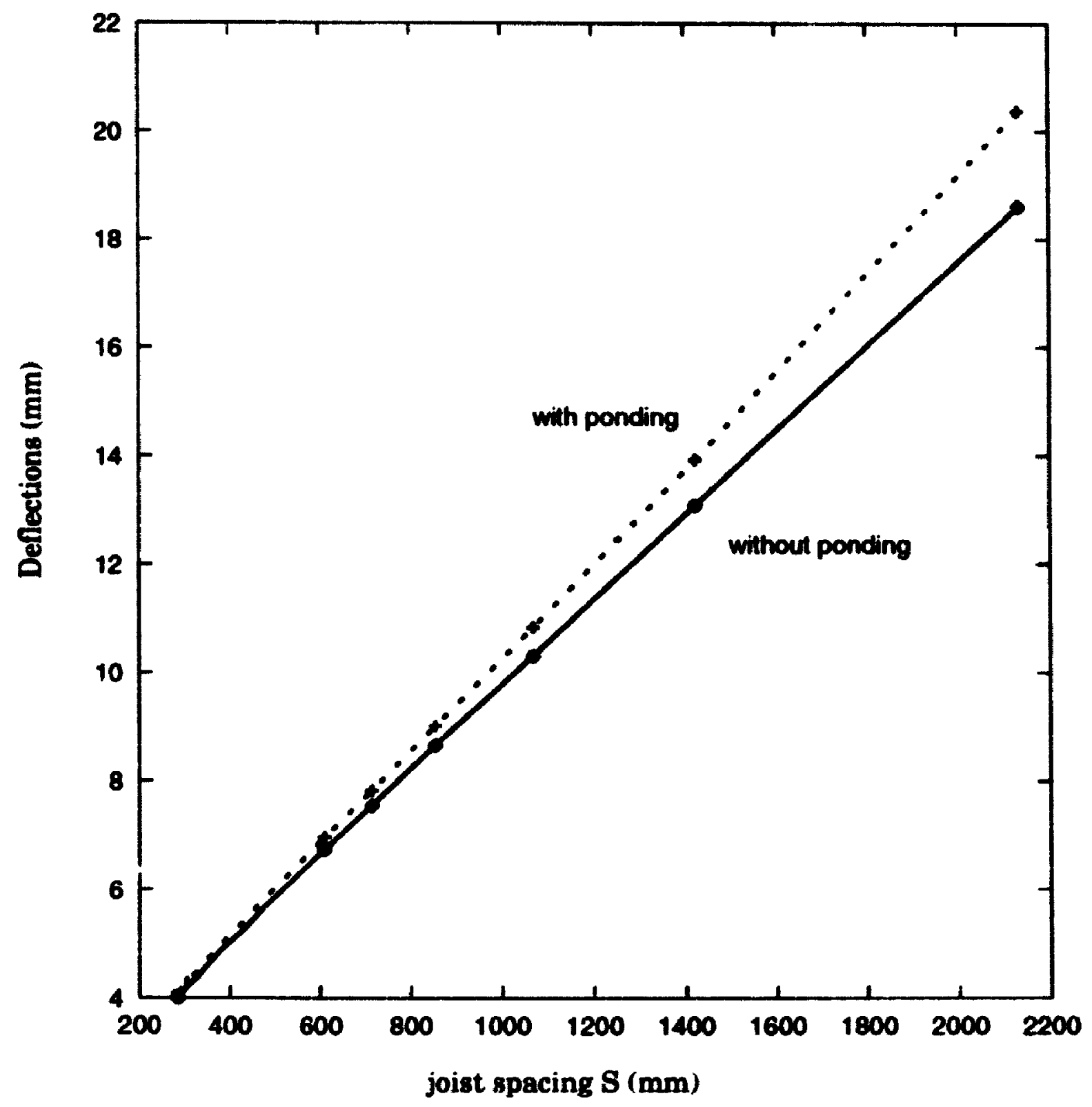

Figure 6.9: Deflection vs joist spacing 


\section{Chapter 7}

\section{Modeling Bending Strength of Wood Members Using Damage Accumulation Concepts}

\subsection{Introduction}

Size efferts on the strength of lumber have been observed by Madsen and Nielson [19]. In 1976. Madsen and Nielsen conducted testing to investigate the size effects ou lumber subjected to bending. It was found that

1. longer hearns had lower st rength

2. deeper beam had lower strength

3. st rengt h depends on load configuration. The beam having iigher stress volume tends to have lower strength.

As illustrated in Figure 7.1 , beam (1) tends to have higher strength than beam (2) provided both beams have the same cross section dimensions. same species. same grade and subjected to the same loading condition.

In Figure 7.2 . beam (2) which is deeper tends to have lower strength. Beams with same dimensions subjerted to different loading conditions will have different strengths. The beam in case (2). Figure 7.3 . tends to have higher strength. 

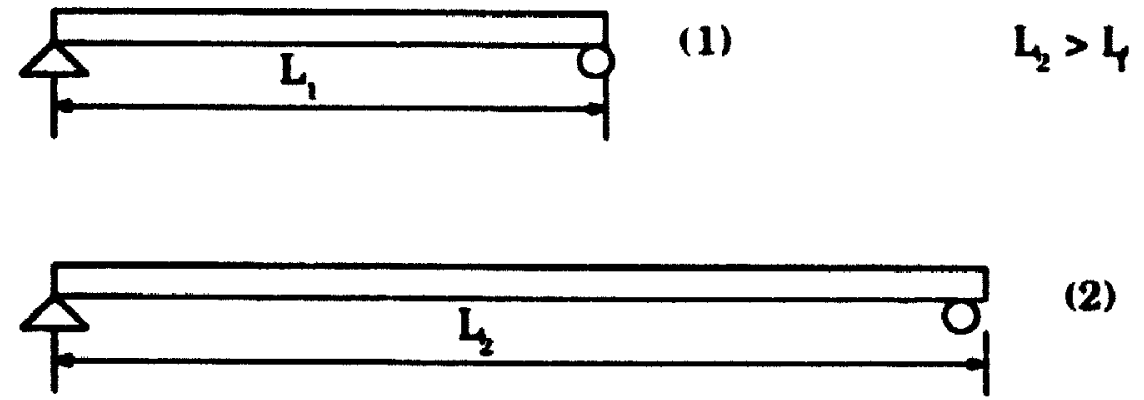

Figure 7.1 : Beams with different length
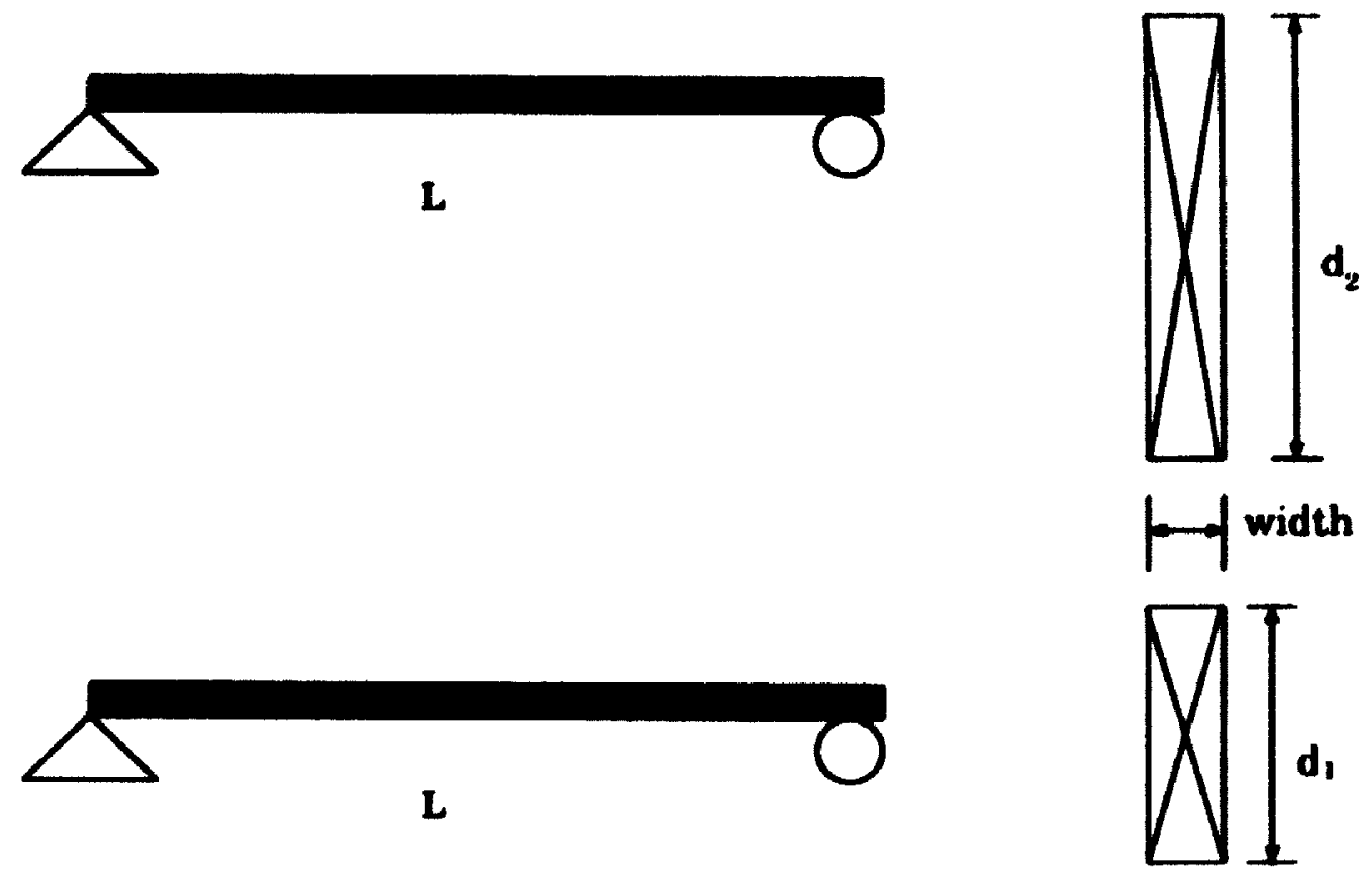

$h-1$ width

Figure 7.2: Beams with different depth 

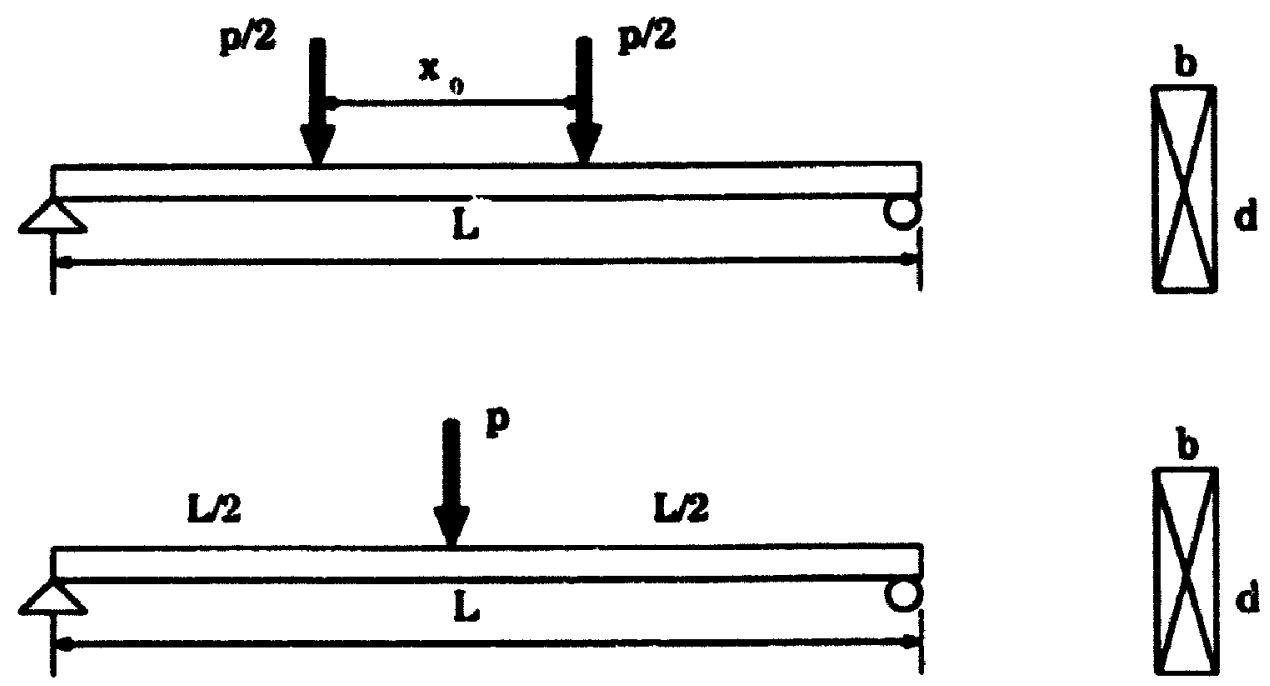

Figure 7.3: Beams with different load scheme

This phenomenon was explained later (1986) by Madsen and Buchanan [46] using the inodified weakest link theory. In this theory, the lumber is considered perfectly brittle. It consists of a series of elements. Failure of any one of these elements (the weakest link) signals the fa.' lure of lumber. In other words. the strength of lumber is governed by the strength of its weakest link.

\subsection{Characterization of Size and Load Configu- ration Effects}

The size effects are quantified as follows:

(1) length effects:

$$
\frac{x_{1}}{x_{2}}=\left(\frac{L_{2}}{L_{1}}\right)^{\frac{1}{L_{1}}}
$$

where $x_{1}$ and $x_{2}$ are the strengths of inembers of length $L_{1}$ and $L_{2}$, respectively. and $k_{1}$ is the length effert parameter. The parameter $k_{1}$ was found to be approximately 4.3 by calibration of equation 7.1 into Madsen s test data [48] [47] [45] [46]. (2) depth effect: 


$$
\frac{s_{1}}{r_{2}}=\left(\frac{d_{2}}{d_{1}}\right) \frac{1}{k_{2}}
$$

where $d_{1}$ and $d_{2}$ are depth of the beams. $k_{2}$ is the depth effect parauketer.

(3) load configuration entent:

The load configuration effect was quantified by comverting the speritiv type "of loading to an equivalent length which can lne used in 7.1 . For example. for Ilu- load configuration in Figurr $7.3(1)$ :

$$
L_{+}=\frac{1+\frac{r_{0}}{l} k_{1}}{1+k_{1}} L
$$

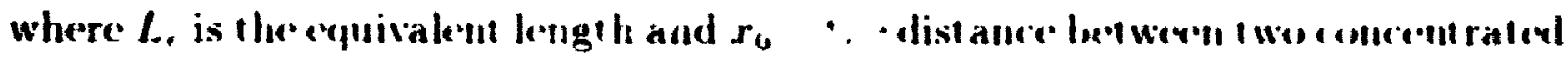
loads on a simply supported beam of span $I$.

Foschi [24] included the size effeces results into the design formmla using relialbility analysis.

However. all the studies so far have separately comsiderevi the differemt sige of fects and load configurations. In this chapter. we will include the sive e.fferets, load configuration effects and rat. of loading effects into ome unified formula ly losking at this problem from another point of rew. namely. tot al damage are t.anulation in the luminir [11].

\subsection{The Total Damage Accumulation Model}

At any point in a piece of lumber. a parameter a can be used 1o, descrile. the dallage accumulation at that point. Parameter $\alpha$ is a random varialble which ranges frun! zero to one. A value of a equals zero means no datnage acrumulated al the jmint described at a specific time. while a value of I for a reprexents failure. Sime lumber is full of cracks and flaves. $\alpha$ is one al points where crarks or Haws exist. Haws are randomly distributed in a piece of lumber. Figure 7.4 showe the iritial daruag! distribution on a cross-scction of a beam.

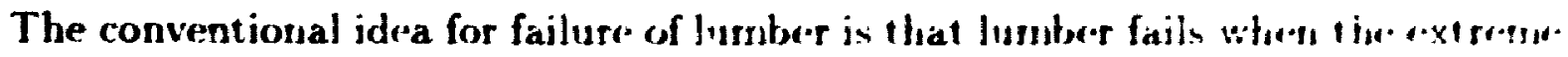

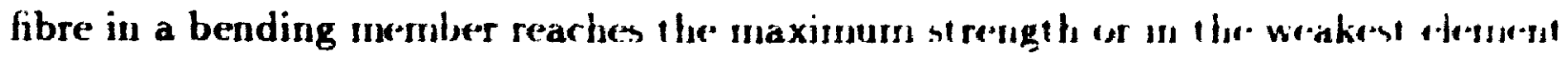



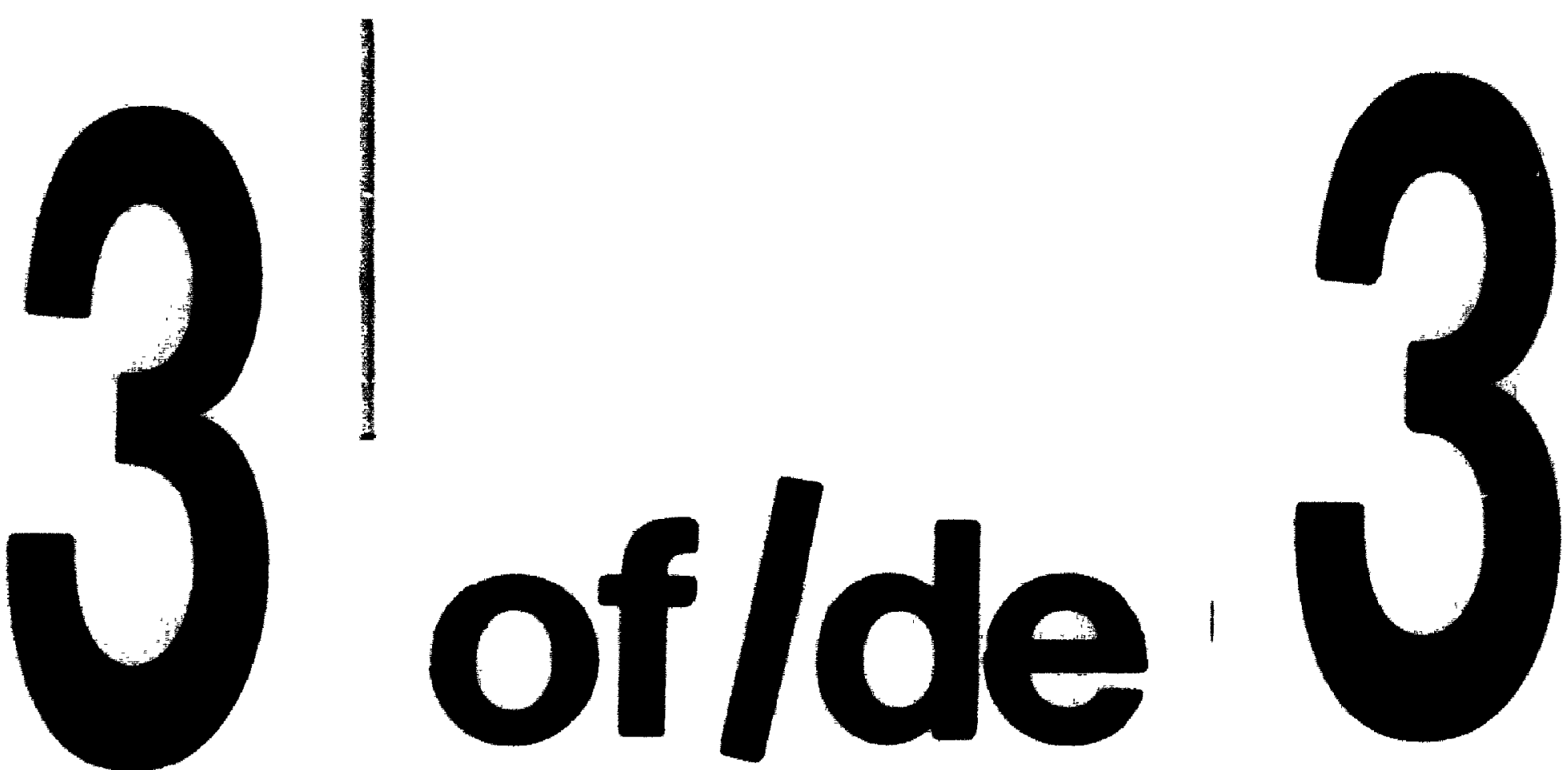

PM-1 3\%"ze" pwotocan muc umcagcopr taned

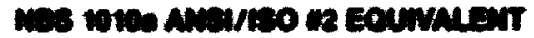

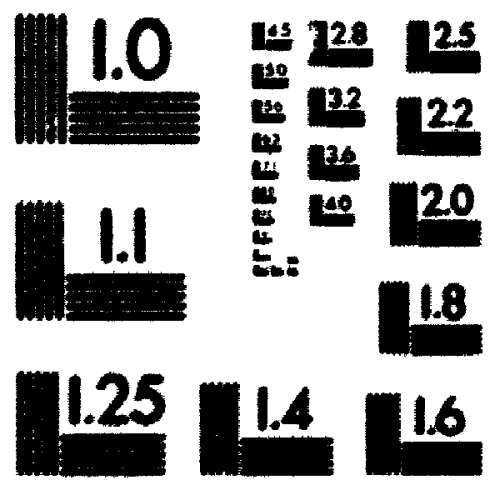

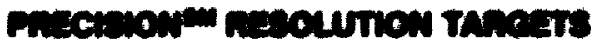




\section{Damage Distribution}

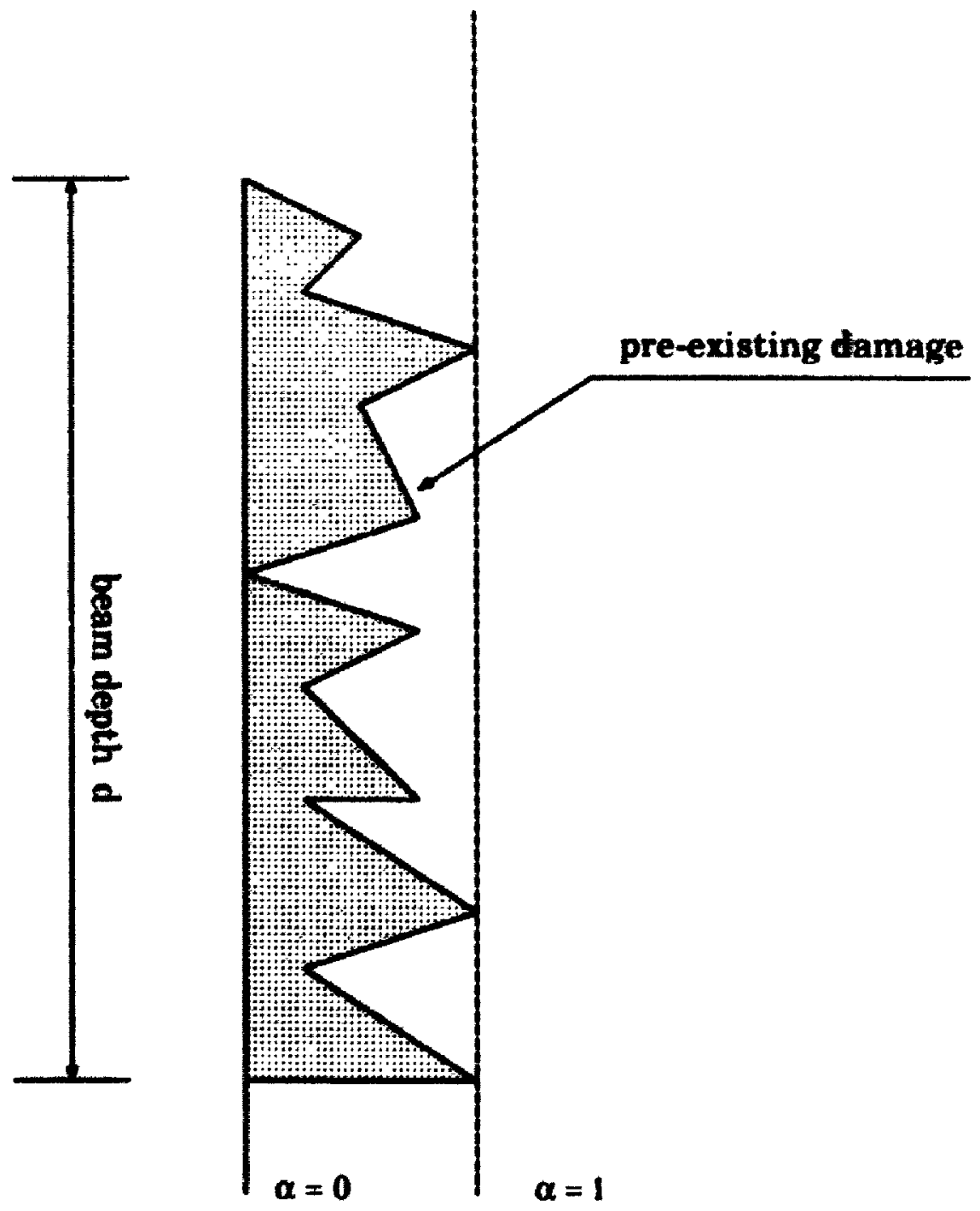

Figure 7.4: Pre-existing damage: 
in the lumber fails. However, this is not true in at least the following two cases: (1) initial damage already exists in every piece of lumber. as shown in Figure 7.4. Its density and distribution depends on grade. (2) in the case when a hole is drilled (or other kind of man made damage), the strength of the broken fibres is zero in this rase: and hence such fibres become the weakest link. But the strength of the lumber is obvinusly not zero.

Lumber fails when damage is accumulated to a certain amount in the whole volume of the lumber. Lumber may not fail if one or even a bundle of fibres is broken. This can be expressed as follows:

$$
\Omega=\int_{v} \alpha d v
$$

where

$$
\begin{array}{ll}
\Omega & \text { total damage accumulated in the lumber } \\
\alpha & \text { damage accumulated at a point, per unit volume } \\
v & \text { volume }
\end{array}
$$

The damage accumulation rate depends on the stress level and the damage which has already accumulated at that point. The higher the stress, the higher is the damage accumulation rate. Pre-existing damage accelerates damage accumulation. The damage accumulation rate then can be written as:

$$
\frac{d \alpha}{d t}=f_{n}(\sigma, \alpha)
$$

where

$$
\begin{array}{ll}
\text { a } & \text { damage accumulation at a point } \\
t & \text { time } \\
\sigma & \text { stress level at a point }
\end{array}
$$

This concept was used to study the long term strength of lumber [48] [47] [46] [23] [24].

The Canadian model to describe the long term strength is [24]: 


$$
\frac{d \alpha}{d t}=a\left[\sigma\left(t i-\sigma_{0} \sigma_{s}\right]^{b}+c\left[\sigma(t)-\sigma_{0} \sigma_{s}\right]^{n} \alpha\right.
$$

where

$\begin{array}{ll}\text { a.b.c.n } & \text { model parameter } \\ \sigma(t) & \text { stress at time t } \\ \sigma_{s} & \text { short term strength } \\ \sigma_{0} & \text { threshold stress ratio }\end{array}$

The U.S. model is $[18][17][16][23]$ :

$$
\frac{d \alpha}{d t}=\exp \left(-a+b \frac{\sigma(t)}{\sigma_{s}}\right)
$$

where
a,b model parameter
$\sigma(t) \quad$ stress state
$\sigma$ short term strength

To demonstrate the damage accumulation in a bending member. let's choose the simplest relation:

$$
\frac{d \alpha}{d t}=\sigma
$$

for a beam in bending:

$$
\sigma=\frac{M(x)}{I} y
$$

where

$\mathbf{M}(\mathbf{x})$ moment at a cross section $\mathbf{x}$

I moment of inertia of the cross section

$y$ distance from the neutral axis 


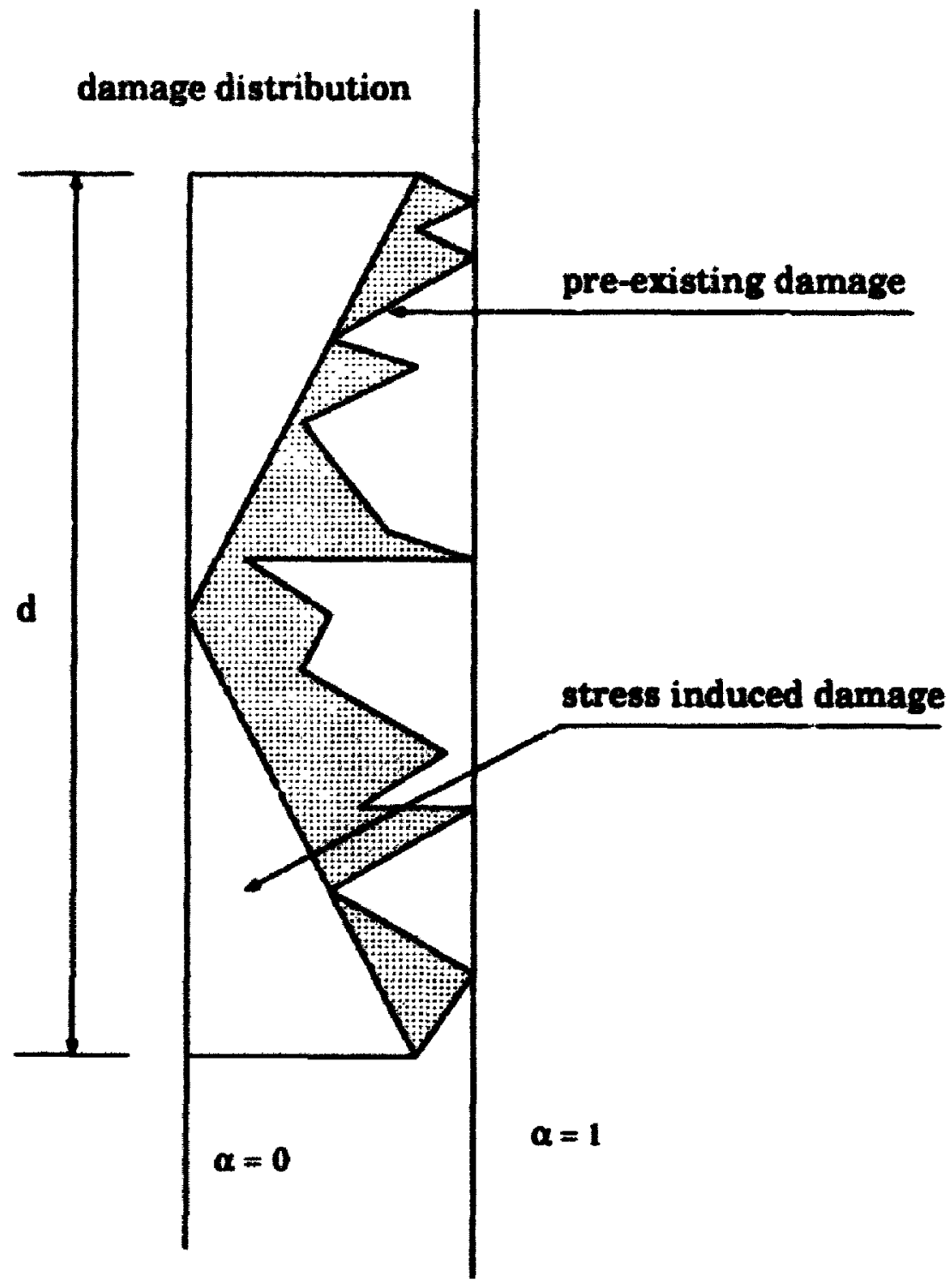

Figure 7.5: Stress induced damage accumulation 


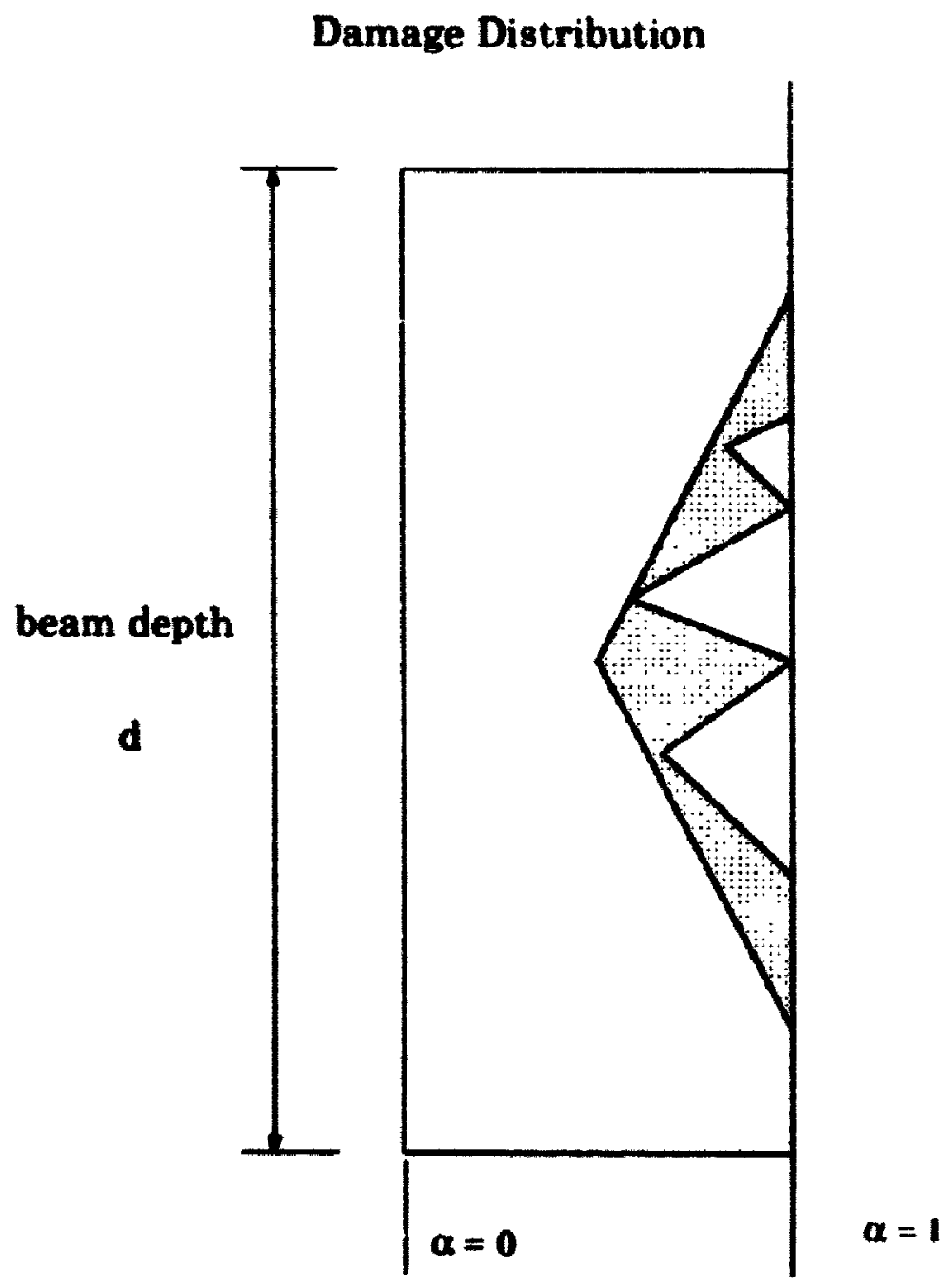

Accumulated Damage at Failure

Figure 7.6: Accumulated damage at failure

hence

$$
\alpha=\alpha_{0}+\frac{M(x)}{I} t y
$$

After time $t$. at a cross section $x$. the damage accumulation distribution will look like in Figure 7.5.

At this stage, the damage accurnulated in some of the fibres has reacherd one. These fibres have already failed. But the total damage in the whole: volume has not reached the critical value. The member has not failed yort.

After another time interval has elapsed, the darnage distribution would look 

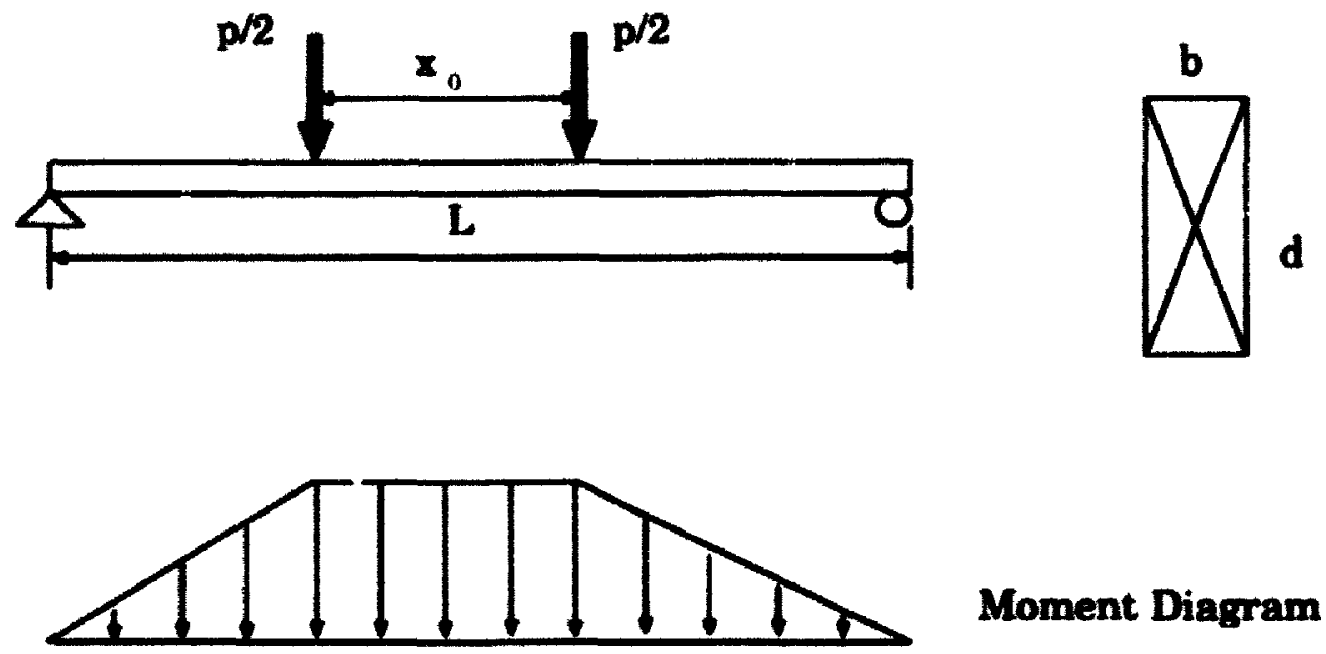

Figure $7 . \overline{7}$ : Beam subjected to 2 points load

like that shown in figure 7.6. At this stage. the damage in the whole volume has arcumulated to a critical amount, and the member fails.

\subsection{Interpretation of Test Results}

Consider a member subjected to loading as illustrate in figure $i . \bar{T}$.

$$
\begin{aligned}
& \sigma=\frac{M(x)}{I} y \\
& M(x)=\frac{p}{2} x \quad x<\frac{L-s 0}{2} \\
& =\frac{R}{1}\left(L-x_{0}\right) \quad \frac{L-x_{0}}{2}<x<\frac{L+x_{0}}{2}
\end{aligned}
$$

Assume a simple damage accumulation model:

$$
\frac{d a}{d t}=a \sigma^{6}
$$

where $a$ and $b$ are model parameters. They are constant with respect to time and size of member.

From equation 7.4 , we have

$$
\frac{d \Omega}{d t}=\int \frac{d \alpha}{d t} d v
$$


Combine equation $7.11,7.12,7.13$ and 7.14 :

$$
\begin{aligned}
\frac{d \Omega}{d t} & =\int_{V} \frac{d a}{d t} d t \\
& =\int_{v} a \sigma^{h} d t \\
& =\frac{a}{(b+1)^{2}} \sigma_{t}^{h} I\left(1+\frac{x_{0} b}{L}\right)
\end{aligned}
$$

where

$$
\sigma_{t}=\frac{p\left(L-x_{0}\right)}{4 l}\left(\frac{h}{2}\right)
$$

is the stress at the extreme fibre. To study the short term strength. assumme

$$
\begin{aligned}
& \sigma_{t}=h^{\prime} t \\
& h^{-}=\frac{k_{0}\left(L-x_{0}\right)}{4 I}\left(\frac{h}{2}\right)
\end{aligned}
$$

where

$k_{0} \quad$ rate of loading related to the concentrated load

$K$ rate of loading related to stress

then

$$
\sigma_{s}=K T
$$

where

$\sigma$ short term strength

T total time needed for lumber to fail

then. from equation 7.15

$$
\Omega=\frac{a}{(b+1)^{3}} d h\left(L+x_{0} b\right) \sigma_{a}^{b} T
$$

Lumber fails when $\Omega$ reaches a critical value. From erjuation 7.20 . we "an wer" that for a certain value of $\Omega$ 
1. $\sigma$, decreases when $h$ increases $\Rightarrow$ depth efiect

2. $\pi$, derreases when $L$ increases $\Rightarrow$ length effect

3. $\sigma_{s}$ decreases whon $r_{0}$ increases $\Rightarrow$ load configuration effect

4. $\sigma_{s}$ decreases when $T$ increases $\Rightarrow$ rate of loading effect

These trend. ... ve been proven by tests.

The only thing found in the tests that is contrary to what is predicted is the width effect. Strength increases when width increases. This chapter will not discuss width iffect.

\subsection{A Unified Approach}

Equation 7.20 shows the relation between the strength of lumber and the dimensions of lumber, rate of loading and load configuration. But, the accuracy of this relationship depends on the accuracy of the assumption of Equation 7.13. The damage accumulation model ( Canadian and I.S. ) for long term strength may be used. A more accurate model may be found in order to get a more accurate formulation of $\boldsymbol{\Omega}$.

However. Equation 7.20 can be modified as follows:

$$
\Omega=A L^{a_{1}} h^{a_{2}} T^{a_{3}}\left(1+\frac{a_{4} x_{0}}{L}\right)^{a_{s}} \sigma_{s}
$$

where A. $a_{1}, a_{2}, a_{3}, a_{4}$ and $a_{5}$ are model parameters which can be determined by calibrating test results into the formulation.

\subsubsection{Length Effects}

Considering two beams with same dimension of cross sections subjected to a third point loading with the same rate of loading. i.e. $h_{1}=h_{2}, T_{1}=T_{2}$ and $x_{0}=0$. The member fails when $\boldsymbol{\Omega}=\boldsymbol{\Omega}_{\mathbf{0}}$. Therefore, 


$$
\Omega_{0}=A L_{1}^{a_{1}} h^{a_{2}} T^{a_{1}} \sigma_{s 1}=A L_{2}^{n_{1}} h^{x_{2}} 7^{a_{3}} \sigma_{s 2}
$$

It can be rewritten as

$$
\frac{\sigma_{s 1}}{\sigma_{s 2}}=\left(\frac{L_{2}}{L_{1}}\right)^{u 1}
$$

Compare equation 7.23 with 7.1 . then

$$
a_{1}=\frac{1}{k_{1}}
$$

\subsubsection{Depth Effects}

Following the same procedure, we obtain

$$
a_{2}=\frac{1}{k_{2}}
$$

\subsubsection{Load Configuration Effects}

Comparing equation 7.21 with 7.3 . we get:

$$
\begin{aligned}
& a_{5}=\frac{1}{k_{1}} \\
& a_{4}=k_{1}
\end{aligned}
$$

Therefore, the total damage accumulation over the volume is

$$
\Omega=A h^{\frac{1}{k_{2}}} T^{2_{3}}\left(L+x_{0} k_{1}\right)^{\frac{1}{k_{1}}} \sigma_{0}
$$

The only parameter that needs to be calibrated is the rate of loading parameter $a_{3}$. The formula can also be written as:

$$
\frac{\sigma_{0}}{\sigma_{0}}=\left(\frac{h_{0}}{h}\right)^{\frac{1}{k_{2}}}\left(\frac{T_{0}}{T}\right)^{23}\left(\frac{L_{0}}{L+k_{1} x_{0}}\right)^{\frac{1}{k_{3}}}
$$

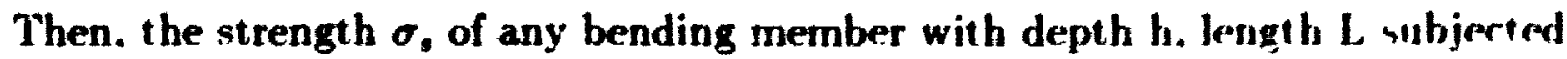
to two concentrated loads with a distance of $x_{0}$ from each other with a rate of loading 
$k$ (T) ran be determined in relation to the st rength of a standard third point loading test $\left(x_{0}=0\right)$ with parameters $\sigma_{0}, h_{0}, L_{0}$ and $T_{0}$.

\subsection{Summary}

This chapter has unified the size effects. load configuration and rate of loading effects into one formula using a total damage accumulation model. This model fits well with the existing length. depth and load configuration effect formula. The rate of loading model parameter $a_{3}$ can be determined by calibrating the above formula into rate of loading tests data. This concept has been raised first by professor J.J.Salinas. 


\section{Chapter 8}

\section{Summary and Future Work}

\subsection{Summary}

The following topics have been discussed:

1. Existing methodologies for studying and designing wood joist floors have ber" examined and summarized. A different approach from the existing finite 4 . ement analysis and a simple $T$-beam design is proposed and examined. The floor is modeled as an orthotropic plate. The bending stiffness of the plate is taken as that of the existing $T$-beam and, therefore, the composite action of the floor has been included. The bending stiffness in the transverse direction is taken as that of the plywood and hence the two-way artion is taken into consideration. This model includes parameters like connection type (nailed, glued or loose) between the joists and sheathing, gaps between sheathing, plywoud and joist size. The variability of joists is not included.

2. The results from the proposed approach are compared favorably with test results from previous research by other researchers.

3. Short span floors subject to uniformly distributed load can be designed as a T-beam subjected to load on the tributary area.

4. For floors of medium span, which has aspect ratio $y$ larger than 1 but smaller than a material related value $\%$, T-beam formula can still be used. The rmult should be adjusted by a maximum amount of $10 \%$. 
i. Aspert ratio is not a negligible parameter in the design of long span floors. which has a aspect ratio ; larger than $\gamma_{0}$. The boundary conditions in the transwerse direction will have a significant effect on the deflection of the floors.

6. Floors subjected to concentrated load can not be designed using the $T$-beam theory. They have to be designed as orthotropic plates. A simple formula has been derived to design for concentrated loads.

7. Ponding on flat roofs is examined. A criterion is derived. This criterion divides roofs into two rategorim: st able and unstable. A stable roof is one that will deflect to a finite amount and reach equilibrium. The unstable roof is one in which deflections will increase when the amount of water increases. It keeps deflecting until collapse.

8. A unified theory of size effect and loading configuration effect on the bending strength of wood members is proposed. This is an attempt to unify various factors that affect the bending strength of wood into a single formulation.

Major contributions of this thesis are summarized in following sections.

\subsubsection{Design Procedures for Short Span Floors Subject to Uniformly Distributed Load}

Short span floors are defined as those with aspect ratio, $\gamma=L / B<1$. Then plywood sheathed short span floors can be designed according to $T$-beam formula by simplifying a floor as a $T$-beam subject to load on the tributary area. Figure 8.1.

Deflection of floors can then be calculated by

$$
\Delta=\Delta_{1}\left(\frac{K_{1}}{K_{2}}+f_{\Delta} \frac{f_{v}}{K_{2}}\right)
$$

where $\boldsymbol{K}_{1}$ and $\boldsymbol{K}_{2}$ represent the composite stiffness of an unfastened and glued $T$ beam respectively. $f_{x}$ is the adhesive factor defined in Chapter 2 . The adhesive factor defines the degree of composite action in the T-beam. 

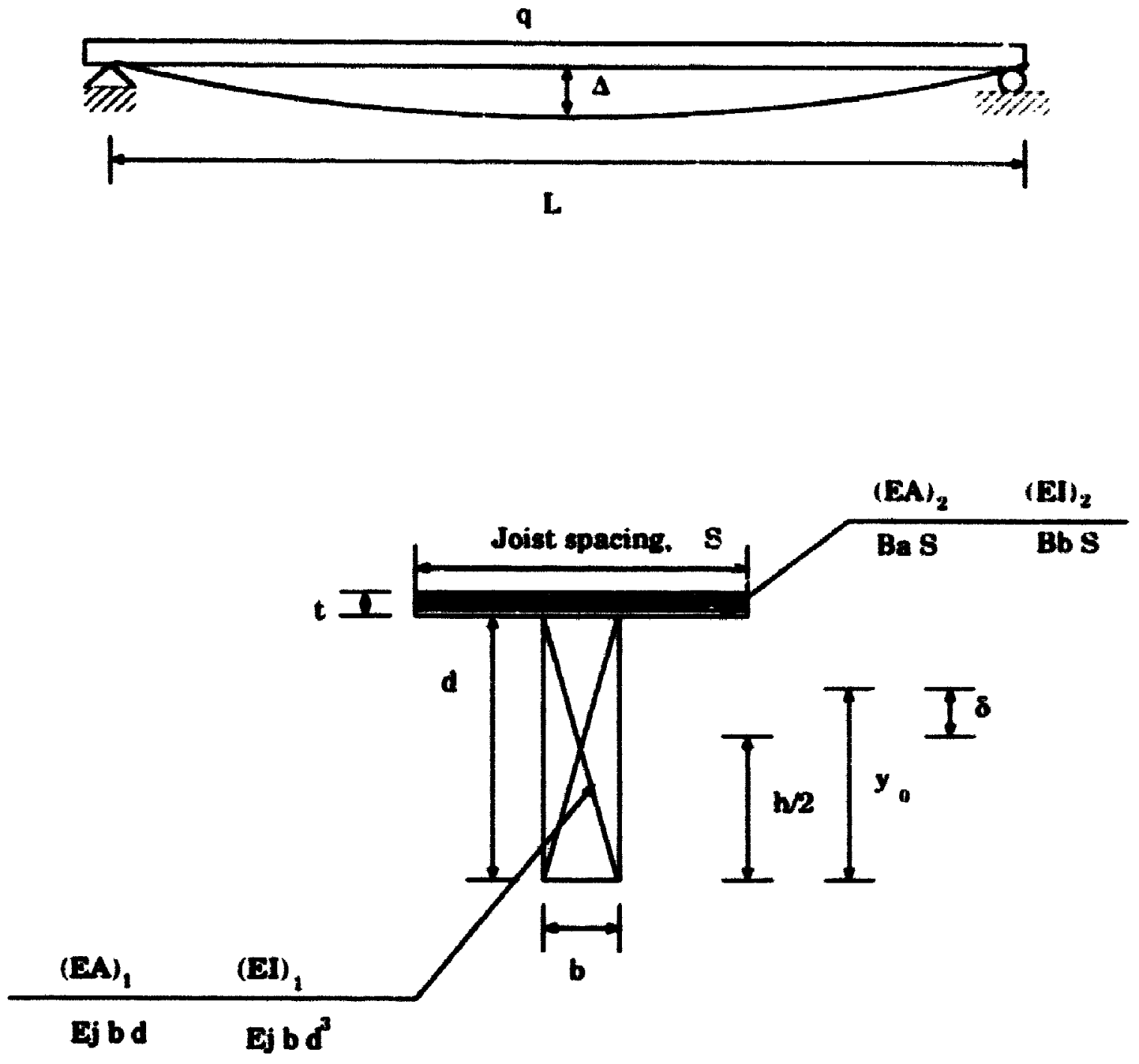

Figure 8.1: Plywood sheathed floor modeled as a T-beam subjerts to losal on the tributary area. 


$$
\begin{gathered}
h_{1}=(E I)_{t}=(E I)_{1}+\left(E^{\prime}\right)_{2} \\
h_{2}=(E I)_{1}+(E A)_{1} \delta^{2}+(E I)_{2}\left(\frac{d+t}{2}-\delta\right)^{2} \\
\delta=\frac{d+t}{2} \frac{(E A)_{2}}{(E A)_{2}+(E A)_{1}} \\
f_{v}=(E A)_{1} \delta^{2}+(E A)_{2}\left(\frac{d+t}{2}-\delta\right)^{2} \\
د_{1}=\frac{5}{384} \frac{q S L^{4}}{K_{1}^{\prime}} \\
f_{\Delta}=\frac{10}{\left(L^{\prime} \alpha\right)^{2}+10} \\
\alpha^{2}=\frac{\left(\frac{t+h}{2}\right)^{2} S_{n}}{K_{2}-K_{1}}\left(\frac{K_{2}}{K_{1}}\right) \\
S_{n}=\frac{P / \delta_{0}}{s_{n}}
\end{gathered}
$$

where

$(E I)_{1}$ bending rigidity of the joists

$(E A)_{1}$ axial rigidity in tension for the joists

$(E I)_{2}$ bending rigidity of the plywood

$(E A)_{2} \quad$ axial rigidity in tension for the plywood

q uniformly distributed load acting on the tributary area of $T$-beam

L length of the T-bearn or span of joists

$L^{\prime} \quad$ Length of plywood between gaps

in spacing between nails

$P / \delta_{0} \quad \mathrm{load} / \mathrm{slip}$ ratio

S joist spacing 
$K_{1}$ and $K_{2}$ can also be written in the form commonly used in Canadian code:

$$
\begin{gathered}
h_{1}=\frac{b d^{3}}{12} E_{j}+B_{b} S \\
K_{2}=\frac{b d^{3}}{12} E_{J}+E_{2} b d \delta^{2}+B_{b} S\left(\frac{d+t}{2}-\delta\right)^{2} \\
\delta=\frac{d+t}{2} \frac{B_{a} S}{B_{a} S+E_{j} b d} \\
f_{1}=B_{3} S \delta^{2}+B_{2} S\left(\frac{d+t}{2}-\lambda\right)^{2}
\end{gathered}
$$

where
$B_{a} \quad$ axial stiffness in tension for plywood
$B_{b} \quad$ bending stiffness of plywood
EJ modulus of elasticity of joists
$b, d \quad$ width and depth of joists
$t \quad$ thickness of plywood

\subsubsection{Design Procedures for Medium and Long Span Floors Subject to Uniformly Distributed Load}

A long span floor is defined as one with aspect ratio.,$>1$. To design for a long span floor:

- Calculate the deflection of $T$-beam, $w_{b}$, according to $T$-bream formula in last section.

- Calculate $\gamma_{0}$.

$$
q=\gamma_{0}=\sqrt{\frac{(1-27 k) \beta_{1}+\sqrt{(27 k-1) \beta_{1}^{2}-\left(4(3 k-1)(243 k-1) \beta_{2}\right.}}{2(243 k-1) \beta_{2}}}
$$


- If $1<\gamma<\%$, then it is termed medium span floor, use T-beam formula. The maximum deflection thus calculated will be adjusted upward by $10 \%$. i.e.

$$
w_{p l}=1.1 w_{b}
$$

- If $\gamma=\frac{h}{B}>\gamma_{i \theta}$. it is termed long span floor, then calculate the deflection using T-beam formula and adjust the result using an adjustment factor:

$$
u_{p l}=w_{b} \alpha_{11}
$$

where $\alpha_{11}$ is the first order of the modification factor $\alpha$

$$
\begin{gathered}
\alpha_{11}=\frac{4 A}{1+\beta_{1} \gamma^{2}+\beta_{2} \gamma^{4}} \\
A=\frac{1536}{5 \pi^{6}} \\
3_{1}=\frac{2 H}{D_{x}} \\
3_{2}=\frac{D_{y}}{D_{x}}
\end{gathered}
$$

$D_{x}=$ the bending rigidity of the T-beam $D_{y}=$ the bending rigidity of the plywood $690^{\circ} \mathrm{H}=$ the torsional rigidity of the plywood

\subsubsection{Design Procedures for Floors Subject to Concen- trated Load}

In order to design for a wood joist floor subjected to concentrated load, the following procedures can be followed:

- Deflection or floors at any point $(x, y)$ 


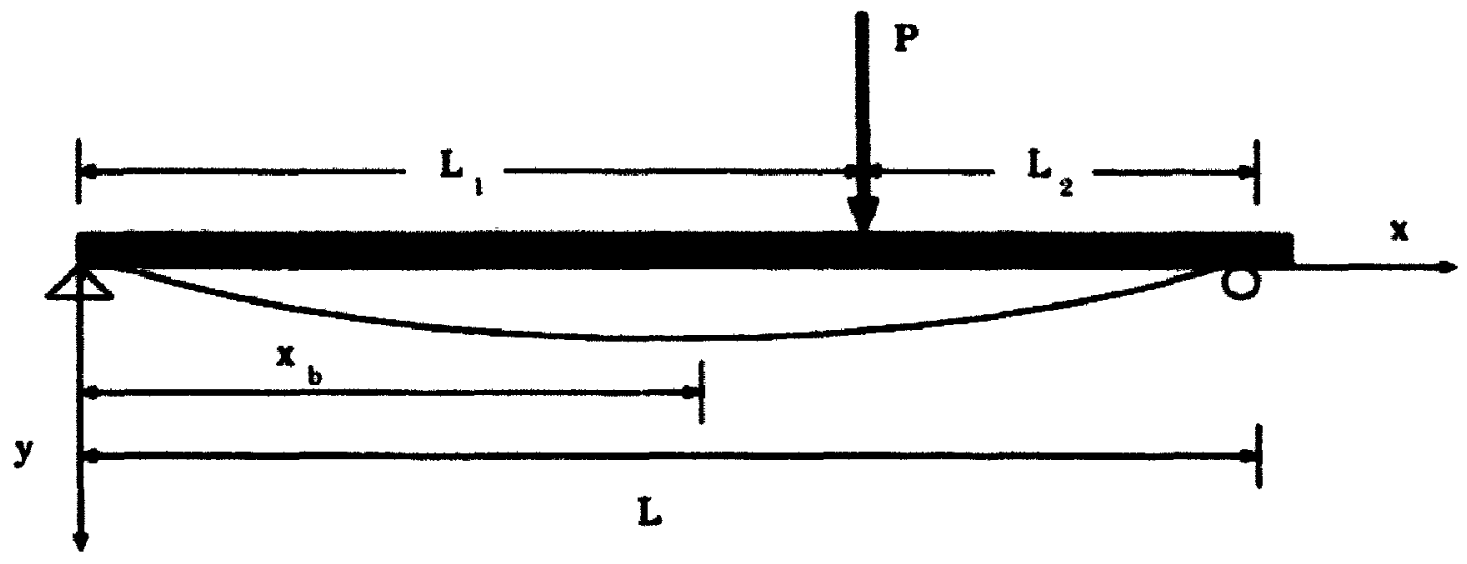

Figure s.2: A beam subjects to a concent rated load. P

$$
\begin{aligned}
u \cdot(x . y) & =\sum_{m=1}^{\infty} \sum_{n=1}^{\infty} \omega_{m n} \sin \frac{m \pi x}{L} \sin \frac{n \pi y}{B} \\
w_{m n} & =\frac{q_{m n}}{D_{m n}} \\
q_{m n} & =\frac{4 P}{L B} \sin m \pi \xi \sin n \pi \eta \\
D_{m n} & =D_{x}\left(\frac{m \pi}{L}\right)^{4}+2 H\left(\frac{i l l \pi}{L}\right)^{2}\left(\frac{n \pi}{B}\right)^{2}+D_{y}\left(\frac{n \pi}{B}\right)^{4}
\end{aligned}
$$

- Find the location of the maximum deflection of a beam subjected to conrentrated load: $x_{b}$. Figure 8.2.

$$
x_{b}=\sqrt{\frac{L^{2}-L_{2}^{2}}{3}} \quad L_{1}>L_{2}
$$

- Calculate the deflection of the floor at point $\left(x_{b}, \eta B\right)$. This deflection will $t_{x}$ the approximate maximum deflection.

$$
w(x, y)=\sum_{m=1}^{x} \sum_{n=1}^{x} w_{m n} \sin m \pi \frac{x_{b}}{L} \sin n \pi \eta
$$

$w_{m n}$ can also be written as

$$
u_{m n}=C \cdot \frac{\sin m \pi \xi \sin n \pi \eta}{L_{m n}}
$$




$$
\begin{aligned}
C & =\frac{4 P L^{3}}{B D_{x} \pi^{4}} \\
L_{m n} & =m^{4}+\beta_{1} m^{2} n^{2} \gamma^{2}+\beta_{2} n^{4} \gamma^{4} \\
y_{1} & =\frac{2 H}{D_{x}} \\
g_{2} & =\frac{D_{y}}{D_{x}} \\
\gamma & =\frac{L}{B}
\end{aligned}
$$

Where $(\xi L, \eta B)$ is the point of loading, $P$ is the concentrated load. $L$ and $B$ is the span and width of the floor. $D_{x}$ is the bending rigidity of the T-beam and $H$ and $D_{y}$ the torsional rigidity and bending rigidity of plywood perpendicular to the joists. The convergence of the series is fast.

\subsubsection{Design Procedures for Roofs Subject to Ponding Load}

Critical dimensions that define a stable roof under ponding load are as follows:

$$
\begin{aligned}
& \text { width }=B<\pi\left(\frac{D_{y}}{k}\right)^{\frac{1}{t}} \\
& \text { span }=L<\pi\left(\frac{D_{x}}{k}\right)^{\frac{1}{4}}
\end{aligned}
$$

where $k$ in the density of fluid, $D_{y}$ and $D_{x}$ are rigidity along the width and span respectively.

If any one of the above two conditions is satisfied, the roof is defined as a stable roof under ponding load. The roof will not collapse due to the accumulation of rain water. However, the deflection will be amplified. The amplification factor is defined in Chapter 6.

$$
A_{m n}=\frac{1}{1-\frac{k}{D_{m n}}}
$$

The maximum deflertion can be calculated according to theories developed in above sections and modified with the amplification factor. $D_{m n}$ is as defined in last section. 


\subsubsection{Damage Accumulation Model for Bending Strength of Wood Members}

Total damage in the colume of bending wood member is definerl as

$$
\Omega=A h^{\frac{1}{k_{2}}} T^{a_{3}}\left(L+r_{0} k_{1}\right)^{\frac{1}{k_{1}}} \sigma_{s}
$$

The stress of any bending member can be calculated through

$$
\frac{\sigma_{9}}{\sigma_{0}}=\left(\frac{h_{0}}{h}\right)^{\frac{1}{k_{3}}}\left(\frac{T_{0}}{T}\right)^{z_{3}}\left(\frac{L_{0}}{L+k_{1} x_{0}}\right)^{\frac{1}{k_{1}}}
$$

where $k_{1}$ is the length effect parameter. $k_{2}$ depth effect parameter. $h$ dipth of joist. $T$ loading time. $L$ length of the beam. $x_{0}$ distance bet weren two point londs. The strength $\sigma$, of any bending member with depth h. length $L$ subjected to I wo com. centrated loads with a distance of $x_{0}$ from each other with a rate of loading $k$ (T) can be determined in relation to the strength of a standard third point kading test $\left(x_{0}=0\right)$ with parameters $\sigma_{0}, h_{0}, L_{0}$ and $T_{0}$.

\subsection{Future Work}

The topics to be further investigated includes:

- The joists in a wood-joist floor assembly all have different properties such as MOE. modulus of elasticity. The sheathing dist ributes load from weaker joists to the stronger ones. A formula based on the proposed approarh has to bedeveloped to account for the material variability among joists using simulation and reliability analysis.

- The effects of using materials other than plywood as sheathing are yet to bse examined.

- Effects of other boundary conditions surh as fixed on bosth sides should bro studied in detail. 
- Reliability baserl design formula should be derived that bases on the the design procedures proposed in this thesis. 


\section{Bibliography}

[1] A Design Guide and Commentary Wood Structures ASCE 1975, Compiled by Task Commitree on State-of-the-Art: Wood. Committer on IViod, ASCF: Structural Division '

[2] The Subcommittee on Wood Research of the ASC 1 F Committer on Worsl; "Structural Wood Research Needs"; J. of Structural Engincrring. Vil.112. No.9. September 1986. . ISCE. pp2155-2165

[3] Ang. Alfredo.H.S.: Tang. Wilson.H.: "Probability Concepts in Enginerering Planning and Design": Volume I/II:. 1981 John Wiley and Sons

[4] Berkoh.F.O.:J.J.Salinas:C.Liu: “Assessing the Reliability of Joist Ilangers" Proceedings, 1991 International Timber Enginerring Confercucr. London. England: pp2.432-2.439

[5] Bolotin. V.V. "Statistical Methods in Structural Mechanics": I969 Holdon Day Inc.

[6] Canadian Wood Council, Wood Design Manual. 1990

[7] Chao, Ta; "Stability of trusses subjected to ponding loads"; Journal of structural engineering, Volume 99. No.ST6. June 1973

[8] Chinn, James: A.H.Masouri: S.F.Adams; "Ponding of liquids on flat roofs"; Journal of structural division. ASCE. May 1969, p797-807

\footnotetext{
${ }^{1}$ Not all of the literatures liated here have been referenced dirctily in the thrsis. They are the. ones that I came across during the reseasch and relevant to the lopic of study. I licterd thom here. hoping that they will be useful to the future study.
} 
[9] Chui,Y.H.: Hu,L.J.: "Dynamic Response of Floors Built With Wood I Joists"; IUFRO Timber Engineering Group Meeting, Saint John, New Brunswick, Canada, 90

[10] CIB-W18A; International Council for Building Research Studies and Documentation Working Commission W18A - Timber Structures, Volume 1/II, Meeting Twenty Two, Berlin. September, 1989

[11] Cramer, Stephen M.; Wolfe. Ronald W.; "Load-Distribution Model for LightFrame Wood Roof Assemblies"; J. of Structural Engineering, Vol. 115. No.10, October 1989. ASCE. pp2603-2616

[12] Cunliffe,I.Richard; "Proof-Loading Effects on Lumber". 1988,M.Eng. These, Civil Engineering, Carleton University

[13] Dawson Paul R.; Goodman,James R.; "Variability Simulations of Wood Joist Floor Systems”; Wood Science vol.8, No.4; April 1976, p242-251

[14] Ellingwood, B.; Rosowski, D.;" Duration of Load Effects in LRFD for Wood Construction"; J. of Structural Engineering, Vol.117, No.2, February, 1991. ASCE. pp584-599

[15] Filiatrault, A.; Folz.B. and Foschi.R.O.; "Finite-Strip Free- Vibration Analysis of Wood Floors"; Journal of Structural Engineering, Vol.116, No.8, August, 1990. pp2127-2142

[16] Folz. B.; R.O.Foschi "Reliability of Timber Beams Subjected to Ponding"; Journal of Structural Engineering; Vol.116, No.2, Feb.1990

(17) Forintek Canada Corp.; "First International Conference on Wood Fracture"; August 14-16, 1978, Banff,Alberta.Canada

[18] Forentek Canada Corp.; "Duration of Load Effects in Lumber in Bending, Compression and Tension: An Analysis Report on the Up-To-Date Experimental Data" 
[19] Forentek Canada Corp.; Proceedings of the International Workshop on Duration of Load in Lumber and Wood Pro lucts: September. 1985. Richmond. B.C.Canada

[20] Foschi,R.O.: "Structural Analysis of Wood Floor Systems": Journal of the* Structural Division, ASCE. Vol.108. No. ST7. July. 1982

[21] Foschi,R.O.; "Wood Floor Behaviour : Experimental Study"; J. of Structural Engineering, Vol.111. No.11, November, 1985. ASCE. pp 2497-2508

[22] Foschi.R.O: "Reliability of Wood Structural Systems"; Journal of Structural Engineering. Vol.110. No.12, December 1984. pp:2995-3013

[23] Foschi,R.O.;Barrett.J.D.;"Load-Duration Effects in Western Hemlock Lumber"; J.of the Structural Division, ASCE. Vol.108. No.ST7.July.1982. pp1494. 1510

[24] Foschi,R.O.; Folz,B.R.:Yao,F.Z. "Reliability-Based Design of Wood Structures” Structural Research Series, report No.34, Department of Civil Engineering, University of British Columbia. Vancouver. Canada, 1989

[25] Foschi, R.0.: Bonac, Thomas; "Load-Slip Characteristics for Connertions With Common Nails"; Wood Scjence Vol.9. No.3, January 1977

[26] Gerhards,C.C.; L.L.Link; "A Cumulative Damage Model to Pridict Load Duration Characteristics of Lumber" Wood and Fibre Science, 19(2), 1987. pp.147-164

[27] Gerhards, C.C.;"Time-Related Effects of Loading on Wood Strength: A Linear Cumulative Damage Theory"; Wood Science Vol.11. No.3, January 1979. pp139-144

[28] Golley, Bruce W.; Grice, Willian A. and Petrolito, Joseph; "Plate-Bending Analysis C'sing Finite Strip-Elements": J.of Structural Engineering Vol.113. No.6, 1987. pp1282-1296 
[29] Goodman. J.R.: "Governing Equations for Timber Shell Structures"; Forest Product Journal Vol.16. No.10. October 1966. pp49-55

[30] Goodman J.R.: Vanderbilt M.D.: Criswell. M.D.: Bodig, J.: “Composite and Two-way Artion in Wood Joist Floor Systems"; Wood Science Vol.T. No.1, July 1974; p25-33

[31] Grainger G.D.: "Lateral Distribution of a Concentrated Load on Timber Floor Panels": Civil Engineering and Public Works Review, April 1969, pp341-344, Ministry of Technology, Forest Products Research Laboratory

[32] Hart,Gary C.: "Incertainty Analysis, Loads. and Safety in Structural Engineering”, 1982, Prentice - Hall Inc.

[33] Haussler. Robert. W.; "Roof deflection caused by rainwater pools: Civil Engineering, October 1962. pp58-59

[34] Hooley, R.F.: Hibbert. P.D.; "Stress Concentration in Timber Beams"; J.Str.Div.ASCE, Vol.93, No.ST2, April 1967

[35] Hoyle, Robert.J.; Woeste, Frank,E.: "Wood Technology in the Design of Structures"

[36] H", L.J.; "Vibration Analysis of Wooden Floors by Model Synthesis - Part 1: Frequency Analysis"; IUFRO Timber Engineering Group Meeting, Saint John. New Brunswick. Canada. 90

[37] Keenan.F.J.;" Limit States Design of Wood Structures”

[38] King, E.G.Jr; “A Research Program for Establishing the Strength Properties of Structural Plywood";Materials Research and Standards, October 1866

[39] Kuenzi, Edward W.: Billy Bohannan; "Incresses in deflections and stresses caused by ponding of water on roofs; Forest Products Journal. p421-424: September 1964 
[40] Lekhnitskii.S.G. “Anisotropic Plates”. 1968. Gordon and Brearh Sriencr Publishers

[41] Liu.C.: Salinas.J.J.: F.Berkoh: "Toward a I'nified Throry of Bending for Wood" Proceedings. 1991 International Timber Enginerring ('onforence. London. England: pp2.311-2.318

[42] Liu.C.: Salinas.J.J.: "The Failure Criteria of Flat Roofs Subjertud to Ponding Load" Paper submitted to SECTAM XVI. SouthEastern Conference on Theoretical and Applied Mechanics. April, 1992.

[43] Madsen. H.O.: Krenk.S.: Lind.N.C.: "Methods of Structural Safety": I986. Printice-Hall Inc.

[44] Madsen, B.; "In-Grade-Testing, Degree of Damage Due to Proof Loading of Lumber in Bending”: Structural Research Series Report No.17. I.S.S.N. 03183378, October. 1976. Department of Civil Engineering, L'niversity of British Columbia

[45] Madsen. B.; Johns. K.; "Duration of Load Effects in Lumber. Part III: Code Considerations ${ }^{-}$; Can.J.Civ.Eng.9,526-536(1982)

[46] Madsen.Borg; Andrew H. Buchanan: "Size Efferts in Timber Explained by a Modified Weakest Link Theory" Can.J.Civ.Eng. 13, 218-232, 1986

[47] Madsen,B; "Size Effect in Lumber for Bending" Proceedings on Wood Fracture, 1978, pp.101-110

[48] Madsen,B.; "Duration of Load Tests for Wood in Tension Perpendirular to Grain"; Structural Research Series Report No.7, November 1972, Civil Engineering. University of British Columbia

[49] Madsen,B. and P.C. Nielsen "In-Grade Testing Size Investigation on Lumber Subjected to Bending" Structural Research Series, Report No.15, I.S.S.N. 0318-3378, Civil Engineering, Iniversity of British C'olurnbia. Vancouswer. Canada, 1976 
[50] Madsen,B. and P.C.Nielsen; "In-Grade testing, Investigation of test Parameter in Parallel-to-Grain Tension: Structural Research Series. Report No.24, Revised June 1981

[51] Manutt J. Dobbin; "Static Bending Properties of Structural Wood Based Panels: Large Panel versus Small-Specimen Tests"; Forest Products Journal Vol.34. No.4; April, 1984

[52] Rosowsky D. Ellingwood B; "Limit-State Interactions in Reliability-Based Design for Wood Structures." Journal of the Structural Division, ASCE. Vol. 118, No.3, p813-827, 1992

[53] Rosowsky D.V., Fridley K.J.; "Reliability-Based Design of Wood Members Subject to Ponding” Journal of Structural Engineering, Vol. 119. No. 11. November, 1993

[i4] Masse,D.L.;Salinas,J.J.; (1990). "Strength and Stiffness of Metal-clad Wood Frame Diaphragms"; Canadian Agricultural Engineering Journal, Volume 32, Number 1, pp 117-122

[55] Masse,D.I.;Salinas,J.J.; (1989). "Structural Reliability of Nailed Connectiona"; Canadian Agricultural Engineering Journal, Volume 31, Number 2, pp 195-203

[56] Masse,D.L.;Salinas,J.J.; (1988). "Analysis of Timber Trusses Using Semi-Rigid Joints"; Canadian Agricultural Engineering Journal, Volume 30, Number 1, pp 111-124

[57] Masse, D.I.;Salinas,J.J.;Turnbull,J.E.(1988); "Strength and Resistance of Nailed Plywood Joints for Canada Plan Service Trusses"; Canadian Agricultural Engineering Journal, Volume 30, Number 2, pp 283-288

[58] Masse.D.I.;Salinas,J.J. (1987); "Reliability analysis of Site-Constructed Farm Building roof Trusses": Proc.Am.Soc.of Agr.Eng.. Chicago, December 1987. Contribution number 87-4322. 27pp 
[59] Masse.D.I.: Salinas.J.J.; (1988) "Diaphragm Strength. Stiffess and Design Values for Light-gage Metal Cladding in Farm Buildings": Fing.א.Stat.Rsch Ctr., Research Branch. Agriculture Canada. Ottawa. Cont. No. C-028. Am. Soc. of Agricultural Engineering.. Sorth Atlantic Region Merting. Ilatifax. N.S., Aug 1988. Paper No.NAR-88-301. 21 pp.

[60] Mazur, S.J.; Gangopadhyay, P; "Orthotropic Design in Timber": EIC-73-HR + STR 3, Vol.16. No.A-1, March 1973. The Engineering Journal

[61] McCutcheon, W.J.; Tuomi. R.L.: “Simplified Design Procedure for CiluerlLaminated Bridge Decks": USDA Forest Service Research Paper. FPL 2:33. 1974

[62] MeCutcheon. W.J.; "Method for Predicting The Stifness of Wixod-Joist Flour Systems With Partial Composite Action”. USDA Research Paper FPL 289, 1977

[63] McCutcheon, W.J.; "Deflections of Uniformly Loaded Floors, A Heam-Spring Analog"; USDA, Research Paper FPL-449, 1984

[64] McCutcheon, W.J.; "Stiffness of Framing Members with Partial Composite Action" Journal of the Structural Division, ASCE, 112(7), 1986, p/fi2:3-1637

[65] McFarland D.; Smith B.L.; Bernhart W.D.; "Analysis of Plates". Macmillan

[66] McGahan,A.R.F.; "Wide Span Timber Roofing"; Timber in Civil Esnginewering, February, 1957 (19), pp195-197

[67] Nagarajan.S.; Zak,A.R.; "Composite Materials and Structures, FINITE FL.E. MENT MODEL FOR ORTHOTROPIC BEAMS"; Computers and Structures Vol.20, No.1-3;pp443-449, 1985

[68] NLGA Submission to CSA Technical Committee on Engineering Dexign in Wood Re Bending Strength of Dimension Lumber, June 1981

[69] Petawawa National Forestry Institute; "Canada's Forest Inventory" : ('anadian Forestry Service, 1988 
[70] Salama, A.E.:Moody. M.L.; "Analysis of Beams and Plates for Ponding Loads": Journal of Structural Division. ASCE. February 1967. p109-126

[71] Salinas,J.J.: Gillard.R.G.:(1985) "Strength and Structural Safety of Long-span Light Wood roof Trusses": Canadian Journal of Civil Engineering. Vol.12. No.2March 1985. pp 114-125

[72] Salinas.J.J.A.J.Abes:J.T.Rogers (1985); "Risk Assessment Methodology for Pipeline Systems": Structural Safety. February 1985. pp225-237

[73] Salinas. J.J. (1989). "Lifet ime Performance and Test-induced Damage in Wood Structures": Proceedings of the International Seminar "The Life of Structures. The Role of Physical Testing“" Institution of Structural Engineers and Building Research Establishment. Brighton. England. April 1989. pp262-272

[74] Salinas. J.J. and R. Cunliffe (1988). "A Probabilistic evaluation of the Effects of Proof Loading on the Strength of Wood Products"; ASCE Engineering Mechanics Division. Specialty Conference on Probabilistic Methods. Blacksburg, VA, may 1988. pp131-139

[75] Salinas.j.J.: D.I.Masse (1988);"Reliability of Nailed Connections"; Proceedings of the 1988 International Conference on Timber Engineering. Seattle. September 1988. pp 11-19

[76] Salinas,J.J. (1988); "Reliability Bonds for Bolted Connections"; Proceedings of the 1988 International Conference on Timber Engineerine. Seattle, September 1988. pp 143-139

[77] Salinas.J.J.; R.G.Gillard (1988); “Reliability of Serviceability Limit States for Engineered Wood Structures"; Proceedings of the Symposium/Workshop on the Serviceability of Buildings. National Research Council of Canada. Ottawa. May 1988. pp 62-72

[78] Salinas, J.J.: Cunliffe.R.(1987) "Lifetime Performance and Load Tests of Wood Structures": Proceedings of the 5th int. Conference on the Applications of Statistics and Probabilities. Vancouver, May 1987. Vol I, pp 246-253 
[79] Salinas. J.J.: Gillard. R. (1987) "Equivalent Criteria in Acceptance Testing"; Proceedings of the 5th International Conference on the Applications of Statistics and Probabilities. Vancouver. Mi..y 1987. Vol I, pp 325-333

[80] Salinas, J.J.: Gillard. R. (1987) "Reliability Degradation of Wood Floor Systems"; Proceedings of the 5th International Conference on the Applications of Statistics and Probabilities. Vancouver. May 1987. Vol II, pp 141-449

[81] Sawyer, D.A.:"Ponding of Rainwater on Flexible Roof Systems": Journal of Structural Division. ASCE. February $196 i$ pl2i-14 7

[82] Sazinski Richard J.: Vanderbilt Daniel M.: "Behaviour and Design of Wood Joists Floors": Wood Science Vol.11. No.4: April 1979, p209-220

[83] Spencer. Richard; "Rate of Loading Effect in Bending for Douglas-Fir Lumber" pp259-279,

[84] Sherwood. G.; R.C. Moody; "Light-Frame Wall and Floor Systems, Analysis and Performance"; LSDA, General Technical Report FPL-GTR-59; 1989

[85] Thompson. Erik G.; Vanderbilt M. Daniel: Goodman J.R.; "FEAFLO: A Program for the Analysis of Layered Wood Systems"; Computers and Structures, Vol.7, pp237-248: 1977

[86] Thompson, E.G.;Goodman, J.R.; Vanderbilt,M.D.; "Finite Element Analysis of Layered Wood Systems"; J. of Structural Division, ASCE, Vol.101, No.ST12, December 1975

[87] S. Timoshenko; "Theory of Plates and Shells", 1987, second edition, McGrawHill

[88] Tuomi,R.L.: McCutcheon, W.J.; "A Conventional House Challenges Simulated Forces of Nature"; Forest Products Journal. Vol.25, No.6, June 1975, pp13-20

[89] Tuomi,R.L.: McCutcheon, W.J.; "Testing of a Full-Scale House Vinder Simulated Snowloads and WindLoads"; USDA Forest Service Research Paper. FPL. 234. 1974 
[90] Turnbull, J.E.; Salinas,J.J. and D.I.Masse (1988) "Lateral Strength of Bolted Wood Fastenings . . LSD Vs WSD Methods"; Report of the Task Group on Bolted Wood Fastenings, Tech.Comm.Engineering Design in Wood, CSA 086. Sp.Pub.of the Eng. \& Stat.Rsch. Ctr., Rsch Branch, Ag. Canada, Ottawa,Pub.No.I-889,12pp.

[91] Vanderbilt, M.D.; Goodman,J.R.; Criswell,M.E.; "Service and Overload Behaviour of Wood Joist Floor Systems"; Journal of the Structural Division, ASCE, Vol.100, No.ST1, January, 1974

[92] "The C Language", Brian Kernighan, Denise Ritchi, 1988, Prentice Hall, 2nd Edition

[93] Warren,W.G.;Madsen,B.;"Computer-Assisted Experimental Design in Forest Products Research: A Case Study Based on Testing the Duration-of-Load Effect"; Forest Products Journal Vol.27, No.3, March 1977, pp45-50

[94] Wheat, Dan L.; Gromala, David S.; Moody, Russel C.; "Static Behaviour of Wood-Joist Floors at Various Limit States"; J. of Structural Engineering, Vol.112, No.7, July 1986, ASCE. pp1677-1961

[95] Xu,Zhilun; "Mechanics of Elasticity"; 1982, Publishing Agency for Advanced Education of China

[96] Yokoyama T.; "Parametric Instability of Timoshenko Beams Resting on an Elastic Foundation"; Computers and Structures Vol.28, No.2, pp.207-216, 1988, pp207-215

[97] Zahn, John J.; "Lateral Stability of Wood Beam-And-Deck Systems"; ASCE.Vol.099, No.ST7, July, 1973; p1391-1408

[98] Zahn, John J.; "Shear Stiffness of Two-Inch Wood Decks for Roof Systems"; USDA Forest Service Research Paper FPL 155, 1972 


\section{Appendix A}

\section{Symbols}

a constant, $m m^{-1}$

a ratio of $w_{p l} / w_{b}$

a damage accumulated at a point in lumber, per unit volume

$\alpha_{0}$ initial damage accumulated at a point in lumber, per unit volume

$\beta_{1} 2 H / D_{x}$

$\beta_{2} \quad D_{y} / D_{x}$

$\Delta$ maximum deflection of a T-beam, $\mathbf{m m}$

$\Delta_{1}$ maximum deflection of a $T$-beam with loose connection, $m m$

$\delta$ distance between the neutral axis of a $T$-beam and the centerline of the joist s, $\mathrm{mm}$ 
( $\zeta \mathrm{L}, \eta$ B) the loading point of a concentrated load

$\mu_{1}, \mu_{2}$ Poisson's ratios

$\gamma$ aspect ratio, $/ / B$

$\sigma$ stress state at a point, $\mathrm{N} / \mathrm{mm}^{2}$

$\sigma(t)$ stress state at a given time. $\mathrm{N} / \mathrm{mm}^{2}$

$\sigma$, short term strength, $\mathrm{N} / \mathrm{mm}^{2}$

$\sigma_{0}$ threshold stress ratio

- performance factor, LRFD

$\Omega$ total damage accumulated in lumber

\section{A constant}

$A_{m n}$ constant in a Fourier series, $\mathbf{m m}$

$A_{i k}$ constant in a Fourier series, $m m$

$A_{1}$ area of cross-section of joists. $\mathrm{mm}^{2}$ 
$A_{2}$ area of the flange of theo $\mathrm{T}$-beam, $\mathrm{mm}^{2}$

$L$ span of the $\mathrm{f} \quad \mathrm{an}$ of the joists. $\mathrm{mm}$

a model parameter

$B$ a tensile rigidity of plywood . $N \mathrm{~mm} / \mathrm{mm}$

$B_{3}$ bending rigidity of plywood $. x \mathrm{~mm}^{2} / \mathrm{mm}$

$B_{m n i}$ constant, $N / m^{3}$

$B$ width of the floor, $\mathrm{mm}$

b model parameter

$b$ width of joists

$C$ a constant, $m m$

c model parameter

$D_{m n}$ constant, $\mathrm{N} / \mathrm{mm}^{3}$

$D_{x}$ bending stiffness of a floor in the direction of joists, $N \mathrm{~mm}$ 
$D_{y}$ bending stiffness of a floor in the direction perpendicular to joists.. $\mathrm{mm}$

d height of web of $\mathrm{T}$-beam or a joist. $\mathrm{mm}$

dy width of supports, $\mathrm{mm}$

$d_{1}, d_{2}$ depths of beams. $m m$

$E$ modulus of elasticity. $\mathrm{N} / \mathrm{mm}^{2}$

$E_{1}$ modulus of elasticity of the joists. $. \mathrm{N} / \mathrm{mm}^{2}$

$E_{2}$ modulus of elasticity of the plywood in the direction of joists, $. \mathrm{V} / \mathrm{mm}^{2}$

(EI). effective bending stiffness of a T-beam, $\mathrm{N} \mathrm{mm}^{2}$

$(E I)_{b}$ bending stiffness of a joist. $\mathrm{N} \mathrm{mm}^{2}$

$f_{v}$ adhesive factor. difference between $K_{2}$ and $K_{1}, N \mathrm{~mm}^{2}$

$f_{\max }$ maximum deflection of a $\mathrm{T}$-beam. $\mathrm{mm}$

$G$ shear modulus. $\mathrm{N} / \mathrm{mm}^{2}$

$H$ torsional rigidity of floor. $N \mathrm{~mm}$ 
$h$ rate of loading related to stress

$K_{1}$ effective rigidity of a loose floor. $N \mathrm{~mm}^{2}$

$K_{2}$ effective rigidity of a glued foor. $V \mathrm{~mm}^{2}$

$k$ water density. $\mathrm{N} / \mathrm{mm}^{3}$

$k$ constant representing percentage of errors permitted

$k_{1}$ length effect factor

$k_{2}$ depth effect factor

$k_{0}$ rate of loading related to the concentrated load

$L^{\prime}$ length of plywood between gaps, $\mathrm{mm}$

$L_{e}$ equivalent length of beam subjected to two concentrated loads.min

$n$ model parameter

$P / \delta \mathrm{load} / \mathrm{slip}$ ratio of nails. $\mathrm{N} / \mathrm{mm}$

$P$ concentrated load. $\boldsymbol{N}$ 
$p(x, y)$ load on roofs including ponding. $.1 / \mathrm{mm}^{2}$

$Q(x, y)$ normal load acting on the floor. $. V / \mathrm{mm}^{2}$

$Q,(x, y)$ reaction from the joists. $N / m m$

$Q_{m n}$ constant. $N / m m^{2}$

$q(x, y)$ load acting on the floor. $N / \mathrm{mm}^{2}$

$q_{m n}$ the (m,n)th term of the Fourier series expanded from $q(x, y), N / m^{2}$

9o uniformly distributed load, $. \mathrm{V} / \mathrm{mm}^{2}$

$S$ joist spacing. $m m$

$s_{n} \quad$ spacing between nails. $m m$

$T$ time needed for lumber to fail

$t$ thickness of plywood. $\mathrm{mm}$

1 volume of beams, $\mathrm{mm}^{3}$

$u \cdot(x, y)$ deflection of floor. $m m$ 
$w_{b m a x}$ maximum deflection of a beam subjected to uniformly dist ributed load. $m m$

$w_{b}$ deflection of a beam. $\mathrm{mm}$

$w_{p l}$ deflection of a plate. $m m$

$x_{0}$ distance between two concentrated load acting on a beam. $\mathrm{mm}$

$x_{1}, x_{2}$ strength of bending members of length $L_{1} . L_{2}$ respectively, $m m$

$x$ coordinate in the direction of joists, $\mathrm{mm}$

$y$ coordinate in the direction perpendicular to joists, $\mathrm{mm}$

$y_{0}$ distance between the neutral axis of the T-beam and bottom of the web, $\mathrm{mm}$

$y_{j}$ position of the jth joist, $m m$ 

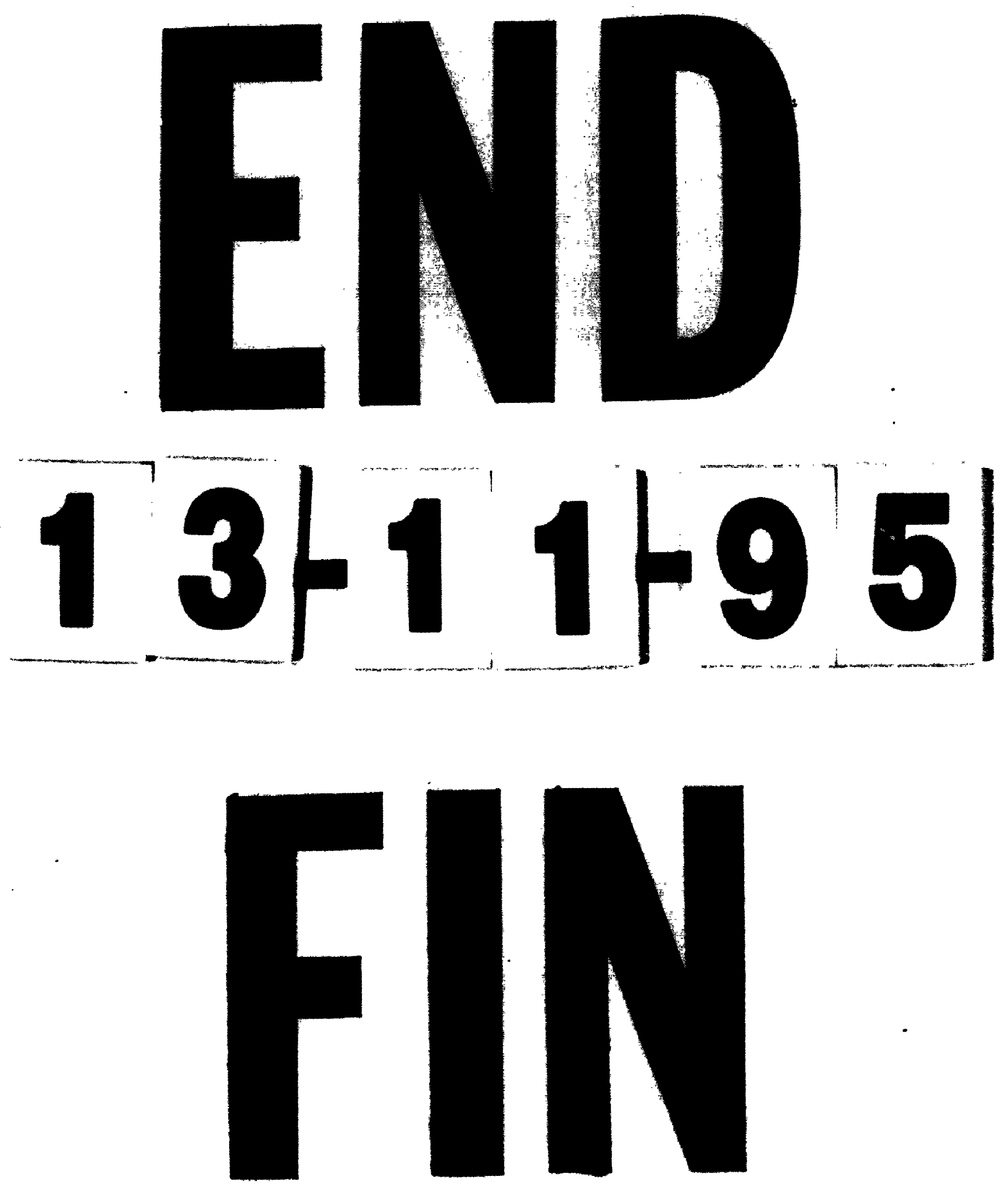